\title{
CITIZENSHIP IN OUR PLACE: \\ EXPLORING NEW ZEALAND YOUNG PEOPLE'S EVERYDAY, PLACE-BASED PERSPECTIVES ON PARTICIPATION IN SOCIETY
}

BY

BRONWYN ELISABETH WOOD

\begin{abstract}
A thesis
submitted to the Victoria University of Wellington in fulfilment of the requirements for the degree of Doctor of Philosophy
\end{abstract}

Victoria University of Wellington 2011 



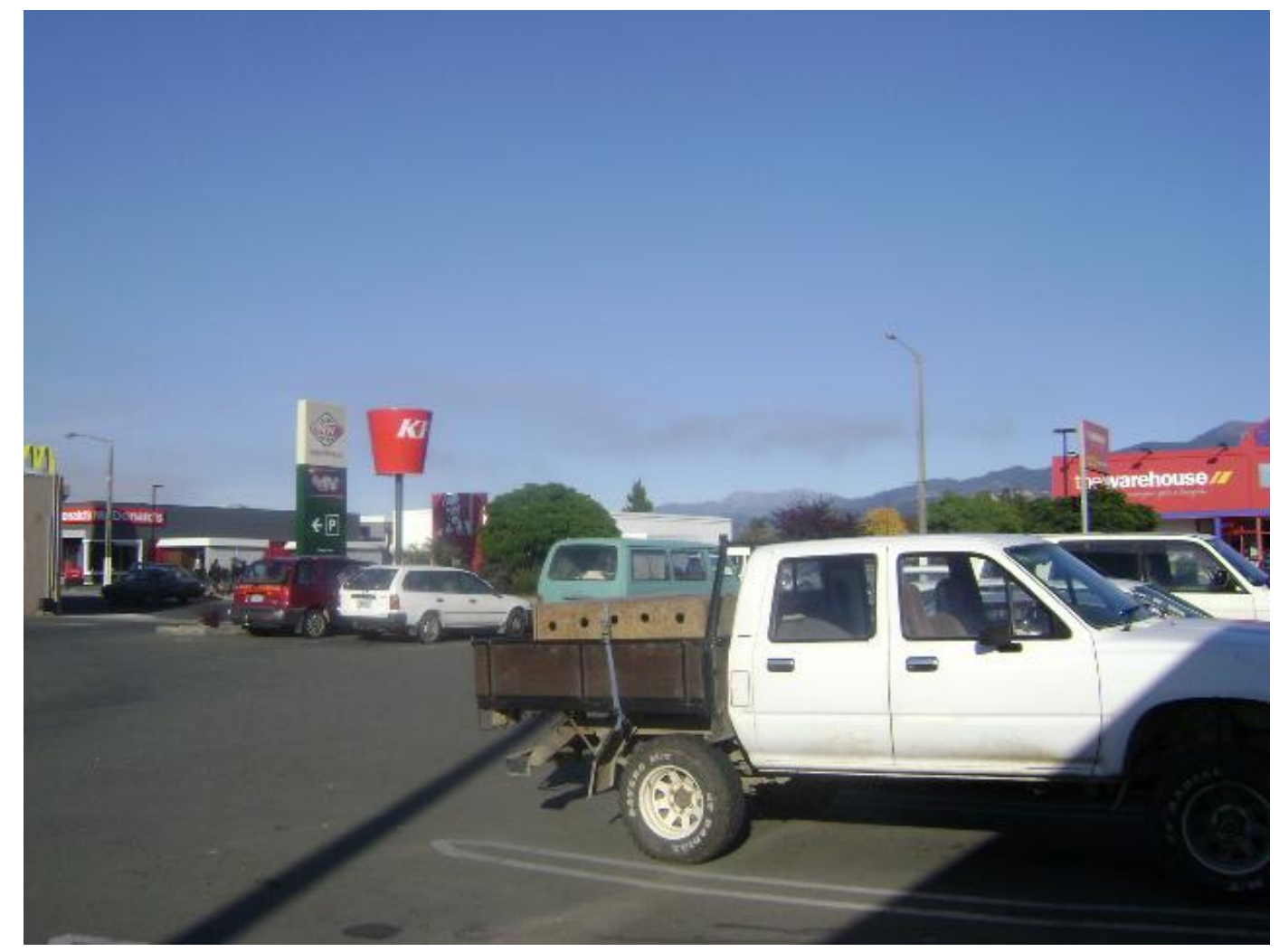

Flora: See how they've got like McDonalds and KFC on one corner...and see how we've got our mountains in the background and it kind of just kills it. It kills our town's identity. Identification... It kind of spoils the nice scenery. (14 years, female, College $\mathrm{C}$ ) 



\section{Abstract}

Developing more active citizens has been a feature of policies in many nations in recent years. Educational curricula in particular have been viewed as an important way to deliver this goal. The revised New Zealand Curriculum (2007) is an example of this, with a vision to develop young people who will be confident, connected, actively involved, lifelong learners (p. 8) who will themselves "participate and take action as critical, informed, and responsible citizens" (p. 17). In this thesis, I explore how New Zealand young people are currently participating as citizens by examining their conceptions and practices of social action alongside those of their teachers. My approach draws attention to spatial and relational aspects of young people's everyday, place-based perspectives on participation in society.

The conceptual and theoretical framework underpinning this research is developed through Bourdieu's analytical concepts of habitus, field and capital, and Mills' (1959) "sociological imagination". Participants in this research included 122 social studies students $(n=122)$ aged between 14 and 18 years old, and their teachers $(n=27)$ from four diverse secondary schools in New Zealand. Data collection included café-style focus groups with young people, as well as visual data generated by participation in Photovoice research. More traditional focus groups were also undertaken with social studies teachers at each of the four schools.

Taking an everyday, place-based approach to youth participation opened up new and relatively unexplored landscapes of participation. Young people provided many examples of how they were "taking action" through formal opportunities (provided by their teachers, schools and communities), as well as informal ways, such as standing up against a bully, or reducing water usage. Through their identification of social issues that needed addressing, it was possible to see their citizenship imaginations at play. Social studies teachers played a significant role in shaping young people's awareness of social issues as well as providing them with opportunities to take action on these issues. The 
findings revealed the enduring importance of young people's everyday experiences of inclusion/exclusion within places, as well as the contribution of the participatory capital of their teachers, families and communities, in shaping their citizenship perceptions, imaginations and actions.

Keywords: citizenship, curriculum, youth participation, social action, participatory citizenship, social studies, Bourdieu, participatory capital 


\section{Acknowledgements}

I would like to express my gratitude and thanks to many people who have encouraged and supported me through this doctoral process.

I am indebted to the wisdom, timely feedback and encouragement of my two supervisors, Joanna Kidman and Mark Sheehan. I have appreciated the freedom they gave me during the research process, as well as their guidelines, advice and critique. Under their supervision, I also gained many insights into the wider academic world, issues of social justice and was reminded that there is little in the world that hasn't already been seen in history.

I would like to thank the Postgraduate Social Sciences Reading Group (Andrea Milligan, Mike Taylor, Rowena Taylor, Brian Shawa, Antonio Garcia, Fiona Beals, Rachel Tallon and Juvena Jalal), and my Te Papa Reading Group (Michael Harcourt, Amanda Rohloff, Sue McDowall and Simon McLellan) for thoughtprovoking discussions and opportunities to explore new ideas. I have enjoyed friendship and multicultural food feasts with my postgraduate office colleagues (Shukry, Azizah, Bew, Shoba, Linda, Anna and others). A special mention goes to Adisorn Juntrasook for his reading recommendations and timely words of encouragement and wisdom. I have been fortunate to meet a great bunch of people through the ISA RC34 (Sociology of Youth), and would like to thank Clarence Batan, Ani Wierenga, Dan Woodman and Maurice Devlin for their encouragement and friendship.

I am particularly grateful to all the young people and teachers who took part in this research with such creativity and good will. This thesis could not have happened without their insights, imaginations and generosity. I am honoured to be able to share the ways so many of these participants are making an everyday difference in the world.

I would like to gratefully acknowledge funding for this research from the Bright Futures Scheme for their Top Doctoral Scholarship and The Wallace Scholarship 
provided by the Electoral Commission of New Zealand. The contribution of a Victoria University of Wellington Faculty of Education Grant toward fieldwork and conference costs has also been hugely appreciated.

This thesis could not have happened without the support of my family, and in particular, my mum, Beulah Wood, for her careful editing, childcare and encouragement in my academic pursuits, and my parents-in-law, Fred and Bev Greig, who provided assistance and accommodation on so many occasions. My special thanks go to my husband Andy, for his support, good humour and unfaltering belief in my ability to complete this thesis.

Finally, this thesis is dedicated to my sons, Josiah and Oliver, whose insights into the world, and participation in it, are a source of constant inspiration and delight to me. 


\section{Table of contents}

Abstract
Acknowledgements
Table of contents
List of figures
List of appendices
Glossary of terms

CHAPTER 1 INTRODUCTION: ACTIVE YOUNG CITIZENS - A GROWING

PRIORITY IN SOCIETY?............................................................................................. 1

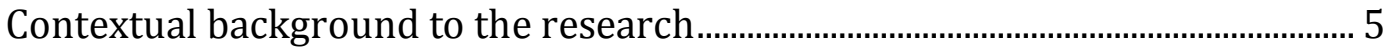

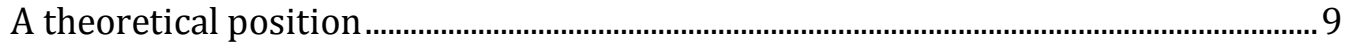

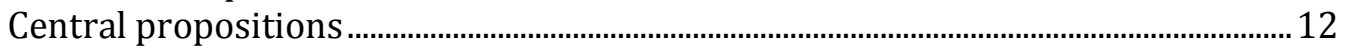

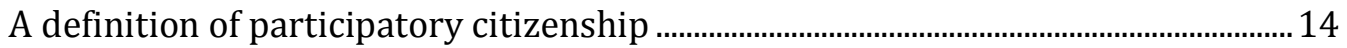

Curriculum focus: social studies................................................................................... 15

Research questions .................................................................................................. 17

Personal motivations for research in this area............................................................ 17

Outline of the thesis .................................................................................................................... 18

CHAPTER 2 LITERATURE REVIEW: KEY DEBATES AND PERSPECTIVES ON

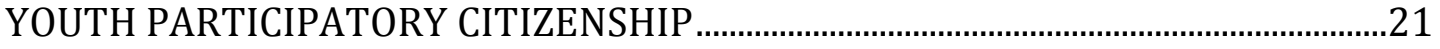

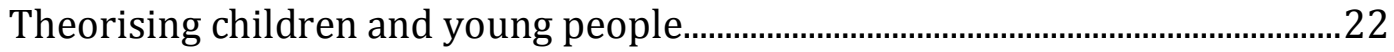

Traditions of citizenship participation............................................................................. 24

Liberal citizenship traditions .................................................................................... 25

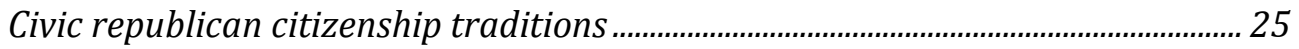

Communitarian citizenship traditions........................................................................ 25

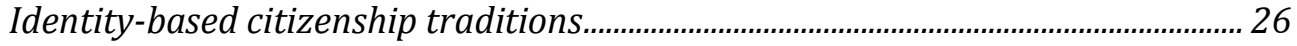

Global and cosmopolitan citizenship traditions........................................................ 26

Two policies promoting participation in New Zealand ............................................28

'Third Way' policies........................................................................................................... 28

Knowledge society policies .......................................................................................... 29

Contested conceptions of participatory citizens ……................................................32

Patterns and experiences of youth participation ........................................................35

Young people's participatory experiences in New Zealand ............................................ 36

The problematic status of young people and citizenship................................................. 41

New approaches to exploring youth participatory citizenship ..............................43

The case for exploring young people's everyday, place-based perspectives on participation in society........................................................................................................... 45

CHAPTER 3: A THEORETICAL AND CONCEPTUAL FRAMEWORK FOR EXAMINING THE PARTICIPATORY CITIZENSHIP OF YOUNG PEOPLE....................49

Bourdieu's conceptual triad: habitus, capital and field ...........................................51

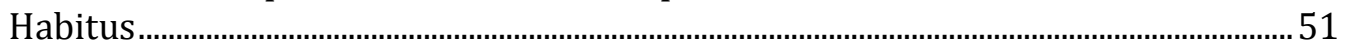

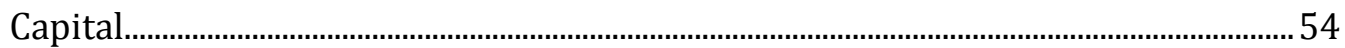

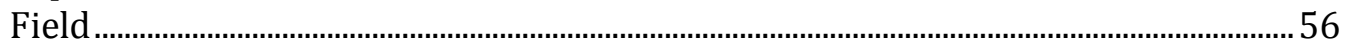

Limitations of Bourdieu's theory for exploring youth participation ........................... 59

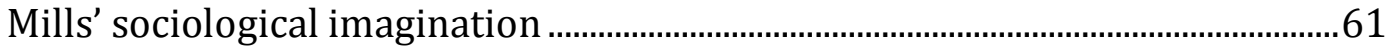


Exploring young people's participatory citizenship through Mills and Bourdieu 63

A place-based focus on participatory citizenship.............................................................65

CHAPTER 4: METHODOLOGY...................................................................................67

Critical, constructionist approaches to research .....................................................68

Qualitative research with young people................................................................70

Privileging participatory and place-sensitive approaches ............................................. 70

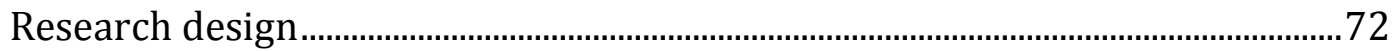

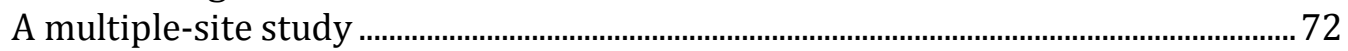

Gaining informed consent within schools ........................................................................ 74

Summary of selected schools and participants ................................................................... 76

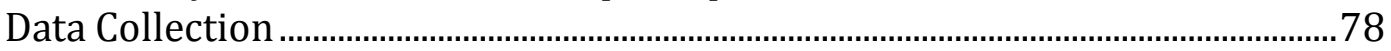

Café-style focus group interviews .................................................................................... 79

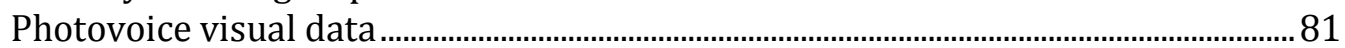

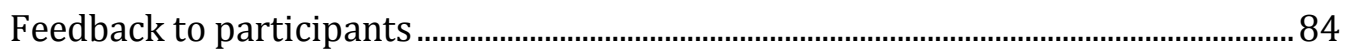

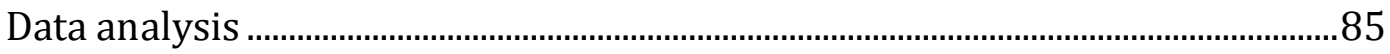

Analysis of interview-generated data............................................................................ 86

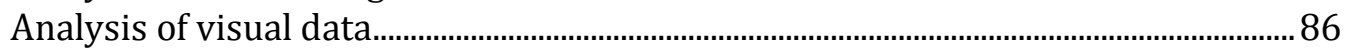

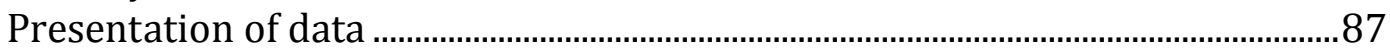

Analysis and reporting of group-generated data.......................................................... 88

Developing keyhole narratives ………………………............................................... 88

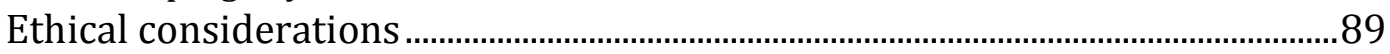

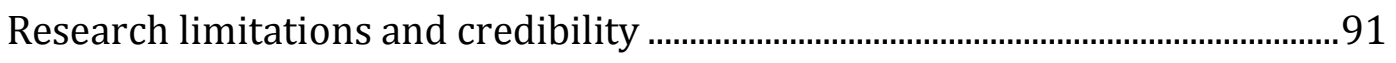

CHAPTER 5: SOCIAL STUDIES TEACHERS' CONCEPTIONS AND PRACTICES OF

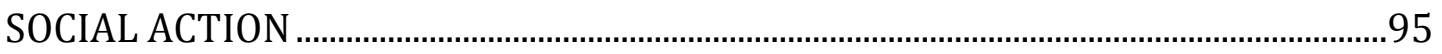

Teachers' multiple, contested conceptions of participatory citizenship ...........96

Conceptions of "social action" held by New Zealand social studies teachers .......... 97

Teacher talk: conceptions and practices of social action .......................................99

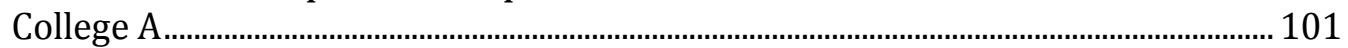

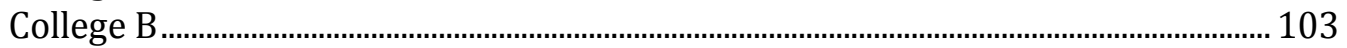

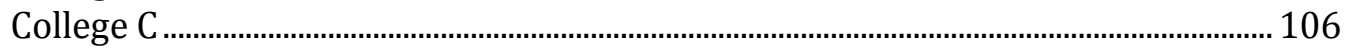

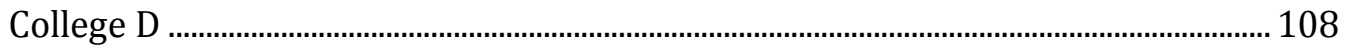

Participatory learners or participatory citizens? .................................................... 111

Social action and "risk" .......................................................................................................... 113

School-based participatory dispositions .................................................................114

Spatial orientation (local/global) ………………….................................................. 114

Engagement in horizontal and vertical participation...................................................115

Pedagogical approaches to social action ........................................................................ 116

CHAPTER 6: BELONGING TO “OUR PLACE”: THE CITIZENSHIP IMAGINATION

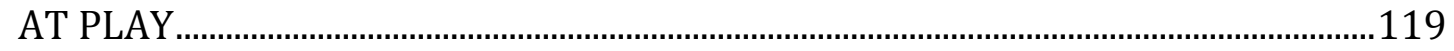

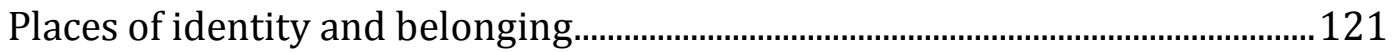

What is special about "our place" ................................................................................. 122

Portraits of "our place" ................................................................................................ 125

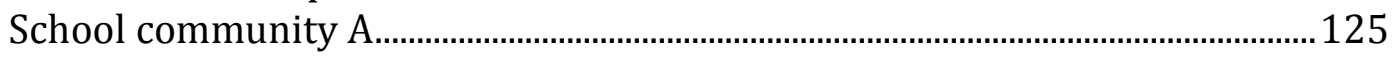

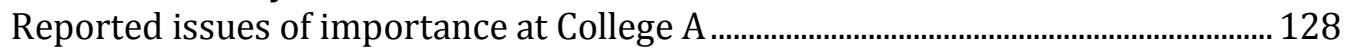

Air pollution - "we're already dealing with it" ...................................................129

School Community B ..................................................................................................... 132

Reported issues of importance at College B .................................................................... 134

"When other visitors come here, all they can see is tagging"....................................136

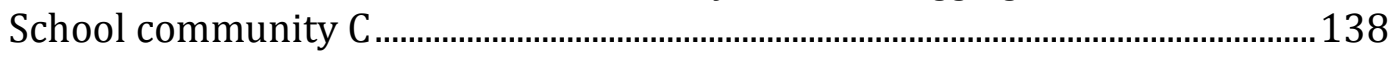


Reported issues of importance at College C ………................................................... 141

"Bus crisis!"..............................................................................................................................142

School Community D ....................................................................................... 144

Reported issues of importance at College D ................................................................. 146

"It's like our place - and it's quite important to us".................................................146

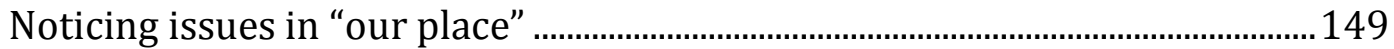

Citizenship imaginations in "our place" ................................................................ 151

CHAPTER 7: DEFINING AND PARTICIPATING IN FORMAL AND INFORMAL

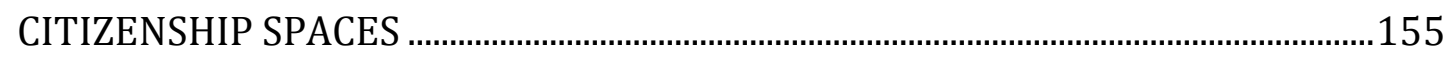

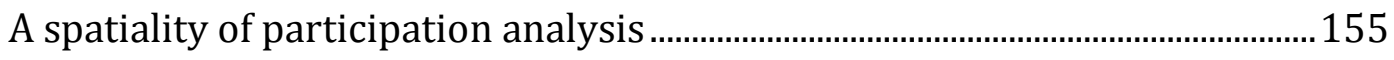

College A................................................................................................................................ 156

"I'm just saying it's a stereotype"......................................................................................162

College B.......................................................................................................................... 164

"To keep our children safe, that's the important thing"............................................166

College C .......................................................................................................................... 169

"We're saying we have too much [fast food] for a small town"...............................171

College D ....................................................................................................................... 174

"That's a waste of water"...........................................................................................176

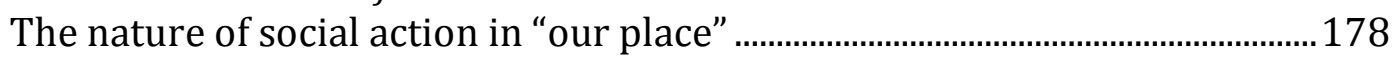

\section{CHAPTER 8: DISCUSSION: PATTERNS AND POSSIBILITIES OF YOUTH}

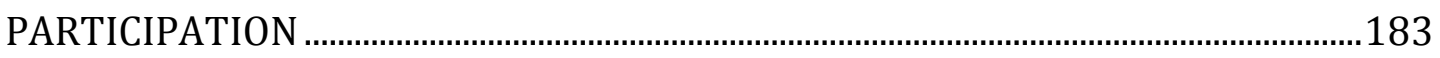

Identity, belonging and citizenship spaces........................................................... 184

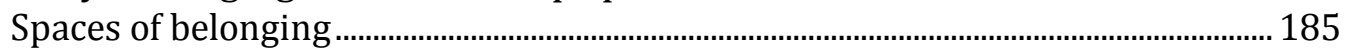

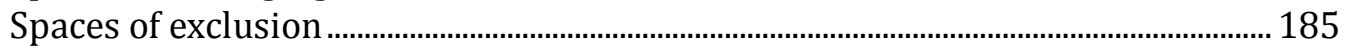

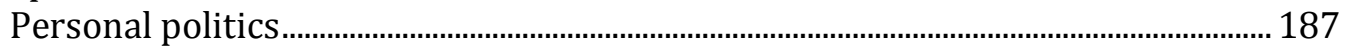

Informal and everyday citizenship actions ...........................................................189

Local/global patterns of perception and participation ......................................... 192

Participatory capital and citizenship dispositions ................................................195

Partnerships of participation ................................................................................... 199

Maximal or minimal social action? ………………..................................................... 201

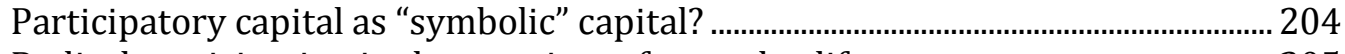

Radical participation in the practices of everyday life.................................................... 205

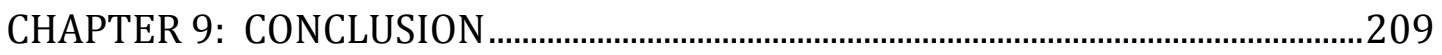

Review of findings.......................................................................................................... 209

Avenues for further research ............................................................................................ 212

Concluding reflections ........................................................................................................... 213

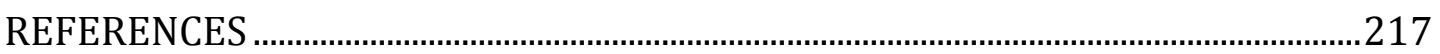

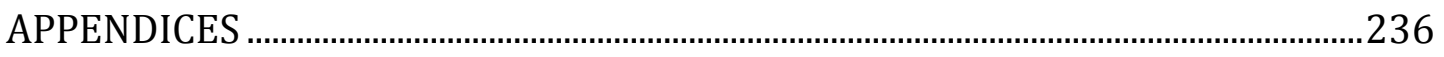




\section{List of figures}

Figure 6.1: "That's my tree" .........................................................................124

Figure 6.2: "Our family" ..............................................................................124

Figure 6.3: "That's the sun cos its sunny [city]"................................................126

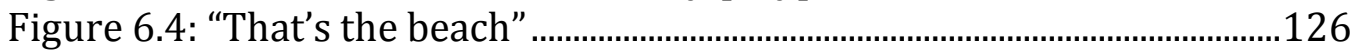

Figure 6.5: "Pollution" .........................................................................................130

Figure 6.6: "That's air pollution" ..........................................................................130

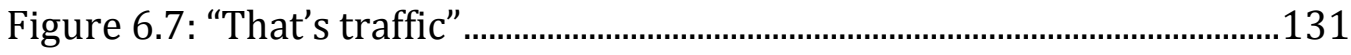

Figure 6.8: "Fireplace. It's enclosed, which is good" .........................................131

Figure 6.9: "More taro"................................................................................133

Figure 6:10: “...it's a multicultural community” ..................................................133

Figure 6.11: "It's just vandalism” ..................................................................136

Figure 6.12: "That's tagging on one of our fences" ...........................................136

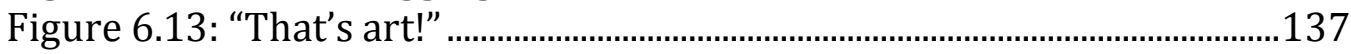

Figure 6.14: "It makes our suburb look bad" ......................................................137

Figure 6.15: "Really clean water" ........................................................................138

Figure 6.16: "That is significant to tourists - it's where they love to go" "...138

Figure 6.17: "That's connecting us to the outside world" ...............................140

Figure 6.18: "The window's fully broken at the back - now that's bad!" ...140

Figure 6.19 "We'd miss the sunsets in [our city]" .............................................144

Figure 6.20 "That's the city at night"...............................................................144

Figure 6.21: "It's our place" ..............................................................................147

Figure 6.22: "That was friends - that was us" ...................................................147

Figure 6.23: "Only one beer bottle there now ..." ..................................................148

Figure 6.24: "It seems like scungy!" ......................................................................148

Figure 7.1: "Racism" ..............................................................................................164

Figure 7.2: "People can be themselves - and not be judged" ..........................164

Figure 7.3: "To keep our children safe, that's the important thing"..............167

Figure 7.4: "Sometimes alcohol can be too cheap" ..............................................167

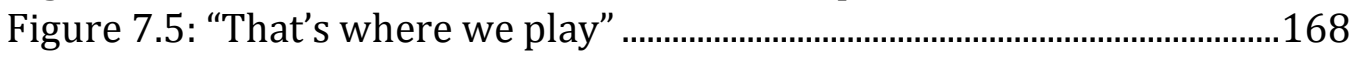

Figure 7.6: "The Cage" .............................................................................................168

Figure 7.7: "That's showing all the companies" ...............................................172

Figure 7.8: "McDonalds is making us fat".........................................................172

Figure 7.9: "It kills our town's identity" .............................................................173

Figure 7.10: "It kind of spoils the nice scenery" ................................................173

Figure 7.11: "They're fundraising...” ..................................................................175

Figure 7.12: "That's us donating clothes for charity" .........................................175

Figure 7.13: "That's the stuff we picked up" .....................................................177

Figure 7.14: "That's the drain pipe....and it looked a bit dodgy" ....................177

Figure 8.1: Perceived importance of local and global issues by participants

in Colleges A-D ......................................................................................................193 


\section{List of tables}

Table 2.1 Models of citizenship participation..............................................................33

Table 2.2: New Zealand percentages for civic participation in the wider community compared to ICCS averages ..........................................................................37

Table 4.1 Summary characteristics of four schools ......................................................76

Table 4.2: Summary of youth participants within four schools ...................................77

Table 5.1: Summary of teacher participants in each school .......................................99

Table 5.2: Some formal opportunities for civic participation provided by schools in 2009

Table 6.1: Photos of what is important or special about "our place" 123

Table 6.2: Most commonly reported "important issues" in Colleges A-D 149

Table 8.1: Pedagogical approaches toward social action in social studies 194 


\section{List of appendices}

Appendix A: The changing face of 'social action' in official social studies curriculum documents in New Zealand (1944-2007) 236

Appendix B: Westheimer and Kahne's "Kinds of citizens" 237

Appendix C: Kennedy's (2006) conceptual framework of citizenship 238

Appendix D: Principal' information/consent letter 239

Appendix E: Student information/consent letter 241

Appendix F: Parent information letter 244

Appendix G: Teachers' information/consent letter 246

Appendix H: Information sheet for Photovoice activity and use of digital cameras

Appendix I: Poster activity 1: Important issues in "our place" 249

Appendix J: Poster activity 2: Location of "important issues". 249

Appendix K: Poster activity 3: Social action is. 249

Appendix L: Poster activity 4: A "good" citizen is. 250

Appendix M: Poster activity 5: Rights and responsibilities of young people .....250 Appendix N: Poster activity: PMI chart (positive, negative and interesting) outcomes/challenges to taking social action 250

Appendix 0: College A: Topics studied and reported "important issues" in focus groups

Appendix P: College B: Topics studied and reported "important issues" in focus groups

Appendix Q: College C: Topics studied and reported 'important issues' in focus groups

Appendix R: College D: Topics studied and reported 'important issues' in focus groups 


\section{List of abbreviations}

DOC Department of Conservation - a government department responsible for the protection and conservation of New Zealand's natural and historic heritage

ERO Education Review Office - this body is responsible for reviewing schools in New Zealand

HOD Head of Department (used within a school context in New Zealand)

ICCS International Civic and Citizenship Education Study (administered by the IEA)

IEA International Association for the Evaluation of Educational Achievement - an independent, international consortium of national research institutions and government research agencies, with headquarters in Amsterdam

INCA International Review of Curriculum and Assessment frameworks Internet Archive

NCEA National Certificate in Educational Achievement

NZQA New Zealand National Qualification Authority

OE Overseas Experience - a New Zealand colloquialism for an international working and travelling holiday

UNCRC United Nations Convention on the Rights of the Child

VSA Voluntary Services Abroad, an international non-government organisation that provides skilled volunteers to majority world countries. 


\section{Glossary of terms}

Active
citizenship

Citizenship

imagination

Decile rating

Enterprise
Education

Enviroschools

Key

competencies

Horizontal
participation

Hauora

Hui $^{1}$

Lived experiences
This refers to a more participatory form of citizenship which involves the development of citizenship as an active (rather than passive) process (J. Nelson \& Kerr, 2006). Used interchangeably with concepts such as participatory citizenship and civic action in literature.

I have coined this term as an extension of Mills' (1959) notion of the "sociological imagination" (see glossary) to focus specifically on the aspects of their personal experiences (issues, people and places) that young people wish to protect, preserve or transform.

In New Zealand, a school's decile indicates the extent to which a school draws its students from a low socio-economic community, with Decile 1 representing a low socio-economic community, and Decile 10, a high socio-economic community. The decile rating for a school is calculated by using a number of census-related variables from the school community (including household income, parental occupation and qualifications, income support and household crowding) (Ministry of Education, n.d).

Also known as E4E, enterprise education is an additional focus beyond the eight essential learning areas prescribed in the curriculum. E4E encourages the development of "enterprising attributes" and encourages schools to develop links with local businesses. See http://education-for-enterprise.tki.org.nz/ for further details.

Schools can opt to become Enviroschools. These schools are committed to a whole school and community approach toward working for sustainable environments and communities. Their progression is acknowledged by the presentation of 'bronze', 'silver' and 'green-gold' awards. Approximately $25 \%$ of all New Zealand school are involved in Enviroschools (Enviroschools webpage, n.d.). See http://www.enviroschools.org.nz/about-enviroschools for further details.

Described in the New Zealand Curriculum as skills, knowledge, attitudes and values that lead to action (Ministry of Education, 2007, p. 12).

Horizontal participation relates to civic engagement between individuals in communities, such as volunteering, participation in clubs, charities and community activities (Jochum, Patten, \& Wilding, 2005).

(Māori) health or vigour.

(Māori) a gathering, meeting, assembly or conference.

Defined for this thesis as "the meaning that citizenship actually has in people's lives and the ways in which people's social and cultural and

${ }^{1}$ Unless otherwise stated, Māori translated words are derived from the Māori Dictionary (Moorfield, 2003-2011) online http://www.maoridictionary.co.nz/ 
material circumstances affect their lives as citizens" (Lister, 2007b, p. 695).

Marae

Pākehā

Pālagi

Participatory citizenship

Social action

Te Reo Māori

Vertical participation

Whānau

Whanaungatanga
The courtyard in front of the main meeting house (wharenui) - often used to denote the complex of buildings associated with a marae.

(Māori) a New Zealander of European descent.

(Samoan) from Samoan papālagi, to mean non-Samoan. Similar to the Māori word pākehā, it is applied particularly to people of European descent.

Participatory citizenship includes any citizenship actions which work toward the common good of society (Cremin, Warwick, Harrison, \& Mason, 2009). In this thesis, I have used the term participatory citizenship as the primary concept of focus, to explore both participation and citizenship together, recognising that this term is a contested one. Similar concepts used interchangeably in literature include "active citizenship" or "civic engagement/action." The closest concept to participatory citizenship in New Zealand curricula is social action which is the term I explored with New Zealand social studies teachers and students in this research.

The term social action has been used specifically in New Zealand curricula to convey actions taken to participate in the life of the community. See for examples of this definition Department of Education (1977) and Ministry of Education (1994) (Appendix A). In this thesis I have used social action as a locally-derived expression of participatory citizenship in New Zealand curricula.

Social inquiry The social inquiry is an inquiry-based learning approach for studying societal issues that has been developed within the social studies curriculum see (Barr, Graham, Hunter, Keown, \& McGee, 1997) and explicitly integrated in the New Zealand Curriculum (Ministry of Education, 2007, p. 30). In the social inquiry process, students "ask questions, gather information [...] and examine current issues; explore and analyse people's values and perspectives; consider the ways in which people make decisions and participate in social action; reflect on the understandings they have developed and the responses that may be required" (Ministry of Education, 2007, p. 30).

(Māori) Māori language, sometimes contracted to "te reo."

Vertical participation relates to participation in civic and political activities between the individual and the state (such as voting, matters that relate to decision-making of those holding power) (Jochum, et al., 2005). See also horizontal participation.

(Māori) family. The term generally denotes extended kinship networks.

(Māori) A relationship through shared experiences and working together which provides people with a sense of belonging. It develops as a result of kinship rights and obligations, which also serve to strengthen each member of the kin group. It also extends to others to whom one develops a close familial, friendship or reciprocal relationship. 


\section{CHAPTER 1 \\ INTRODUCTION: \\ ACTIVE YOUNG CITIZENS - A GROWING PRIORITY IN SOCIETY?}

Conversation from a café-style focus group, College A:

Claire: What have you done? [to Wonderwoman] $(18$, female)

Wonderwoman: $\mathrm{Oh}$, nothing really great. (17, female)

Claire: It doesn't have to be anything big. It can be like giving a couple of bucks to charity.

Wonderwoman: Oh yeah. I coach different teams and things. That's a social action.

Claire: That's cool. It's helping kids to fulfil their potential.

$-/ /-$

Interview with Teacher C1, Head of Social Sciences Department, College C:

[S]ocial action is something that has been traditionally quite a hard thing to integrate [in social studies] because you haven't always been empowered to go that way. But we're saying from doing this [new curriculum], we're saying, yes, you are empowered, yes it is a major outcome and is a significant part of what you're trying to achieve, then we can take some of the other energy that we may have put into some other things [...], a more traditional pathway, and try and construct it so that's it's not as traditional.

$$
-/ /-
$$

The New Zealand Curriculum (Ministry of Education, 2007) was launched in late November, 2007 amidst claims that through this curriculum students will "learn how to learn ... innovate and problem-solve and become creators of new knowledge" (Trevett \& McKenzie-Minifie, 2007). Central to this revised curriculum is a vision of young people who are active participants in their learning and in society - "confident, connected, actively involved, and lifelong learners" (p. 8). This vision aspires to develop young people as "international citizens," "members of communities", active participants and "contributors to the well-being of New Zealand - social, economic, and environmental” (Ministry of Education, 2007, p. 8). Promoting students as active, global citizens is a theme that is similarly endorsed in the named principles of this document which include citizenship as one of four significant future-focused issues (along with 
sustainability, enterprise and globalisation). ${ }^{2}$ More active conceptions of citizenship through "participating and contributing" (p. 12) are also supported in the new section on key competencies and most specifically in the learning area of the social sciences where students will "explore how societies work and how they themselves, can participate and take action as critical, informed, and responsible citizens" (Ministry of Education, 2007, p. 17, my emphasis).

This revised New Zealand curriculum has been noted internationally for its inclusion of citizenship as an active process "for all young people both through the curriculum, in the culture of the school and in the wider community beyond" (J. Nelson \& Kerr, 2006, p. 9). Similarly, it was endorsed by the New Zealand Electoral Commission for its "strong focus on citizenship":

The framework as a whole emphasises citizenship with its community and participation values and the key competency of participating and contributing, while the social sciences learning area means students' inquiry should see them build practical knowledge and skills to help shape their community and country from an early age. (Electoral Commission (NZ), 2007[online])

New Zealand is not alone in its inclusion of citizenship goals in official curriculum documents. A commitment to develop and extend citizenship curricula has been seen in many countries in recent years, along with an "explosion of sociological, political, legal and literature on citizenship in the past decade" (Brooks \& Holford, 2009, p. 85). Compulsory education has been thought of as an effective vehicle through which governments can address the issues of young people's alleged political apathy, their disengagement from formal politics and lack of knowledge about democratic institutions, as well as a way to foster social cohesion and obligations to society (Brooks \& Holford, 2009; Kennedy, 2008b). Mason (2008) claims that increasingly, citizenship education is:

... viewed by politicians, policy makers and other stakeholders as a panacea, if not the panacea, for the ills that are perceived to plague contemporary society, its young and their youth culture, and which education is expected to ameliorate (p. xi).

\footnotetext{
${ }^{2}$ Citizenship education is defined in the New Zealand Curriculum within these future focused themes as "exploring what it means to be a citizen and to contribute to the development and well-being of society" (Ministry of Education, 2007, p. 39).
} 
A heightened priority for youth participation has also been seen in recent years in a number of social policies which promote the importance of social inclusion and community participation (Davis \& Hill, 2006) and young people's participation in public affairs and in decisions that affect them (Kirby, Lanyon, Cronin, \& Sinclair, 2003; Prout, 2003; Prout, Simmons, \& Birchall, 2006). Pivotal to an increased awareness of children and young people's protection, provision and participatory rights in society, has been the United Nations Convention on the Rights of the Child (UNCRC) adopted by the United Nations in 1989. Regarded by some as "unquestionably the most significant milestone for the development of current child policies" (Woodhead, 2010, p. xx), UNCRC provided a foundation for a new position of children in contemporary societies in which their rights to both protection and participation were outlined clearly (Invernizzi \& Williams, 2008). Many countries have since ratified UNCRC in their respective legislative documents, including New Zealand in 1993.

A second policy area where young people and children have been encouraged to participate is in their role as consumers in society (Kirby, et al., 2003). Gaining strength since the 1970s, the consumer movement recognises the importance of giving consumers a voice in terms of the services and products they consume. Service users are asked to "participate more and more in the planning, provision and evaluation of services" (Prout, et al., 2006, p. 76). Participation in this context however, is narrowly defined as including the opportunity to give feedback and to hold service providers accountable and there is little evidence that children and young people can actually contribute to wider agendas (Kirby, et al., 2003; Prout, 2003).

The integration of participatory citizenship concepts within curricula policies is of particular interest in this thesis. The call within the 2007 New Zealand Curriculum for active citizens reflects a growing international trend toward the inclusion of more participatory and "active" conceptions of citizenship in curricula (Brooks \& Holford, 2009; Kennedy, 2007; Kerr, 1999; J. Nelson \& Kerr, 2006; Ross, 2008). More than a static set of rights and obligations which a 
person acquires within their status a citizen, participatory, or active citizenship, is seen as "something active which has to be seized and transformed" (Wallace, 2001, p. 28), as the "doing" component of citizenship (Kennedy, 2006), and "a more participatory form of citizenship which involves the development of citizenship education as an active process in a range of contexts in and beyond schools" (J. Nelson \& Kerr, 2006, p. iv).

However, emerging research in this area indicates that participatory citizenship is a contested concept (Faulks, 2000), not clearly understood or defined and open to conflicting interpretations in light of the social, political and historical context that it is applied within (Kennedy, 2008a; Kennedy, Hahn, \& Lee, 2007; J. Nelson \& Kerr, 2006). It is also apparent that there are different conceptions of "what counts" as participatory citizenship (Lister, Smith, Middleton, \& Cox, 2003; Marsh, O'Toole, \& Jones, 2007; O'Toole, Lister, Marsh, Jones, \& McDonagh, 2003). For example, the quotation from young people involved in my study at the beginning of this chapter shows that these young people defined many of their small, everyday activities as "social action." Yet, research in this area has rarely defined civic engagement in this way or provided opportunities for school-aged young people to describe how they are currently engaged as citizens beyond a few narrow and adult-centric definitions.

Furthermore, it is also apparent that young people's participation as citizens in society is neither simple nor straight forward. A number of studies have highlighted the importance of recognising that young people's stage in the lifecourse that borders childhood and adulthood (James \& James, 2008), a state of “in-betweenness" (Weller, 2007), renders their experiences of citizenship participation a complex one (Farthing, 2010; Furlong \& Cartmel, 2007; Malone \& Hartung, 2010; Percy-Smith \& Thomas, 2010). Research suggests that schoolaged young people (under 18 years), lack many of the entitlements of citizenship, and experience a form of "partial" or "semi-citizenship" (Lister, 2007a). This status makes the inclusion of participatory citizenship goals in curricula more problematic, and draws attention to the role that adults are likely 
to play in regulating and shaping young people's expressions of citizenship participation.

A growth in policies promoting youth participation and citizenship has resulted in an increasing level of interest and research in this area. For example, the international research profiled in both the Routledge Handbook of Children and Young People's Participation (Percy-Smith \& Thomas, 2010) and the Sage Handbook of Education for Citizenship and Democracy (Arthur, Davies, \& Hahn, 2008 ) is indicative of a growing body of research in this area. However, there is still a paucity of research at the intersection of these two fields of research; namely, young people's participation in citizenship in the context of their schooling, which examines the conceptions and practices of participatory citizenship of both teachers and their students.

In this research, I aim to explore how young people's everyday experiences within places and schools are shaping their conceptions and practices of participatory citizenship. Yet, as Malone and Hartung (2010) suggest, any “one size fits all" model of children/young people's participation will "fail to account for the very contextualised and unique ingredients that make up any children's participatory project with a community" (p. 32). For this reason, rather than assume that young people's experiences of citizenship are universal or homogenous, I have taken an approach in this research that seeks to emphasise young people's everyday, place-based perspectives on participation within their diverse schooling contexts and communities. I will elaborate on the conceptual, theoretical framework which underpins this approach in Chapter 3. In the following section I trace a number of social, cultural and political changes in society that set the contextual background for this research, and add weight to the need for further investigation into this area.

\section{Contextual background to the research}

The priority toward promoting youth participation has taken place within a context of what some see as a set of "unprecedented" challenges facing society today. John Cogan (2000) summarises this sentiment when he states: 
The planet and the human family are facing an unprecedented set of challenges, including the globalization of the economy, a significant level of deterioration in the quality of the global environment, rapidly changing technologies and the uses of the same, loss of a sense of community and shared belief in the common good, ethical questions regarding the use of genetic engineering, large-scale migration both within and between nations and rising crime. (p. 1)

The awareness of these perceived challenges at a global level has been heightened by transnational flows of products, information, images, media, values and people that occur at a pace unprecedented in earlier stages of civilisation. Events occurring nationally and globally during this time, such as growing international migration and refugee flows, the loosening of nation-state borders (such as the formation of the European Union), threats of terrorism and growing technological capabilities that enable more "global" connections of citizens, have challenged traditional assumptions about status, identity and belonging (Heater, 1999; Isin \& Turner, 2007; Osler \& Starkey, 2005). According to Giddens (1994), these global flows have resulted in a growing universalizing of processes and heightened levels of inter-dependence between individuals across the world, as well as a radicalization of modernity (evacuation of tradition) until there are no longer clear paths of development leading from one state of affairs to another. Additionally, Giddens (1994) claims these processes have lead to a world more open and contingent, where opportunity and danger are balanced in equal measure and where calculating risk is an essential part of everyday life (see also Beck, 1992). These social changes have all contributed to a growing interest in promoting an active citizenry to face the scale and complexity of these challenges facing the planet, communities and democracy.

Interest in youth participation in society has been heightened further by findings of declining rates of young people's interest and involvement in formal political processes (such as voting, joining political parties), in membership of groups and associations, as well as declining levels of trust in political institutions (CIRCLE, 2002; Crick, 1998; Furlong \& Cartmel, 2007; Kimberlee, 2002; Print, 2007; Print, Saha, \& Edwards, 2004; Putnam, 2000; Torney-Purta, Lehmann, Oswald, \& Schulz, 2001). Many nations have developed citizenship education initiatives in order to address this perceived youth apathy. For example, in 
England, Crick (1998) claimed that the initial motivation for compulsory citizenship education derived from observations of "worrying levels of apathy, ignorance and cynicism about public life" (p. 14). In Australia, findings of declining political participation rates and a "civic deficit" led to the development of the Discovering Democracy programme (Kemp, 1997) at a cost of $\$ 32$ million to the Australian government between 1997 and 2004 (Kennedy, 2007). Despite this substantial government commitment to citizenship education, only half of Australian students would vote if it wasn't compulsory, and half of the students feel they lack the fundamental knowledge to understand political parties and make decisions about voting (Print, et al., 2004). While there has been less evidence and discussion of disengagement in New Zealand, the Electoral Commission has noted falling rates of enrolment and voting amongst young people in New Zealand (Catt, 2005; Electoral Commission (NZ), 2005), and there is evidence that young people (18-24 years) are less likely than older to participate in political action or discuss political issues (E. Rose, et al., 2005).

The perceived loss of community in contemporary society is another social change which has drawn attention to the need for an active citizenry. In the $21^{\text {st }}$ century, the notion of society as a distinct, geographically bound entity is in decline (Prout, 2003). Researchers such as Robert Putnam (2000) have suggested that there has been deterioration of social capital which is associated with the demise of community and cultural institutions. Putnam cites examples such as falling church attendance, declining enrolments in social organisations and a tendency toward meeting less with friends and neighbours. He argues that as levels of social capital have fallen significantly, so has the fabric of our connections with others - a loss of trust, co-operation, reciprocity and networkbuilding alongside a growing unwillingness by individuals and groups to participate in political and civic processes - thus leaving our communities and lives impoverished (Putnam, 2000). Putnam's research has attracted the attention of many politicians and policy makers and his book Bowling Alone has been widely read (Jochum, et al., 2005). 
The aspects of social change outlined here serve together to present the need for active youth participation within a discourse of "risk" (Beck, 1992), unprecedented social change and moral panic about alleged youth apathy. I suggest that much of the rhetoric of social change outlined above has exaggerated the pace of change and presented a distorted and adult-centric view of youth participation. For example, the focus on declining youth voting rates has frequently overlooked declining adult voting rates during the same period of time (Edwards, 2007). I concur with Furlong and Cartmel (2007) who suggest that while the life experiences and contexts of young people today are quite different from those encountered by earlier generations, there is still evidence of a "continuity with the past" (p. 138), rather than an abrupt rupture from previous experiences. They suggest that while the collective foundations of social life have become more obscure, access to economic and cultural resources continue to provide powerful frameworks to explain young people's experiences and life chances.

I argue also that the measures used to gauge "participation" to suggest their supposed levels of "apathy" have been narrowly conceived, thus overlooking many of the ways young people may be politically and socially engaged (Harris, Wyn, \& Younes, 2007; Marsh, et al., 2007; O'Toole, et al., 2003). For example, Putnam's work has met with significant critique within youth studies for the narrow way he defined and measured social capital, his failure to explore how young people may be engaged in "new ways" and for viewing young people as passive and lacking agency beyond their cultural and social capital status (Holland, Reynolds, \& Weller, 2007; Weller, 2006b). This critique is central to this thesis, as I suggest that we need fresh ways to measure and define young people's participatory citizenship and, in particular, I argue that this needs to link more closely to their "lived experiences" as young citizens in society.

Whilst the inclusion of participatory and citizenship outcomes in curricula holds the potential to "empower" teachers toward more activist citizenship outcomes (as stated by Teacher C1 at the outset of this chapter (p. 1)), it is also apparent that there can be multiple interpretations of citizenship (Wolmuth, 2009). In 
Chapter 2, I will examine two key policies (Third way and Knowledge society

policies), that I suggest have been influential in shaping the nature of participatory citizenship included in the New Zealand Curriculum. Through this critique I reinforce that citizenship education, is not a neutral project, but instead "seeks to predispose citizens to particular ways of knowing, relating and being that are deemed appropriate to the political culture at hand" (Parker, 2001, p. 98). This critique has been informed by a critical, social constructionist theoretical stance throughout this research which I will briefly outline here.

\section{A theoretical position}

A critical theoretical paradigm underpins my approach to exploring youth participatory citizenship in the context of schooling and society. Critical traditions endeavour to not only understand or explain the social world, but also critique patterns and processes of society in relation to who has access to power. Critical theory has evolved into a number of traditions and expressions, yet what a criticalist holds in common is that $\mathrm{s} / \mathrm{he} . .$.

... attempts to use his or her work as a form of social or cultural criticism and who accepts basic assumptions that all thought is fundamentally mediated by power relations that are socially or historically constituted. (Kincheloe \& McLaren, 2008, pp. 404-405)

Applying these ideas to the topic of youth citizenship participation, draws attention to the processes in society which mediate young people's expressions of citizenship and access to participatory experiences. Young people within a critical youth studies approach are positioned as a "marginalised group" in order to draw attention to structural and ideological issues which restrict their full potential in adult society, but also to highlight the active way children and young people exercise their agency in society (James \& James, 2008). This approach also draws attention to social and historical contexts of young people and how these shape young people's agency (R. White \& Wyn, 1998).

Critical ideas have also been widely applied within educational contexts to underscore that "social and ideological contexts orient the general purposes and practices of educational systems" (J. L. Nelson, 2001, p. 27). Authors in this tradition highlight the power relations which underpin the "official knowledge" 
(Apple, 1979, 1993) in schools and curricula and point out that access to this knowledge is highly stratified (Bernstein, 1971; Young, 1971, 2008). In a curriculum context, a critical, constructionist approach draws on an understanding of curriculum as a "socially contextualised process"(Cornbleth, 1990), and thus is inseparable from the social, political and economic context from which it is derived.

Teaching and learning approaches which are infused with ideas from critical theory are known as critical pedagogy. Rather than viewing instruction and learning as a neutral process clinically removed from the contexts of history, power and ideology, critical pedagogues view education as inherently political (Freire, 1985; Giroux, 2009) and work to critique and transform socio-cultural power structures with the aim of creating freedom, social justice and equality of all societal members (Kincheloe, 2007). A key way that critical pedagogues espouse their commitment to emancipatory practices in classrooms is to recognise the importance of viewing education as inseparable from the social and historical contexts that people find themselves in. Rather than try and separate a learner from his or her context, personal themes that drew from the context of lived experiences provide the "generative themes" which become the starting point of "reading the word" and "reading the world" (Freire, 1973/1996).

The importance of focusing on personal and lived experiences has been advanced and linked more specifically to aspects of "place" by authors such as David Gruenewald (2003) and Gregory Smith (2008). Gruenewald (2003) proposes that a conscious synthesis of the traditions of critical pedagogy and place-based pedagogy provides an opportunity to form a critical pedagogy of place. Developing a critical pedagogy of place requires educators to expand the scope of their theory to include the cultural, political, economic and ecological dynamics of places, and to challenge each other "to read the texts of our own lives and to ask constantly what needs to be transformed and what needs to be conserved" (Gruenewald, 2003, p. 94). The starting point for this approach is an engagement with local communities and local places, yet implicitly recognises 
the interconnected of the local with global patterns and processes (Gruenewald \& Smith, 2008). A critical pedagogy of place provides an important conceptual and theoretical approach in the development of this research as it seeks to examine young people's participation within the context of their places and communities, and to pay attention to how their experiences of place shape their conceptions and practices of social action.

My exploration of youth participatory citizenship draws from these critical traditions and a social constructionist understanding of people's interaction in the world. The leading idea behind social constructionism is that "the world we live in and our place in it are not simply and evidently 'there' for participants. Rather, participants actively construct the world of everyday life and its constitutive elements" (Gubrium \& Holstein, 2008, p. 3). My use of these ideas is primarily through Bourdieu's "structuralist constructivist stance" (Bourdieu \& Wacquant, 1992, p.12), which involves a dual focus on the objective social structures and the subjective actions and dispositions of agents, the interplay of which combine to reproduce or transform patterns of society. The focus of this theoretical stance is upon the critical interaction between young people and teachers' participatory social and cultural capital and their citizenship dispositions and actions.

This position will be outlined in Chapter 3, when I explore in greater detail how Bourdieu's theories and concepts could provide a theoretical and conceptual framework for the exploration of young people's participatory citizenship. I also introduce C. Wright Mills' (1959) "sociological imagination" as a methodological tool of inquiry. Mills proposes that the fruit of this imagination is the ability of an individual to understand his or her biography within a broader socio-historical context. The concepts derived from a Mills-Bourdieu approach provide an integrating framework between the disciplines which I have drawn from to inform this research. Broadly, these disciplines include ideas and research derived from the sociology of education, youth sociology and traditions within the geographies of children and young people. My research sits at the 
intersection of these fields and focuses specifically on youth participatory citizenship.

It is important to acknowledge at the outset that the use and understandings of participatory citizenship are far from universal (Faulks, 2000; Kennedy, 2007; J. Nelson \& Kerr, 2006). It is this malleability that makes the study of citizenship especially interesting and important. For these reasons, and as a way to position the stance I take in this research, I begin this thesis by outlining three central propositions which have shaped and informed this study.

\section{Central propositions}

The first proposition is that we need to hear from young people themselves about their conceptions and practices of participatory citizenship. This means we need to move beyond adult-centric definitions and allow for inclusive, generous and youth-centred conceptions of citizenship participation (O'Toole, et al., 2003) in the context of young people's lived experiences (Hall, Coffey, \& Williamson, 1999; Harris, et al., 2007; Harris, Wyn, \& Younes, 2010; Marsh, et al., 2007). As Barber (2009) states, "the achievement of citizenship must be contingent upon relating to the multiple meanings young people themselves attach to this concept" (p. 38).

The second proposition is that children and young people's participation is most meaningful when it is rooted in their everyday lives (Clark \& Percy-Smith, 2006; Thomas \& Percy-Smith, 2010). Importantly, this begins with young people's "lived experiences" of citizenship participation, not just their "performed participation" (Pells, 2010). ${ }^{3}$ Woodhead (2010) proposes that "we may need to move beyond 'listening' and 'giving children a say', and to focus more directly on the meaning of participation in everyday life and on how young people can live 'active citizenship"' (p. xxii). Marsh et al. (2007) suggest that this is one of the most important areas to explore within youth participation research as it holds the potential to explain how young people's lived experiences shape their

\footnotetext{
${ }^{3}$ Kirrily Pells (2010) sets up a distinction between "performed participation" (an extraordinary activity to children's daily lives - such as a one-off consultation of children) and "lived participation" which is rooted in the structures and activities of daily life.
} 
conceptions of the political, whilst still viewing their lived experiences as a structured process (p. 85). That the everyday "lived experiences" of young people are different from those of adults is an important starting point in critical youth studies, yet has only been weakly developed in much citizenship research. The absence of this starting point has lead to research that has compared children and their expressions of citizenship directly with those of adults; it has focussed on children and young people's rights and responsibilities, but failed to acknowledge the constraints that inhibit young people as a result of adult actions and attitudes (Edwards, 2007). Focusing on everyday experiences rebalances this by acknowledging that "the meaning that citizenship actually has in people's lives and the ways in which people's social and cultural and material circumstances affect their lives as citizens" (Lister, 2007b, p. 695).

Third, a more coherent understanding of context is needed if we are to fully understand how and why young people participate (Barber, 2009, p. 38). We know very little about how different contexts and experiences in communities and schools shape young people's dispositions. Yet, there is evidence to suggest that young people occupy distinctive spaces in society compared to those of adults (Hil \& Bessant, 1999; Matthews, Limb, \& Taylor, 2000; Skelton \& Valentine, 1998). Focusing on the significance that "common and modest cultural youth spaces such as school, peer networks and family households" (Harris \& Wyn, 2009, p. 342) have on how young people experience and express their citizenship is likely to render a quite different landscape of participation. Moreover, knowledge of how the social and cultural capital young people are exposed to in these school and community sites may contribute to more nuanced understandings of young people's habitus of citizenship participation (Holt, 2008).

With these propositions in mind, I have taken an approach in this research which endeavours to enable young people to express their "everyday, placebased" perspectives on participatory citizenship. By placing this approach within a theoretical framework informed by Bourdieu's concepts of habitus, capitals and field (Bourdieu, 1977a, 1990), as well as Mills' (1959) “sociological 
imagination," I intend to allow for opportunities to explore how citizenship dispositions and practices of young people and their teachers are shaped by their everyday contexts. For the purpose of this research, I will define the concept of participatory citizenship as I understand it, and explain why I have undertaken this research with a specific focus on social studies students, teachers and curricula.

\section{A definition of participatory citizenship}

Broadly, participatory citizenship includes any citizenship actions which work toward the common good of society (Cremin, et al., 2009). Ariadne Vromen (2003) elaborates on this further and defines participatory citizenship as "acts that can occur, either individually or collectively, that are intrinsically concerned with shaping the society we want to live in" (pp. 82-83). This definition includes a focus on change, transformation or "shaping" which is linked to a "desired" society we live in, thus making an immediate link to the everyday lives of citizens and their communities.

Other concepts used almost interchangeably within the international literature in this area include "active citizenship" (Kennedy, 2006, 2007; J. Nelson \& Kerr, 2006) and "civic engagement" or "civic action" (Cremin, et al., 2009). In New Zealand, the term most commonly used in curricula to convey a sense of working toward the common good in society, is "social action." This term is used specifically in successive New Zealand social studies curricula (Barr, et al., 1997; Department of Education, 1977; Ministry of Education, 1997, 2007) (see Appendix A). In keeping with Vromen (2003) and Lister (2008a), I have found the term participatory citizenship the most useful umbrella concept in defining the focus of my research as it implicitly includes both the concepts of participation and citizenship together. In my research "social action" was the concept I used when talking to New Zealand social studies students and teachers in keeping with how this term has been used in curricula. Arguably, it was also a more accessible concept than "participatory citizenship." While expressions of social action may differ from "participatory citizenship", I would suggest that the concept of social action applied within New Zealand social studies includes an 
implicit understanding of how people contribute (as citizens) to the life of the community (Department of Education, 1977), and therefore is used with similar intent to how concepts of participatory and active citizenship are understood internationally (understanding also that these conceptions lack uniformity) (J. Nelson \& Kerr, 2006).

\section{Curriculum focus: social studies ${ }^{4}$}

The decision to research within the curriculum area of social studies reflects the status this curriculum traditionally has held as the primary vehicle in New Zealand for citizenship education (Archer \& Openshaw, 1992; Barr, 1998; Mutch, 2005a, 2005b; Openshaw, 2004), as well as the curriculum that articulates the concept of participatory citizenship (through "social action") most clearly. Since the introduction of social studies into the common core curriculum of postprimary schools in 1946, successive social studies curricula have illustrated a continuing commitment to the "twin goals of understanding the world and developing the skills of responsible citizenship" (Barr, 1998, p. 110). The more participatory aspects of citizenship in social studies curricula have been conveyed by the concept "social action" (see Appendix A for an outline of how social action has appeared in social studies curricula).

Historically, participation in New Zealand curricula is largely expressed as a type of community service to prepare for future (adult) roles as citizens (G. Aitken, 2005). For example, in the 1940s, students were encouraged to perform community services (Department of Education, 1944, p. 31) and prepare for an "active place in our New Zealand society as worker, neighbour, homemaker, and citizen" (Department of Education, 1944, p. 5). In the 1960s, they were to "act responsibly and intelligently in social situations" (Department of Education, 1961, p. 1), and through the seventies and eighties they were to "contribute to the life of their community" (Department of Education, 1977, p. 5).

\footnotetext{
${ }^{4}$ Social studies is a compulsory curriculum area for all New Zealand students between years 1-10 (ages 5-14) and an optional subject for years 11-13. Prior to the $2007 \mathrm{New}$ Zealand Curriculum, social studies had separate curriculum document, but in the 2007 document it has been placed within an integrated social sciences learning area. For this reason, when I refer to this 2007 document, I revert to social sciences rather than social studies.
} 
Social action became one of the issues of contention during the social studies curriculum turf wars of the mid 1990's. Social action featured in the 1994 social studies curriculum and students were encouraged to know facts, think about an issue and "go on to consider what can be done about the issue and to take positive action as a result of their learning" (Ministry of Education, 1994, p. 17). However, the ensuing outcry by conservatives led to a Revised Draft in 1996 (Ministry of Education, 1996), which was in turn lambasted by liberals for being "a political cop out" (Openshaw, 2004, p. 279). The 1997 document finally had enough support to proceed to final status but not before "social action" which had been introduced as a central concept to New Zealand social studies in the 1997 social studies position paper (Barr, et al., 1997), had been redefined as "social decision making." As discussed earlier, social action has a more "active" connotation in the 2007 social sciences learning area with students required to "take action" as citizens (Ministry of Education, 2007, p. 17). This pattern can also be seen in changes made to senior social studies NCEA assessment, where from 2011, Level 1 students are required to "report on an involvement in a social justice and human rights action" (AS91042), and "describe a social justice and human rights action" (AS91043) (NZQA, 2010).

In light of this heightened attention upon participatory citizenship in the New Zealand Curriculum, and with awareness of the contested and politically charged nature of such concepts, it is important to find out more about the meanings and understandings of participatory citizenship held by schoolaged young people themselves. The primary focus of this research is on school-aged young people, recognising that this group in society are often marginalised from participation in civic society and schools and are viewed as "citizens-in-the-making" (Weller, 2007) or "apprentice citizens" (Owen, 1996) rather than citizens now . However, I was also conscious that "listening to children's voices alone will not suffice" (Mannion, 2007, p. 414) as many of their experiences of participation are mediated through significant adults, especially parents and teachers. My focus therefore also includes the social 
studies teachers of the school-aged young people in this research, with particular interest in how their social and cultural capital shapes the citizenship dispositions of their students. My research is guided by the following three research questions:

\section{Research questions}

1. What are social studies teachers' conceptions of social action and how do these inform their practices of social action?

2. Which social issues do social studies students perceive to be important and why?

3. How do social studies students define and participate in social action?

\section{Personal motivations for research in this area}

The notion of youth participation in society has been a source of interest to me over many years in my roles as a youth leader, Sunday school teacher, and social studies/geography teacher. I was aware from these experiences that providing opportunities for young people to be involved in social action was both thoroughly rewarding, and simultaneously challenging. For example, in my second year of teaching at a low decile, rural New Zealand high school, I was given a Year 12 (age 15-17) class that were deemed unlikely to pass the formal external exams. I was told to occupy them around environmental issues for a year to "keep them out of trouble," and there were few boundaries put on the topics I could choose. So the programme for each term was developed around broad environmental themes that the young people had interest in. That year we climbed volcanic peaks looking for the spread of a wilding pine (pinus radiata) in the name of alpine environmental sustainability; we lobbied the local Council for a safer road crossing for students at the high school (we failed to achieve that goal, but gained a bit more wisdom into local government processes); and all bawled our eyes out as we examined data on the high rate of road deaths for teenagers in rural areas following three such deaths in the school that year. My memories of that class are some of the most distinct I had in any year of teaching as a result of our shared experiences of "social action". 
Yet, I also found that the opportunity to pursue such a programme was rare. Far more frequently, we had set curricula to make our way through, assessments to achieve and grades to be given, especially at the higher year levels of the school. My experience with the environmental studies class was unique because, as long as I didn't get them, or the school, into trouble, I could pursue a programme that was at least partially student-directed, and engaged with the local community. As a young teacher I saw these aspects of teaching in the social sciences an essential part of developing citizenship dispositions in my students. Yet, I was also aware that social action was one of the "hard bits" (Keown, 1998) to teach, as it was difficult to define, potentially controversial to implement and had fewer tangible outcomes than, for example, an exam.

A number of years later, I joined a team to write the social studies component of the revised New Zealand Curriculum. I became aware of many conversations around the concept of "social action" that took place through the Curriculum Project (see, for example, the Social Studies Community Café, Ministry of Education, 2004). It seemed that many teachers were keen to see the presence of social action elevated in social studies, rather than "social decision making"5 of the previous curriculum (Ministry of Education, 1997). So, when social action did feature with an elevated status in the New Zealand Curriculum, I saw this as an opportunity to explore this area further, with a particular focus on school-aged young people toward whom this curriculum policy was directed. As an advocate of social action in social studies, I have also attempted to step back and "trouble" the conception of social action throughout this research, rather than assuming it to be an inherent good.

\section{Outline of the thesis}

The layout of the thesis is as follows. In Chapter 2, I review the patterns and experiences of youth participation in the literature to explore and explain why

\footnotetext{
${ }^{5}$ Social decision making in this 1997 curriculum was described as "making decisions about actions that could be taken on a range of issues and problems in society (Ministry of Education, 1997, p. 18, emphasis mine).
} 
youth participatory citizenship remains a contested and complex concept. I suggest that we need fresh approaches in this area that more closely reflect the everyday lived experiences of young people. I also review recent research that has been exploring alternative conceptions of participation.

The conceptual and theoretical framework which I use throughout this thesis is developed in Chapter 3. This framework is informed by Bourdieu's conceptual triad of habitus, capitals and field (Bourdieu, 1977b, 1990). I also explain how I will operationalise a "sociological imagination" (Mills, 1959) approach to gaining insights into young people's citizenship dispositions.

Chapter 4 provides an overview of the methodology employed for this research. I describe the use of café-style focus groups and Photovoice research methods to generate visual and verbal qualitative data for this project. More traditional focus groups were undertaken with teachers. In this chapter I also outline my approach to data analysis and provide detail on ethical considerations for working with young people.

In Chapters 5, 6 and 7, I report on findings from my research. The focus in Chapter 5 is on the social studies teachers from each of the four schools and on their conceptions and practices of social action. I suggest that these conceptions and practices contribute to an indication of their citizenship dispositions which are reflected their orientation toward local or global social action. In Chapter 6 I examine how the sense of identity and belonging to places, and the social and educational capital derived from school and communities contributed to the issues young people reported to be "important". I suggest that their emerging "citizenship imaginations" provide powerful insights into their citizenship dispositions. In Chapter 7, I then examine youth participant's definitions and examples of social action. In both these chapter I use "keyhole narratives," or vignettes to illustrate young people's perspectives with greater detail.

Chapter 8 discusses some emerging patterns of participation that can be seen from the research findings. In particular I consider how aspects of identity and 
experiences of belonging to places and communities shape citizenship dispositions and actions. I also examine how young people's economic, cultural and social capital informs both their perception of issues and the site of focus (local/global; formal/informal). I propose that "participatory capital" is generated within schools and communities, and shapes relationally and spatially-informed expressions of participatory citizenship. I conclude the thesis in Chapter 9 by reviewing findings from this research and drawing together a number of conclusions. I also offer suggestions for further research in this area. 


\section{CHAPTER 2}

\section{LITERATURE REVIEW: \\ KEY DEBATES AND PERSPECTIVES ON YOUTH \\ PARTICIPATORY CITIZENSHIP}

While there is much consensus that citizenship is a desirable thing, there is much less agreement about what the status should entail, what kind of community best promotes citizenship, and whether the status is inherently exclusive. (Faulks, 2000, p. 2)

In this chapter I review some of the key debates and perspectives on youth participatory citizenship within the literature. I begin with an overview of theories of youth in society from a sociological perspective, followed by an examination of the "vocabularies of citizenship" (Lister, et al., 2003) represented in five traditions of citizenship. In light of the socially and historically constructed nature of citizenship apparent within this examination, I draw attention to two recent social and educational policies (the "Third Way" and the "Knowledge economy") to examine the contemporary socio-political backdrop to the participatory citizenship ideals of the 2007 New Zealand Curriculum. I then investigate current research describing patterns of youth citizenship participation internationally and in New Zealand, drawing attention to the complex and problematic experience of citizenship participation for many young people.

Building on the work of Harris, Wyn and Younes (2010), I propose that there is a need to move beyond "activist" or "apathetic" debates about youth participation which have dominated discussions in this area internationally. Rather than applying adult-centric and narrowly conceived conceptions of participation, I aim to provide opportunities for the diverse experiences of youth citizenship participation to be viewed within the context of young people's everyday, placebased experiences (Harris, et al., 2007; Lister, 2007a; N. Smith, Lister, Middleton, \& Cox, 2005). 


\section{Theorising children and young people}

In Chapter 1, I proposed that there has been a growing priority for young people's participation in society. These changes reflect in shifts in thinking about children and childhood, and the role of children and young people as citizens in society. In 1990, James and Prout (1990) set out a "new paradigm" in approaches to childhood which were informed by sociological theory. Drawing a clear distinction from developmental psychology approaches that construct childhood as a period of development, they called for children to be recognised as social actors (shaping their own and other lives around them) as well as being shaped by their circumstances. The focus on children is not on becoming, which they argue is the domain of developmental approaches to childhood, but rather on being - a child in his or her own right, a social actor (see also Holloway \& Valentine, 2000). This approach has become known as the "the new social studies of children"6 and was developed further by James, Jenks and Prout (1998) in their pivotal book Theorizing Childhood. This approach also considers aspects of social change as an important factor in theorizing childhood.

This shift of thinking generated a "cataclysmic shift in thinking about children as they challenged the prevailing characterization of children as passive actors and instead emphasized children's autonomy and competence as actors in their own right" (Best, 2007, p. 11). This had important implications for conceptions of child participation by demonstrating the agency of children as social actors through theoretical and empirical contributions (James \& James, 2008). The new social studies of childhood also contributed significantly to the development of research methodologies that focused on more active participation of children in the research process (see Chapter 4). In subsequent years, the ideas of the sociology of childhood have been developed and applied in a varied disciplines such as children's geography (S. Aitken, 2001; Holloway \& Valentine, 2000; Weller, 2007), social work (Hill, 2006 in V. Morrow, 2008) and across a range of critical youth studies (Best, 2007).

\footnotetext{
${ }^{6}$ Also referred to as the "new sociology of childhood" or "new childhood studies" (Best, 2007), or simply "childhood studies" (James \& James, 2008).
} 
Accompanying the ideological shifts of the "new" social studies of children has been a body of similar theorising in the area of youth sociology by Johanna Wyn and Rob White's (1997) in particular. In their book Rethinking Youth, they propound the importance of viewing youth as a socially and culturally constructed concept, rather than a universal stage of development or "age" (implicit in psychological and "adolescent" approaches to young people). They suggest that concepts of youth and adulthood only have meaning within their local social and historical context and advocate for contextualised understandings of youth in their diverse and varied localities beyond that of a universalised experience.

A second key idea of Wyn and White (1997) is that youth is importantly understood as a relational concept "because it exists and has meaning largely in relation to the concept of adulthood" (p. 11). ${ }^{7}$ This idea illuminates the liminal position that youth occupy between childhood and adulthood - not quite child yet not quite adult. This state is problematic as it renders young people's position in society as one of ambiguity (Sibley, 1995; Skelton, 2000; Weller, 2007). The response of adult society to this ambiguity has often been to view youth in a state of "becoming" rather than "arrived", a state of "dependency" rather than "independence", "... as the time of youth is about a future (real) life adulthood" (Wyn \& White, 1997, pp. 12-13).

Viewing youth as a socially constructed and relational concept has important implications within the field of youth participation as it draws attention to the social, political and historical contexts of participatory citizenship, as well as the ambiguous and contradictory positions of young people in society. White and Wyn (1998) suggest that:

Taking a contextualised approach to researching and writing about young people exposes the extent to which young people negotiate, contest and challenge the institutionalised processes of social division. Youth agency becomes more visible as more than just the exercise of predetermined choices (p. 324).

\footnotetext{
${ }^{7}$ But see Smith et al. (2002) who suggests that this category can also be reclaimed by youth as a "powerful self-determining category" (p. 177).
} 
Viewing the liminal status of youth in relation to adulthood also explains how young people are encouraged to participate as citizens on one hand, yet paradoxically told to return to a more child-like status when they transgress the boundaries of adults spaces and rights (Hil \& Bessant, 1999; Sibley, 1995). This appears to be the case for younger teens in particular who are subjected to higher levels of regulation and adult control than older teens (Weller, 2006a). A critical youth studies approach within this research area then seeks to expose young people's experience of marginalisation and subjection to adult regulation within their geographic and sociological contexts and also highlight young people's agency within structural and adult-imposed constraints. Only by taking this approach can we "provide a sensitive and realistic picture of the nature of the choices available to, and actually made, by young people” (R. White \& Wyn, 1998, p. 325).

This theorising about youth has informed my approach toward young people in this study. This is reflected in the terms I have used throughout the thesis. Instead of using the term "students" as is common practice in educational writing, I have used, where possible the terms "youth" or "young people". Both of these terms convey the social construction of teenagers in society, rather than a universal stage of development (James, et al., 1998; Wyn \& White, 1997). Theories about how young people are socially constructed also influence how they are perceived as citizens. As the following section reveals, there are multiple traditions of citizenship and citizenship participation that reflect varying ideological political positions.

\section{Traditions of citizenship participation}

Definitions and conceptions of citizenship have been influenced by differing social, cultural and political ideas since the inception of the concept in Ancient Greece and Rome. In this section I outline how five traditions of citizenship, namely, liberal, civic republican, communitarian, identity-based citizenship and global cosmopolitan citizenship, each give rise to different constructions and meanings of the concept of citizenship participation. 


\section{Liberal citizenship traditions}

The emphasis in liberal citizenship is on individual rights, choice and agency, albeit within the political constraints of democratic nations (Abowitz \& Harnish, 2006; Kennedy, 2008a). A liberal approach relies on strong legal and human rights frameworks to guide and support the entitlement to rights of individuals. Possibly the most well known early proponent of a primarily liberal notion of citizenship was the English sociologist T. H Marshall who viewed citizenship as "a status bestowed on those who are full members of a community. All who possess the status are equal with respect to the rights and duties with which the status is endowed" (Marshall, 1950, pp. 28-29). ${ }^{8}$ Participation in a (neo)liberal sense is in the private sphere, (Liebel, 2008), as well as fulfilling the obligations and duties of a citizen (such as voting) and involves ensuring personal freedoms and rights, and personal responsibility in area such as economic or family matters (Lister, 2008b).

\section{Civic republican citizenship traditions}

An alternative ideology to liberalism is that of civic republicanism which reinforces the responsibility of members of community to contribute to the wellbeing of all in that society. This approach is characterised by "commitment to the political community, respect for its symbols, and active participation in the common good" (Abowitz \& Harnish, 2006, p. 657). The obligations of citizenship within this tradition are primarily political, with a focus on approaches which benefit the "common good" of communities, and also, to a lesser degree, the development of the individual (Lister, 2008b). Participation within a civic republican tradition includes actions to protect democracy (such as involvement in political parties) and participating in activities to reinforce the well being of all in society.

\section{Communitarian citizenship traditions}

Communitarian traditions emphasise the rights and responsibilities for people as part of their inclusion within communities. Communitarians hold that the

\footnotetext{
${ }^{8}$ Lister (2008b) notes that Marshall's primary focus on status and rights of citizens still require an acknowledgement of citizenship as 'practice' when he describes the 'duties' citizens perform which raises the question of whether his contribution to citizenship theories fits neatly within liberal conceptions.
} 
community, rather than the individual or State, should be at the centre of our analysis and our value system (Arthur, 2003). The rise in communitarian citizenship is associated with Third way policies and is reflected in new policies promoting volunteering and participation in community services (in the UK and US in particular) (Annette, 2009; Arthur, 2003; Hahn, 2008). As discussed in Chapter 1, communitarian participation has become more attractive in light of a perceived loss of community in modern times.

\section{Identity-based citizenship traditions}

The emergence of identity-based citizenship has been a feature of the last two decades. There is a growing recognition of "critical citizenship" and "cultural citizenship" (Rosaldo, 1989) approaches which take more consideration of issues of representation, identity and engagement of otherwise marginalised citizens within a nation (Ben-Porat \& Turner, 2008). Participation in this tradition emphasizes self expression, identity and difference along with flexibility of social membership (Isin \& Turner, 2007).

\section{Global and cosmopolitan citizenship traditions}

Beck (2007) refers to a growing "cosmopolitanisation", which he defines as the "erosion of distinct boundaries dividing markets, states, civilizations, cultures, and not least of all the lifeworlds of different peoples" (p. 1). Rather than a boundary-less world, he describes one in which borders are more "permeable" and less distinct. Others have also argued that citizenship is layered and operates simultaneously at local, regional, nation-state, and global levels, thus requiring more global, cosmopolitan and transnational conceptions of citizenship (Heater, 1999; Osler \& Starkey, 2005). Osler and Starkey (2005), for example, suggest that citizenship education needs to more explicitly recognise issues of diversity by working toward creating citizens of a world community based on common human values. Cosmopolitan and global citizenship participation includes responsibility for global issues beyond the nation-state and includes advocacy, fund-raising and international lobbying.

The varying interpretations and perspectives of citizenship amongst these five traditions of citizenship described here (which are by no means exhaustive) 
illustrate how citizenship has a "dynamic identity" (Faulks, 2000, p. 6). For this reason, citizenship is understood in this research as a contested concept, the understanding of which cannot be divorced from the context in which it is developed and the ideology that drives it (Cremin, et al., 2009; Kennedy, 2008a). As a concept it has proven malleable and adaptable to the changing needs of governments, officials and educators through time as it has the potential to serve the aims of both the right and the left (Brooks \& Holford, 2009). As Wallace (2001) succinctly states, empowerment and citizenship have become attractive options for governments:

This is because they can accommodate the fragmentation of social groups, the movement from collectivistic toward individualistic beliefs, the retreat of the welfare state and the scepticism of the 'grand narrative' solutions to social problems which we are all part of in a general 'postmodernisation' of societies. (p. 11)

This has contributed to the "almost universal appeal" (Faulks, 2000, p. 1) of citizenship.

Importantly, the concept of citizenship is "neither neutral nor innocent" (Cohen, Manion, \& Morrison, 2000, p. 33), but instead represents "socially organised knowledge" that reflects the inherent political and ideological tensions that are present in society (Young, 1971). Within curricula then, the nature of citizenship presented will reflect changing values and priorities of a nation depending on the salience of particular ideologies (Kennedy, 2008a). It follows from this that citizenship curricula "will always reflect current conceptions of the 'good citizen' as the ends towards which the curriculum is directed" (Kennedy, 2008a, p. 486). Drawing from an analysis of the New Zealand Te Whariki (early childhood) curriculum, Duhn (2008) points out that a curriculum document "is not a neutral document but a cultural artefact", representing "the desires, aspirations and ambitions for the child as a future contributor to society from the view point of powerful adults" (p. 84). With this in mind, "curriculum analysis is political analysis" (Duhn, 2008, p. 84).

In the following section I will introduce two social policies in New Zealand (the Third way and the Knowledge economy) that have both promoted a type of 
participatory citizenship. I will suggest that the integration of these ideas into the New Zealand Curriculum provide a way of seeing how this concept of citizenship is unendingly malleable at the hands of government officials who will always find new ways to construct citizenship "to give form to the changing needs and aspirations of the citizen and community" (Faulks, 2000, p. 6).

\section{Two policies promoting participation in New Zealand}

\section{'Third Way' policies}

In the 1990s, a form of governance known as the "Third Way" began to be discussed in the United States (under Bill Clinton) and the United Kingdom where it was closely linked to the rise of Tony Blair's "New Labour" government (Annette, 2009; Prout, 2003; Wolmuth, 2009). Third way proponents speak of a "third" political pathway which embraces the mutual benefit of a strong society and a strong economy by arguing that strengthening the bonds of community and trust within society will lead to economic prosperity and stability (Giddens, 2000). By blending aspects of the political left and right, Third way administrations "believe that the judicious use of market forces can contribute greatly to the state's social and economic objectives" (Strathdee, 2006, p. 240). These policies placed a strong emphasis on promoting social inclusion and community responsibility for social issues, marked by a parallel shift of governmental responsibility away from provisions previously made through state welfare. The concept of the citizen is transformed and:

the so-called 'passive' citizen of the welfare state becomes the autonomous 'active' citizen with rights, duties, obligations and expectations - the citizen as active entrepreneur of the self; the citizen as morally superior. (Davies \& Bansel, 2007, p. 252)

Ideas about a Third way began to emerge in New Zealand in the 1990s and became a feature of the fifth Labour government. This was in part a response to the increasing tax burden of welfare that appeared likely to worsen given the emerging financial pressure created by aging baby boomers. Third way policies were greeted with enthusiasm as a way to highlight the contribution that high levels of 'social capital' and community participation could have in developing a 'productive' economy and society, whilst still maintaining many of the free 
market neoliberal ideals that Labour inherited from that National government (Kelsey, 2002). These "new social democracy"9 policies centred on "re-engaging citizens with decision-making processes" (Jochum, et al., 2005) which included building networks between government and business, with a renewed recognition of volunteers and charities as the "glue - the network of connections - that binds communities together" (Maharey, 2001 in Kelsey, 2002, p. 83).

While many of the ideals promoted by the Third way have not seen fruition, and critics (for examples, see Codd, 2005b; Fitzsimons, 2006; Kelsey, 2002) suggest that many of its claims of greater social inclusion, pluralism and democratic participation have been replaced by neoliberal economic managerialism, the Curriculum Stocktake Report (Ministry of Education, 2002) which served to guide the subsequent 2007 curriculum development, "picked up on the notion of fostering citizenship as a means to addressing social ills" (Mutch, 2008, p. 210). The Stocktake called for a greater recognition of the "future focused themes" of citizenship, social cohesion, enterprise and sustainability, as well as advocating for the inclusion of social outcomes in the proposed new curriculum such as the attention to values and citizenship education (Ministry of Education, 2002). A second key idea that I propose has influenced the new curriculum and the nature of participatory citizenship in it, is the idea of the "Knowledge economy" or, as it became known in New Zealand the "Knowledge society."

\section{Knowledge society policies}

Rapid technological change and intensifying globalisation processes during the 1990s began to highlight the key role that knowledge plays in an informationrich and networked society (Castells, 2000). Knowledge economy proponents argue that instead of producing items and products, the "new" global economy requires ideas, innovation, creativity and critical thinking to ensure economic competitiveness (Gilbert, 2005) and were promoted in the OECD publication The Knowledge-based Economy (1996). Ideas about a "knowledge economy" began to surface in New Zealand in the late 1990's, notably when the Information

9 The concept of the Third Way in New Zealand was later replaced by the term "new social democracy" (Kelsey, 2002). 
Technology Advisory Group submitted to the New Zealand government their landmark report, The Knowledge Economy (1999). This report marked a clear shift in thinking for the transformation of New Zealand from "a pastoral economy into a knowledge-driven economy" (Information Technology Advisory Group, 1999, p. 1).

These shifts in thinking about knowledge required a new emphasis for "learning how" rather than "learning what" (Kennedy 2008) in order to develop the problem solving and critical thinking skills which are seen as the drivers of innovation and enterprise in a knowledge society (Grossman, 2008).

Competencies, rather than skills, were seen to be an essential part of the need to develop flexible, adaptable employees for rapidly-changing, knowledge-based societies. Competencies, as defined in the DeSeCo Report (OECD, 2005), also include relational and participatory goals such as the ability to relate to others, to form strong social networks and develop empathy. Underpinning the competencies is a belief that new knowledge is social in character and created by individuals working together (Strathdee, 2006). The development of these competencies are recognised as important for promoting social cohesion as well as innovation and economic success (OECD, 2005).

In addition, as education can no longer be seen as static or complete within a set period of time, the concept of "lifelong learning" is now "almost a mantra" (Kennedy, 2008b, p. 17) in official government and curricula documents around the world, placing the responsibility firmly on individuals to meet the changing needs of the labour market by re-educating themselves in a process of "individualized and recurrent continuous learning and qualification pathways" (Chisholm, 2001, p. 65). Ideas about new approaches to knowledge within education were outlined by Jane Gilbert $(2003,2005,2007)$ in New Zealand and her work was profiled closely by the Ministry of Education in the curriculum developments between 2004-2007.10

${ }^{10}$ For example, Gilbert's paper "New knowledges and new ways of knowing" (2003) was handed out to teachers who attended the Curriculum Hui in May, 2004, and her presentations profiled on the New Zealand Curriculum online site (http://nzcurriculum.tki.org.nz/Curriculumstories/Keynotes-and-presentations). 
I suggest that the integration of themes from both these policies can be seen in the New Zealand Curriculum. In an earlier paper (Wood, 2009), I argue that Third way and Knowledge society policies have, firstly, contributed to a heightened priority for citizenship participation in the New Zealand Curriculum, and secondly, have influenced the nature of the participatory citizen evoked within this curriculum document. For example, in keeping with the principles endorsed in Third way policies, there has been an increased emphasis on community responsibility with school-based curriculum development, (Ministry of Education, 2007, p. 37), and an increased level of citizenship responsibility to address social issues (such as enterprise, globalisation sustainability, and citizenship) (Ministry of Education, 2007, p. 9). In addition, the more flexible, inquiry-driven curriculum, with an emphasis on lifelong learning, problemsolving, innovation and enterprise, along with the development of key competencies (Ministry of Education, 2007, pp. 12-13) ${ }^{11}$ illustrates how closely the ideas of the Knowledge society are also reflected in this curriculum document. Codd (2005b) surmises that the integration of Third way and Knowledge society ideas under neoliberalism has resulted in economic objectives replacing citizenship as the primary purpose of New Zealand's public education.

By examining active citizenship within the context of these two neoliberal policies, it is possible to read two very different interpretations of this curriculum document. One interpretation is that this curriculum document offers opportunities to develop active citizens who challenge existing power relations, and question underlying issues of social injustice in society. Within the traditions of education, theorists such as Freire (1973/1996) and Giroux (1997) have promoted education that develops the critical consciousness of citizens and equips them to make critical interventions in society. This type of citizenship can be described as "maximal" (McLaughlin, 1992) or "justice-oriented" citizenship

\footnotetext{
${ }^{11}$ The key competencies include thinking, using language, symbols and text, managing self, relating to others and participating and contributing (Ministry of Education, 2007, pp. 12-13).
} 
(Westheimer \& Kahne, 2004). These ideas are developed further in the next section.

An alternative interpretation, and one which is arguably more likely within the backdrop of neoliberal reforms outlined above, is that this new curriculum promotes a type of active citizenship within narrowly framed parameters of social and economic acceptability. A number of authors, reflecting on New Zealand curricula question whether the participation agenda more closely falls into line with a neoliberal agenda narrowly conceived as creating self-managing civic agents and citizen-workers (Codd, 2005a; Duhn, 2006; Harris, 2006; Kidman, 2005; Wallace, 2001), or what Cameron White refers to as "participation through passivity" (C. White, 2005). Youth citizens in this "minimal" (McLaughlin, 1992) sense of citizenship participation are encouraged to participate within their capacity as young entrepreneurs, consumers, future workers and helpful citizens that support the status quo. Perhaps the critical question to turn to is the nature of ideal citizens: Just what kind of citizen does our society want?

\section{Contested conceptions of participatory citizens}

The concept of participation is highly contested and in many ways ill defined theoretically. At best we can model a notional spectrum of involvement from the 'passive' to the 'active' and observe behaviours and outcomes which support our assertions, but then we must ask, who defines that which is passive/active and the complexities which locate in between? (Barber, 2009, p. 27)

As introduced above, one of the ways in which we can make sense of how people make meaning of citizenship in society and in curricula, is by examining the degree to which the "ideal" citizen evoked within curricula discourses contributes to "minimal" and "maximal" conceptions of citizenship (McLaughlin, 1992). McLaughlin suggests that minimal views of citizenship relate primarily to formal and legal citizenship status and participation, which includes obeying the law, voting and helping neighbours (Table 2.1). Westheimer and Kahne (2004) similarly refer to these as personally responsible citizens (see Appendix B). These 
have a good character and are honest, law-abiding members of the community. These citizens participate in conventional activities such as voting, standing for office or joining a political party (Kennedy, 2006) (see Appendix C). Within a school setting, minimal participation of students includes bums on seats (attending school) or engagement (completing set lessons) (Thomson \& Holdsworth, 2003) (see Table 2.1).

Table 2.1 Models of citizenship participation

\begin{tabular}{|c|c|c|c|}
\hline $\begin{array}{l}\text { McLaughlin } \\
\text { (1992) }\end{array}$ & $\begin{array}{l}\text { Westheimer \& Kahne } \\
(2004)\end{array}$ & Kennedy (2006) & $\begin{array}{l}\text { Thomson \& Holdsworth } \\
(2003)\end{array}$ \\
\hline \multirow[t]{4}{*}{$\begin{array}{l}\text { Maximal } \\
\text { citizenship }\end{array}$} & $\begin{array}{l}\text { Justice-oriented } \\
\text { citizenship }\end{array}$ & $\begin{array}{l}\text { Social change } \\
\text { citizenship }\end{array}$ & $\begin{array}{l}\text { Political action, student } \\
\text { activism }\end{array}$ \\
\hline & & & Active citizenship \\
\hline & $\begin{array}{l}\text { Participatory } \\
\text { citizenship }\end{array}$ & $\begin{array}{l}\text { Social movement } \\
\text { citizenship }\end{array}$ & $\begin{array}{l}\text { Student voice - involved in } \\
\text { decision making }\end{array}$ \\
\hline & & $\begin{array}{l}\text { Neoliberal active } \\
\text { citizenship }\end{array}$ & $\begin{array}{l}\text { Engagement - taking part at } \\
\text { school }\end{array}$ \\
\hline $\begin{array}{l}\text { Minimal } \\
\text { citizenship }\end{array}$ & $\begin{array}{l}\text { Personally responsible } \\
\text { citizenship }\end{array}$ & $\begin{array}{l}\text { Conventional } \\
\text { citizenship }\end{array}$ & $\begin{array}{l}\text { 'Bums on seats' - being } \\
\text { present at school }\end{array}$ \\
\hline
\end{tabular}

Source: author's own

At the other end of McLaughlin's continuum are "maximal" conceptions of citizenship. These favour a more fully participatory approach to democracy, with citizens expected to actively question the decision-making of society and work toward the empowerment of all citizens in a democracy (McLaughlin, 1992). Westheimer and Kahne (2004) refer to social-justice oriented citizens who question established social structures and work against injustice in society (Kennedy (2006) refers to this as social change citizenship) (see Appendix B). Their active citizenship activities may be legal (such as making petitions and writing letters) but also illegal (such as blocking traffic, graffiti or occupying a building). It is about vertical participation ${ }^{12}$ (bringing about change) through

12 Jochum et al. (2005) suggest that vertical participation relates to participation in civic and political activities between the individual and the state (such as voting, matters that relate to decision-making of those holding power), whereas horizontal participation relates to civic engagement, such as volunteering, participation in clubs, charities and community activities. 
attempts to influence the decision-making process (Kennedy, 2006). Thomson and Holdsworth's (2003) "maximal" category is political action or student activism such as the school-sanctioned and unsanctioned protests against the Iraq war in 2003 in the United Kingdom (see Weller, 2007).

In the central rows of Table 2.1, between the minimal and maximal extremes, are conceptions of participatory citizenship which include engagement in voluntary and community activities within established community structures to improve society and collect money for good causes. This is often called the "civic virtues" approach to citizenship and is largely about horizontal participation (Jochum, et al., 2005). Kennedy refers to this as social movement citizenship. Within a school setting, this includes "student voice" (Thomson \& Holdsworth, 2003) or shared decision-making by adults with children (Hart, 1992), and includes a range of ways which students in schools are consulted or offered opportunities for representation (such as student Councils). These opportunities rarely extend to decisions about curriculum reform, or school direction, which Thomson and Holdsworth (2003) place in a separate category of "active citizenship" and link to deliberate democracy, "where student leadership is seen as diffuse and extending to many" (p. 374).

A fourth category Kennedy introduces is the neoliberal active citizen who is enterprising and innovative, equipped with problem-solving and decisionmaking skills, especially with regard to economic and business management. This is often referred to as the economic model of active citizenship and has individualistic rather than collective traits associated with being a good and responsible citizen (Kennedy, 2006). Reflections of this conception of active citizens can be seen in promoting participation and feedback by consumers to hold service providers accountable and to contribute to the types of services to which they are entitled in light of a retreating responsibility for social provisions by governments (Kennedy, 2007; Prout, 2003).

These models of citizenship participation offer a lens through which we can critique youth participation. For example, Kerr (1999) and DeJaeghere (2007) 
have used McLaughlin's notion of minimal and maximal conceptions of citizenship to critique citizenship education in the United Kingdom and Australia. In Chapters 5, 6 and 7 when I examine participatory citizenship dispositions and actions of both teachers and young people, I use these models as a critical framework of analysis. In the following section, I review research which begins to paint a picture of what we currently know about youth participation internationally and in New Zealand. I draw on this to reflect on what we still do not know, and therefore the contribution that this research can make.

\section{Patterns and experiences of youth participation}

In Chapter 1 I outlined the paradoxical state of youth participation in society whereby despite a growing rhetoric of enhanced opportunities for young people's participation, it would appear that there is evidence of a weakening of young peoples' engagements in formal politics and growing levels of disinterest in political and civic issues (CIRCLE, 2002; Furlong \& Cartmel, 2007; Print, 2007; Print, et al., 2004). However, much of this research has been conducted with young people aged 18 years and older. Pivotal to current understandings of these trends internationally for young people under 18 years, has been the contribution of the International Civic and Citizenship Education Study (ICCS), a project for the International Association for the Evaluation of Educational Achievement (IEA).

The ICCS has conducted a number of studies of civic and citizenship education. These began in 1971 (with nine countries, including New Zealand), and repeat studies were made in 1999 (with 28 countries) and 2009 (38 countries, including New Zealand). Evidence from the 1999 study data in particular drew attention to the higher levels of youth disengagement and disinterest in formal political participation than in previous surveys (Torney-Purta, et al., 2001). For example, this study indicated that 14-year-olds were only moderately interested in politics, and the majority (approximately 80\%), did not intend to participate in conventional activities such as joining a party, writing letters to newspapers 
or running as a candidate for local office in the future (Torney-Purta, et al., 2001, pp. 114-127). This trend is repeated more recently in the 2009 survey, with low rates of reporting of participation in the wider community amongst the 14-yearold students, and only a minority stated that they expected to be involved more actively in joining parties, trade unions or standing as a candidate themselves (Schulz, Ainley, Fraillon, Kerr, \& Losito, 2010). While limited research on young people's participation exists in New Zealand, there are signs of similar patterns emerging in young people.

\section{Young people's participatory experiences in New Zealand}

The value of consultation with children and young people in decision-making has been acknowledged by a number of government organisations in New Zealand in recent years (Harris, 2006; Ministry of Youth Development NZ, 2008). Wider opportunities for youth involvement in decision-making at various levels have also been promoted in schools and in the community, such as student councils, youth reference groups for government and community-based advisory groups (Harris, 2006; Nairn, Sligo, \& Freeman, 2006). However, similar to the international research reviewed earlier, there are some signs in New Zealand that young people aged 18 and over are less inclined to participate in formal political activities. For example, the Electoral Commission has noted falling rates of enrolment and voting amongst young people in New Zealand (Catt, 2005; Electoral Commission (NZ), 2005). There is also evidence from the Public Life Values study that young respondents (18-24 years) are less likely than older to have participated in political action (such as signing petitions or joining boycotts) and are more likely than older respondents to report that they never discussed political issues (E. Rose, et al., 2005). However, apart from the ICCS data, there is very little longitudinal research on youth participation in civic and community organisations for under 18 year-olds in particular, and even less on informal participation (such as sports clubs and cultural groups) to draw on. ${ }^{13}$

${ }^{13}$ New Zealand participated in the 1971 and 2010 ICCS study, but not in the 1999 study, leaving a 38 year gap in our ability to make comparisons within and beyond New Zealand young people. 
The New Zealand-specific data from the ICCS study was derived from a survey of 3,979 Year 9 (13-14 year-old) students from 146 schools in 2009. The findings show that New Zealand students had high levels of civic knowledge, repeating a trend observed in the 1971 data where New Zealand students were found to be among the top performing students in the world for civic knowledge. New Zealand students showed average rates of interest in political and social issues and higher than average rates of students expected to vote in national elections in the future (84\%), but lower rates of expected adult participation in political activities such as joining a political party or trade union (49\%) (Schulz, et al., 2010). Higher than (the ICCS) average numbers of students in New Zealand reported that they participate in community volunteering, collect money, and belong to a cultural organisations or political party/union (Table 2.2).

Table 2.2: New Zealand percentages for civic participation in the wider community compared to ICCS averages

\begin{tabular}{|l|l|l|}
\hline Reported participation in civic activities outside school & $\begin{array}{l}\text { \% of } \\
\text { students }\end{array}$ & $\begin{array}{l}\text { ICCS } \\
\text { average }\end{array}$ \\
\hline Probably or definitely expect to vote in National Elections & 84 & 81 \\
\hline Youth organisation affiliated with a political party or union & 13 & 10 \\
\hline Environmental organisation & 21 & 29 \\
\hline Human rights organisation & 7 & 16 \\
\hline A voluntary group doing something to help in the community & 40 & 34 \\
\hline An organisation collecting money for a social cause & 47 & 39 \\
\hline A cultural organisation based on ethnicity & 23 & 14 \\
\hline A group of young people campaigning for an issue & 14 & 29 \\
\hline
\end{tabular}

Source: (Schulz, et al., 2010, p. 132) .

Less (than the ICCS average) reported involvement with environmental and human rights organisations and New Zealand had one of the lowest rates of youth participation in campaigns for an issue (13\%) along with Chinese Taipei, Czech Republic, Denmark and Sweden. New Zealand students showed low levels of trust in the media with only $49 \%$ of reporting they trust the media "completely" or "quite a lot," significantly lower than the ICCS average of $61 \%$. They reported higher levels of trust in the national government than the ICCS average, but rated trust in political parties, schools and people in general average or lower. 
New Zealand's overall national average for students' expected participation in political activities as ranked by the ICCS scale (49) is below the ICCS average (50) and on a par with England, Italy, Spain, Norway, Lithuania and Switzerland. However, this large, comparative quantitative study tells us much less about why these patterns might exist. Furthermore, the homogeneity of such results renders invisible the contextually-based differences between diverse groups of young people which are of interest in my research. In order to draw attention to the complexities and ambiguities of young people's (under 18 years) experiences of participatory citizenship, I now turn to a small (largely qualitative) body of research in New Zealand on young people's experiences of participation to focus the lens somewhat closer.

Findings from New Zealand suggest that young people's participation is not universal, but remains limited to small proportions of the youth population and still remains heavily regulated by adult society (Harris, 2006; Nairn, et al., 2006). Nairn et al. (2006) suggest that youth participation initiatives in New Zealand "tend to be ad hoc, unevenly distributed and reactive rather than proactive" (p. 249). For example, Nairn et al. (2006) examined how local government authorities targeted distinctive groups of young people to represent their communities in various participation initiatives. They found that the selected young people were generally either "achievers" or "troublemakers," and rarely the young people who occupy "the excluded middle" between these extremes. They suggest that this produces a polarized representation of young people, and excludes the participation of “ordinary" young people (Nairn, et al., 2006).

Experiences of citizenship are often reported by New Zealand young people to be ones of exclusion rather than inclusion. For example, "exclusion from participation as citizens in the public domain" was a commonly voiced theme by Maori rural young people who were interviewed as part of the Youth First Project in 2002 (L. T. Smith, et al., 2002). Some young people in this research referred to abuse of their rights by schools and the police. While some young people had been involved in these youth participation initiatives, many had high degrees of cynicism about the style of participation either modelled or presented 
to young people (such as consultation meetings, youth councils and youth parliaments) and were "were 'turned off' by the existing models of participation" (L. T. Smith, et al., 2002, p. 175).

A further example of young people's marginal status and exclusion as citizens is how young people's spatial occupation of public spaces in New Zealand is restricted by adult monitoring and regulation. For example, an analysis of print media's coverage of young people's presence in public spaces in Otago, New Zealand concluded that young people 'hanging out' in public places is presented as a problematic behaviour in much of the print media, leading the authors to question whether public space was indeed open to all members of society (Panelli, Atwool, \& McCormack, 2002). More recent examples of a type of spatial constraint on young people in New Zealand include the playing of old style music (such as Bach and Barry Manilow) at a Lower Hutt bus stop and mall in a bid by the city council and the police to limit the number of young people hanging out there (Klein-Nixon, 2009). These examples illustrate the degree to which young people can experience a type of "partial citizenship" where their participation in certain public spaces in restricted, controlled and constrained.

When young people in New Zealand do mobilise politically, research suggests that the adult response is primarily one of restraint and regulation (Beals \& Wood, 2011; Kidman, 2005). Kidman (2005) describes how the protest of several thousand students during school time to support their teachers' pay claim in 2002 resulted in widespread condemnation by adult society. This was in spite of the students' "excellent behaviour" at all times during their protest. A further example is the adult responses to two youth-led activist groups (Radical Youth and Youth Organised and United) when they took to the streets to support a youth minimum wage claim in New Zealand in 2006. Beals and Wood (Beals \& Wood, 2011) describe how these young activists were rebuked, ridiculed and reprimanded by adults (police, teachers, bloggers, Members of Parliament and media representatives) for their actions online and in public spaces. They conclude that: 
New Zealand adults do not want young people to be placid, malleable, docile individuals.... However, adults also want to define and regulate this agency, the parameters that surround it, and the outcomes that could be achieved.

(Beals \& Wood, 2011)

The findings discussed here from New Zealand (and other countries) indicate that young people's experiences of participation are often piecemeal, polarised in representation, regulated by adults and limited to certain spatial domains. This suggests that there is a paradoxical state of affairs for young people's civic participation. While there is evidence of increasing opportunities provided for young people to participate in society (Prout, 2003), when they do mobilise politically, their actions can be subject to rebuke, ridicule and reprimand by adult society and high levels of adult regulation, rather than being taken seriously as democratic citizens (Wyn \& Harris, 2004).

It is difficult not to conclude that young people occupy a marginalised status as citizens in society. In spite of the increased adult awareness of young people's rights to participation in society, children and young people "do not enjoy genuine equality of status as citizens in the here-and-now" (Lister, 2008b, p. 13), but instead, a position of "partial" or "semi-citizenship" (Lister, 2007a). This lack of recognition that children and young people are citizens now, "has served to deny the possibility of young people exercising agency over their lives, making their own experiences and being engaged in purposeful and strategic analyses of social structures" (L. T. Smith, et al., 2002, p. 177). These findings highlight the role that critical youth studies has to play in identifying issues of power, regulation and control over young people in society, and also in exploring participation and citizenship in ways which are meaningful and realistic to young people. In the following section I examine more closely this contested and problematic site of youth citizenship and some of the emerging responses to these debates. 


\section{The problematic status of young people and citizenship}

More than at other points of the life-course, youth is a time when the relationship to citizenship is in a state of flux. This makes it a particularly interesting period during which to study understandings of citizenship and any changes in self perceptions as citizens. (Lister, et al., 2003, p. 236)

Central to an understanding of why youth participatory citizenship is problematic is a recognition of the differences that exist between young people and adults. These differences are manifested most notably by age, but less obviously by status, access to power, resources and places (Liebel, 2008; Valentine, Skelton, \& Chambers, 1998). Young people's liminal position in society, "positioned on a boundary of threshold" (Weller, 2006a, p. 102) and therefore as one of "in-betweenness" (Weller, 2007) is at the heart of the problematic relationship of children/young people and citizenship. A young person can occupy a position as an adult at times, and a child at other times. However, they fit neither into a clear cut category of child, nor adult and in falling between these binary positions experience an often marginalised status in society (Skelton, 2000).

As a result of these ambiguities, the link between young people and citizenship is neither straight forward nor linear. Drawing parallels between the grounds given in previous times to exclude women's participation as citizens, and children's exclusion from citizenship today, Ruth Lister (2008b) provides four often cited reasons why children as citizens is viewed as problematic. First, their capacity and competence is brought into question on the grounds of their age. The distinction between age groups of children and young people is important to consider here - for example, the differences in decision-making ability between a 15-year-old and a 15-month-old baby are significant (Roche, 1999). Second, their lack of economic independence and their level of dependence on adults is often seen as a barrier to full citizenship where the autonomy of the rational individual is central to modern liberal thought (Roche, 1999). Levels of dependency have been heightened in late modernity where traditional transitions from youth to adulthood are disrupted (such as youth continuing to dwell in the family home and remaining in education for longer) which can 
exacerbate the failure of young people to receive the entitlements of full citizenship (Furlong \& Cartmel, 2007; Hall, et al., 1999; Harris, 2006).

Third, the presence of children and young people in mainly private spheres rather than public also serves to perpetuate young people as citizens-in-waiting. Finally, the differences between children/young people and adults (such as the rights and responsibilities they hold) have also been given as a reason for their exclusion. As Roche (1999) comments, "save from the 'child liberationists', no one is arguing that children are identical to adults or that they should enjoy the same bundle of civil and political rights as adults" (p. 487). Instead, Lister (2008b) suggests that the responsibilities young people do exercise should be recognised, and their right to participate/not participate must also be respected.

To help find a way forward in addressing the problematic status of youth citizenship, Lister $(1997,2003)$, advocates for a "differentiated universalism". Rather than setting up an absolutist category which defines children and young people as citizens/not citizens, a differentiated universalism approach provides a lens through which to acknowledge the ambiguities of youth; children should be regarded as equal citizens with the right to belong as "differently equal" members of society (Lister, 2006, p 25 in Liebel, 2008). In the same way that women are different to men, yet equal, children can be recognised as different to adults, yet equal. This shifts the debates from extending an ever-expanding circle of adults' rights (and obligations) on to children and young people and recognises "that their citizenship practice (where it occurs) constitutes them as de facto, even if not complete de jure, citizens" (Lister, 2008b, p. 18). Lister argues for a child-sensitive theorization and practice of citizenship, and is joined by growing groups of researchers who are employing new approaches and perspectives to explore how young people are participating as citizens today. 


\section{New approaches to exploring youth participatory citizenship}

Perhaps asking whether young people today are active or apathetic, is the wrong question. Harris, Wyn and Younes (2010) propose that we need to move "beyond apathetic or activist youth" and find new ways of considering how "ordinary" young people are participating in society. The critique by Lister and others draws attention to the limitations of many traditional approaches to youth citizenship participation. These limitations centre on three main areas.

First, traditional perspectives have narrowly defined what "counts" as youth participation. A focus on what might be termed "mainstream" or "citizen orientated activities" (Norris, 2003), such as voting, joining groups and voluntary work potentially overlook another whole landscape of participation which is more closely linked with the everyday ways young people experience and express their place in society. Harris et al. (2007) argue "...it is important to broaden our understandings of engagement...it may also be necessary to bracket adult-centric views of what engagement means and explore the everyday ways in which young people experience and express their place in society" (p. 22).

In response, a number of researchers have drawn attention to "new" ways young people are engaging in society. These "new engagements" offer a more generous conception of citizenship participation and include, for example, forms of youth resistance in the form of music, art and everyday cultures (Willis, 1990), and boycotting products and online networking (Coleman, 2005). These practices are said to be occurring through less collective affiliations, the use of emergent information technologies and engagement with recreation and consumer choice as "life politics" (Bang, 2009). For example, there is growing interest in the less visible role of "young netizens" in cyberspace (Robertson, 2009) and participatory potential of the internet (Harris, 2008). These new engagements are more diffuse, less visible and less formal than previous generations' engagements (Harris, 2006). 
Another way researchers have reframed the examination of youth citizenship engagement is by drawing attention to how young people are "connecting" with others. As outlined in the work of Lister above, feminist researchers have highlighted how a focus on public expressions of participation overlooks the importance of private and domestic spheres. In what I regard to be a leading piece of research in this area, rather than looking exclusively to traditional measures such as voter turnout and political affiliations, Harris et al. $(2007,2010)$ focus their attention on examining how young people are "connected". In their survey of 15-16 year-olds ( $n=970)$, they found that Australian young people were unlikely to belong to a political party (4\%) or union (3\%). While a good number of them were "joiners" of formal institutions such as sporting clubs (51\%) and online groups (29\%), they found that a majority of young people enjoyed "hanging around" with their peers (75\%), and playing sport (71\%). It would appear that the informal associations of friends and family are emotionally and socially important to young people and Harris et al. (2007) surmise that "having a family and being connected to a place may have become of heightened significance to young people today" (p. 24).

A third way researchers have begun to reconceptualise youth citizenship participation, is to give prominence to young people's differentiated abilities to access the resources, status and places of participation. Young people are not a homogenous group any more than adults are (R. White \& Wyn, 1998), yet the multitude of differences between young people often go overlooked in research on citizenship participation. There is a need to contextualise and analyse research in this area to expose the very real structural barriers that continue to restrict young people's democratic expressions (Bessant, 2004; Harris \& Wyn, 2010; Roche, 1999). Marsh et al. (2007) call for widened conceptions of the political which recognise how the economic, social and cultural resources that young people have access to, shape their experiences and these in turn shape their definitions of politics and view of political institutions (p. 213). As Roche states, "children have to start from where they are socially positioned. This 
means they have to make their own space in spaces not of their making" (Roche, 1999, p. 479).

These ideas bring us to some new starting positions for exploring citizenship. First, it is likely that young people's participation is best understood as everyday "lived citizenship" (Lister, 2007b) in the context of relationships, institutional practices and everyday experiences (see also Clark \& Percy-Smith, 2006; Mannion, 2007; Marsh, et al., 2007; Woodhead, 2010). And second, that youth citizenship participation is framed by the places they inhabit and the interactions with key people in these sites, such as families, teachers and community group. In the following section I advance the case for exploring young people's participation through their everyday, place-based perspectives.

\section{The case for exploring young people's everyday, place-based perspectives on participation in society}

In the spirit of looking beyond adult-centric and formal definitions of citizenship participation, we also need to find out more about how young people themselves conceive of citizenship and social action in their ordinary and everyday lives. Marsh et al. (2007) suggest that a focus on everyday lived experiences allow the potential for individuals to express what politics means to them and how they relate to it:

By carrying out an in-depth exploration of young people's conceptions of politics, rather than surveying young people's attitudes towards a limited range of political issues and arenas, we can begin to develop a much more nuanced understanding of the relationship between their lived experiences and their engagement and interest in politics. (Marsh, et al., 2007, p. 212)

A focus on "the already here - the everyday" (Dickinson, Andrucki, Rawlins, Hale, \& Cook, 2008, p. 108) is a proposition put forward by a number of feminist, political science and youth researchers working broadly in the area of citizenship (Dickinson, et al., 2008; Dyck, 2005; Harris \& Wyn, 2009, 2010; Harris, et al., 2007, 2010; Lister, 2003; Marsh, et al., 2007; Nava, 2007). These researchers recognise the importance of excavating the mundane, habitual and taken-for-granted arenas of everyday life as an appropriate and empowering site 
to investigate political and social actions and perceptions of young people. Dickenson et al. (2008) suggest that if we see everyday life as a lived process within which citizenship acts accumulate, we come closer to understanding "how everyday life can also operate as an arena for the contestation and transformation of dominant, often oppressive modalities of citizenship" (Dickinson, et al., 2008, p. 105). This has particular value with a focus on youth participatory citizenship as it provides the basis for a much broader, inclusive and generous conception of citizenship and allows the everyday actions of young people to be read as actions of agency and participation.

A focus on the everyday also necessarily draws attention to the space, place and scale of these everyday lived experiences. As Weller (2007) states, "space matters at the micro-level as it illuminates teenagers performative role as citizens" (p. 171). In the tradition of feminist geographers, (Dyck, 2005; Lister, 2003), a focus on everyday experiences of young people re-draws our attention to local and domestic sites. Harris and Wyn (2009) suggest that in contrast to the popular portrayal of young people 'today' as citizens of global communities, local spaces remain of high importance to young people. However, studies of youth citizenship and participation "continue to focus on the public and the formal as the real sites of politics, and neglect young people's embeddedness in the domestic and the local" (Harris \& Wyn, 2009, p. 342).

However, an attention to the scale of everyday "is not merely an interest in the "local" but a valuable methodological entrée to understanding processes operating at a variety of interlocking scales" (Dyck, 2005, p. 242). Dyck (2005) suggests that an everyday, local focus "holds tremendous potential for the opening up, understanding of processes operating at regional, national and global scales" (p. 243). One way to examine these interlocking scales is through a focus not only on young people's practices, but also the "political imaginaries" of young people (Marsh, et al., 2007). In Chapter 3 I outline my intention of using Mills' (1959), "sociological imagination” as a methodological vehicle to do just this, by enabling young people (through visual and verbal ways) to show their sense of responsibility, care and pride in their places, as well as what they wish 
to change. I refer to this as their "citizenship imagination." I suggest that recognising this space of participatory and political possibility takes into account young people's liminal position in society, yet recognises their current role as citizens, as well as their imagined role as political agents.

Research within the geographies of children tradition provides a number of insights into the value of including spatial perspectives on young people's lives. For example, the early work of Roger Hart (1979) in an unidentified US town revealed how children appropriate public space for themselves, by giving names to their favourite places and making traditions of their familiarity of space. Other researchers of children's geographies have drawn attention to how young people are (re)claiming spaces as examples of their agency and resistance as young citizens (Holloway \& Valentine, 2000; Matthews, et al., 2000; F. Smith, 1998). Horton, Kraftl and Tucker (2008) suggest that one of the most successful and challenging interventions made by "children's geographers" in the context of broader social science domains, has been the attention they have drawn to children and young people's participation/non-participation. Citing examples such as Hart (1997) and Matthews (2001), they describe how geographers' recognition of children's contributions has informed discussions on the political agency of children and young people. Illuminating young people's everyday spatialities and the way these reflect power relations within wider society (Massey, 1998) has also been a characteristic of research in this area.

Recognising that young people's experiences of participation are importantly framed by not only their everyday spaces, but also their relationships with other people is another component of the approach in this research. Mannion (2007) suggests that to gain a deeper understanding of youth participation we need to "go spatial" and "go relational." His argument is that children's participation research can usefully become more spatially and relationally sensitive by acknowledging the intergenerational aspect of much participation of children. He suggests that "without a focus on the relations between adults and children and the spaces they inhabit we are in danger of providing a narrow view of how children's 'voice' and 'participation' are 'produced"' (Mannion, 2007, p. 417). 
Clark and Percy-Smith (2006) suggest that "[t]his twin emphasis on the environment and the "everyday" enables participation to be discussed as a relational and experiential concepts concerned with lived realities rather than as an instrumental concept of consultation abstracted from everyday life" (p. 4).

In summary, pivotal to gaining a more nuanced understanding of participation as reflection of experiences and relationships within neighbourhoods, families and schools, is the attention paid to connections with others (social capital), access to participatory educational resources (cultural capital) and place. This research contributes to a relatively under-explored area of work highlighting how young people's sense of belonging to places and communities, and their social and cultural capital informs their citizenship dispositions (Holland, et al., 2007; Weller, 2006b, 2007; Weller \& Bruegel, 2009). For example, Weller's (2006b) research with young people on the Isle of Wight showed how many young people were "active social capitalists" (p. 572) who used their social networks and connections to revitalise their facilities and improve their neighbourhoods. Similarly, Weller and Bruegel's (2009) research concluded that children are "active agents in the development and maintenance of social capital at the level of the family and neighbourhood" (p. 641).

In Chapter 3, I develop the theoretical and conceptual basis to this approach by explaining how Bourdieu's concepts of habitus, capital and field provide insights into the patterns of participation within school communities. This approach highlights how experiences of the social and cultural capital associated with differing conceptions of participation, may influence citizenship dispositions. I also introduce Mills' (1959) notion of the "sociological imagination" as a way to gain insights into how young people conceptualise and practice social action within their everyday places. 


\section{CHAPTER 3:}

\section{A THEORETICAL AND CONCEPTUAL FRAMEWORK FOR EXAMINING THE PARTICIPATORY CITIZENSHIP OF YOUNG PEOPLE}

In the literature reviewed in Chapters 2, I identified a number of limitations in how youth participation has traditionally been researched and understood. These limitations include the narrow focus on certain types of youth participation (with a higher priority placed on formal expressions over informal), a narrow focus on certain places of participation (public prioritised over private), and a failure to recognise the significance that young people's limited access to resources, places and status plays in their ability to participate as citizens. If children and young people occupy largely private and domestic spheres as citizens (Lister, 2008b), then we need a focus that enables us to see how their experiences of citizenship are shaped in these sites and contexts. As John Annette suggests:

We need to have more research into how young people do understand the 'political' as it relates to the everyday concerns in their communities as compared to the more formal political sphere of voting, political parties and holding office. (Annette, 2009, pp. 151-152)

With this critique in mind, I turn to a theoretical approach that endeavours to provide a strong platform through which to understand youth participation in a more inclusive, everyday and youth-centred way - one that takes account of how young people conceptualise and participate in citizenship embedded within the context of their own lived experiences. As described in the introduction, my theoretical position draws from a critical paradigm, and in particular, the theories of Pierre Bourdieu and C. Wright Mills. In this chapter I provide further detail about how this theoretical base provides a conceptual framework to explore youth participatory citizenship. 
Underlying my approach is a desire to highlight the nature of exclusion within citizenship rather than the traditional citizenship approach which focuses on the inclusionary side (Lister, 2008a). This approach is broadly aligned with the aims of critical theory which focuses on the legitimacy of power within society and how some groups use power to regulate the participation, inclusion and freedom of others (Cohen, et al., 2000). Critical theory therefore includes an element of emancipation or transformation within the process of a critique of society, as critical theorists have "systematically rejected a value-neutral position, and they conduct research that aims openly at meeting the goals of human liberation and social justice" (Prasad, 2005, p. 139).

Critical theory has been usefully applied within educational, sociological and geographic theories of youth participation to highlight young people's exclusion from aspects of participatory citizenship (Wyn \& White, 1997) and sites of citizenship participation (Hil \& Bessant, 1999; R. White, 1996). Traditionally, ideas from critical theory focus on the interplay between structure and agency (R. White \& Wyn, 1998). This approach examines the degree to which either structural aspects (such as socio-economic status, ethnicity and gender) or youth agency mediates their social action (often referred to as the "free will" and "determinism" problem). Whilst these ideas hold considerable merit in gaining an understanding of young people's experiences of youth participation, much research employing these ideas ends up in a "middle ground" position" between structure and agency (such as Gidden's (1984) theory of "structuration") thus reducing the option of many other fruitful explorations (Woodman, 2010).

In contrast, Bourdieu "jettisons" (1992, p. 10) this structure-agency debate through his concepts of habitus, capital and field. He proposes that the actions of individuals are a reflection of the interaction of different social fields that combine to transform or reproduce patterns produced by the interplay of structure and agency. In the following section I provide details of Bourdieu's concepts of habitus, capital and field and explore how these offer a useful theoretical and conceptual approach for examining participatory citizenship. 


\section{Bourdieu's conceptual triad: habitus, capital and field}

One of Bourdieu's primary concerns throughout his work is to address the question "what motivates human behaviour?" (Hillier \& Rooksby, 2002, p. 4). Rather than turning to psychology for an explanation, Bourdieu (Bourdieu, 1977b, 1990) developed the concepts of habitus, capital and field as a way of gaining a deeper understanding of how the practices of individuals and groups can be seen within a context of both structure and agency. Bourdieu describes the interconnection between "the conceptual triad of habitus, capital and field" (Bourdieu \& Wacquant, 1992, p. 25), and "practice" in the formula he provides in his book Distinction:

[(habitus) $($ capital) $]+$ field $=$ practice $($ Bourdieu, 1984, p. 101)

An individual's dispositions and actions (practice) therefore can be seen as a reflection of the inseparable interplay of habitus capital and field (Bourdieu, 1984). I introduce each of these concepts in turn, and describe how and why they may be of value to consider in the context of youth participatory citizenship research

\section{Habitus}

Habitus is the concept Bourdieu developed to describe the dispositions that embody both individuals and groups as a result of their social conditioning within that context of a group. This habitus then gives rise to "schemata of perception, appreciation, and action" (Bourdieu \& Wacquant, 1992, p. 16), mostly commonly referred to by Bourdieu as "dispositions." He describes habitus as "a system of lasting and transposable dispositions which, integrating past experiences, functions at every moment as a matrix of perceptions, appreciations and actions and makes possible the achievement of infinitely diversified tasks" (Bourdieu, 1977b, p. 95). Rather than something consciously acquired, these dispositions are "deposited" within bodies, and are therefore the embodied version of the objective structures of society, "thus destroying the false antinomy ordinarily made between sociology and social psychology" (Bourdieu \& Wacquant, 1992, p. 13). Habitus then provides us with a link, connecting structure and agency in a dialectical relationship. 
Bourdieu suggests that the similarity of practices of social groups can be explained by the habitus generated by the "homogeneity of their social conditions of existence" (Bourdieu, 1990, p. 58). In this way, habitus can be defined as a "system of dispositions common to all products of the same conditioning"(p. 59), or as Cresswell (2002) puts it "a set of embodied durable dispositions that tends to reproduce the society that produced it" (p. 379). Habitus is a form of "embodied history" with a "generative principle" that then explains patterns of similarity in dispositions and actions between generations of family members (Bourdieu, 1990, p. 56). The concepts of habitus, capital and field also provide an analytical framework that enables a simultaneous focus on the individual and the family/social group.

For Bourdieu, an agent (or groups of agents) is always situated within a historical and social context, and an understanding of their "practice"14 is informed by this. ${ }^{15}$ As Bourdieu (1990) explains "habitus is an infinite capacity for generating products - thoughts, perceptions, expressions and actions whose limits are set by the historically and socially situated conditions of its productions" (p. 443). A Bourdieusian-informed approach suggests that the lived experiences of young people within their families, schools and communities will influence the nature and expressions of their participatory citizenship as habitus "reflects the different positions people have in society, for example, whether they are brought up in a middle class environment or in a working class environment" (Bourdieu, 2000, p. 2). The workings of habitus can be seen by a bodily disposition when it:

encodes certain cultural understandings that are shared by a particular group. It therefore represents the physical and spatial knowledge displayed by group members in ways of which they may or may not be consciously aware. (Gill \& Howard, 2009, p. 119)

\footnotetext{
14 In keeping with Reay (2004), I am using the word "practice" to equate with "agency". She suggests that "according to Bourdieu it is through the workings of habitus that practice (agency) is linked with capital and field (structure)" (p. 432).

${ }^{15}$ He critiques many researchers in his time who applied a perfunctory "situational analysis" to account for variations, exceptions or accidents in their findings, as well as researchers who place far too high an emphasis on agents' unstructured rational free choice.
} 
Applying ideas of habitus to youth participation highlights aspects of political socialisation (such as exposure to volunteering and civic engagement as a child) experienced primarily within families and communities, but also as a reflection of the cultural and social capital gained through schools. Differences in participatory citizenship dispositions can then be seen as a reflection on experiences young people derive from immersion within social groups and social contexts. Following Holt (2008), I suggest that incorporating habitus into research on youth participation facilitates a more nuanced understanding of youth social action in the context of subconscious and intergenerational processes that contribute to both reproducing and transforming practices.

While Bourdieu (1990) argues that the processes of social domination are reinforced and reproduced through this process of habitus, he goes to some lengths to explain that knowing about habitus does not imply a teleological assumption about practice. This would imply a far too "mechanistic theory of practice," as the theory of habitus also allows for practices of "misadaptation as well as adaptation, revolt as well as resignation" (Bourdieu, 1990, p. 62). What Bourdieu's work does show, is that while practice is strongly informed by habitus, capitals and fields and their interrelations, habitus can also be transformed and modified:

Habitus is not the fate that some people read into it. Being the product of history, it is an open system of dispositions that is constantly subjected to experiences, and therefore constantly affected by them in a way that either reinforces or modifies its structures. It is durable but not eternal! (Bourdieu \& Wacquant, 1992, p. 133)

So, at the same time as focusing on social and structural influences on youth participation, conceptions of habitus, capital and field also open up the way to a focus on how young people resist, and move within and beyond the participatory citizenship dispositions attributed to them by nature of their upbringing. Holt (2008) argues that incorporating habitus into research on youth participation facilitates a more nuanced understanding of agency within social capital as it sheds light on how subconscious dispositions and actions that reflect intergenerational processes contribute to both reproducing and transforming practices. 
Habitus then, is both an explanation for how society reproduces itself as well as the potential to move beyond social reproduction. A critical approach to research on youth participation through Bourdieu requires an acknowledgement of the unique position of young people in society, many of whose lives are still strongly mediated by others - at school, home and in communities (Valentine, et al., 1998), and, at the same time, looking for expressions of participatory citizenship that attempt to move beyond the trajectories inscribed by habitus. As outlined in the previous chapter, this involves opening up more inclusive and broad definitions of participation, as well as providing opportunities for young people to express these in meaningful ways.

\section{Capital}

According to Hiller and Rooksby (2002), "capital is effectively the resources which actors take to the field" (p. 9). Bourdieu proposes a variety of "capitals" that individuals can possess: these include social, cultural, economic and symbolic capitals which contain "concealed intergenerational processes that serve to reproduce socio-economic advantage, disadvantage and privilege" (Holt, 2008, p. 234). The processes which give rise to Bourdieu's capitals are also the processes which tend to reproduce them. He explains how individuals with capital which matches that of the dominant culture have a far greater chance of "success" in society, thus reproducing in turn the structures of the dominant culture (Bourdieu \& Passeron, 1977). This is apparent, for example, within educational institutions which tend to reward those who already have an "initial familiarity with the dominant culture" (Bourdieu, 1977a, p. 494).

Cultural capital refers to the knowledge, skills and information people acquire through formal or informal education. Bourdieu suggests that "just as our economic institutions favour those who already possess economic capital, so our educational institutions are structured to favour those who already possess cultural capital, in the form of the dominant cultural fraction" (Harker, 1990, p. 87). Bourdieu proposes that cultural capital can exist as an embodied state (such 
as jargon, music), an objectified form (such as books, scientific instruments) and in an institutionalised form, most often represented by educational credentials.

The application of Bourdieu's concept of social capital has usefully been applied as a way of understanding youth citizenship participation in a number of studies (for examples, see Bang, 2009; Fahmy, 2006; Putnam, 2000; Weller, 2006b). Bourdieu refers to social capital as the sum of resources (actual or virtual) that accrue to an individual or group as a result of social connections and relationships (Bourdieu \& Wacquant, 1992). Social capital is held to be an important driver of civic action "because it facilitates the development of the type of co-operative social relations that are a prerequisite of collective action" (Fahmy, 2006, p. 103). Social capital is necessarily understood within the context of other interrelated capitals (cultural, economic and symbolic) (Holland, 2008). Nicole Schaefer-McDaniel (2004) makes a connection between children and young people's social capital and their environments. She proposes a focus on young people's social networks and sociability, levels of trust and reciprocity and sense of belonging within their neighbourhoods and communities as a theoretical framework for exploring social capital. I incorporate her ideas into Chapter 6, when I examine how young people perceive their inclusion/exclusion as young citizens in their schools and communities. In this approach, social and cultural capital are seen to be held within the context of lived experiences and interactions between people and places, and reflects the interplay between habitus and field.

Applying these ideas to the context of participatory citizenship then necessitates the question "is there social and cultural capital associated with participatory citizenship?" There is some evidence that young people acquire political dispositions through familial and educational exposure (Fahmy, 2006; McFarland \& Thomas, 2006). McFarland and Thomas's (2006) analysis of young people's "political socialisation" suggests that differing social backgrounds and resources (cultural and social capital) can contribute to different reserves of political experiences (habitus) within social and educational fields, which can in turn lead to differentiated patterns of political participation. McFarland and 
Thomas propose that young people from wealthier, higher educated families, as well as young people from all social backgrounds who had participated in political and social volunteering as youth, both had higher levels of "political capital" as adults later in life:

For political socialization, this means that youth from wealthier, higherstatus families will have resources and experiences that enable them to not only enter and lead various youth voluntary organisations, but also become active in adult politics years later. (McFarland \& Thomas, 2006, pp. 402-403)

However, whilst their research found patterns that supported the social reproductive nature of this statement, they also conclude that "social learning" factors played an important role in influencing patterns of adult participation, not just class and social background characteristics (McFarland \& Thomas, 2006, p. 420). Fahmy (2006) likewise concludes that the relationship between social capital and civic action is not uniform, "but differs across the lifecycle and in relation to the type of participation under investigation" (p. 115). These findings highlight the importance of the strategic role that schools, teachers, families and communities potentially play in both maintaining and transforming participatory cultural capital.

In my research, I am interested in two aspects of social and cultural capital firstly, how young people's lived experiences in families, communities and schools influence their definitions of citizenship participation (social capital and habitus), and secondly, how schools (and curricula) work toward promoting (consciously or unconsciously) a certain type of participatory capital as the one which "counts". As my research takes place within the context of the social studies curriculum and with social studies teacher and students, I wish to pay particular attention to how participatory capital reflects exposure to educational ideas through social studies programmes, and how these in turn shape citizenship dispositions of young people studying social studies (see Chapter 6).

\section{Field}

A field is the social space within which individuals operate. Bourdieu refers to the concept of field as "a patterned system of objective forces...a relational configuration with a specific gravity which it imposes on all the objects and 
agents which enter in it" (Bourdieu \& Wacquant, 1992, p. 17). For example, Bourdieu refers to artistic, religious, or economic fields, each one containing its own logic, networks and practices that are specific to that field (Bourdieu \& Wacquant, 1992). Positions of individuals (agents) within this field are held largely with respect to their degree of power, which in turn reflects the capital held by that agent. In this way, a field can be seen as "a site of struggle over a particular form of capital" (Harker, 1990, p. 97). Bourdieu proposes that the concept of field is also a space of social agency. It is "a simultaneous space of conflict and competition" (Bourdieu \& Wacquant, 1992, p. 17) as the actors struggle to maintain or transform the social structure which they find themselves in. This "gives any field a historical dynamism and malleability that avoids the inflexible determinism of classical structuralism" (Bourdieu \& Wacquant, 1992, p. 18):

In such fields, and in the struggles which take place in them, every agent acts according to his [sic] position (that is according to the capital he or she possesses) and his habitus, related to his personal history. His [sic] actions, words, feelings, deeds, works and so on, stem from the confrontation between dispositions and positions.... which may even be contradictory. (Bourdieu, 2002, p. 31)

The concept of field applied within my research provides opportunities to explain the different ways young people may define and express participatory citizenship in the context of varying social fields. For example, an educational field may influence participation through the opportunities schools provide and the examples teachers hold up to be of value. The concept of field also provides an analytical framework which explains how these patterns of learned dispositions often reflect the values and capital of the dominant culture (Harker, 1990).

In summary, Bourdieu's conceptual triad (habitus, field and capital) provides a broad conceptual framework through which to explore youth participatory citizenship. As illustrated in the equation introduced at the start of this section, the conceptual triad of habitus, capital and field are relational, in the sense "that they function fully only in relation to one another" (Bourdieu \& Wacquant, 1992, p. 19). The relation between habitus and field operates in two ways. On one side 
there is conditioning (the field structures the habitus) i.e. individuals' perceptions, appreciations and actions are influenced by their field. On the other side, there is a relation of knowledge or cognitive construction, i.e. habitus constitutes the field as meaningful through embodied social practices (habitus). In this way, sets of dispositions (perceptions, appreciations and actions) embodied in habitus, capital and field are "created and reformulated through the conjuncture of objective structures and personal history" (Mahar, Harker, \& Wilkes, 1990, p. 10). Richard Harker (1990) adds that this process of reproduction (such as that within education) is not as static as it appears, but also embodies a process of reformulation in response to specific historical circumstances which give rise to a change in habitus (Harker, 1990, p. 101)

These concepts alert me as the researcher to pay particular attention to how young people's interactions with family and teachers, as well as their exposure to aspects of participation through their school programmes, will inform their cultural and social capital. I have coined the term "participatory capital" to define more clearly the nature of capital associated with participation. Participatory capital, as I define in this thesis, includes the sum of resources gained through social, economic and cultural exposure to participation, as well as the participatory habitus of the family/social group. The social context which this occurs in (field) then operates to distinguish between forms of participatory capital that receive distinction, and results in differing participatory citizenship dispositions and actions. This can be summarised as an adaptation of Bourdieu's equation which was cited earlier:

[(participatory habitus) (participatory social/cultural capital)] + field $=$ participatory citizenship dispositions and actions

There are however, a number of limitations to the application of Bourdieu's theoretical framework to examining participatory citizenship. In the following section I address some of these critiques and limitations and suggest the integration of two further conceptual foci in this framework which I argue will provide more nuanced understandings of young people's participation in society: first, Mills' (1959) notion of the "sociological imagination" and, second, a 
more specifically geographic focus on the impact that space and place have on young people's perception of social issues and participatory responses.

\section{Limitations of Bourdieu's theory for exploring youth participation}

There are a number of limitations to Bourdieu's conceptual triad of habitus, capital and field when I apply them to the context of youth participation. While they provide a useful explanation of how and why social conditioning leads to patterns of dispositions which are generally reproducing, and thus provide a "method for analysing the dominance of dominant groups in society and the domination of subordinate groups" (Reay, 2004, p. 436), habitus in particular has been "subject to widespread criticism, mainly on the basis of its latent determinism" (Reay, 2004, p. 432). Bourdieu addresses this critique of his concept of habitus as overly deterministic on multiple occasions (see Bourdieu, $1990,1999,2000,2002)$. Yet while Bourdieu advanced habitus as a concept to explain both social reproduction and transformation, he never proposed a theory or conceptual base for how social change could be achieved (Friedmann, 2002). Even in his latter writings when he talks of the "politics of protest" (Bourdieu, 2000), Bourdieu provides much less guidance as to how social agents can move within and beyond their conditioning and transform or change their circumstances. ${ }^{16}$ This is unusual for a theorist writing in the area of critical theory (Sayer, 2005).

For this reason, in my research into youth participatory citizenship I have found it useful to intertwine Bourdieu's conceptual triad with Mills' (1959) notion of the "sociological imagination" (outlined below). Using the sociological imagination primarily as a methodological approach (through visual methodologies of Photovoice), I intend to provide participants with opportunities to express their "citizenship imaginations" through describing what aspects of their community they wish to preserve, protect or transform (see section below). This Mills-Bourdieu synthesis then provides a conceptual

${ }^{16}$ Reay (2004) asserts that we begin to see moments of resistance to habitus and field which may give rise to social change in Bourdieu's later writing - especially in Weight of the World (Bourdieu, 1999). However, this is far less common in his earlier writings about habitus. 
framework to examine this process of identification of social issues as an important indicator of their citizenship perceptions, interests and dispositions (this aspect is explored specifically in Chapter 6).

A second limitation of Bourdieu's concepts of habitus, capitals and fields is his lack of explicit acknowledgement or sensitivity to spatial differences within his concept of habitus (Holt, 2008; Painter, 2001). I would agree with Holt (2008) who suggests that Bourdieu's concept of place within habitus lacks "a critical conceptualization of space" (p. 230) in contrast to complex conceptualisations of space and spatiality forwarded by geographers. When Bourdieu was challenged to defend this by Hillier and Rooksby (2002), he referred to his research in Algeria and France as an example of the dialectical confrontation between habitus and social space (Bourdieu, 2002). However, despite applying a metaphoric concept of space to his concept of field in particular, he fails to examine more closely how place and space impact on people's lived experiences and therefore their habitus, capital and field. In my research I have attempted to integrate to Bourdieu's concepts a more explicit "place-based" examination of the participation of young people.

With these suggested additions to Bourdieu's original concepts, I could be accused of changing the intent of his work too much. However, from my reading of Bourdieu, my understanding is that Bourdieu's concepts are designed as open concepts rather than closed ones, more like theoretical principles than fixed entities, or a method of enquiry rather than a completed theoretical edifice (Harker, 1990, p. 99). Hillier and Rooksby (2002) contend that habitus for Bourdieu provides "a certain theoretical viewpoint of looking at the world; of interpreting the world, rather than a neat conceptual map of the world that can be read off from the application of the notion" (p. 377). Bourdieu referred to the concepts he developed as "tool kits" to help him solve problems. He says:

The peculiar difficulty of sociology then, is to produce a precise science of an imprecise, fuzzy, woolly reality. For this, it is better that its concepts are supple and adaptable, rather than defined and calibrated and used rigidly. (Bourdieu \& Wacquant, 1992, p. 23) 
His argument is that there is a need for "supple" and "adaptable" concepts which are to be applied and reapplied in differing theoretical and situational frameworks and to be tested again and again. Thus, in his view, concepts are always to be wedded to theory and research as a form of "fusion of theoretical construction and practical research operations" that causes them to “interpenetrate each other entirely" (Bourdieu \& Wacquant, 1992, pp. 34-35). Reay (2004) says:
what he is stressing is that first and foremost habitus is a conceptual tool to be used in empirical research rather than an idea to be debated in texts. Also the difficulties, inconsistencies, risks of determinism, and aspects of circularity inherent in habitus can be viewed as far less problematic if habitus is viewed more fluidly as both method and theory; a way of understanding the world (p. 439).

My application of Bourdieu's conceptual triad is not so much to prove the theory of habitus for example, but instead, uses his concepts more fluidly as "both method and theory" (Reay, 2004, p. 439) to be applied within my context of research as a method of inquiry which also entails a capacity to explain phenomena. Carol Mutch's (2006) adaptation of Bourdieu's field theory to decision-making in educational policy is a similar attempt to provide an analytical model that is not prescriptive, but descriptive, thus allowing for space to explore "multiple processes and complex interplays" (p. 170). My integration of Bourdieu's concepts with Mills' sociological imagination and a more specific focus on young people's everyday places aims to provide "a way of understanding the world" (Reay, 2004, p. 439) which gives fresh insights into youth participatory citizenship. I will briefly give more detail on the background to the sociological imagination and place-based notions of participatory citizenship before suggesting how these ideas can be integrated together with Bourdieu's concepts to provide an everyday, place-based framework for exploring citizenship participation.

\section{Mills' sociological imagination}

C. Wright Mills (1959) developed the concept of the sociological imagination as an approach for social scientists as well as the "ordinary man" to examine the interplay between personal troubles and public structures. Mills describes how 
individuals are well aware of their personal troubles and problems (such as unemployment, domestic disputes, poor housing), yet "they do not understand the interplay of these personal troubles of their milieux with problems of social structure" (Mills, 1959, p. 187). The failure to locate these shared everyday problems with others within the social-historical structure of their times means that the solution to these problems is often misread as requiring personal responses, rather than societal and structural ones. Mills suggests that the ability to translate these personal troubles into public issues forms the starting point of the "sociological imagination":

What they need, and what they feel they need, is a quality of mind that helps them to develop reason in order to achieve lucid summations of what is going on in the world and of what may be happening within themselves. It is this quality of what may be called the sociological imagination. [...] The sociological imagination enables its possessor to understand the larger historical scene in terms of meaning for inner life and the external career of a variety of individuals. (Mills, 1959, p. 11)

The capacity to interpret these experiences from the personal to the political lies in the ability to "... grasp what is going on in the world, and to understand what is happening in themselves at minute points at the intersections of biography and history in society" (Mills, 1959, p. 14). In this way, the personal and the social become political, and the starting point for taking action or participating in change in society is at this intersection of biography and history. For Mills, this is the primary role of the social scientist in society - to enhance the awareness of the interconnection of individuals with social-historical structures and their own place within them, and to find ways to make "modifications of the structure of groups in which he lives and sometimes the structure of the entire society" (Mills, 1959, p. 187).

Mills' approach has similarities to educational philosophers such as Paulo Freire and his concept of "conscientization" (1973/1996) which he links closely to everyday lived experiences. I was drawn to Mill's sociological imagination by the potential of its application within methodological traditions (Knowles \& Sweetman, 2004), as well as his commitment to radical social change through 
scholarship. His approach also aligns well with the social inquiry tradition ${ }^{17}$ within New Zealand social studies.

\section{Exploring young people's participatory citizenship through Mills and Bourdieu}

In this section I outline more specifically how the integration of Mills and Bourdieu's theories provides opportunities for fresh understandings of the processes of youth agency and participatory citizenship. I also elaborate on how this focuses the lens of research on to the everyday and local expressions of participation thus providing new insights of how lived experiences of young people shape their citizenship imaginations and dispositions.

So, what does the sociological imagination have in common with Bourdieu and how can they be used together within youth participation research? As a starting point, C. Wright Mills and Bourdieu both support a critical constructionist tradition in their work. For example, Mills (1959) proposes the sociological imagination as a means of gaining deeper understandings about the interplay between personal circumstances and social/historical forces. Similarly, Bourdieu collapses the objective/subjective distinctions and argues that agents' perceptions and appreciations (dispositions) are structured on the inside by their embodied lived experiences in society (Bourdieu \& Wacquant, 1992, p. 11). Both Mills and Bourdieu also have a strong conception of the importance of the social actor in shaping, and being shaped by the society within which s/he exists:

By the fact of his [sic] living he contributes, however minutely, to the shaping of this society and the course of its history, even as he is made by society and by its historical push and shove. (Mills, 1959, p. 12)

Similar to other critical theorists who "have a tremendous appreciation for the extraordinary richness of ordinary life and action" (Prasad, 2005, p. 151), Bourdieu and Mills share a mutual focus on the everyday and ordinary experiences as the starting point for analysis and change in society. Tim

\footnotetext{
${ }^{17}$ The social inquiry is an inquiry-based learning approach for studying societal issues that has been developed within the 2007 New Zealand social sciences curriculum (see glossary for further on how this is used with the New Zealand Curriculum).
} 
Cresswell (2002) describes how Bourdieu's priority for everyday life was a reason he turned away from philosophy (which he regarded as too abstract and removed from everyday life) and took up "deeply unfashionable" (p. 379) sociology instead. Bourdieu's concepts of habitus, capital and field centre on everyday interactions and relationships (within families especially), to explain the largely intuitive, subconscious dispositions of individuals and social groups. For Mills, the premise upon which the sociological imagination rests, is personal biography and the development of "self-consciousness" (Mills, 1959, p. 7) between personal troubles and public issues of social structure, a process which has a chance to "make a difference in the quality of human life in our time" (p. 226).

There are few examples of researchers who have integrated Mills' sociological imagination with Bourdieu's habitus, capital and field. One such study is Clarence Batan's (2010) exploration of "istambay,"18 a group of long-term unemployed young people in the Philippines. A Mills-Bourdieu approach highlighted the intertwining private-public nature of the istambay phenomenon, thus providing insights into how the problem of youth inactivity/unemployment was both a personal and societal (structural) one. The Mills-Bourdieu approach enabled Batan to show how the dispositions of istambay (habitus) were supported by cultural practices of care and sharing by the church and the family. The caring practices of these two groups covered for the deeply-rooted structural inequalities within the educational and economic fields of the Philippines, and through their support, the presence of istambay in society are reproduced (p. 275). The istambay's position in society was in turn legitimised by their status in movies, advertisements and films, thus creating a type of legitimate subculture. These findings point to how the Mills-Bourdieu integration enables a focus on both youth agency as well as structural and cultural factors.

Yet, in light of the earlier discussion on Bourdieu's limitations in outlining a theory of social change (and related concerns about an overly deterministic

${ }^{18}$ The term "istambay" is derived from the English word "on standby." 
theory of social reproduction), I propose that Mills' sociological imagination be used as a vehicle of agency in my research to enable young people to more actively demonstrate their participation in society, but also their "cares, concerns and commitments," or moral agency, which Sayer (2005) suggests are largely overlooked by Bourdieu. One other limitation of Bourdieu which I described above was his lack of attention to spatial conceptualisations of his concepts. In the following section I describe why it is important to re-address concepts of space and place within research on youth participation.

\section{A place-based focus on participatory citizenship}

Critical geographic traditions highlight the importance of examining spaces, identities and geographies of exclusion which impact upon young people as citizens in a society (S. Aitken, 2001; Hil \& Bessant, 1999; Holloway \& Valentine, 2000; Sibley, 1995; Valentine, et al., 1998). As discussed in Chapter 2, the mobility, identity and experiences of young people are frequently confined within limited spatial arenas (Hall, et al., 1999; Matthews, Limb, \& Percy-Smith, 1998; Nava, 2007). Harris and Wyn (2009) suggest that young people's political interest and actions are shaped, expressed and constrained within the microterritories of the local spaces of neighbourhoods, homes and schools. They argue that these constraints shape their social networks and their everyday opportunities for positioning themselves as political.

With these findings in mind, I wish to employ a more "spatialised" conception of habitus than Bourdieu has traditionally used (Hillier \& Rooksby, 2002). The intention of a place-based habitus approach is to pay close attention to young people's sense of space, place, experiences of mobility and conceptions of belonging and identity in those places, as important influences on their participatory dispositions and actions. In doing this I hope to build on the findings of a number of researchers in the field of geographies of children and young people who provide insights into how social capital and sense of place informs and shapes young people's citizenship perceptions and agency (Holland, 2008; Holland, et al., 2007; Mitchell, Kearns, \& Collins, 2007; Schaefer-McDaniel, 2004; Weller, 2006b, 2007; Weller \& Bruegel, 2009). 
These researchers highlight the importance of using child-centred and spatiallysensitive methods to develop nuanced understandings of the complexity that surrounds perceptions and experiences of children and young people. The value of a place-based approach to participatory citizenship, is that it enables "a more explicit spatialised analysis of citizenship that explores the complexities of space and place; an analysis that seeks to highlight the struggles, challenges and conflicts inherent in acts of citizenship which occur in these arenas" (Weller, 2007, p. 47).

In summary, by using the sociological imagination as a methodological tool I extend the idea of citizenship participation to include reflections on society and anticipated or intended conceptions of change. So, when I ask young people to capture what is special and important about their place and what they would like to change (see Photovoice research in Chapter 4) I am asking them to employ their "citizenship imaginations". This focuses specifically on the aspects of everyday, personal experiences (issues, people and places) that young people wish to protect, preserve or transform, but may not necessarily have the means or ability to change. Through a Mills-Bourdieu approach I intend more explicitly to link young people's sense of belonging and everyday interactions within space with their participatory dispositions and actions.

I propose that gaining insights into young people's place-based, everyday perspectives of participation will enable us to explore more closely how young people's citizenship dispositions are forged within their lived experiences of people, schooling and places. In particular I will explore the critical interaction between teachers' participatory social and cultural capital (Chapter 5), and young people's social and cultural capital derived from their social studies education and experiences of communities (Chapter 6). I then consider how these interactions inform young people's practices of participatory citizenship (Chapter 7). This theoretical and conceptual stance has significant implications for the methodology I put in place to explore this, and in Chapter 4, I outline and explain the methodological design I have employed in this study. 


\section{CHAPTER 4: \\ METHODOLOGY}

My focus in this chapter is to describe and explain the research strategies I employed for research with the youth participants as the primary focus of this study. I also outline my research approach with teachers. The aim of this research, to explore young people's everyday, place-based perspectives and experiences of participation in society, pointed the way toward a "respondentled" (Marsh, et al., 2007, p. 60) approach that enabled open-ended perspectives and "thick" descriptions to be collected. Paramount to achieving this was a research design that provided spaces for young people's recognition and representation (S. Smith, 2001) and therefore enabled them to participate in meaningful ways. While I have worked to create such a research design, it is important to acknowledge the imbalance in power between adults and young people in the research encounter (Heath, Brooks, Cleaver, \& Ireland, 2009; V. Morrow, 2008; V. Morrow \& Martin, 1996), and the inability to displace this entirely in the research encounter (Barker \& Smith, 2001).

I begin by outlining the critical, social constructionist philosophical framework which underlies my stance toward knowledge production in this research. I then describe the multiple-site, qualitative research design employed which aimed to privilege participatory and place-sensitive perspectives. Data collection included the use of both verbal (café-style and traditional focus groups) and visual (Photovoice) research techniques. The steps which I took to analyse both these data are outlined. Understanding that ethical decisions "permeate every phase of the research process" (Denzin \& Lincoln, 2003, p. 30), I describe measures I have taken to ensure ethical care of participants and their data throughout this chapter. I conclude by briefly examining two specific ethical issues related to my use of visual methodologies. 


\section{Critical, constructionist approaches to research}

As outlined in Chapter 3, a critical theoretical paradigm underpins the approach and motivation for research in this area. This approach has been informed primarily by Bourdieu's conceptual triad of habitus, capital and field and Mills' sociological imagination. This approach draws attention to how experiences, interactions and relationships within social groups (in the form of capital, habitus and field) within places, shape participatory citizenship practices and conceptions. Bourdieu's theory of sociocultural reproduction is "among the strongest constructionist programs ever proposed" (Faubion \& Marcus, 2008, p. 75 ) in the social sciences, and points to the importance of considering both what participants understand and perceive, and how this knowledge is constructed within the context of differing social settings (Gubrium \& Holstein, 2003). A critical constructionist approach to data analysis and interpretation, seeks to place the research encounter and generated data within the wider context of societal patterns of power, privilege, inequalities and place (R. Morrow \& Brown, 1994).

Critical and social constructionist positions share a number of commonalities. First, social constructionists and critical theorists both understand data as subject to interpretation within the context and conditions from which it was derived (Silverman, 2006). Rather than attempting to uncover "facts" or "truths" behind narratives, constructionists are interested in "documenting the way in which accounts are part of the world they describe" (Silverman, 2006, p. 129). Respondents' accounts therefore are not treated as potentially true pictures of reality; instead, "the situated, or locally produced nature of accounts is to the fore" (Silverman \& Marvasti, 2008, p. 195). Applying these understandings within my research involves drawing attention to the social, educational and community contexts from which the data was derived, and recognising that these social interactions influence the understandings and meanings people hold toward participatory citizenship, which in turn informs their agency. 
Second, through critical and constructionist approaches, researchers understand that knowledge produced in the research encounter is always partial and informed by the interpreter who is "immersed in this production of knowledge" (S. Smith, 2001, p. 25). In this way,

... research accounts are mediated by the tellers' experiences, by their perceptions of the researcher and of the research context. Thus all accounts are equally likely to be a cocktail of the 'experienced', the 'perceived' and the 'imagined'. (Valentine, et al., 1998, p. 22)

Making the reflexivity of the research encounter more explicit is an important aspect of qualitative research (Best, 2007; Dwyer \& Limb, 2001). Acknowledging my own identity, power, values and biases (R. Morrow \& Brown, 1994) and the "epistemological and political baggage" (Kincheloe \& McLaren, 2008, p. 406) that I bring to the research process is an important step in positioning myself in this research.

In many ways, my research with diverse participants is "cross-cultural" in the sense that my identity (represented in my gender, ethnicity, age and educational and employment experiences), does not match many of my participants. For example, my former experience as a social studies teacher and in curriculum development renders me at ease in a social studies classroom, and familiar with curriculum issues and activities. Yet, at the same time, my age (in my thirties) significantly restricts my ability to understand some of the subtleties associated with the lives of young people today. Similarly, my gender and ethnicity (female, pākeha/pālāngi19/NZ European) positions me with varying degrees of both insight and ignorance as I examine and interpret participants' data. These research findings therefore do not make claims to hold universal truths, but instead are acknowledged as holding partial and situated claims that have been developed within this research encounter.

Third, a critical, constructionist stance acknowledges that knowledge produced in research is not only partial, provisional and situated, but it is also a site of struggle between competing social constructions, representations and

\footnotetext{
${ }^{19}$ See glossary.
} 
performances (S. Smith, 2001). By choosing to place non-dominant and neglected knowledges at the heart of the research agenda, researchers are also undertaking research with a critical agenda (S. Smith, 2001). Attempting to privilege the ways that young people define and participate in citizenship is part of the critical agenda in this research. These starting points have a direct influence on my research methodology, as "a consistent critical method which treats society as human construction and people as active subjects of that construction would be based on dialogue with its subjects rather than the observation or experimental manipulation of people" (Comstock, 1982, p. 371).

\section{Qualitative research with young people}

The beauty of qualitative research is that it gives you access to the nittygritty reality of everyday life viewed through a new analytic lens. (Silverman \& Marvasti, 2008, p. 213)

Qualitative methodologies were selected for this research, in keeping with my aim to gain more nuanced, inclusive and detailed perspectives on participatory citizenship. A strength of qualitative research is its ability to give us insights into lived experiences and shared meaning developed through people's everyday social worlds and realities (Dwyer \& Limb, 2001) which then contribute to "nuanced views of reality" (Flyvbjerg, 2004, p. 422). Qualitative research provides a means by which "the 'messiness' and complexity of everyday life can be explored by using research methods that do not ignore such complexity but instead engage with it" (Dwyer \& Limb, 2001, p. 2). A commitment to enabling the experiences, perceptions and voices of young people to be seen and heard, underpins the attempts to develop critical, participatory and youth-centred approaches in this research.

\section{Privileging participatory and place-sensitive approaches}

The attention drawn to the agency and competency of children and young people in the research process by the "new" social studies of childhood (James, et al., 1998; James \& Prout, 1990) has resulted in a plethora of youth/childcentred methodologies. These are characterised by mutuality and negotiation 
(rather than imposition), with an intention of finding ways to work with children and young people that enable them to express their own opinions and understandings in creative and meaningful ways (Barker \& Weller, 2003; Valentine, 1999). Many researchers applying child/youth-centred qualitative approaches have also endeavoured to include more participatory research practices committed to "actively involving research subjects in the construction of data" (Gallagher, 2008, p. 138).

The benefits of using participatory approaches with children and young people, centre on the belief that they will produce more "authentic" knowledge about children's subjectivities, and that they are more ethically acceptable than traditional methods as they offer children and young people opportunities to "have a voice" in the research (Gallagher, 2008). Examples of participatory research which involve youth/child participants in constructing or creating the data include the use of written techniques such as diaries or drawing (Barker \& Weller, 2003; Sargeant, 2008), story writing (Mitchell, et al., 2007), child/youthled photography (Allen, 2009; Dodman, 2003; Lee \& Abbott, 2009; Mitchell, et al., 2007; Weller, 2007) and performance-based techniques such as a Youth Tribunal (L. T. Smith, et al., 2002).

Later in this chapter I outline the two participatory research methods I used with youth participants in this study: namely café-style focus groups and Photovoice research. My intention in integrating participatory approaches in my research is to disrupt more adult-centric definitions and enable young people to actively shape and direct the data. However, by using these participatory approaches I do not presume this will entirely displace adult-centred power in research (Barker \& Smith, 2001), nor do I suggest that young respondents are without the ability to assert power in research (Gallagher, 2008). A recognition of the pre-existing landscapes of power in places such as schools, as well as the "multiple shifting relations of power" (Gallagher, 2008, p. 143) within research underpins my use of youth-centred and participatory approaches in this study. 
As well as privileging participatory approaches with young people in my research design, I also sought to privilege aspects of "place." Many have taken up the challenge to integrate specific geographic and spatial themes within their research methods with children and young people (see, for examples Elwood \& Martin, 2000; Skelton, 2001b; Weller, 2007). However, Jon Anderson and Katie Jones (2009) claim that while social science research has paid greater attention to the significance of social relationships in methodology (such as researcher reflexivity), less attention has been paid to the "where of method" (p. 292). I applied these ideas by developing research methods which allowed for opportunities for the research encounter to involve both within classroom experiences (café-style focus groups) and beyond classroom experiences (Photovoice). Drawing children and young people's attention to their own environments within research is another way that place can be privileged in research design (Hart, 1979; V. Morrow, 2001). In my research, I deliberately used undefined spatial terms such as "our place" throughout the visual and verbal research tools to allow participants to define this as they wished, thereby capturing a sense of their lived and perceived lifeworlds or "lifescapes" (Maira \& Soep, 2005).

\section{Research design}

\section{A multiple-site study}

A multiple-site study has a number of advantages over a single site or case as it enables a researcher to describe what is common and unique within and across sites. A comparative site approach also offers the potential to explore the significance of spatial and relational factors in the development of citizenship dispositions and actions. Comparison can also bring many advantages to the interpretation of data whereby this approach can highlight the "contextual sensitivity" (Silverman, 2006, p. 17) of concepts (such as "participation" or "citizenship"), recognising that these concepts are likely to have a variety of meanings in different contexts (McLeod \& Yates, 2006). ${ }^{20}$

\footnotetext{
${ }^{20}$ Most educational research uses "case study research" to achieve these aims. My impression is that this term is over-used in research. While I initially used the term case study, I became aware that my focus in schools on one class, and a small number of teachers could scarcely be a "case"
} 
In selecting a variety of settings, my aim was not to establish a representative sample, but rather to give comparative attention to the significance that context (including socio-economic circumstances), education and place-based experiences could have upon youth participation and citizenship dispositions. My selection of secondary schools was made on the grounds of two criteria: first, that they represented a diversity of socio-economic and geographic indicators, and second, that they demonstrated a prior interest in, or familiarity with, "social action" and/or community engagement in their social studies or wider school programmes. This focus was to ensure that both teachers and students in these schools had an interest in active citizenship, and/or had some exposure to how this was currently being enacted.

The primary way that I selected for a diversity of socio-economic indicators was through the use of the 'decile' rating system of schools used by the New Zealand Ministry of Education to provide equitable funding for schools. A school's decile indicates the extent to which a school draws its students from a low socioeconomic community, with a Decile 1 used to represent a low socio-economic community and Decile 10, a high socio-economic community. The decile rating for a school is calculated by using a number of census-related variables from the school community (including household income, parental occupation and qualifications, income support and household crowding) (Ministry of Education, n.d). Similar to Marsh et al. (2007), I assumed that these school sites were "classed," or in Bourdieu's terms, "they are institutional embodiments of fields" (p. (p. 64) and therefore provided opportunities to explore differential access to social, cultural and economic capital. As I was also interested in how experiences within different geographic places could influence perceived issues of importance and participatory citizenship, I also purposively selected schools to reflect an urban/rural, large city/small city mix to allow for these variations to be part of the comparative approach.

and so, in keeping with McLeod and Yates (2006) and Marsh et at (2007) I have termed this a multiple site approach. 
To gauge a school's interest in social action/community engagement I drew on my prior knowledge and experience in a number of schools and also that of my supervisors. I also sought out further information of a school's participatory practices with their students by examining school websites and ERO reports. In consultation with my supervisors, I refined an initial list of ten potential schools down to four. These choices took into account my prior contacts and relationships with staff in various schools (Allen, 2009; Powell \& Smith, 2009), and my ability to access accommodation and transport with minimal expense in the school locations.

\section{Gaining informed consent within schools}

The process of inviting children and young people to participate in research in schools generally involves a "chain of negotiation" (Valentine, 1999, p. 145) with multiple parties involved. The initial chain of negotiation in my research began with sending a letter to the principals of each of the four selected schools informing them of the project and asking permission to conduct research within that school (see Appendix D). This letter also asked the principal to identify a lead social studies teacher for me to liaise and negotiate the research process with. All four of the invited schools accepted the invitation to participate.

The next part of the negotiation chain involved meeting and consulting with the designated lead teacher to work out how the research process should proceed and how I could work in with their timetables and programmes. We also discussed which of their social studies classes would be most appropriate to invite to participate. My aim was to invite the whole class thus including "ordinary students" rather than just the "good talkers" or young people at risk (Nairn, et al., 2006) which would offer me the potential to examine how the conceptions and practices of students toward social action compared with their teachers'.

Participants made an informed choice about whether or not to participate in the research. I visited each class to discuss the project and allow them to ask questions. I had two versions of the information and consent sheets - a "youthfriendly" version for students (Appendix E) and an adult-oriented version for their 
parents (Appendix F) with the intent of effective communication to each audience (Alderson, 1995; Powell \& Smith, 2006). I ensured participants knew that their consent was an ongoing negotiated process throughout the research (Valentine, 1999). I organised for the lead teacher to collect these over the following week to ensure those invited to participate had "time to think before agreeing whether or not to participate" (Valentine, 1999, p. 145) as well as consult with their parents.

In keeping with the ethical guidelines of Victoria University of Wellington, participants under the age of 16 were required to obtain parental support if they opted in to the research. ${ }^{21}$ I was asked by a number of students who were under 16 if they could "give consent for themselves without their parents' permission" (Field notes, May, 2009), an issue identified by other researchers in this field (Powell \& Smith, 2009; Skelton, 2008). Young people aged 16 and over were allowed to give informed consent themselves. I ensured these participants also received parental information forms so the parents were aware of the research. Of the 125 youth participants invited to participate, 122 went on to participate in the research. Only one young person opted out of the research and two 14 year-olds were sadly excluded as they had not brought back the parental consent forms in the time required. ${ }^{22}$

The second group of participants in each school were the social studies teachers. My primary contact was with the lead teacher, but I also invited all members of the social sciences department who taught social studies to participate in a focus group discussion about social action and the social studies curriculum.

Participation in these discussions was voluntary and teachers were fully informed of their rights in the project (see Appendix G). I conducted these focus group interviews at a time suggested by the lead teacher which was either before or after school (generally timed to coincide with their regular department meeting). These focus groups took place following the data collection with students so I could also

\footnotetext{
${ }^{21}$ There are ambiguities between institutions in New Zealand regarding the age of consent (Loveridge, 2010; Powell \& Smith, 2006), so my decision here was guided by my local ethics committee at Victoria University of Wellington.

${ }^{22}$ In each school I had worked out with the lead teacher what we would do with students who did not want to "opt in" to the project (such as working in the library).
} 
provide some feedback to the teachers of my findings and discuss emerging themes. Twenty-seven of the 28 social studies teachers, who were invited to participate, chose to opt in to the research. ${ }^{23}$

\section{Summary of selected schools and participants}

The final selection of four schools represented a wide range of social and geographic variables (see Table 4.1). All of the schools were state schools, three were co-educational and one was single-sex girls' school. Two schools were from a large city, one from a smaller provincial city and one from a small rural town. Two schools were from the North Island and two from the South Island.

Table 4.1 Summary characteristics of four schools

\begin{tabular}{|c|c|c|c|}
\hline College & Decile & $\begin{array}{c}\text { Nature of } \\
\text { school }\end{array}$ & Location and student mobility \\
\hline $\mathbf{A}$ & 6 & State, co-ed & $\begin{array}{l}\text { South Island regional city } \\
\text { Suburban area - middle income } \\
\text { Majority of students attend from nearby suburbs; } \\
\text { some bus }\end{array}$ \\
\hline B & 1 & State co-ed & $\begin{array}{l}\text { North Island city } \\
\text { Suburban area - low income } \\
\text { Majority of students attend from the immediate } \\
\text { suburb (walking) }\end{array}$ \\
\hline $\mathbf{C}$ & 4 & State co-ed & $\begin{array}{l}\text { South Island small rural town } \\
\text { Low to middle income } \\
\text { Approx. } 50 \% \text { of students bus in from outlying } \\
\text { rural areas }\end{array}$ \\
\hline D & 8 & $\begin{array}{l}\text { State Girls' } \\
\text { school }\end{array}$ & $\begin{array}{l}\text { North Island city } \\
\text { Central location in city } \\
\text { Middle to high income } \\
\text { Majority of students bus in from nearby suburbs }\end{array}$ \\
\hline
\end{tabular}

The final numbers, gender, ethnicity and age of youth participants within the six social studies classes were influenced by opportunity and invitation in each school (see Table 4.2). The sample includes more female (74\%) than male (26\%) students as a result of the inclusion of an all girls' school (College D) and the allocation of a class at College B that included only females even though the school was co-educational. The ethnicity of youth participants was self-identified, with

\footnotetext{
${ }^{23}$ One teacher attended the focus group interview but remained silent and withdrew her participation by not handing in the informed consent sheet at the end of the interview.
} 
the majority, (70\%),24 identifying as New Zealand Pākeha, with smaller numbers of Māori (7\%), Pacific Nations (9\%) and other ethnic groups (14\%). College A had higher numbers of participants than the other schools as it served as a pilot school to trial the research tools with two senior classes. The data from this pilot study of two senior social studies classes was included in the research findings as the research tools only required minor modifications (see Nairn, et al., 2006 for similar approach). This study was not conducted with the aim of providing representative or generalisable statistical data, so whilst the "unevenness" of variables associated with participants' gender, ethnicity etc. is significant, the primary focus is on gaining detailed understandings of youth participatory citizenship.

Table 4.2: Summary of youth participants within four schools

\begin{tabular}{|c|c|c|c|c|c|}
\hline College & $\begin{array}{l}\text { Year } \\
\text { level }\end{array}$ & Male & Female & $\begin{array}{l}\text { No. of } \\
\text { parti- } \\
\text { cipants }\end{array}$ & $\begin{array}{l}\text { Ethnicity of } \\
\text { participants } 25 \\
\text { (self identified) }\end{array}$ \\
\hline \multirow[t]{3}{*}{$\begin{array}{c}\mathbf{A} \\
(n=56)\end{array}$} & 10 & 6 & 16 & 22 & \multirow{3}{*}{$\begin{array}{l}\text { NZ Pakeha (52) } \\
\text { Māori (3) } \\
\text { Pacific Nations (1) } \\
\text { Dutch (1) } \\
\text { Indian (1) } \\
\text { Japanese (1) }\end{array}$} \\
\hline & 12 & 7 & 12 & 19 & \\
\hline & 13 & 2 & 14 & 16 & \\
\hline $\begin{array}{c}\mathbf{B} \\
(n=10)\end{array}$ & 12 & 0 & 10 & 10 & $\begin{array}{l}\text { Samoan (6) } \\
\text { Cook Island Maori (2) } \\
\text { Māori/Samoan/Korean (1) } \\
\text { Tuvalu(1) }\end{array}$ \\
\hline $\begin{array}{c}\mathbf{C} \\
(n=29)\end{array}$ & 10 & 16 & 13 & 29 & $\begin{array}{l}\text { NZ Pakeha (28) } \\
\text { Māori (1) }\end{array}$ \\
\hline $\begin{array}{c}\mathbf{D} \\
(n=26)\end{array}$ & 10 & 0 & 26 & 26 & $\begin{array}{l}\text { NZ Pakeha (12) } \\
\text { Māori (4) } \\
\text { Pacific Nations (2) } \\
\text { Chinese (1) } \\
\text { Australian (1) } \\
\text { Assyrian (1) } \\
\text { English (1) } \\
\text { Czech (1) } \\
\text { US (1) } \\
\text { Jedi (2) }\end{array}$ \\
\hline Totals & & 31 & 91 & 122 & \\
\hline
\end{tabular}

24 Participants who wrote "New Zealand," "Pākeha" or "NZ European," were categorised as New Zealand Pākeha. Pākeha is the Maori term for people of European descent and is widely used in New Zealand (see Dyck \& Kearns, 1995, for a discussion on issues of representation in New Zealand research). Participants who stated a specific European origin (such as Czech, Dutch or English), were listed in a separate category.

25 Youth participants were asked to self identify their ethnicity and no "tick boxes" were provided. This practice is common in research in New Zealand (for examples, see Allen, 2009; L. T. Smith, et al., 2002), however, it does present some challenges, such as the two participants in College D who wrote "Jedi". 


\section{Data Collection}

Data collection in schools occurred between late October in 2008 and September, 2009. I visited each of the four school sites eight to ten times. Data collection for my research drew upon two major sources of information. First, verbal data from the café-style focus group interviews and the more traditional focus group interviews with social science staff members. Secondly, I gathered visual data through the Photovoice research. In the following section I will explain why these research tools were used for this project and describe in more detail how this data was collected. Issues of analysis and interpretation are covered in the following section.

All youth participants completed a card to provide me with biographical data (such as age, ethnicity and gender) during the initial visit. In keeping with a number of other projects (Gallagher, 2008; McLeod \& Yates, 2006; Weller, 2007), I allowed the youth participants to select their own pseudonym or "code name" for the project to protect their identity. ${ }^{26}$ Youth participants took a great deal of care in selecting their pseudonyms, many of which reflected contemporary pop culture and celebrities in vogue at the time (Heath, et al., 2009). For example, participants chose names of famous singers and film stars (Miley Syrus, Joey Tribbiani (Friends, TV show), Hip Hop Potamas and Rhymenocerus (from "Flight of the Conchords," a New Zealand comedy duo), contemporary movies and books (Smoove Cullen and Emmett Cullen after the popular Twilight series), or political figures (such as Rodney Hyde, a Member of Parliament). Two participants wrote their own names backwards which I later changed to initials to protect their identity.

The chosen pseudonyms of the young people can at times be disruptive to the reading of research (Valentine, 1999), and some of the name choices in this research could mean that the reader is less inclined to take the young people's

\footnotetext{
${ }^{26}$ I didn't collect biographical data from teacher participants or ask them to choose pseudonyms as the primary focus of the research was on the youth participants. Instead, I allocated each teacher a name as a reflection of their school $(\mathrm{e}, \mathrm{g}, \mathrm{A} 3$, is the third teacher to contribute to the discussion at College A).
} 
contributions seriously (Barker \& Weller, 2003). ${ }^{27}$ However, I feel that their choice of "unusual, playful or amusing names" (Gallagher, 2008, p. 148) also reflected the sense of fun and personal creativity that many showed in their approach throughout the project.

\section{Café-style focus group interviews}

My aim in using focus groups with young people was to create a safe space to explore ideas with young people in the context of their interaction with others (Eder \& Fingerson, 2003, in Heath, et al., 2009). Through the use of focus groups I also intended to reduce the power of the interviewer in the research encounter and thus create a less threatening environment for young people (Marsh, et al., 2007). As a former secondary teacher however, I was aware that a researcher arriving in my class to facilitate focus group discussions which relied heavily on group interaction was ambitious (Nairn, Munro, \& Smith, 2005). With this in mind, and inspired by a "world café" approach (Brown \& Isaacs, 2005) which uses small group conversations to develop a community of inquiry to explore real-life issues and questions, I developed a variation on the traditional focus groups interview, which I have termed 'café-style' focus groups. While I have used a number of ideas from the world café, I also deviate from this approach in a number of ways - such as not moving participants from group to group to "cross-pollinate" ideas.

Café-style focus groups differ from a traditional focus group because they are largely self-facilitated by the participants who are guided by a set of activities to complete (Brown \& Isaacs, 2005). Posters were used in the café-style focus groups as a type of "task-based" activity to stimulate discussion, and generate more easily comparable data (Punch, 2002). The posters were a series of five A3 sheets with open-ended statements, such as "important issues in our place..." or "a good citizen is...," pre-written on them (see Appendices I-M). The openness of these statements was designed to avoid imposing adult-defined categories (Punch, 2002).

\footnotetext{
${ }^{27}$ With this in mind, Susie Weller returned to her participants and asked them to reconsider their pseudonyms at a later stage once she showed them how they appeared in text.
} 
To create a hospitable, "café-style" atmosphere within a classroom I grouped tables together with bright tablecloths, coloured marker pens, the poster to be worked on and a digital recording device in the centre. Participants selected the peers they wished to work with, with the aim of facilitating naturalistic and open conversation in a social setting (Grudens-Schuck, Lundy Allen, \& Larson, 2004). In smaller classes participants worked in pairs, but in general, groups had three to five members. After an initial introduction groups worked at their own pace, I asked groups to appoint a writer/recorder of ideas and a reporter who would provide a summary at the end. Conversations in each group were recorded and sessions ended with a report back of thoughts and ideas from each of the small groups to the whole class to allow opportunities to share findings, reflect and listen together for patterns, insights and deeper questions (see Brown \& Isaacs, 2005, pp. 127-135).

My role in the café-style groups was as a roving facilitator to answer questions, probe deeper on some of their ideas and occasionally keep groups on task. So, while my presence could not be discounted for contributing to and shaping the conversations, there were also many rich discussions that occurred in my absence (that I only heard when transcribing). The café-style focus group approach enabled the youth participants to shape the direction and flow of the conversation more than a traditional interview, thus releasing the research agenda exclusively from the hands of the adult researchers (Skelton, 2001b). Sometimes the level of freedom enabled through this approach resulted in participants' conversations wandering off into discussions about areas beyond the research focus. However, this lack of self-consciousness in the interview process enabled me to capture more of their "natural" conversations, and, as Alderson (1995) suggests, "rambling might introduce highly relevant issues which you had not considered" (p. 171). While a couple of individuals did dominate a couple of groups (as discussed by Gallagher, 2009), generally, the peer-selected, semi-informal set up resulted in contributions from all participants. Thirty café-style focus groups were conducted with 122 youth participants in the four schools. 
A more traditional focus group interview was conducted with the teacher participants which I led using a semi-standardized questions. Similar to the caféstyle focus groups, I began each session by asking teachers to complete a poster in pairs identifying what they found positive, negative and/or interesting (a PMI chart ) about social action within the social studies curriculum (see Appendix N). The report back of their posters to the whole group was recorded. Four focus group interviews conducted with the 29 teacher participants (see Table 5.1).

\section{Photovoice visual data}

My second source of data was generated by a participatory visual methodology known as Photovoice. ${ }^{28}$ Originally developed by health researchers, in this approach participants are provided with cameras and asked to record and represent their everyday lives and then reflect on these photos through critical dialogue (Wang, 1997; Wang \& Burris, 1994; Wang, Cash, \& Powers, 2000). Taking its inspiration from Freire's concept of conscientization and from feminist theory, Photovoice techniques aim to enhance the power of marginalised groups within society by providing opportunities for reflecting on potential change and taking actions to address change (Wang, et al., 2000). Photovoice has also been employed when researching with young people as a way of gaining their perspectives (see, for examples Hilfinger Messias, Jennings, Fore, McLoughlin, \& Parra-Medina, 2008; Mitchell, et al., 2007; Strack, Magill, \& McDonagh, 2004; Wilson, et al., 2007). For example, Photovoice research in the New Zealand suburbs of Clendon and Mangere encouraged young local residents to reflect on social issues within their communities and environments with the aim of allowing opportunity to express what young people wished to change or celebrate (Jensen, Kaiwai, McCreanor, \& Moewaka Barnes, 2006).

I had three main motivations for including aspects of visual methods in my data collection. First, I wanted to provide the opportunity for young people to

\footnotetext{
${ }^{28}$ Other terms for similar approaches include photo-elicitation (Allen, 2008, 2009), autophotography (Dodman, 2003) and participatory photo interviews (Jorgenson \& Sullivan, 2010). I have preferred the term and methods of Photovoice in my research as its theoretical origins fit closely with the broad critical traditions which underpin my research.
} 
communicate through images rather than just the spoken word. Photography provides an alternative way for young people to express themselves in research (V. Morrow, 2001), especially for those who are reticent to speak out in public or have English as a second language (Allen, 2009). Photography generated by informants also offers the potential to capture specific everyday processes and events that otherwise might have been considered trivial, as well as opportunities that enable the researcher to explore the more sensory and affective dimensions of experience (Jorgenson \& Sullivan, 2010; Kidman, 2009).

Second, as a participatory research approach, visual methodologies provide the potential for participants to shape and influence the data more significantly than many adult-centred methods of research, by enabling them to "choose and control what they wanted to depict" (V. Morrow, 2001, p. 258). Photovoice techniques also provided opportunities to move the research beyond the four walls of the classroom/the school institution and gain a wider perception of young people's lives (Anderson \& Jones, 2009; V. Morrow, 2001), in keeping with my focus on the spatiality of participation.

My third motivation in using visual methods, was the desire to enable participants to show their "sociological imaginations" in relation to the issues they perceived to be important in the context of their everyday lives (Mills, 1959). Photovoice offered young people opportunities to "engage thought, extend the imagination, and to undermine the implicit authority of the written word" (Walker, 1993, in Dodman, 2003, p. 294) by encouraging them to reflect on the intersection of their personal lives with the wider social and political world. Applying the sociological imagination in this way offers "a way into understanding how the personal is social and the social personal" (Knowles \& Sweetman, 2004, p. 8). Within the context of my research, I hoped that visual methodologies would provide an opportunity for participants to tell a visual narrative about the social issues that were perceived to be important, why this was the case (in light of what they valued) and what they wanted to change. 
The Photovoice research in my research was conducted with one class from each of the four schools in the study. The Photovoice activity was framed by two key questions:

- What is special or important about your place? What makes you feel like you belong?

- What do you want to change/take action on? What makes you mad? (See Appendix H).

The youth participants were asked to capture their response to these questions through photographs. Six cameras were available for the visual research so participants planned for the Photovoice activity in groups that were as close as possible to the café-style focus groups. ${ }^{29}$

The timing of the Photovoice activity was made in consultation with the lead teacher and resulted in a few different approaches between the schools. At College $\mathrm{C}$, the Photovoice activity was conducted during school hours during an allocated social studies lesson which stretched between Interval and Lunch this allowed us about 90 minutes for participants to walk in their groups to the town centre and conduct the activity from there. At Colleges A, B and D cameras were given out overnight with students conducting the activity in their groups where possible and nominating a lead photographer when not possible. I returned to collect the cameras the following day (and in College D's case, after a weekend). These differences between schools had significant implications for the nature of the photographs taken and the geographical distance over which students moved during the activity. I reflect more on the implications that these differences had on collected data in Chapter 6.

All participants were given a practical lesson on the use and care of digital cameras (see Appendix H). The lead teacher was always present during these discussions and we both discussed with participants ways to ensure their safety and respect the privacy of members of the community during the activity. In keeping with the ethical constraints of the project, participants were encouraged

\footnotetext{
${ }^{29}$ The university loaned me five cameras for my research and I gave out my own camera. Following each Photovoice research experience, these were returned in perfect condition.
} 
to take photos of inanimate objects and non-identifiable people to minimise confidentiality risks for all involved.

The Photovoice interview following the photography took a number of variations across the schools in keeping with the processes established with the lead teacher. In College A, B and D this took place with the whole class present, using either a data projector (in Colleges A and D) or sitting round my laptop (College B). In College C, groups were interviewed in an adjoining office to enable the rest of the class to continue with work. The interviews were taped. The format of questioning, adapted from Wang et al.'s (2000) format ${ }^{30}$, included The two semi-standardized questions:

- What is this photo of? (What's happening here?)

- Why did you take this photo? (I.e. this was often phrased as why is this 'special' OR why do you want to change this?)

I occasionally asked the photographers what would you like to do about it/or how does it make you feel? to uncover more sensory detail about their motivation for taking the photo (Jorgenson \& Sullivan, 2010).

The Photovoice research generated 440 useable photos. This did not include some photos that were removed due to lack of clarity, or were a direct copy of another photo (a duplicate). Photos of recognisable people and places were analysed but were not used for presentation in the thesis.

\section{Feedback to participants}

Following an initial analysis of data from each school, I returned to the participants with a summary of some of the emerging themes and patterns that I had identified (Valentine, et al., 1998). I presented this on a double-sided sheet containing a summary both visual and voice findings in the form of raw and lightly coded data. ${ }^{31}$ I also used this opportunity to return the young people's

\footnotetext{
30 For example, in their approach the acronym SHOWeD is used to describe the five questions Photovoice participants are to address: What do you See here? What's really Happening here? How does this relate to Our lives? Why does this asset or problem exist? What can we Do about it? (Wang \& Burris, 1994; Wang, et al., 2000).

${ }^{31}$ These summaries are not included in appendices as some photos on these sheets included identifiable people and places.
} 
photos to them in printed and digital form as part of my reciprocity and as a way of acknowledging their ownership of the photos (G. Rose, 2007). Photos that included recognisable people were returned in print and digital form to the participants but not used for my research. The feedback sessions were met with a very positive response by the participants who were generally very keen to view their photographs and to see how their comments had been used.

I asked the youth participants to reflect on these summaries and consider if they matched their own experiences and understandings. I also asked the young people to interpret and classify some of their own data with me as one way of addressing the limitations of an adult-only perspective on photo analysis (Cook \& Hess, 2007) and to acknowledge that the knowledge produced in the research was locally situated and constructed and therefore the participants had insights about the analysis which would be worth hearing. The practice of shared analysis also was a way of illustrating how their contributions would be used within an academic context (Cook \& Hess, 2007; Valentine, 1999). I recognise that asking young people to help me interpret data "does not negate the role of the researcher who must ultimately make the final decisions about interpretation and dissemination" (Loveridge, 2010, p. 121).

\section{Data analysis}

Throughout the data analysis process it was important to find ways to approach the rich and complex data generated by my research in appropriate and meaningful ways. The verbal and visual data collection strategies had generated a lot of qualitative data so one of the first strategies (after transcription) was to find ways to organise and reduce the data to clarify emerging themes (Huberman \& Miles, 1998). For example, data generated by the poster construction was able to be reduced to bullet points on tables which enabled comparison within and between schools (see discussion on analysing groupgenerated data below). Through this initial working with the data, I identified themes and patterns (see Berg, 2007) that were linked closely to the research questions. This analysis generated a series of codes which became the tree nodes used with the qualitative data analysis software NVivo (QSR International). The 
five broad themes included aspects of our place, important issues in our place, kinds of citizens, rights and responsibilities of young people and social studies education. The process of re-classifying the data into further sub-nodes (NVivo refers to these as parent and child nodes) was another step in getting to know the data better.

\section{Analysis of interview-generated data}

Outlining the philosophical stance toward social reality and the production of knowledge is especially important when it comes to the analysis of data (Dwyer \& Limb, 2001). In keeping with the interpretive practice outlined by Gubrium and Holstein (2003) earlier in this chapter, I have used an approach to data analysis of focus group interview-generated data that examines both what people say as well as how they say it (i.e. how people construct their experiences in the world and the meanings they develop as a result). This involved analysing the data in terms of broad themes across all participants and then returning to examine how these themes reflected the socially constructed context of each site. This comparative approach was essential to the examination of contextually-based citizenship dispositions. As I became more familiar with the data, I considered how the perceptions and understandings held by participants reflected their lived experiences, thus generating understanding of their "cultural stories" (Silverman, 2006).

\section{Analysis of visual data}

My interpretive framework for analysing the visual data generated through the Photovoice research derives from the critical and social constructionist origins of Photovoice (Wang, et al., 2000). Gillian Rose (2007) outlines a critical approach to visual images as one that "thinks about the agency of the image, considers the social effects of its viewing, and reflects on the specificity of that viewing by various audiences" (p. 26). An image can be viewed with multiple meanings both for the photographer and the viewer (Cook \& Hess, 2007). Dodman (2003) asserts this position when he states that "claims for value-free assessments of visual productions are both unjustifiable in theory and impossible in practice" (p. 299). If we acknowledge that images are never 
transparent windows onto the world, but instead they "interpret the world, and display it in very particular ways" (G. Rose, 2007, p. 2), we arrive at an understanding that a photograph is always subject to interpretation through the theoretical lens of the interpreter. It is important then to make this process of interpretation as transparent as possible (Thomson, 2008).

Applying this to my context of participatory citizenship required acknowledging the agency and creativity associated with the young people's participation and photos, and looking for opportunities to examine the cultural significance, social practices and power relations in which the visual data is embedded (Cook \& Hess, 2007; G. Rose, 2007). The Photovoice tradition promotes the integration of voice data with visual data. This involved tagging the photos with the associated verbal data so that both could be analysed together. While using the participants' voice to analyse the photos went some way towards providing me with interpretations, I didn't want to reduce the visual image only to a verbal one, as the purpose of visual analysis is to "explore the relationship between visual and other (including verbal) knowledge" (Pink, 2007). Pink (2007) elaborates by suggesting that when analysing visual images, it is useful to examine how people's use of visual data provides insights into particular ideologies, worldviews, histories and identities. In applying this, I developed a narrative approach which attempted to integrate visual images with themes which emerged from the café style focus groups by looking for place-based cultural stories (see keyhole narratives, described later in this chapter).

\section{Presentation of data}

As outlined earlier in this chapter, data representing social interactions and perceptions "do not group into neat mappable parcels of policy-relevant units" (S. Smith, 2001, p. 25). In this section I describe two ways I negotiated my way round the "messiness" of qualitative data - first, by findings ways to analyse and present collective and group-generated data; and second, through the development of cultural stories as a way to integrate visual and verbal narratives. 


\section{Analysis and reporting of group-generated data}

As I analysed the data collected from the young participants (verbal and visual), I realised that most of the collected data for this project was a result of group collaboration in the form of discussions, debates and decision-making. This was particularly the case in the café-style focus groups where all students worked in groups, but also the Photovoice data which was generated more commonly by groups than individuals. Therefore the data were more a reflection of the groups' understandings and perceptions than those of an individual. In order to capture this, I decided to analyse and report findings within groups.

A whole-group analysis approach meant that I chose, where possible, to analyse and present discussion data in the context of group interactions, rather than as isolated snippets of conversation. This allowed the processes of group dissension and consensus to be observed (Marsh, et al., 2007). Group data analysis also provided me with a way to cope with the large amounts of data generated by the research tools and the large number of participants. For example, when analysing discussions about "important issues in our place," I found that 17 out of 29 café style focus groups reported that climate change (or global warming) was an important issue. While these numbers do not have statistical significance, some simple numeric reporting can provide an indication of the degree of reported instances which "gives the reader a chance to gain a sense of the flavour of the data as a whole" (Silverman, 2006, p. 52).

\section{Developing keyhole narratives}

As part of the presentation of data for each school, I developed what I have termed keyhole narratives (in Chapters 6 and 7). Each keyhole narrative is a vignette or "montage" (Denzin \& Lincoln, 2003) of "images, sounds and understandings" (Denzin \& Lincoln, 2003, p. 215) developed within the qualitative research traditions of the researcher as a bricolear - a "jack-of-all-trades" who tinkers about to form a creation from bits and pieces, in the spirit of a quilt maker or a montage creator in filmmaking (Denzin \& Lincoln, 2005)). The blending together of both verbal and visual data was a way of forming a new "cultural story" (Silverman, 2006) of participants that shared a common social and cultural 
context (in this case their school/community). I use the term "keyhole" to imply that these are partial and situated insights into the lives of my participants and not representative of all young people. Their creation was influenced by the auspices of an academic research project and my own interpretive bias and limitations.

The creation of these keyhole narratives became an important way for me to present and explore the young people's "sociological imaginations" within the contexts of their community/school setting and social landscapes. The choice of which narratives to include in the final thesis was guided by my research questions, the emerging themes generated through the data analysis and the significance of reporting. For example, the keyhole narrative "We're saying we have too much fast food for a small town" (Chapter 7) was a theme that was reported and photographed by all Photovoice research groups at College C. Other narratives reflect a recurring theme from participants at one school which built toward a cohesive narrative (see, for example, "To keep our children safe - that's the important thing" Chapter 7). Through these keyhole narratives I wanted to convey the sociological and citizenship imaginations of these young people in a way that conventional approaches that rely heavily on words cannot do.

\section{Ethical considerations}

The research was approved by the Victoria University of Wellington Ethics Education Committee. ${ }^{32}$ Participants "opted in" to the project by giving their informed consent, and participants under 16 years were also required to gain their parents' permission. All participants were made aware of their right to withdraw consent and attempts were made to ensure the information provided was easy for young people to understand (Alderson, 1995; Powell \& Smith, 2009). The confidentiality of both participants and schools was protected by the use of pseudonyms throughout the reporting of the research.

The use of visual methodologies presented some specific challenges in regard to issues of confidentiality. I wish to briefly outline two issues that arose. While I

\footnotetext{
${ }^{32}$ Reference number PSTE/2008/35, RM 15818.
} 
was ethically obliged not to produce any image of a person that was identifiable in this study, I had underestimated how much young people wanted to be in the photos. Knowing these constraints, they also exhibited considerable creativity and agency to ensure that they were present in the photos. This presented an ethical tension between respecting young people's rights for participation and rights for protection and confidentiality (Heath, et al., 2009; Powell \& Smith, 2006). For example, during the Photovoice activity at College $C$, a group of three female participants found three paper bags and then proceeded to appear with these on their heads in almost every photo they took (see for example, Figure 7.8). Others went to considerable lengths to appear in photos where their faces were hidden, or unrecognisable due to intentional over-exposure of light, which enabled me to include many of the "clever" shots in published research. In doing so, the youth participants were simultaneously complying with the broader aims of the research but subverting its constraints creatively as well (Allen, 2008, p. $566)$.

A second specific issue with visual images related to issues of confidentiality of the school sites and environments. Many of the places and landscapes photographed and described had the potential to be recognised and therefore were removed from the presentation of data (they were still analysed, but could only be used for their verbal potential not visual). The inability to name regions and places also significantly reduced my ability to describe the contribution of socio-historical factors to creating identities and citizenship dispositions. This also watered down my ability to examine the historical and social aspects of the "sociological imagination" (Mills, 1959). I found that many of the youth participants' interests in social issues would have been helpfully explained by social and historical contexts, but instead I was compelled to play a game of camouflaging details and reducing links to identifiable places and events. In this research I was unable to name the schools or their regions as one of the four schools had given their consent for the research to occur conditional upon not being named in any way. For future research, I would recommend conducting place-based research with schools willing to be identified to enable deeper analysis of socio-historical factors. 


\section{Research limitations and credibility}

As a small-scale qualitative project, rather than focusing on the "reliability" of the findings from this research, Lincoln and Guba (1985) suggest thinking about "dependability" or "consistency" of the results obtained from the data. This involves providing an "audit trail" to enhance the trustworthiness of the research process (Janesick, 2000) as well as acknowledging the limitations of the research. As stated earlier, my aim in this research was not to produce generalisable conclusions, but instead, my focus was on exploring the complexity and nuances of young people's perceptions and practices of citizenship. So while this study offers critique on other research, and identifies a number of insights and patterns, it also had a number of limitations. For example, my application of Mills' sociological imagination was constrained by my inability to explore the link between socio-historical factors and young people's identification of social issues. To do this would have necessitated more of an action research approach, which would have required further commitment from teachers, as well as changes in the confidentiality of school participation (as discussed earlier). In Chapter 9, I propose that this area would be well worth further exploration.

A further limitation in this research stems from the inability to report with any depth on familial influences upon young people's participatory citizenship dispositions. It is likely that familial effects and socialisation are very significant in youth participation (Bourdieu, 1977b; Furlong \& Cartmel, 2007; McFarland \& Thomas, 2006; Schulz, et al., 2010). The school-based focus of this study as well as issues of access and privacy meant that I didn't collect this data, thus reducing my ability to make comment in this area. Examining how familial social and cultural participatory capital informs young people's participation would be a valuable avenue for future research.

Key to the credibility of my research has been the development of relationships of trust and respect with participants in the research experience. I worked to develop a rapport with both students and teachers in all of the schools in this study. The school where this was potentially most challenging in terms of 
cultural difference was at College B where all of the participants were of Pacific Nations backgrounds. I was conscious that with my pālāgi background I could be seen as an outsider with very little in common to build rapport around. However, I had under-estimated the impact that having familial connections in this school with a cousin who taught there and an uncle on the Board of Trustees. On the day I met the class, Teacher B1 introduced me as the cousin of Mr X. The students were immediately interested in how we were related and Bubbly gurl (the Board of Trustees representative) immediately then stated she knew my uncle on the Board. This familial link was far more important than I had anticipated in gaining a degree of trust with these participants, as references to my cousin and uncle were made at almost every subsequent visit to College B by the participants.

As stated earlier in this chapter, a central aim in my research design had been to use approaches which were inclusive and enabled young people to participate in creative and meaningful ways. This was achieved in many ways through both the use of peer-selected cafe style focus groups and in Photovoice activity where young people had more control over the pace and direction of data generation than, for example, traditional focus group interviews. However, as I reflected on the data I was aware that some voices were more dominant than others. This was particularly the case with the Photovoice data. In part this reflected the limited number of cameras I had available (six), so even though groups had planned the activity together, often one individual had taken the camera home and then been responsible to "voice" the images to me following the activity. The Photovoice activity had also caught the imagination of some young people more than others, and they had committed more time to the activity and taken more photos which also contributed to the dominance of some voices. Reflecting on this, I realise that this unevenness of representation raises the ongoing challenge of inclusion in qualitative research projects which aim to privilege youth voice (Cook \& Hess, 2007). These findings also are indicative of the messiness of qualitative data (Dwyer \& Limb, 2001), that simultaneously enables us to gain new insights into the complex and 
nuanced experiences of young people's participation as well as presenting another layer of challenges in this area.

Making the research process as transparent as possible was another way I tried to build credibility into this research and develop relationships of trust.

Providing feedback to all participants and asking for their interpretations was one way I tried to address the power imbalance between the researcher and the researched, as well as showing respect to participants' ability to contribute. Yet in spite of putting such processes in place, the unequal balance between my power as the researcher, and theirs as the participants, still meant that I held the power of the "last say" in the research. It is also important to acknowledge that my representation of participants' worlds and understandings are partial and limited. Throughout the process of writing up this research I have struggled with finding the balance of "not appropriating or speaking for those we have worked with but at the same time in some way telling their stories in their own words" (Skelton, 2001a, p. 95). This tension of representation sits at the base of much adult research with young people. 


\section{CHAPTER 5: \\ SOCIAL STUDIES TEACHERS' CONCEPTIONS AND \\ PRACTICES OF SOCIAL ACTION}

Unless we focus specifically on the tangled contexts of the classroom, it is difficult to get a sense of the most viable instances of citizenship education, particularly given the value-laden nature of the citizenship curriculum. (Sim, 2010, p. 221)

In response to the "explosion" (Brooks \& Holford, 2009) of interest in citizenship education internationally since the 1990s, there has been a growing body of research into the conceptions that teachers hold toward citizenship and their practices in implementing citizenship curricula. There has been a smaller but growing interest in research at the intersection of conceptions and practices, or as Evans (2006) puts it, "what teachers say and what teachers do" (p. 410). In this chapter, I aim to contribute to this area by exploring both the conceptions and practices of social action by New Zealand social studies teachers $(n=27)$ in my four participant schools.

In keeping with the theoretical framework outlined in Chapter 3, my interest is in gaining an understanding of how teachers' social and cultural capital may give rise to their participatory capital and "citizenship dispositions". My unit of analysis here was the social sciences department. ${ }^{33}$ By examining teachers' shared perceptions, appreciations and actions (Bourdieu \& Wacquant, 1992) derived from their collective experiences of belonging to a social studies/social sciences department at one school (an educational field), I am attempting to gain a sense of their shared dispositions toward citizenship. I was also interested to explore how these teachers acted as "curricular-instructional gatekeepers" (Thornton, 2005) who control both the content of what is taught and how it is

\footnotetext{
${ }^{33}$ In New Zealand high schools, most social studies teachers teach both junior social studies (Years 9 and 10) as well as a senior social science subject such as history, geography or economics.(Years 11-13). A smaller number teach senior social studies (Years 11-13). These teachers all belong to the social sciences department/faculty. Departmental involvement includes planning shared classroom programmes, assessments, field trips, competitions, fundraising and general philosophical approaches.
} 
taught in the classroom. This concept of gatekeepers reinforces the multiple ways even a prescribed curriculum can be interpreted and enacted within a classroom (Sim, 2010).

I begin this chapter by reviewing international and New Zealand-based research describing what we currently know about teachers' conceptions and practices of active citizenship and "social action". As discussed in Chapter 1, my use of the term "social action" with New Zealand social studies teachers (and students) reflects the historical status of this concept within social studies curricula (see Appendix A), and the similarities between understandings of this concept with the more widely used concepts of participatory or active citizenship internationally. I then examine the responses of teacher participants from each of my four schools in turn, focusing in particular how these teachers' conceptions inform their practices of social action. I conclude the chapter with a discussion on how teachers viewed social action as a way to promote both participatory learners and citizens, then how their practices reflected differences in their orientation toward participation.

\section{Teachers' multiple, contested conceptions of participatory citizenship}

It is apparent that teachers conceptualise citizenship in multiple ways both across and within cultural contexts (Kerr, Cleaver, Ireland, \& Blenkinsop, 2003; J. Nelson \& Kerr, 2006; Prior, 1999, 2005; Sim, 2010; Torney-Purta, Richardson, \& Barber, 2005). These multiple conceptions held by teachers reflect the conflicting theoretical perspectives upon which citizenship is based, and the political and social context and differences in the conceptual understandings held by individuals - for example, "individualist vs. collectivist, political rights vs. social rights, local vs. global" (Evans, 2006, p. 413). Nelson and Kerr's (2006) INCA ${ }^{34}$ thematic study on "active citizenship" across 14 countries (including New Zealand) found that the term active citizenship is not yet clearly understood or defined within and across these countries. Instead, it was related

\footnotetext{
${ }^{34}$ International Review of Curriculum and Assessment Internet Archive
} 
to "shifting notions of citizenship and citizenship education" (p. iv) and closely linked to cultural and historical contexts.

There is evidence that teacher practices do not always reflect their conceptions of participatory citizenship. For example, Evans (2006) suggests that citizenship education teachers in Canada do not necessarily do what they say and cites evidence of incongruity between their rhetoric and practice. His research suggests that teachers still revert to practices which favour learning content and facts (transmission), rather than the transformative approaches they may have spoken about. In contrast, Jasmine Sim's (2010), researching social studies teachers in Singapore, found that teachers conceptualised and approached citizenship education in a number of different ways, "even in the context of a hegemonic state" (p. 241). Teachers in her study demonstrated four distinct approaches to citizenship education: expository and highly controlled, rationalistic and persuasive, interactive and participative, and constructive and experiential. These findings highlight the complex, and contestable nature of citizenship education and the importance of finding out more about locallyderived expressions of both citizenship and agency of teachers within and beyond the "official knowledge" (Apple, 1993) of the curriculum. In the following section, I review the limited research that has been conducted to date on New Zealand teachers' conceptions and practices of social action.

\section{Conceptions of "social action" held by New Zealand social studies teachers}

While little empirical research has been done in this area, it appears that some New Zealand social studies teachers avoid social issues and topics which lend themselves to social action and values exploration (ERO, 2001; Harrison, 1998a;

McGee, 1998; Taylor, 2008). Paul Keown (1998) describes social action (and values exploration) as the "hard bits" (p. 137) of social studies education in New Zealand. The Education Review Office (ERO, 2001) found that approximately half of New Zealand social studies teachers of Years 4 and 8 "focused mostly on increasing knowledge of a topic and literacy development" (p. 12) and rarely engaged their learners in the area of values and decision-making. However, it is 
apparent that some New Zealand social studies teachers hold more "activist" and transformative conceptions of social action. For example, social studies teacher Kay Harrison (1998b) reflects:

My colleagues and I tried to build in the possibility for social action in each of our units of work...real action was linked to their study to promote a sense of their agency in society and to counteract learned helplessness. (p. 7)

In a small survey $(n=48)$ into the frequency of social studies teachers' application of social action in social studies, Rowena Taylor (2008) found that only $27 \%$ reported that they "frequently" used social action approaches, 58\% reported "occasionally" and 15\% said "never/not relevant". ${ }^{35}$ The majority of these teachers were "guarded" when asked if they considered themselves a social activist in their social studies teaching, with 60\% stating "occasionally," and 28\% stating "never," "not relevant." RES20 (cited in Taylor, 2008, p. 143) exemplified a response that favoured a sanitised and value-free conception of curriculum delivery: [The question about whether I am a social activist is] "Not Applicable. I am a teacher applying the principles of the curriculum. That is my job." Only $12 \%$ described their approach to social studies as quite "activist" including one who stated:

I can't teach social action without modelling a real interest in the world around me and a desire to make change. (RES13b, cited in Taylor, 2008, p. 143)

The reason for avoiding social action (and values exploration) in social studies have largely been attributed to the conflict, controversy and complexity embedded in many social studies contexts (Wood, 2007). Keown (1998) suggests that teachers are apprehensive about the contentious nature of values and social action teaching which opens up the potential for accusations of social engineering, indoctrination and community condemnation (see also Harrison, 1998a; McGee, 1998). He suggests that there is also a lack of knowledge about how to approach the study of values and contentious issues in social studies and concludes that:

35 Taylor (2008) defines social action in her research as "an activity or activities undertaken by a student or group of students in an effort to contribute constructively toward social change as a result of their studies" (p. 140). 
The net effect of all this is that the teacher, while knowing values and social action are important, feels the problems and the risks here are just too great and it is safer to stick to knowledge and skills and avoid values and social action. (Keown, 1998, p. 141)

If, as this research suggests, social action is viewed as slightly "risky," then what approaches have social studies teachers used when integrating it into their programmes? In Taylor's (2008) survey, the most common examples of social action provided by teachers included letters to newspaper editors/NGO's / the government (30\%), encouraging school-based student leadership (16\%), practical environmental action (12\%) and collecting money for campaigns such as World Vision (4\%) (p. 141). Taylor surmises that these examples of social action reflect the intensity of teacher workloads and the operating requirements of school contexts, and therefore social action was largely restricted to what teachers found manageable within the classroom and school context. To gain further insights into the nature of teacher's conceptions and practices of social action, I now turn to my research with teachers in schools which I had identified as being committed to social action and/or community engagement (see Chapter 4).

\section{Teacher talk: conceptions and practices of social action}

As outlined in Chapter 4, 27 social studies teachers were interviewed as part of a focus group discussion on their conceptions of social action and their experiences of putting it into practice in the context of their social studies teaching. Focus groups ranged in size from three to eleven teachers, reflecting the varying sizes of the social science departments and the extent of the voluntary participation in the research (see Table 5.1).

Table 5.1: Summary of teacher participants in each school

\begin{tabular}{cccc}
\hline College & \multicolumn{2}{c}{$\begin{array}{c}\text { Social studies teachers } \\
\text { Male }\end{array}$} & $\begin{array}{c}\text { Total number of } \\
\text { teachers }\end{array}$ \\
A & 3 & 4 & 7 \\
B & 3 & 8 & 11 \\
C & 2 & 1 & 3 \\
D & 0 & 6 & 6 \\
\hline Total & $\mathbf{9}$ & $\mathbf{2 0}$ & $\mathbf{2 7}$ \\
\hline
\end{tabular}


In analysing teacher's talk, I was especially interested in the links they made between their conceptions and practices of social action in order to gain a sense of their shared dispositions toward participation as a group of social studies teachers in one school. Through their discussions, I attempted to get a sense of their "cultural story" (Silverman, 2006), or the way they drew from their social and cultural contexts to develop their understandings of social action. In doing so, I address a criticism of much citizenship research for its failure to pay enough attention to the question of context (Faulks, 2000).

While my one-off focus groups interview with teachers provided only a limited glimpse into teachers' participatory cultural/social capital, habitus and field, the findings presented here are also developed from my time spent in the school, ERO reports and information provided by the school such as the prospectus, website and social studies unit planning. Table 5.2 provides an overview of some of the formal opportunities offered for civic participation in the four schools in 2009.

Table 5.2: Some formal opportunities for civic participation provided by schools in 2009

\begin{tabular}{|c|c|c|c|c|}
\hline $\begin{array}{l}\text { Participation opportunities offered } \\
\text { by Colleges }\end{array}$ & $\mathbf{A}$ & $\overline{\mathbf{B}}$ & $\mathbf{C}$ & $\overline{\mathbf{D}}$ \\
\hline Active environmental group & $\overline{\mathbf{a}}$ & & $\bar{\square}$ & $\bar{\square}$ \\
\hline School Council with elected students & $\mathbf{\square}$ & $\mathbf{\square}$ & $\mathbf{\square}$ & $\mathbf{\square}$ \\
\hline Cultural performance groups & $\mathbf{\square}$ & $\boldsymbol{\square}$ & $\mathbf{\square}$ & $\mathbf{\square}$ \\
\hline Support for 40 Hour Famine & $\mathbf{\square}$ & $\boldsymbol{\square}$ & $\mathbf{\square}$ & $\mathbf{\square}$ \\
\hline Support group for gay and lesbian youth & घ & & $\mathbf{\square}$ & \\
\hline Student activism group & & & & $\mathbf{\square}$ \\
\hline Students Against Driving Drunk (SADD) & $\mathbf{\square}$ & & $\mathbf{\square}$ & \\
\hline Sporting groups & घ & $\boldsymbol{\square}$ & $\mathbf{\square}$ & $\mathbf{\square}$ \\
\hline Amnesty International group & 口 & & $\mathbf{\square}$ & \\
\hline Human Rights group & & & $\mathbf{\square}$ & \\
\hline
\end{tabular}

Sources of information: School websites, teachers and field notes.

I include Table 5.2 as an example of the wider "facilitating conditions" that Ireland et al. (2006) suggest contribute to more active conceptions of citizenship in the school setting. The examples provided in Table 5.2 include both traditional conceptions of citizenship (such as the school council) as well as 
broader conceptions of citizenship that include opportunities for expressions of cultural identity, rights and connections of young people (Harris, et al., 2007).

\section{College A}

College A is a Decile 6, co-educational state high school established in a suburban area of a regional city in the South Island. Students are predominantly from New Zealand Pakeha European backgrounds, with smaller percentages of Māori and Asian backgrounds. The college is renowned for the broad curriculum, cultural, sporting, leadership and service opportunities it offers its students, as well as the effective relationships between staff and students (Education Review Office, 2007-2010). ${ }^{36}$ The school is an Enviroschool ${ }^{37}$ with an active, student-led Environmental Committee, lobby groups such as Students Against Driving Drunk (SADD) and Amnesty International, as well as student-led groups that raise funds for the World Vision 40 Hour Famine and child cancer (CanTeen) (see Table 5.2).

The teachers at College A were active in implementing the 2007 school curriculum and had evidence of a number of re-worked units and assessment. Their conceptions of social action centred on "doing something" in response to their social studies learning, that created ways to "connect with the outside world." They described how they worked to make social action relevant, authentic and engaging to students. As one teacher put it "if they don't own it, it won't engage them" (A6). Teacher A2 described it like this:

You see, I could state a topic such as rubbish needs to be picked up [at College A], which I could do as social action. But that's my project not theirs. And if they don't want, it won't engage them. We need genuine empathy for an issue.

The teachers discussed how taking social action was part of their whole approach to developing participatory skills and responsibility in their students, which they saw to be closely associated with the development of key

\footnotetext{
${ }^{36}$ Information from schools has been gathered from ERO reports but I have not provided a link to a specific school report in order to maintain the confidentiality of the school. Some details, such as the exact percentages of students' ethnicities have been deliberately left approximate for the same reason.

${ }^{37}$ See Glossary.
} 
competencies and the social inquiry process in the 2007 curriculum. The teachers explained how they were grappling with how to assess both the key competencies and social action in an appropriate way, as "we don't want to do it mechanistically" (Teacher A1). They described how their focus in social studies is to develop in their students' skills for life:

I have a student who can quote facts, facts, facts and knowledge, but not translate that into learning. In the end, skills for life are what count...not facts or figures. (Teacher A3)

In this vein, Teacher A3 surmised that "social action is almost a set of dispositions or values."

The participatory capital that teachers appeared to value and practice at this school were toward creating active, global, cosmopolitan citizens. This was reflected in their planning of units for their students' programmes (see Appendix 0) as well as the opportunities they offered students. New Zealand social studies is a conceptual rather than a topic-led curriculum which enables a fair degree of teacher choice over contexts of study guided by conceptual achievement objectives at each level (G. Aitken, 2005; G. Aitken \& Sinnema, 2008; Milligan \& Wood, 2010). The social studies units included an integrating theme for global citizens for Year 10 students and many social issue-based themes of international significance such as child labour, war and terrorism and gender issues. Within these units, the social studies teachers provided a number of opportunities for their students to "take action." For example, this included selling friendship bracelets to raise money for Voluntary Services Abroad (VSA), collecting food for local food banks, and writing submissions to the Council on local issues.

Beyond the classroom, Teacher A1 had initiated a field trip to a majority world country ${ }^{38}$ for social studies students to experience and take social action by volunteering in a number of organisations. This had also involved fundraising before they left New Zealand so they could take donations for schools and communities they met with. Further international trips were being organised for

\footnotetext{
${ }^{38}$ The term majority world country is used here to describe poorer, less developed countries where the majority of people in the world live.
} 
social studies students in future years. Teacher A1, the HOD, was a passionate advocate for global issues and encouraging global social responsibility from her students. I heard her say to her classes on a number of occasions:

Your grades in social studies are important, and I will do everything I can to help you get the best grades possible. But what counts to me more than anything else is that you will contact me in years to come and tell me what you have done for others. (Field notes, October, 2008)

Having trialled a number of 'social action' approaches in their social studies programme, this department were consolidating their approaches and reflected that "if we do [social action] regularly it becomes a norm and therefore we are more comfortable" (Teacher A1).

\section{College B}

Set in a low income suburban area of a large city, College B is a Decile 1, state, coeducational high school. Students come from a wide range of cultural backgrounds, particularly Pacific and Māori. This cultural composition reflects migration patterns into this suburban area predominantly from Pacific Nations (such as Samoa, Tokelau, Cook Islands and Niue) in the past 40 years, with many of the more recent migrants having non-English speaking backgrounds. The celebration of students' cultures is a notable feature of the college. Many students belong to cultural groups and are active in performing in school and local cultural festivals (Education Review Office, 2007-2010). The college is also known for its strong relationships with the local community and effective Student Council (Education Review Office, 2007-2010). When I was in the school in 2009, the social studies teachers had begun to adapt their units and programmes to align with the New Zealand Curriculum.

The teachers at College B conceptualised social action primarily as a way of encouraging participation and strengthening relationships with the local community. For example, teachers B5 and B6 discussed how the purpose of social action was for "coming together," "community building" and "creating relationships with others." This theme was echoed by other social studies teachers at College B who affirmed that in taking social action, "a sense of positive community needs to be paramount," to "make students feel part of 
society" and to be "fully involved." Teacher B3 told a story about a recent debating competition where College B students had competed against an elitist private school. The College B students had held their own in the debate, but lost. However, Teacher B3 recounted with pride that teachers from the private school had commended the students for the high levels of empathy and care toward others that they had shown throughout the debate.

Teacher B2, the Maori language teacher, saw social action as "whanaungatanga" 39 which she defined as "building community and then participating in it" (B2). As a concept, whanaungatanga has been used in many educational contexts to convey a commitment to bicultural and whānau-centred approaches to education which foster strong relationships (see for an early childhood example, Ritchie \& Rau, 2006). Teacher B2 described how social action also involved preserving culture, such as Te Reo (the Maori language), te taiao (the environment) and tikanga (cultural traditions). This commitment to preserve the cultural traditions of their student population was evident in the school's endorsement of musical, performative and oral traditions in much of the school life. College B's language acquisition programme (for Pacific languages and Te Reo) was awarded a Human Rights award in recognition of the rarity of such a commitment in New Zealand secondary schools and the leadership this school demonstrated (School website, 2009).

In line with the need to keep positive relationships with the local community, the teachers at College B referred to the "risks" of social action more than the other three schools. For example, they discussed how social action "could provoke angry responses or greater resistance" as "putting yourself out there could be risky for the teacher, so it could have the affect of destabilising relationships as opposed to the positive outcomes of strengthening" (Teacher B2). It also "could get the students into trouble" (Teachers B7 and B8). The teachers were also concerned that social action activities, if not run well, could have the effect of

39 Whanaungatanga (Māori) conveys a sense of whānau, family relationships gained through shared experiences and working together which provides people with a sense of belonging (see glossary for further details). 
creating disillusionment in young people. They shared a number of examples where actions taken in the past had dried up:

We did that recycling thing. One of the teachers, he's gone now, he set it up for plastics, for tins. And that was great while he was here but then he left. And so did that idea. Now everything just gets chucked into the bin. It'd be really good for us, as teachers, to, you know how we're supposed to model stuff? It'd be really good to model that. (Teacher B2, emphasis participants' own)

The teachers described how churches in their local community (mostly Pacific Island congregations) were very influential and therefore, by taking social action, "families might get upset or get involved and you run into ethical issues with different belief systems and you have to get permission from various people" (Teacher B3).

This awareness of their more conservative community was reflected in their practices of social action in social studies. Social studies teachers at College B referred to a number of one-off events and a couple of units which had used a social action approach, such as a survey of local businesses in response to a theme on the McDonaldisation of society. In this unit, Teacher B1 described how he had used recording equipment and digital cameras and this had encouraged student engagement and the ability to "learn to relate and communicate on different levels ... with what's appropriate in society" (B1). On another occasion, social studies students had conducted research into a number of human rights issues for Human Rights Day. This had culminated in the release of hundreds of balloons describing human rights. The event led Teacher B3 to reflect:

One thing that would have been a bit more of social action would be if we got the newspaper in to photograph it. Then we really would have been making a statement. That would have been good. (B3)

Their discussions highlight a cautious, relationship-centred approach to social action in both conceptions and practice, with a strong focus on supporting cultural activities, and less emphasis on environmental and human rights groups compared to the other three schools in the study (see Table 5.2). 


\section{College C}

College C is a Decile 4, co-ed high school based in a small rural town in the South Island. Over half of the students at this school arrive by bus from outlying rural towns and farming areas (School website). Students come from predominately New Zealand Pakeha backgrounds with about one fifth Māori. Many local families with children at the school were dependent on seasonal work (school website). The school is involved in Enterprise Education and is an Enviroschool with an active student-led environmental group. A commitment to develop "well rounded citizens making a positive contribution to the community" is espoused in the School Prospectus (2010) and more than 15 service groups are active in the school (School Prospectus, 2010) (see Table 5.2).

Teachers at College $\mathrm{C}$ had a strong tradition of interest in social action, and a conceptualisation that it was an essential part of social studies teaching and learning. In fact, as a social studies department a number of years earlier, they had initiated a "Community Issues" class in response to what they saw as a very passive social studies curriculum (Ministry of Education, 1997) which focused only on "social decision-making" and not "social action" (Field notes, March, 2009). They referred to this community issues class as "social studies with boots on" as it enabled their students to get "more real" by engaging with community issues and talking to people in the community (Field notes, April, 2009). In light of this history, Teacher C1 described how the New Zealand Curriculum conveyed to them a new sense of being "empowered" for social action:

$[\mathrm{S}]$ ocial action is something that has been traditionally quite a hard thing to integrate [in social studies] because you haven't always been empowered to go that way. But we're saying from doing this [new curriculum], we're saying, yes, you are empowered, yes it is a major outcome and is a significant part of what you're trying to achieve, then we can take some of the other energy that we may have put into some other things [...], a more traditional pathway, and try and construct it so that's it's not as traditional.

As highlighted by the instigation of a Community Issues class at College C, Teacher C1 had a strong conceptualisation of social action that involved connecting students with the immediate community:

Well, for me, it is making the learners more connected to the community that they're in and that's not something that just happens in the four walls within 
which you study. So if other people come in to your classroom or go out and deliver your thoughts to other people, you know, when that happens its quite empowering for them to feel that it's been listened to. (Teacher C1)

As well as empowering students, social action also allowed students to connect with "the real people who are doing the real things" (Teacher C1, participants' emphasis). C1 described how this was the strength of the community issues class which allowed students to interact with the community and pose problems.

When I was in the school in 2009, the Community Issues class had been operating for a number of years. All Year 10 students at College $\mathrm{C}$ rotated through this Community Issues class over the four school terms, with students selecting a community issue of interest to them each term. For example, when I was in the school, this class was working on the issue of 1080 poison which was aerially dropped on to nearby forests to reduce the infestation of possums. ${ }^{40}$ Students had surveyed local residents on their opinions toward this issue and conducted their own research into this to form their own opinions. They presented their findings through a PowerPoint presentation to members of the community (Field notes, April, 2009). These findings are also published on the school website and in the local newspapers so there are high levels of awareness of the selected issues within the school and community. In fact, community groups now approach the school to ask if their issues can be selected (Field notes, April, 2009).

However, the ability to enact this sense of empowerment at College C in 2009 was hampered by staffing instability in the social sciences department in recent years. When I undertook the focus group of the three teachers (the whole social science department at College $\mathrm{C}$ ), two of the three teachers had joined Teacher $\mathrm{C} 1$ in the past eight months. As a result, Teacher C1 described how "we've never had enough staffing stability...to get a collective cohesiveness in how we want to get social action working...but we're heading that way." As the following

\footnotetext{
${ }^{40}$ Possums have become an issue in New Zealand following their introduction from Australia in 1837 as they have no natural predators and have multiplied rapidly causing considerable environmental damage to New Zealand's vegetation.
} 
discussion shows, their collective understandings of social action were still being worked out:

Teacher C2 (to C1): So where does the general content stop and the social action start - how are they different?

Teacher C1: Like for me, they're infused together. If you've had a successful unit, you know that's one of the things we looking at [both content knowledge and social action]. [...] It's become something we buy into as our department, which is why Community Issues has worked cos it's been bought into across the board.

While the Community Issues class was regarded as a "real success" both in the school and the community (Teacher C1), the separation of social action into Community Issues had meant that their social studies programme had less social action components. During the focus group, the teachers discussed how they were working to "infuse" more social action into their social studies programmes. For example they discussed how students could write to Members of Parliament and the newspaper to express their opinions, or survey local businesses on their policies on plastic bags (Teacher C2). Some of these activities were already happening. For example, social science students had recently written a letter to an energy company to ask them what they were doing about wind power. Their social studies units also had a strong social issues focus (such as fair trade, and environmental themes). However, they also expressed that these "little pieces that we've been trying to infuse into our programmes" could be taken "to the next layer" (Teacher $\mathrm{C} 1$ ).

\section{College D}

College D is a Decile 8, state, single-sex girls' school located near the centre of a North Island city. Students with a diverse range of cultural backgrounds attend the school with significant populations of refugee and recent migrants represented. The college has a commitment to enhancing a culture which fosters, respects and develops a sense of belonging and understanding of cultural diversity (School charter, 2008) and there are many opportunities for students to be involved in leadership, sporting, cultural and service groups (Education Review Office, 2007-2010). The school is an Enviroschool and has an active student council and a leadership programmes for students. The wide range of cultural activities supported in the school reflect the "multicultural environment 
where diversity is celebrated" (Education Review Office, 2007-2010). The school promotes student action and there is a "student activist" group, a student-led environmental group and a student-led 40 Hour Famine Committee (Figure 5.2). The school had also joined an Enterprise Education cross-curricula initiative which involved the social studies and science departments and made significant headway into implementing the New Zealand Curriculum when I was there in 2009.

The teachers at College D were keen to integrate social action into their programmes in a way that was meaningful and engaging for their students. They had a strongly student-led conception of social action, placing a lot of emphasis on how social action "validates youth voice which I think is really important because there's often a self-imposed stigma from young people, [...] that nobody wants to hear what young people have to say, so why bother?" (Teacher D3). Teachers reflected that taking social action enhanced student engagement and made social studies learning more authentic:

Classroom learning becomes more meaningful - being able to see that even if it doesn't exactly eventuate but being able to visualise it and knowing that there is a possibility of it having greater significance, because it moves beyond the four walls. (Teacher D3)

For example, Teacher D1 described how making the assessment for the unit a submission letter to the Council motivated students because they knew it had a real audience:

And even if they're not particularly able in the skill of structuring an essay, it's still empowering for them to think, well they can still be heard. Cos some of them will never be particularly strong writers, but they still could be hounding the Council for years... (Teacher D1)

Teachers at College D referred a number of times to how their exposure of students to social action could open up the potential for them to "go out on their own" (D3) by taking social action in society later in life. Teacher D3 questioned, "Isn't the whole idea of this part of the [social inquiry] process is that we're making more active, you know, future citizens, that will be greater participants, and want to be, in our society?" The teachers saw their conceptualisation of social action as a work in progress, and in the focus group interview reflected 
how there had been a "massive unfurling" (Teacher D1) of how to integrate social action in the past year, and that it was a "rolling process of moving with the ideas" (D1). Teacher D2 commented that this process included "broadening our definition of what social action might mean."

The social studies teachers at College D described a number of ways in which they provided opportunities for social action in their programmes and practices. For example, teachers described how students were active in writing submissions to the Council (see earlier comment by Teacher D1). The Enterprise Education initiative had led to the development of a water conservation focus for Year 10 students which involved studying water as a resource at global, national and local levels as well as auditing water flows in their school. They also took a field trip to a local stream to observe water flows and human responses to the stream, and partook in a rubbish clean up. The unit culminated in a student-led social action to fundraise for more water tanks for their school to conserve water.

The integration of "enterprise" themes within their social studies programme led teachers to reflect on how these fitted together. In this vein, Teacher D3 stated how she "looked at enterprising as a process that led toward social action." She described how the development of both enterprising attributes and key competencies could be seen as a part of the whole social inquiry process. Teachers also described how they were conscious of the economistic overtones of Enterprise Education, and by selecting the social issue of water had worked to make this a much bigger social justice project.

Teachers at College D saw social action as "a real opportunity for students to drive actions" (D2 and D3). This involved handing over a lot of the responsibility for the direction of the social action to the students. Part of this philosophy involved "a huge amount of suspension of teacher control required at certain points.... and then the control has to be put back in very carefully as I don't think it's reasonable to say that it can be completely student-led" (Teacher D1). 
This included allowing students the opportunity to fail and helping them to learn "we are not going to manage every little step of the process" (Teacher D2):

One of our positives [about taking social action] is that it creates the opportunity to fail. The negative is that quite often things do fail. And partly that's due to us needing to learn how to manage something that's outside the classroom and that will take on a life of its own in which the students' have a lot of ownership...agency. (Teacher D2)

Teacher D1 described how this approach to social action empowered students and "builds their sense of agency. And they can actively work without a teacher. They recognise that if they can shape a process then they can succeed. And similarly if they can't shape it, it won't work either."

Social action was not without its challenges - in particular, managing the time commitments for a more participatory social action approach and "learning how to not let it get too big, but big enough" (Teacher D2). However, their experience in the past year in integrating social action was serving to provide ways that it could be fitted more "organically" and naturally. In this way, they were working to "sit social action within the social inquiry within our normal teaching framework" (Teacher D1, my emphasis).

\section{Participatory learners or participatory citizens?}

Teachers from all four schools were generally enthusiastic about the opportunities for social action afforded within the New Zealand Curriculum, with teachers at College B more cautious than the other three schools. Their enthusiasm centred on the potential for social action to promote both participatory learners and participatory citizens.

Many of the teachers' conceptions of social action as a way to promote participatory learners were discussed in relation to the development of key competencies which were perceived to invoke a certain type of flexible, problem-solving type of learner. For example, teachers described how as a result of participating in social action, students could develop new skills and competencies in group work (College A), problem-solving and independent 
learning (College D), decision-making, communication, community building, self management, relating to others and critical thinking (College B). Teachers described how student-centred, participatory and interactive approaches to social action had significant educational and personal outcomes for students and would promote independent learners and "allow them to take ownership for their learning" (Colleges A and D) which "could open a career path" (College A).

Enthusiasm for social action also centred on the opportunities it provided to create participatory citizens. Teachers in all four schools referred to how taking social action could "make a difference" in society. For example, the teachers at College $\mathrm{C}$ referred to the potential for social, economic and political change through taking social action and how "the fact that [students] can make a difference" (C2) was a prime reason for integrating social action into social studies. Teachers at College D described that one of their greatest goals was to create citizens who would "go out on their own" later in life. They hoped that opportunities to take action offered to students, such as writing a submission to the local council, could result in students "hounding the Council for years" (D1). Teachers at College B described how social action held the potential to "bring better outcomes to people and communities" and could "create activists."

However, the goal to create both participatory learners as well as participatory citizens through social action does raise some dilemmas. Was social action in these schools serving to create participatory citizen-learners, narrowly constructed within minimal educational and neoliberal conceptions of lifelong learners and citizen-workers, or more maximal conceptions of participatory citizens in keeping with Westheimer and Kahne's (2004) justice-oriented citizens? Much of the teachers' rhetoric about participatory learners aligned closely with the language of the Knowledge society, and its implicit aims to create flexible, lifelong learners, able to meet the changing needs of the market place. Yet some of the teacher's rhetoric about active citizens conveyed a far more maximal conception of citizens who could challenge those in power and work toward justice in society. In light of the "risks" associated with taking social action (in section below) and the tension between these two approaches to 
social action, it appears that teachers largely favoured "safe" and risk-free practices of social action, with some examples of more change-oriented social action. I will return to this issue and explore it in greater depth in Chapter 8.

\section{Social action and "risk"}

While teachers were enthusiastic about the potential social action offered their students, taking social action was also seen to hold a number of challenges and risks related to learning, students and communities. For example, Teacher A2 spoke of the danger of "going off half-cocked without the bigger picture" and elaborated by describing how some attempts at social action were not especially meaningful for students as they didn't fit wider learning context. The risk of students not coping well with social action was also identified as social action could place "massive expectations on students" that required their "maturity" and "elements of trust" (College A). Teachers were also cautious about raising students' awareness and "false expectations" (Colleges B, C and D) by taking social action which could open up the potential for disillusionment and failure as that "that might make them reluctant to do it again in the future" (D2). Teacher B10 stated that "one of the things that you risk too when doing social action with young people is destroying the belief in it and the effectiveness of it, if you don't manage those learning opportunities well."

Similar to research in England (Ireland, et al., 2006), time constraints were identified by teachers in all schools as a significant challenge to taking social action, as well as school compliances if students had to leave the school grounds. Participants at College A and D also described how social action placed higher expectations on community members and groups which could prove timeconsuming for them, and teachers from College B were concerned that taking social action could cause "angry responses" (B2 and B3) and lead to conflict with the community. A fear of imposing values and indoctrination also led to some hesitation about social action:

To students, you have to be careful that you're not imposing your views on students, because we have different world views about things. I mean, even defining what's given a rightness to democracy for example - it's a worldview. (Teacher B10) 
With this in mind, teachers in Colleges A, B and D discussed how social action needed to be relevant, and where possible, allowed for students to "opt in" rather than be imposed upon them by teachers. For example, teachers at College B emphatically stated "there's no social action if they don't buy in" (Teachers B1 and B10). Similarly, the teachers at College D affirmed that social action could make social studies more relevant, yet, "it can't be a forced relevance. If you're not really convinced that this is relevant to you, then why would you go ahead and take some action when you weren't actually convinced about it to start with?" (D6). She continues:

And that's something that bothers me that maybe the things that we think are relevant, that we're taking action on, are not theirs. And there's a huge range of responses to some things. And some kids may want to take action on behalf of an issue and some just may not 'cos they just don't care enough. And, yet we tell them that they need to follow through this process. (Teacher D6)

These statements appear to confirm Keown's (1998) suggestion that fears of the imposition of values is a significant issue when integrating social action in social studies, especially in light of curricula which require social action to be "performed" (Pells, 2010).

\section{School-based participatory dispositions}

It is evident from these findings that there were differences in both conceptions and practices toward social action in social studies. Yet, there were also strong similarities between teachers from the same school in the nature of their orientations toward social action (local/global) (horizontal or vertical) and their pedagogical practices. I suggest that these patterns can be read as examples of differences in participatory capital, the conceptions and practices of participation as a reflection of the shared social, economic and cultural exposure to participation held within a school community.

\section{Spatial orientation (local/global)}

An analysis of the spatial orientation of social action across the four schools reveals that two schools (Colleges A and D), had more of a "global" focus to their 
conceptions and practices of social action, and two schools (Colleges B and C) had more of a "local" or community focus. College A had particularly global and cosmopolitan participatory dispositions with a sense of citizenship that was not limited to that of the nation (Osler \& Starkey, 2005). This included providing opportunities for some students to participate in social action in a majority world country, as well as a focus on supporting a number of international organisations. Similarly, College D's focus on both global issues, such as human rights/child labour as well as the global issue of water conservation (see Appendix R) which was examined at global, national and local levels, highlighted the importance they placed on understanding the links between these.

In contrast, College C's Community Issues class had a strong local issues focus that aimed to build strong links between the school and groups and individuals in the community. College B's whanaungatanga approach also revealed a strong local focus with teachers committed to supporting and building relationships with community members. This local-global divide between the schools also reflects the relative socio-economic position of schools, with the lower decile schools (B and C) exhibiting a prevailing local/community focus, and higher decile schools (A and D) with more of a global awareness.

\section{Engagement in horizontal and vertical participation}

The degree to which this participation is "horizontal" or "vertical" (Jochum, et al., 2005) (see glossary for this definition) also appeared to reflect the social and cultural capital of teachers in each school. Overall, all schools described more horizontal than vertical opportunities for participation in their practices of participation, reflecting previous research with social studies teachers (Milligan, Taylor, \& Wood, forthcoming). Examples of horizontal participation included fund-raising to support various charities, participating in clubs and community activities such as cultural, religious and sporting events. For example, at College A, students organised a food bank collection when they heard that supplies were very low. College D's fundraising for more water storage tanks for their school could also be described as horizontal participation. College B and C's strong 
commitment to local cultural and social groups also reflected their horizontal participation.

Teachers at three of the four schools (A, C and D) cited a smaller number of examples of vertical participation. These actions included getting students to send submissions to the local council (Colleges A and D), writing to businesses about their environmental policy (College $\mathrm{C}$ ) and conducting surveys of the local community and presenting their findings to relevant groups in the community to effect change (Community Issues class, College C). While teachers at College B did not give any specific examples of vertical participation, teachers did describe community-centred conceptions of transformative participation to enable "better outcomes for people and communities" (Teachers B1, B9 and B10).

\section{Pedagogical approaches to social action}

The approaches to social action in all schools (and Colleges A and D in particular) reflected a blend of social constructivist and progressive, "child centred" views. Teachers described how taking social action provided opportunities to "connect with communities and the outside world" thus making social studies more "authentic" and "real" and able to engage and empower students (Colleges A, B, C and D). This included experiential learning approaches through exposure to field trips and "hands on" experiences of participation (such as fundraising, advocacy and student decision-making). Many student-centred, progressive educational ideals were also favoured by teachers (in particular Colleges A and D), as student-centred social action could empower young people, enhance young people's status and "give them a feeling of hope and being proactive" (College B) and "builds their sense of agency" (D1). The teachers also endorsed critical thinking and problem solving skills as part of their approaches to both social issues and social action. These findings reflect Kennedy's description of curricula in the Asia-Pacific region, which he describes as an 
amalgam of Kliebard's (1986) classification of progressive approaches to school curriculum. ${ }^{41}$

It is possible to see two patterns emerging in the participatory orientations of teachers in these four schools. The more globally focused teachers and schools (Colleges A and D) had also embraced social action as a way to deliver new pedagogical aspects of the curriculum (key competencies, inquiry learning and enterprise). Community-focused schools (College B and C) applied social action as a way to develop relationships within the community and to foster a sense of connections. I suggest that a Bourdieusian analysis of the contribution of social and cultural capital toward social action (conceptions and practices) provides a useful explanation of some of these patterns. If the school is viewed as a micro educational field (and the social studies department embedded within this (see Mutch, 2006), differences in participatory orientations reflect the social, cultural and economic capital of teachers within this school, and the value they hold toward social action. Bourdieu suggests that schools are artefacts of the dominant social and cultural faction which award certain forms of capital with greater status than others (Harker, 1990). Could it be that the higher decile schools favour a more global, cosmopolitan form of social action than the lower decile schools? I shall return to this in Chapter 8 when I ask the question, do certain forms of participatory capital also have symbolic capital?

So how do these teachers' conceptualisations and practices of social action impact on their students? I will examine this in the next two chapters in which I turn my focus to the students, the young people, to whom these teachers' social action conceptions and practices are directed. I begin in Chapter 6 by examining how young people's social and cultural capital, gained through belonging to schools and communities, shapes their emerging citizenship dispositions and imaginations. In Chapter 7, I explore how young people define and take action in the context of their lived experiences in school and communities.

\footnotetext{
${ }^{41}$ Kliebard's (1986) classification includes a child development approach (pedagogies are student/child-centred); a social efficiency approach (preparing workers who can contribute to an efficient, smoothly run economy) and social reconstruction (preparing future citizens as agents of social change and social justice).
} 


\section{CHAPTER 6: \\ BELONGING TO “OUR PLACE”: THE CITIZENSHIP IMAGINATION AT PLAY}

In this chapter I address my second research question which asks which social issues do social studies students perceive to be important and why? As stated in the introduction, we know very little about the social issues which would motivate young people to "take action". However, rather than viewing young people's perception of important issues in a social vacuum, or indeed viewing young people as a homogenous group unit, a central aim in my research was to explore how young people's perceptions are constructed within spatial and educational contexts. Through a conceptual and theoretical framework informed by Bourdieu and Mills, I was interested to see how their exposure to types of cultural capital (such as the social studies programmes and practices described in the previous chapter) as well as the social capital they derive from experiences and relationships within neighbourhoods and communities informed their citizenship dispositions and actions.

Knowing more about how young people's everyday, lived experiences inform the issues which hold young people's interest and shape their citizenship responses has been identified as an important area which requires further research (Annette, 2009; Harris \& Wyn, 2009; Marsh, et al., 2007). Research into the area of children's concerns and perceptions of important issues has typically taken the form of examining children and young people's concerns in relation to the future (Harris, et al., 2007; Holden, Joldoshalieva, \& Shamatov, 2008; Sargeant, 2008). For example, studies have found that Australian children are genuinely concerned and pessimistic about the threat of future global issues (such as war, terrorism, global warming and pollution) (Harris, et al., 2007, 2010; Sargeant, 2008). Sargeant (2008) also found that Australian children are more positive about local and personal issues. Holden et al. (2008) identified that children from England, South Africa and Kyrgyzstan all shared hopes for a good job and 
good relationships, but expressed concerns about local issues (such as violence or natural disasters) which reflected much more localised contexts, leading the researchers to conclude that "local circumstances also significantly influence their responses and the extent to which they are informed about current issues" (Holden, et al., 2008, p. 6). Similarly, Harris and Wyn (2009) noted significant differences in reported issues of concern between young people residing in three different local government areas and concluded that "for all young people, the local area was important" (p. 332).

These findings highlight the importance of knowing how contextual factors and experiences of local environments influence the issues young people pay attention to (Mitchell, et al., 2007; V. Morrow, 2001; Warrick, 2008). Yet, while the importance of context has been highlighted, very few studies go on to explore how a sense of belonging and experiences of neighbourhoods and schooling inform citizenship awareness, dispositions and actions.

In order to do this, I set out with a twin focus on young people's experiences of the environment and on their everyday participation. As outlined in Chapter 2, an everyday, place-based perspective on participatory citizenship places the spotlight on how young people's "embeddedness in their local worlds shapes their thinking about politics and their political and social action" (Harris \& Wyn, 2009 , p. 329). In order to explore the relationship between young people's experiences of the local places and the social issues of interest to them, I needed to find a way to capture their sense of belonging to places and identity as young citizens within those places, as well as exploring the influence of social and educational factors. I begin this chapter by providing an overview of how I have approached the exploration of young people's place-based social capital and sense of place before describing the social issues which they perceived to be important. For each school site, I include a "keyhole narrative" (see Chapter 4 for an explanation of this) to provide more detailed insights around one key social issue in "their place." 


\section{Places of identity and belonging}

A small number of studies have specifically explored spatial aspects of social capital and young people's participation and engagement in communities (Gill \& Howard, 2009; Weller, 2006b, 2007; Weller \& Bruegel, 2009). In order to explore aspects of social capital in the context of young people's everyday lives and places, I have drawn on Nicole Schaefer-McDaniel's (2004) framework for examining young people's social capital. She suggests that there are three dimensions that need exploring: social networks and sociability (young people's interactions and relationships), trust and reciprocity, and sense of belonging/place attachment (the sense of community and symbolic attachment to place). In her framework, these three elements are grounded in the physical environment:

... it is necessary to explore young people's use of physical spaces in their everyday environments and identify areas that enhance or foster social interactions as well as recognise areas that restrict or prohibit such activity. Spaces that enhance social interactions and a sense of belonging [...] thus can contribute to building social capital. (Schaefer-McDaniel, 2004, p. 166)

Importantly, Schaefer-McDaniel urges that social capital must be explored by talking to young people themselves rather than their parents or teachers.

As the primary focus of my research was young people's everyday and placebased perspectives of participation, I have foregrounded aspects of belonging and place attachment over the other two dimensions of social capital outlined by Schafer-McDaniel. My interest in schooling has also meant that I have also focused on how cultural capital acquired by young people through education shapes their perceptions of social issues and citizenship dispositions and imaginations.

Experiences of place identification and belonging are rather abstract concepts to explore. Leach's (2002) schematic framework for a theory of identification with space, and in particular, his concepts of "narrativisation," and "performativities," provide useful insights into how we can explore belonging to place. Drawing on the work of Michel de Certeau (1988), Leach describes narrativisation as the 
spatial narratives held by individuals as a result of their familiarisation with territory through their everyday experiences. These insights are further enhanced when we examine the spatial practices of individuals, or what Leach refers to as "performativities", to explain how these spatial movements help to forge a sense of identity. Seeing belonging as performative by viewing patterns of movement and spatial territorialisation, provides opportunities to explore how actions may shape identification with place (Leach, 2002).

By examining the spatial narratives and spatial practices of the youth participants in my research, I hoped to be able to explore the more sensory and affective dimensions of experience (Jorgenson \& Sullivan, 2010) and to gain insights into how young people "see, know and understand their world" (Cresswell, 2004, p. 11). In particular, I wished to explore how young people's sense of inclusion/exclusion as citizens, and their sense of responsibility/lack of responsibility for social issues reveal their citizenship imaginations (see Chapter 3). Photovoice visual data were the primary data with which I began to gain a sense of their belonging and place attachment.

\section{What is special about "our place"}

Participants had more to say/show about what was positive and special about their communities, than what was negative or needed changing (a similar findings to Freeman, 2010). Out of a total of 440 photos taken, 302 (69\%) were photos of what is special or important about their place and only 137 (31\%) depicted aspects which participants described as needing addressing or changing. 42

Through a thematic analysis of photographs from the Photovoice activity, it was possible to see three key areas that young people identified as "special" or "important" about their place. First, participants frequently framed what was special about their place by reference to surrounding natural features. These included general scenery and weather, as well as specific natural features such

\footnotetext{
${ }^{42}$ The participant's classified their own photos into these two categories as they described each photo (see methodology chapter for description of this).
} 
as rivers, mountains or beaches. Second, places of importance also included cultural sites, such as historical and civic/community buildings, local shops and parks. "My street" and "my school" were identified by participants from all schools. A third significant theme was that of friends, families and community people. As Cresswell (2004) suggests, the most familiar example of place and its significance to people is the idea of home (see Table 6.1).

Table 6.1: Photos of what is important or special about "our place"

\begin{tabular}{|c|c|c|c|c|c|c|}
\hline & \multirow[t]{2}{*}{ Aspects of photo } & \multicolumn{4}{|c|}{ Colleges } & \multirow[t]{2}{*}{ Totals } \\
\hline & & $\mathbf{A}$ & B & $\mathbf{C}$ & D & \\
\hline \multirow{4}{*}{ 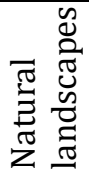 } & Trees/greenery & 4 & 3 & 2 & 10 & 19 \\
\hline & Mountains/hills & 3 & 3 & 2 & & 8 \\
\hline & Water/rivers/beaches & 8 & & 5 & 8 & 21 \\
\hline & General scenery and weather & 4 & 3 & 5 & 16 & 28 \\
\hline \multirow{6}{*}{ 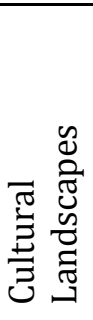 } & My house/streets/ where we hang out & 5 & 13 & 1 & 5 & 24 \\
\hline & School & 1 & 2 & 3 & 4 & 10 \\
\hline & $\begin{array}{l}\text { Community/cultural and civic sites (incl. } \\
\text { churches, marae) }\end{array}$ & 2 & 15 & 16 & 14 & 47 \\
\hline & Parks/playgrounds & 2 & 1 & 9 & 2 & 14 \\
\hline & Statues/murals/historic sites & 4 & 5 & 24 & 3 & 36 \\
\hline & Local shops/businesses & & 5 & 25 & 1 & 31 \\
\hline \multirow{5}{*}{$\begin{array}{l}\frac{0}{2} \\
\frac{0}{0} \\
0\end{array}$} & Family & 2 & 1 & & 2 & 5 \\
\hline & Friends & 3 & 2 & 11 & 12 & 28 \\
\hline & Community people & 4 & 5 & 2 & 1 & 12 \\
\hline & Pets/animals & 5 & 1 & 2 & 7 & 15 \\
\hline & Music/sport & & 2 & & 2 & 4 \\
\hline & TOTALS & 47 & 61 & 107 & 87 & 302 \\
\hline
\end{tabular}

The use of the personal pronouns (me, our, us) to describe these special or important features and places is notable. For example, Saphira (14, female, College D) refers to a photo of a photo of a tree in her backyard (Figure 6.1) and says:

Saphira: That's my tree. It's kind of not really important to anyone else but it's like...

Bron: Is it in your garden?

Saphira: Yeah, It's huge and my grandad planted it.

Saphira also took photos of "my view" and "my street" indicating a strong sense of identification and belonging with her neighbourhood - a sense that seemed to be heightened by the knowledge that her family had been in the area for three generations. 
The selection of sites and features notable for their familiarity and everydayness was reiterated by a number of participants. For example, Smoove Cullen (16, female, College B) took a photo of her house stating, "you asked us yesterday to take a picture of if we go somewhere else what would we miss, and I'd miss my home. So that's my house!" Wiggles (16, female, College B) took a photo of her street sign "[because] that's important to me." And Crunchy's (15, female, College B) explanation for taking a photo of a shop was "I just took it 'cos like it's the shop that I've been going to ever since I was little." Mequity X $(14$, female, College D) describes her photograph of her house and street (Figure 6.2):

This is my street because my group got together and wrote a whole lot of stuff about what was special to us and we all said our street, so this is a picture of mine. Because I live there...and I've lived there my whole life.

Much of what was special in these mundane sites had little to do with the site itself, and more to do with a sense of attachment infused with contexts of social interaction and memory (de Certeau, 1988; Stokowski, 2001). For example, Blinky (14, female, College A) describes a playground that was important: "You know, you go with a friend and you sit and talk and just hang out. .." (See also, Figure 6.4 later in this chapter).

Figure 6.1: "That's my tree" Photographer: Saphira, College D

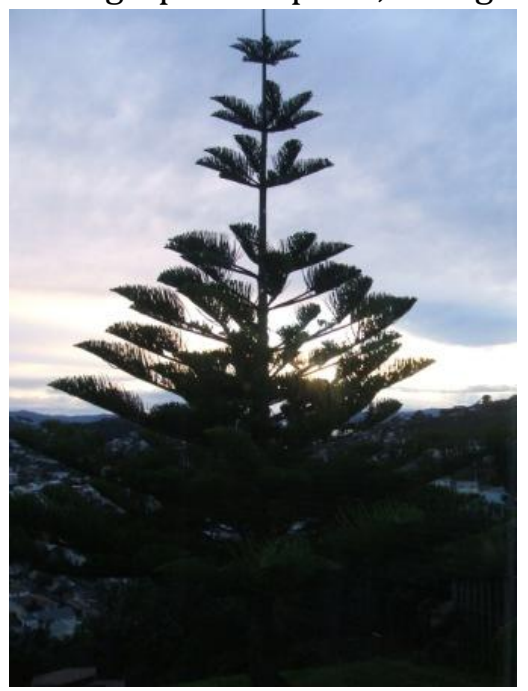

Figure 6.2: "Our family"

Photographer, Mequity X, 14 female, College D

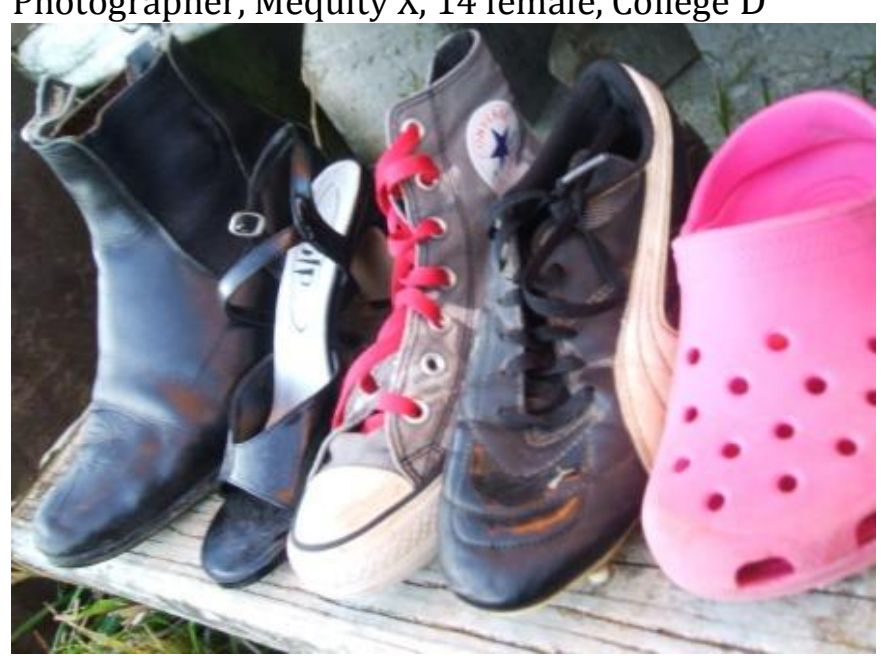

Family members and friends were also a significant part of these sites of belonging. Mequity X explains how in her group's planning for the Photovoice activity, "we said 'our family', so this is all their shoes" (see Figure 6.2). Blinky (14, female, College A) took photos of her brother, her house, her driveway and 
trees just to show she was “celebrating what's around you." But do these experiences of belonging to places in turn shape young people's perceptions of which social issues are important, and in turn, their citizenship dispositions and imaginations? In the following section I begin to explore the relationship between places of significance and the nature of reported issues of significance through four portraits of "our place."

\section{Portraits of "our place"}

The following portraits of the four communities from which the youth participants were located in are described through their own visual and verbal narratives. Following Matthews, Limb and Taylor (2000), I have attempted through these narratives to "connect the real (material geographies of place) with the imagined (symbolic geographies of space) to better understand how the social construction of identity is mapped and performed" (p. 64, my emphasis). Yet, it is also important to acknowledge the incompleteness of these portraits, as Dodman (2003) reminds us:

Each specific picture was taken at a specific moment by a specific person and cannot be taken to represent the entirety of that person's lived experience or even how they feel about a particular place...(Dodman, 2003, p. 297)

Moreover, my own limitations as the interpreter and bricolear (Denzin \& Lincoln, 2003) need be stated at the outset. These community portraits then, are more like a snapshot than a textured and detailed painting. They provide a small but valuable insight into these school communities.

\section{School community A}

Youth participants from College A $(n=57)$ spoke with pride about the natural landscape and features surrounding their regional city. References to what was special about their place included the mountains, the bay, a rock feature which was regarded as "a symbol," as well as a number of "special" rivers. Da Second Banger $(14$, male) took photos of some grape leaves explaining that they were important to the region, for "wine and stuff - you know [our region] has a lot of 
that". Three of the five Photovoice groups took photos of the sun (Figure 6.3), which they linked to the image of their city.

Figure 6.3: "That's the sun cos its sunny [city]" Photographers: Joey Tribbiani, KOTH, Buzz lightyear, Elmo and Pac Man

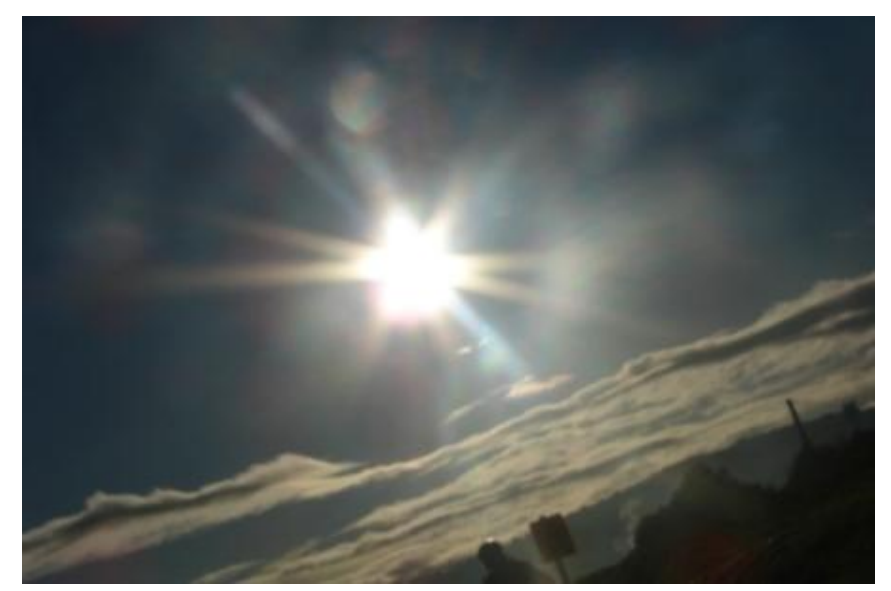

Figure 6.4: "That's the beach" Photographers Fishy Fish, GawJus and Werewolf

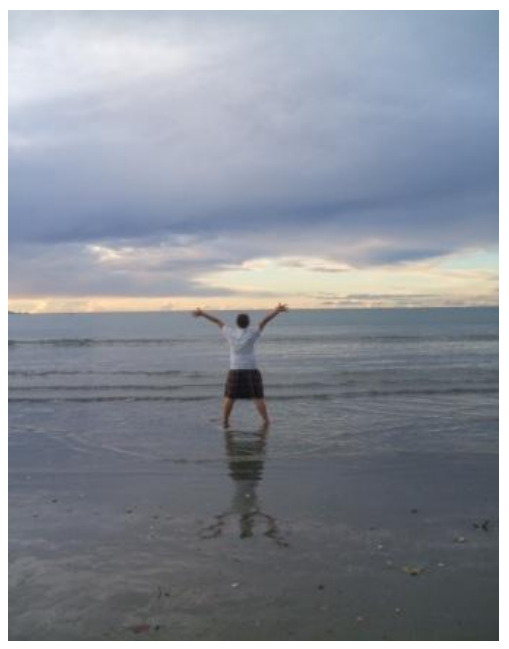

The beach was regarded as an "important" place (see Figure 6.4), notable for the associated spatial practices of young people. Two female participants (aged 14) explain:

Fishy Fish: That's the beach. Cos it's cool. It's important for [city].

Gaw-Jus: That's me at the beach. That's where we hang out some times. It's important.

When I asked participants what it was like growing up in this city, participants described it as "very cruisy" (Leaf, 18, female), and a place where "everyone knows everyone." Bella (18, female) described it as “...kind of a small town-city kind of thing." A couple of participants also described their city as boring for young people, although one responded that "we make our own fun". They described a number of local Council initiatives for young people in the city, such as the creation of a youth drop-in centre and New Year's events for young people, although some older participants described this as something for "losers" and more for younger teens.

One aspect that generated a lot of discussion with participants for this school was how they were perceived by adults in their community. The presence of three different school Year levels amongst my participants at this school (se 
Table 4.2) enabled me to see some interesting age-related responses to this issue. For example, older teens from College A generally felt very positive about how they were perceived in the local community as the following discussion with three 17-18 year-old students illustrates:

ITMaster: I believe we're perceived as pretty good compared to other places round the country like Auckland and big cities. (18, male)

Claire: There are some groups that are perceived as worse. Like there are always going to be different group within an age group. (18, female)

Hip Hop Potamas: Yeah, we do particularly well considering there are so many older people, like retirement villages. We lose the twenty-year-old age group so there is a big gap. (17, female)

Teacher A1: As a lot of kids go away to uni or to an OE.

Students: Yeah

Teacher A1: So you do have a big gap.

It is notable that all three youth members in this discussion held positions of responsibility in the school and community. ITMaster was the Youth representative on the Council, Hip Hop Potamas led the school environment club and Claire was a leader at her local church youth group.

However, their experiences contrast starkly with Year 10 participants in the same school. Members of one of the Photovoice groups photographed an elderly man on a mobility scooter in front of an "Elderly" sign, stating they had taken the photo "because old people are important to us" (Buzz lightyear, PacMan, Joey Tribbiani, Elmo and KOTH). In contrast to this statement, participants from this group and others in the class described a number of recent experiences with adults in their community which were less positive. For example, Joey Tribbiani (14, male) describes a recent interaction he had with a mother and her children:

Joey Tribbiani [to audio]: Let me tell you a personal story. I was walking to school one day and there was a mum and her daughter and her son and they were both primary kids, and they were young, and they were walking to their school the opposite way to me and we collided. Not literally, but we walked past each other. And the little kids just looked at me and they hid behind their Mum, and I thought that was sad 'cos I hadn't done anything.

Pineapple Lumper and Happy-go-Lucky (both 14, females) relayed some personal examples to illustrate a similar point:

Pineapple Lumper: [In our city there are] no good places for young people to hang out and when you do hangout in town you sit there and like 'ooh teenagers'. 'Oooh. They're going to beat me up and smoke and stuff'. That's the label put on teenagers. 
Happy-go-Lucky: ...Like when you go to town they think you smoke and drink and beat each other up...

Pineapple Lumper: ...like when you walk into shops, like, go figure. We went into The Warehouse to have a look around cos we wanted some costumes as it was just before Halloween. And there was a group of about ten of us, and as soon as we walked in there we got heaps of looks from the staff. And we walked straight to the Halloween aisle and then a guy came and actually told us to leave. He asked us if our parents were with us...We were just looking and they kicked us out... And it just shows sort of how much they think of us - they just judged all of us by a small group of young people.

It is interesting to note just how differently older and younger teens at College $\mathrm{A}$ felt about the perception of young people in the same community.

\section{Reported issues of importance at College $A$}

In the 16 café-style focus groups at College $A$, many participants expressed concern about issues related to the environment such as environmental sustainability (9/16), global warming $(7 / 16)$, and pollution $(7 / 16)$. This theme reflected their descriptions of their community which had a strong emphasis on the natural environment. Participants also defined a number of concerns related to human rights (racism (9/16), discrimination (8/16), bullying (8/16)) and issues related to alcohol abuse (11/16) and drug abuse (9/16) (see Table 6.2 later in this chapter).

There were notable differences between older and young teens taught by the same teacher (Teacher A1), at the same school. Younger teens reported higher levels of personal and health related issues (such as smoking (6/8), peer pressure (4/8) and bullying (5/8) and two younger groups also listed stereotypes of young people as an important issue (reflecting their discussions above). In contrast, older teens didn't report smoking or peer pressure at all and only three out of eight focus groups reported bullying to be an issue. Older teens were more likely to voice concerns about global issues such as poverty (6/8), war (5/8) and cultural conflict (4/8) than younger teens in the same school.

There was a high rate of concordance between the issues reported to be "important" by these participants, and the topics that they were studying in 
social studies (see Appendix 0). ${ }^{43}$ For example, all of the Year 12 and 13 focus groups (8/8) reported that poverty was an important issue and both these classes had studied social studies topics related to global inequalities of development (Appendix 0). The reporting of war and conflict (6/8) by older teens at College A also mirrors their topics of study with both groups studying issues of religious conflict. Younger teens had recently completed a unit on global warming which is likely to have influenced their high reporting of issues related to climate change (4/8), issues of environmental sustainability (5/8) and pollution (4/8). ${ }^{44}$ However, as discussed in the keyhole narrative below, the attention of many of these young teens was drawn to a specific environmental local issue - air pollution.

\section{Air pollution - "we're already dealing with it"}

In contrast to the descriptions of their place which celebrated natural features and the environment, participants reported that air pollution in particular was an issue that needed addressing. For example, focus groups specifically mentioned air and water pollution (1/8), not preserving their regional city's environment (1/8), and traffic pollution (1/8) and three out of five Photovoice groups took photos of air pollution and smog over their regional city (see Figure 6.5 and 6.6). Da Second Banger (male, 14 years) described this issue in relation to his city:

Da Second Banger: (describing photo to class) [This is] pollution.

Teacher A1: Evening or morning?

Da Second Banger: Evening.

Bron: Is it a problem here?

Da Second Banger: Yeah there's quite a bit of smoke there.

Teacher A1: The Council's banned open fires and are changing the regulations.

\footnotetext{
${ }^{43}$ Focus group interviews with Year 12 and 13 participants at College A were conducted at the end of the school year - just before final exams - so these participants had experienced the complete social studies programme for the year. All of my other research in Colleges B, $\mathrm{C}$ and $\mathrm{D}$ (and year 10 in College A) occurred midway through the school year. Appendices 0 - $R$ reflect this by including only topics that had been covered to date.

${ }^{44}$ As noted in Chapter 4, only the Year 10 participants at College A took part in the Photovoice activity.
} 
Figure 6.5: "Pollution"

Photographer: Da Second Banger, 14, male

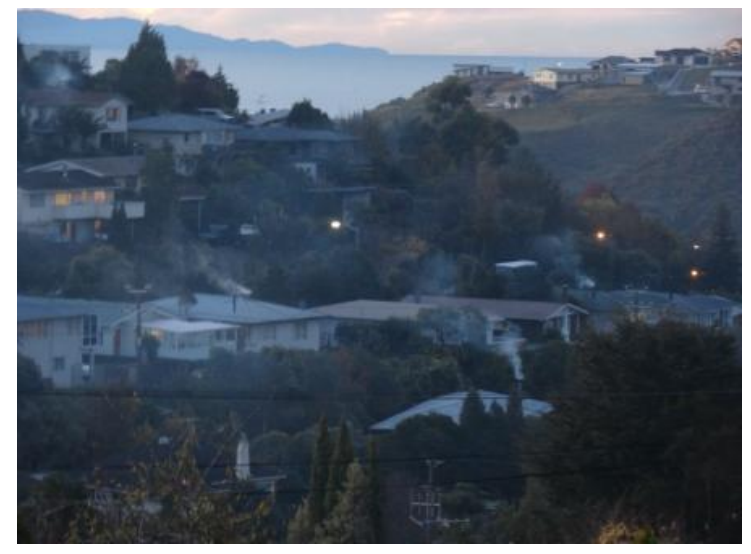

Figure 6.6: "That's air pollution"

Photographer: TC, 14, female

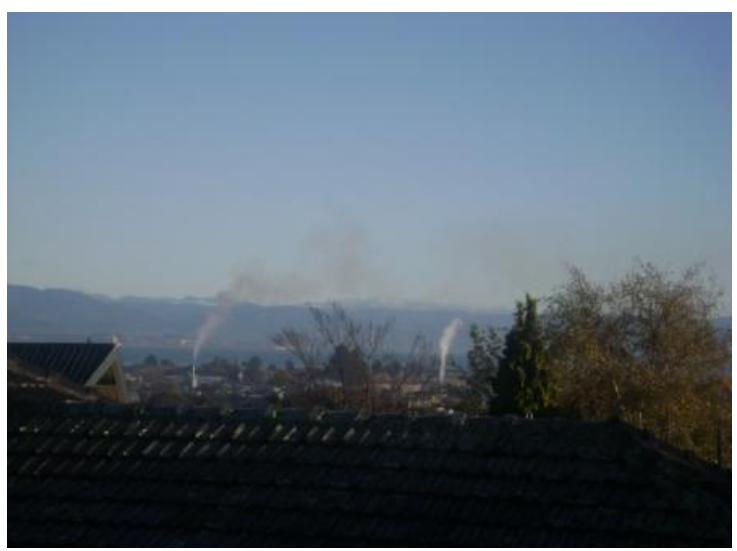

Participants associated the issue of air pollution with exhaust fumes, car pollution, poor traffic flows (see Figure 6.7) and global warming, as illustrated by three 14-year-old females when I asked them which their most important issue was:
Allerbag: Lack of traffic flow? Pollution?
EE: Pollution.
Bat Boy: Why?
EE: Global warming!
Bat Boy: Traffic's not going to get any worse for this generation.
Bron: Which is the most important issue then?
EE: Pollution.

However, a number of participants pointed out that local people had gone to some effort to make improvements on this issue. For example, Jazzie and A.S, (14 year-old-females) discuss how air pollution is "good" in their city now:

Jazzie: What about fires? Air pollution with fires?

A.S.: It's OK in [our city] cos they've done all the work. [later] Actually air pollution is good in [our city] now cos they've done that with the council person.

Jazzie and Blinky went on to debate whether pollution was "the most important issue":

Jazzie: I reckon pollution. If the pollution takes over the world, we'll all die. Blinky: It's not that big a deal.

A.S.: We're not doing anything wrong. Its other countries like America that are the problem. They need to cut down on pollution. We're already dealing with it. 
Figure 6.7: "That's traffic"

Photographers: Gaw-Jus, Fishy Fish and Werewolf (all 14, female)

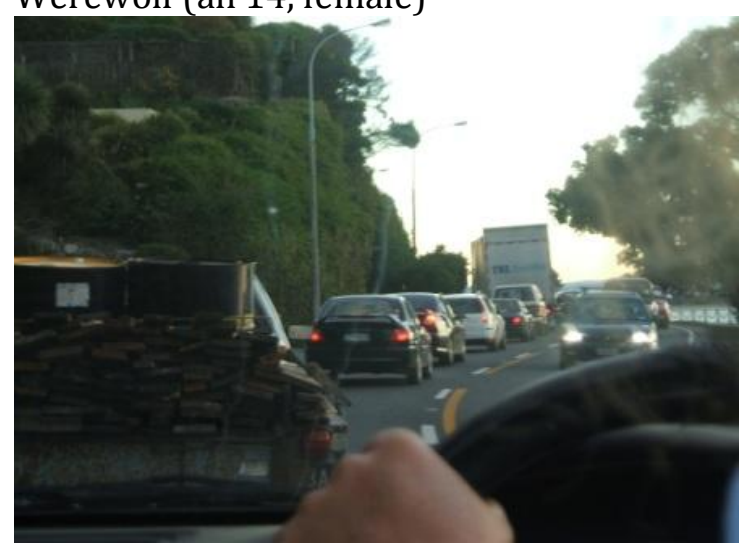

Figure 6.8: "Fireplace. It's enclosed, which is good"

Photographer: Blinky, (14, Female)

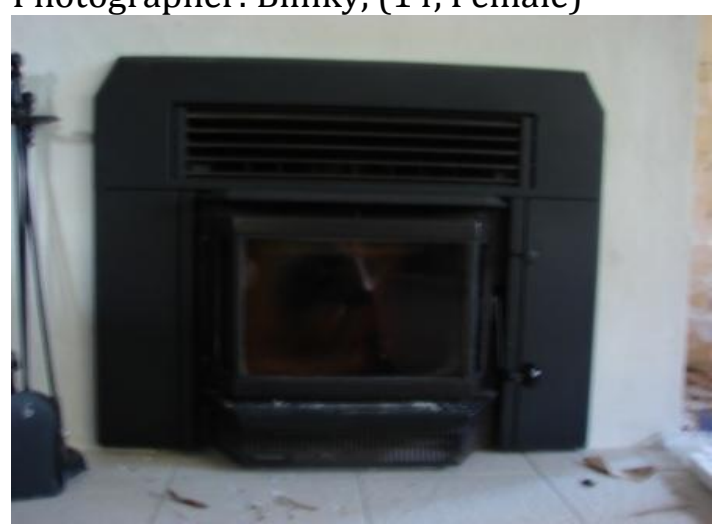

Participants described what the local Council were doing to reduce smoke pollution over their small city and how their fireplaces were being replaced by new more efficient, cleaner burners. Blinky (14, female), photographed her fireplace to illustrate that it was "enclosed, which is good" (Figure 6.8). The ability to make a difference in the issue of smoke-related air pollution in their regional city (by local Council regulations about fireplaces, such as the one in Blinky's photo - Figure 6.8) appeared to be important in how these young people perceived the significance of air pollution in their city. For example, in the discussion above, Blinky and A.S. decided that pollution isn't a big problem in their place (unlike in America) because "we're already dealing with it" (A.S.). Furthermore, KOTH, Pac Man and Joey Tribbiani demonstrated cynicism of reported rates of global warming and comment:

Pac Man: I think they're making a slightly over-exaggerated fuss of global warming.

KOTH: Exactly. The world has been warming up for ages.

They decide later not to highlight global warming as the "most important issue" as "it's not a 'fact"' (KOTH, 14, male).

The discussions here highlight how these young people were developing their own conceptions toward social issues such as pollution in light of their own experiences and observations about it. Their observations that air pollution was 
"being dealt with" appeared to have heightened their sense of agency toward the issue of air pollution, and for some, this had diminished their perceptions of its significance.

\section{School Community B}

The ten participants from College B were all females between 15 and 17 years with Pacific Nations backgrounds (see Table 4.2). While participants alluded to the natural landscapes around their suburban centre (see Table 6.1), the focus of their attention was on the immediate (cultural) neighbourhood and people. They described this focus to me with specific reference to the cultural mix of their community in the following discussion:

Bron: What is cool about growing up in this area? Being a teenager in [your suburb]?

Cimzoc Pop: Mingling...

Yuuki-Chan: I don't really know cos I don't hang out...

Bubbly gurl: I like it 'cos it's more like a Pacific community - everyone just gets along...

Spronx: You can be yourself - unique.

Bubbly gurl: (cont) ...There's a spirit sort of in the community.

Doodlebop: Everyone has respect for each other's cultures.

They reinforced this conceptualisation of a "Pacific community" on many occasions during the focus groups discussions and the photographs. For example, they included photographs of a number of cultural centres (such as the Cook Island Hall and the local marae), as well as churches which are "quite important for the community" as Emmett Cullen (14, female) explains:

I particularly wanted a photo of my church ...That street is important to me. Because I always walk on that street after school and before school and going to church.

One participant in particular (Bubbly gurl, 16, female) made a concerted effort to find visual ways of representing and celebrating her multicultural community, stating to me on a number of occasions that "I was trying to show that our community is multicultural." She used a great deal of creativity to do this. For example, she photographed the back of a bus which had an advertisement promoting Maori health care (Hauora) between the generations, cultural art on the side of a bus stop and a kindergarten (Figure 6.10), reiterating: "The patterns 
and that - I was just trying to show it's a multicultural community." She also took photos of Pacific food sold at her local shops, including taro and green bananas (Figure 6.9).

Figure 6.9: "More taro"

Photographer, Bubbly gurl, 16, female

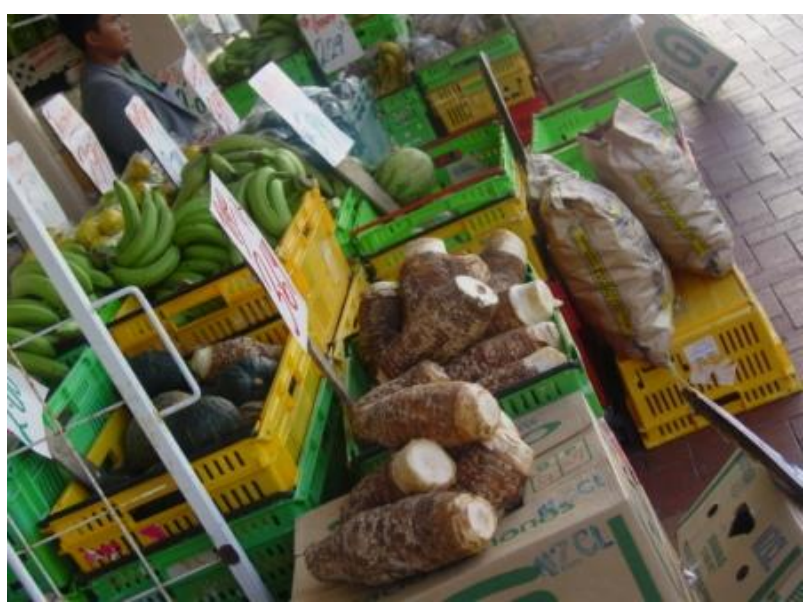

Figure 6:10: “...it's a multicultural community" Photographer: Bubbly gurl, 16, female

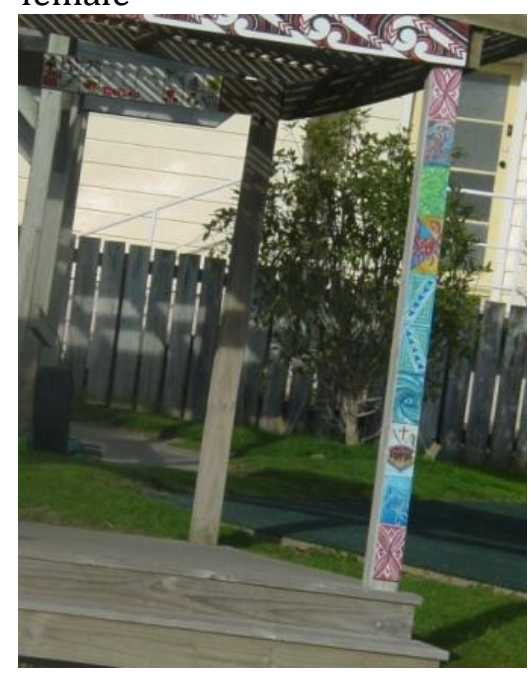

Bubbly gurl described this community as one that worked hard to respect others cultures and traditions. For example, she photographed the marae to show that "we respect the Māori culture in our community." The importance of cultural performing arts and music was discussed by participants on a number of occasions. For example, participants in one focus group noted that the rights of young people in society included "the right to showcase talent," and society in turn had a responsibility to look out for, and develop youth talent:

You could get talented people out of school or from church or from any other organisation. So, the society has to do something to get those people together [and encourage their talents] and in the end it represents our society in a good way (Emmett Cullen, 15, female).

I asked these participants about their experiences as young people growing up in this society and if young people were listened to. They replied:

Yukki-Chan: Nah, they're not listened to.

Bubbly gurl: I guess that the majority of teenagers... like... [pauses]...at church they get listened to.

Doodlebop: At church they get listened to a lot.

Yukki-Chan: They stereotype those little teens. You know, they're so immature. You do have so many immature teenagers.

Doodlebop: I think that's why the youth do some of the things that they do now, like vandalism and tagging. 
Bron: Because why?

Doodlebop: To get attention. Like some people are ignored and they don't get paid attention to. I think that's why they do it.

Bron: On your Council website they show this brochure about opportunities for youth in your area. Do you know about that?

Bubbly gurl: Yeah. I know about it 'cos I'm on the Board of Trustees.

Bron: Do you get consulted by the Council like they say?

Smoove Cullen: Nah. That doesn't happen. [laughs]

Doodle bop: We're not famous enough! [class laughs]

It was at church that this group of young people felt that they were heard. I return to this in Chapter 7 when I explore the responsibilities many of these young people held in their churches and how this was a place they could take social action. In contrast, the idea that the Council would consult with them was almost viewed as a joke, with Doodlebop commenting, "we're not famous enough," hinted at the lack of opportunities they were afforded in formal decision-making in their local community.

\section{Reported issues of importance at College B}

Social, economic and health-related issues dominated those reported to be important by the participants at College B (see Table 6.2). For example, all focus groups mentioned that students leaving school without enough qualifications (unskilled youth) was an important issue, along with teenage pregnancy, alcohol and drug abuse. Participants had a very high number of issues that could be described as youth-related. For example, drugs and drink driving ${ }^{45}$ were described as an important issue "cos there's like lots of people who are dying from drink driving - mostly teenagers - throwing away their lives" (Doodlebop, 16 , female).

College B participants reported a number of the issues and topics that they were studying in social studies to be issues of importance (see Appendix P). These included the Anti Smacking Bill ${ }^{46}$ which was an issue they had studied in social

\footnotetext{
45 "Drink driving" - a colloquialism for driving drunk.

${ }^{46}$ The "Anti Smacking Bill," or Child Discipline Bill was passed in New Zealand Parliament in 2007 and removed the justification of "reasonable force" to correct a child.
} 
studies that year, along with an examination of boy racers ${ }^{47}$ and changes to alcohol legislation (Appendix P). Global warming (2/2) was one of the few global issues they mentioned. However it was interesting to note that participants at College B classified what I saw as local issues (such as teen pregnancy, students dropping out of school or burglary) as global issues based on the grounds that "it happens everywhere" (Smoove Cullen, 16, female). Furthermore, small local problems were also seen as global if left unattended as illustrated in the following conversation:

Emmett Cullen: Cos they might seem like local issues but if they're not dealt with they become global ones... (15, female)

Bron: Oh, like education? What happens if teenagers drop out of school? Emmett Cullen: Well then they don't get an education, then they can't get a job and that becomes a big issue for everyone.

In the feedback session with these participants, I asked them to reflect on why they had focused on more local issues than, for example, same age participants at College A. The participants at College B gave a number of reasons as to why they had such a strong local focus:

Bubbly gurl: Well, that's because our community is so important to us. Our students know our community well.

Yukki-Chan: Like, what kind of community are they (with reference to College A)?

Bron; Decile 6, mostly European, reasonably well off...

Bubbly gurl: Well then, they would see less issues in their community. Yukki-Chan: Cos we have more issues than them, we see more issues Doodlebop: Our students don't travel so far (as them). Our world is smaller. They would connect more with the world than us.

These comments affirmed these participants' close connections with their local neighbourhood and community, and there was a sense of pride to "know our community well." Caitlin Cahill (2000) had similar findings in her research with young people in low socioeconomic urban areas of Manhattan who demonstrated pride in their ability to "read" the environment in personal, cultural and social ways - what Cahill termed their "street literacies." Doodlebop's comments about spatial mobility provide some interesting insights into 'lifeworld' which she saw as smaller and more constrained than what she surmised those young people at College A must have. In the following keyhole

\footnotetext{
${ }^{47}$ Boy racers are a New Zealand colloquialism for young teenagers who like to drive round, often in modified cars and over the speed limit.
} 
narrative, I examine further an issue of concern for many participants at this school - the "image" that their community has, and how frequently this misrepresents their experiences of belonging to this community.

\section{"When other visitors come here, all they can see is tagging"}

One social issue that participants at College B said they would really like to change was the tagging (graffiti) around their local suburb. Bubbly gurl described how tagging made her suburb look "bad" to visitors, thus overlooking the many positive aspects of her community that she was so proud of:

Bubbly gurl: Tagging round [suburb]. That's a big one. It makes our suburb or our town look very...

Yukki Chan:...naughty!

Smoove Cullen: ...very ugly

Bubbly gurl: ...bad. And like when other visitors come to here, all they can see is tagging.

Bron: Yeah. Rather than some of the neat things you're telling me about.

Bubbly gurl: So it's not a good thing.

The issue appeared to be heightened when it became more personal. Two participants had taken photos of tagging "outside my house" (Smoove Cullen, see Figure 6.11) and "on one of our fences" (Crunchy, see Figure 6.12). When I asked Crunchy if this happened regularly, she replied "Not really, that happened ages ago." This comment highlighted that the tagging had not been removed or cleaned since then, which made Crunchy feel "angry."

Figure 6.11: "It's just vandalism" Photographer: Smoove Cullen (17, female)

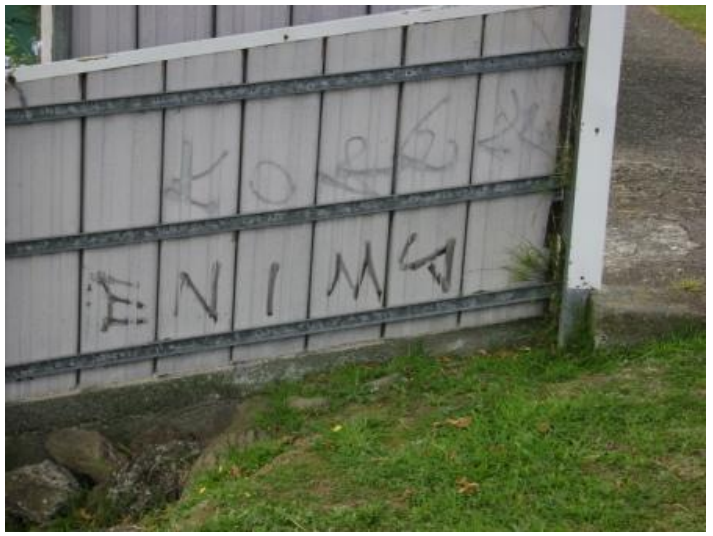

Figure 6.12: "That's tagging on one of our fences"

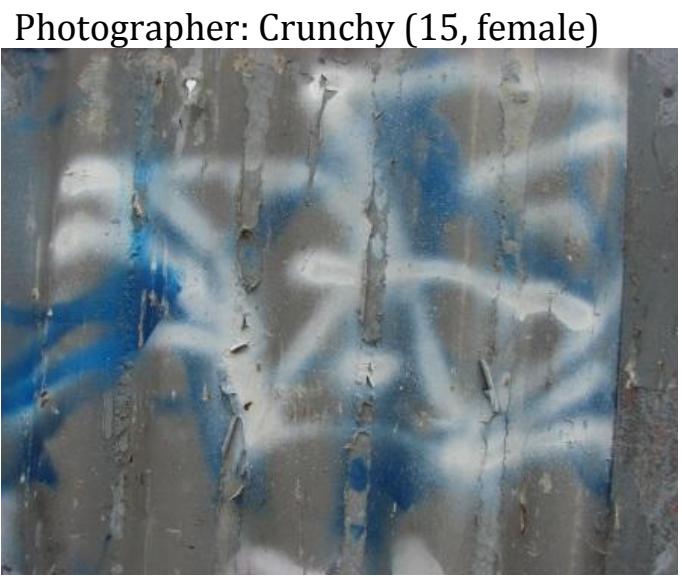


Smoove Cullen's reason for taking her photo of tagging (Figure 6.11) was to point out the different perspectives people have on tagging as vandalism and tagging as art:

Smoove Cullen: And I compared it to how people have mixed feelings about graffiti. Like some people think its art, and stuff.

Bron: And this one you think is art?

Smoove Cullen: No, it's just vandalism. [laughs - class laughs] There's other graffiti that's art - like where the shops are and stuff. . . but that's just damage.

Later, during the Photovoice debrief, when Bubbly gurl showed the class her photo of street art (Figure 6.13), Smoove Cullen burst out, "Now, that's art!"

Figure 6.13: "That's art!"

Photographer: Bubbly gurl

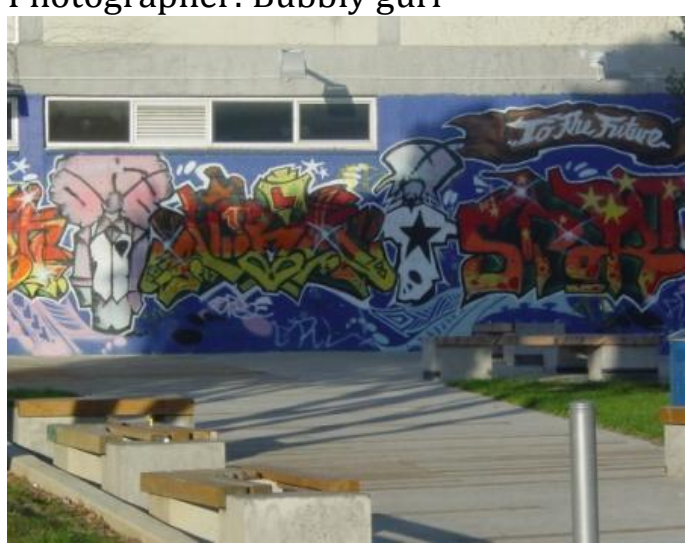

Figure 6.14: "It makes our suburb look bad" Photographer: Bubbly gurl

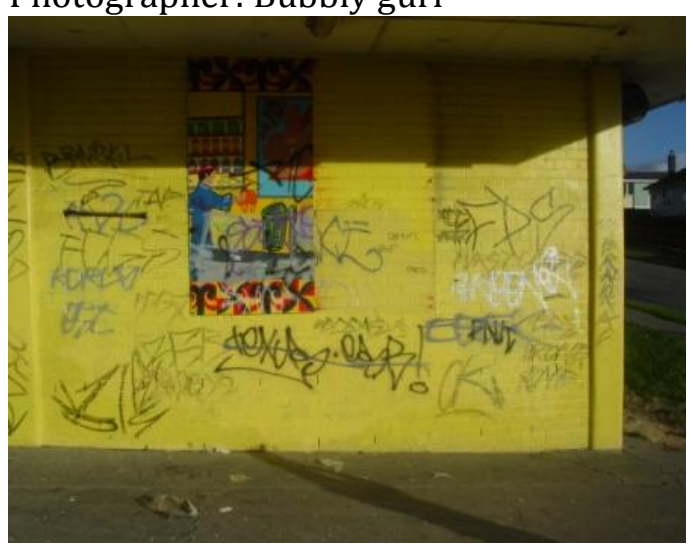

Their sense of disappointment in the tagging was increased when Bubbly gurl showed a photo she had taken of tagging which had been done on top of a painting by younger local students (see Figure 6.14). Yukki Chan knew the students who had done the original painting a number of years earlier and commented, "It was us - our year." They commented that "they did it to the whole building - even the top and the back [...] I find that very unattractive."

Bubbly gurl photographed one other site in her community which "disturbed" her, the local gang headquarters. She describes her photograph:

Bubbly gurl: And that area. It's where the [gang name] kind of hangs out... This one - behind the fence. That's the entrance into the [gang] headquarters.

Bron: So tell me what you think about that? 
Bubbly gurl: (quietly) I feel very disturbed. 'Cos it's scary. I just I don't think it's safe. I think its part of their culture but I don't think that it's safe enough for other cultures as well.

Teacher B1: Is that the [gang]...?

Smoove Cullen: Pad.

Bubbly gurl: They call it a pad or something.

In Bubbly gurl's conversation you can see the dilemmas she is struggling with over who has the right to express their "culture" in her community, and where the responsibility for addressing such issues lies. Her concept of acceptance and respect of cultures in her community was stretched when it came to a culture that she didn't feel was safe for her wider community. Her sense of desire to improve the "image" and perception of this place came in her commitment to the people of this community.

\section{School community C}

Year 10 participants from College C ( $n=29)$, a decile 4, co-ed rural high school in the South island, referred proudly to the natural features in their area which included significant National Parks, many beaches and rivers and a historic township. Many descriptions and photos related to "our beautiful scenery," our "pretty outdoors" and "up the road...we have this river source of REALLY clean water. Like some of the cleanest water in New Zealand" (Figure 6.15).

Figure 6.15: "Really clean water" Photographers: Pete, Lil Man and NED

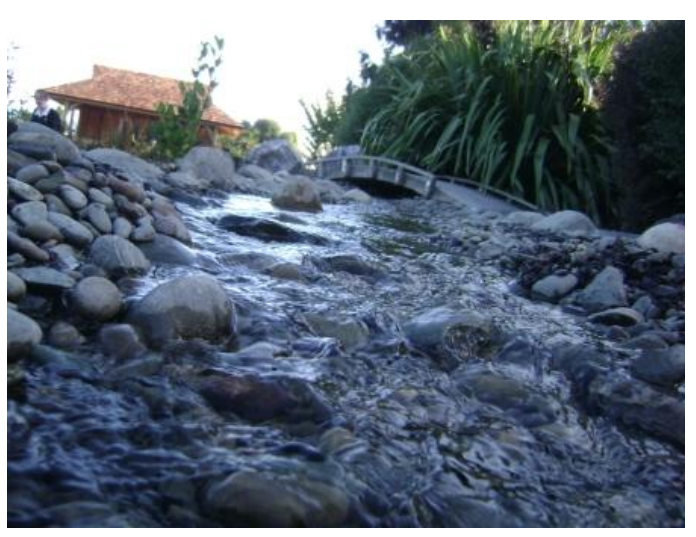

Figure 6.16: "That is significant to tourists - it's where they love to go" Photographers: Happy Dog, Reow and Mad Dowg

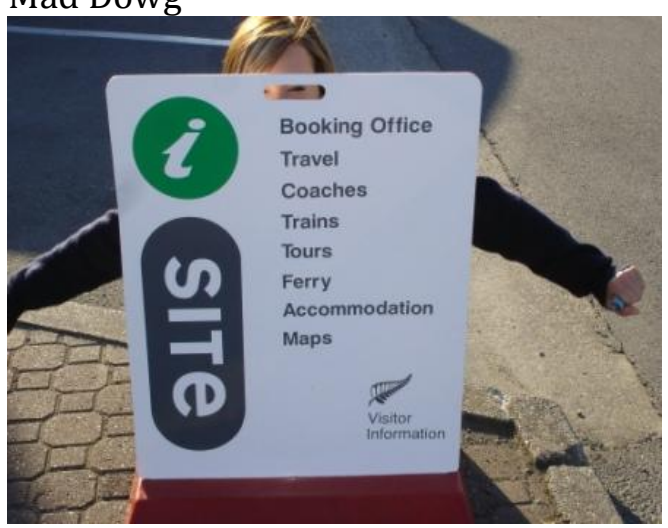


The importance of tourism and orcharding to the local economy was also reflected in participant's comments. Feathers and Flora photographed orchards "right in the middle of town," commenting that "its part of our rural community." Reow's photo of the information centre sign (Figure 6.16) was to show that her town "is significant to tourists. It's where they love to go". The presence of a number of newly renovated restaurants on the main street was also a source of pride to these two female participants:

Autti: Its shows what we can do. We can bring things back to life.

Joker: Like we're not just a like a little town. Its lot's more like [X-Town].48

Young people were ambivalent about growing up in this small rural centre. On one side, participants recognised that there were many good aspects to life as young people here:

It's not like a real huge place, so you know the area and people are quite good.

It's kind of good cos we're not like in a huge city with heaps and heaps of people, but we've got [X-town].

We don't have major crimes like murder very often here.

And I like the librarians, they know my name.

However, alongside these positive comments, were others from participants who described how life growing up in this town was "boring":

Captain Kewi: It's really small and there's nothing to do here. It's kind of boring 'cos there's not many shops you can like go and buy clothes and stuff in. $(14$, male $)$

Reow: Yeah, not much clothes shops. (14, female)

Pete: Yeah, you don't get shopping much. (14, female)

Their relative isolation from the rest of New Zealand (in their perspective) was captured by one group's (all 14 year-old females) photo of "us connecting with the outside world" (Figure 6.17) which they described to me:

Autti: That's connecting us to the outside world. It's connecting us to people ...outside

Joker: Outside the community.

Bron: Do you actually post letters?

48 References to this neighbouring city were made so frequently by this group that I have named it X-Town. 
Collective: Yes. I do.

Bron: Do you use the internet as well?

Autti and Bubbles: No. I hate computers. I'm actually not very good at the internet

Joker: Well, I am!

Bron: Do you feel a bit isolated here?

Autti: I'd say it's more because it's a small town.

Joker: Because normally people that live here they've either got family all around them or they don't have family in the area. It's either all here or real far away.

For some participants, leaving this town was a goal, as articulated by Captain Kewi, a 14-year-old male:

I didn't want to grow up in [this town]. Like I've grown up now but I don't want to live here till I'm like 18. It's just lame. It's boring and everyone moves away eventually from [this town]. That's why I'm moving to X-town.

Figure 6.17: "That's connecting us to the outside world"

Photographers: Autti, Bubbles and Joker

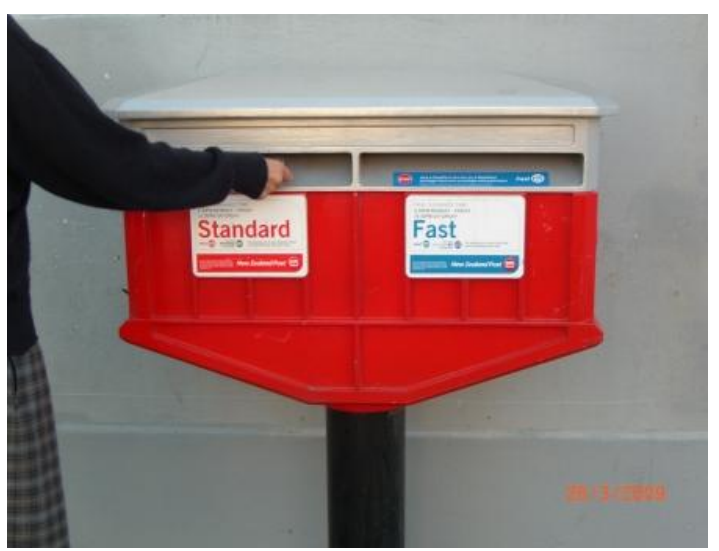

Figure 6.18: "The window's fully broken at the back - now that's bad!"

Photographers: Feathers, Flora, Rangatangtang and Capt Awesome

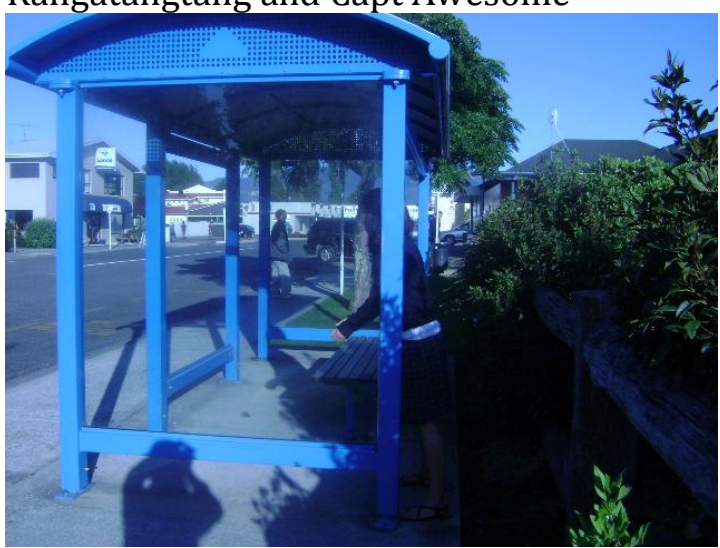

When I asked these participants how young people were valued in their community, they referred to the presence of local youth council which was "under the umbrella of the Council but the youth actually run it - but I don't know much about it" (Feathers, 14, female). The main barriers to participating more in their community were identified as not being old enough "to sign petitions and stuff," not being able to influence people "because you're much younger than them and people think they shouldn't listen to you and stuff" (14, female). Many participants were "joiners" of local clubs such as Scouts, Pony Club and youth groups, as well as active in a wide range of sports (such as snowboarding, skateboarding, sport and horse riding). 


\section{Reported issues of importance at College C}

The most commonly reported issues of importance by Year 10 participants at College $C$ were related to the environment. In particular, participants referred to littering (5/6), climate change (3/6) and two issues, unique to this school, of 1080 poison $^{49}(4 / 6)$ and Didymo $^{50}(2 / 6)$. Participants had a strong awareness of specific local community issues, such as a new bypass, the status of the local community swimming pool or the damming of a nearby river for a hydroelectricity project. Their knowledge of these the issues were closely linked to their experiences in the Community Issues class (discussed in Chapter 5) as revealed in the following discussion between 14 year old boys who were listing "important issues in our place":

Lil Man: 1080 aerial drops, Didymo...

Captain Kewi: You're just taking all this from community issues class. Lil Man: Yeah I know.

Issues that had been studied over the past two years in this Community Issues class included 1080 poison, the expansion of the local swimming pool, the arrival of McDonalds to the town and youth issues (Field notes, 2009). Many of these issues featured predominantly in their discussions. Not only was their awareness of these issues heightened by the Community Issues class, but participants could articulate clear viewpoints and information on many of these issues. For example, two members of the current Community Issues class studying the issue of 1080 poison could both define and state why 1080 was an important issue when asked about it by classmates:

Cadalacwormwald: It's a poison that kills possums. It's an important issue and something that we want to deal with. $(14$, male $)$

Krump Queen: It's a poison - it's a big issue - it's a poison to kill possums that's killing off native birds...It's like spreading and getting rivers and stuff. (14, female)

\footnotetext{
491080 is the name of a poison that has been used extensively in New Zealand to control pests such as possums and stoats. 1080 is generally distributed by aerial drops over forest areas.

50 Didymo, a fresh water alga, was first reported in New Zealand's South island in 2004. There have been extensive advertising campaigns to reduce its spread by Ministry of Agriculture and Fisheries (see http://www.biosecurity.govt.nz/didymo).
} 
There was less reporting of topics taught in social studies class, although on the Photovoice activity students did photograph one fair trade coffee shop in town which reflected their current topic in social studies (Appendix Q).

In the following keyhole narrative participants from College $\mathrm{C}$ elaborate further on the issue of spatial isolation when they discuss a related issue - the lack of public transport.

\section{"Bus crisis!"}

Feelings of isolation and perceived lack of facilities for rural young people have been well documented in research from Australia (Gill \& Howard, 2009; Wierenga, 2009) and New Zealand (Nairn, Panelli, \& McCormack, 2003; L. T. Smith, et al., 2002). For two groups of young participants from College $C$ in this study, this sense of isolation and insufficient facilities was represented by a "crisis" in public transport between their town and the nearest city [X-town]. Martha, Sally, Autti and Mad Dawg describe the issues: ${ }^{51}$

Students 3: We need a bus to go from [our town] to [X-Town]. Student 4: But there already is one.

Student 3: There are already buses but they're horrendously expensive. It's like $\$ 11$ to go one way.

Student 1: Bus crisis! It's public transport issue.

Student 2: I think an important issue is that we don't have cool enough shops...it's like, they're all expensive. And, it's like, for a teenager we need cooler shops.

Bron: OK. Where would you want to go?

Student 3: X-Town. Cheaply.

Student 4: But in X-Town it's so much fun - cos you can just walk round and window shop.

Student 2: Anything.

Student 4: Yeah, there's so much stuff to do.

The "bus crisis" seemed to embody a number of related issues for these participants. Public transport in their experience was very expensive, but also very limited. Students told me there were only three buses a day and occasionally a night bus. The lack of public transport highlighted another issue, the limited variety of shops available in their town.

51 This group of Martha, Sally, Autti and Mad Dawg, all 14, female, had such similar voices that I couldn't distinguish between them, so I have referred to them as Student 1, 2, 3 and 4. 
In a separate group, Feathers, Flora, Rangatangtang and Capt Awesome identified the lack of bus shelters as an important issue. They described to me what they found when they went to photograph the bus shelter (Figure 6.18, earlier):

Feathers: See look. The window is broken. We were trying to show you that's bad - people have busted it... (14, female)

Bron: Is this a bus shelter?

Feathers: Yes, the window's fully broken at the back. Now that's bad.

Flora: That was the only one. (14, female)

Bron: The only bus shelter?

Flora: Yes, this is the only bus shelter in town.

Bron: And it's smashed?

Feathers: Ah - yuh.

The "bus crisis" appeared to be a particular issue for younger teens. The public bus is their connection to the world beyond their rural town - a world inaccessible to 14 year-olds who cannot yet get a driver's license or own a car. This point was made clear in another focus group as they described the activities available for young people in the week-end:

Cadalacwormwald: Well there's not really anything for people in [our town] to do. I normally just end up going to my friends houses and walking downtown. The only real thing is the skate park. (14, male) Sally: Probably the only thing is the youth groups...and the skate parks gets people into bad...you know drugs and stuff. (14, female) [...] Martha: But there's the movies and there's youth group and stuff and if you think about it there is quite a lot to do. And there's the beach and... (14, female)

Cadalacwormwald: ...once you've got your license and you can drive!

Their narratives reflect the constrained patterns of mobility, the "microgeographies" (Matthews, et al., 1998) characteristic of many young people, but exacerbated even further for rural young people without effective public transport. During 2009, local adults advocated for a trial of a more frequent public bus between this town and X-town, but following a month's trial, the scheme was abandoned due to high costs and low usage. The constrained microterritories and everyday arenas of young people in this town appear to frustrate the daily experiences of many young people from College C. 


\section{School Community D}

Participants attending College D ( $n=26)$, a Decile 8, central city girl's school, travelled to this school from neighbouring suburbs, some as far as 15 kilometres away. The site of the school's location was difficult to access by foot which "vastly increases vehicular transport uptake" (Teacher D1). This meant that very few participants demonstrated a connection with the immediate neighbourhood surrounding the school - a point which was reflected in their Photovoice activity and descriptions of "our place." Instead, photographs taken to describe what was special and important about "their place" frequently included wide vistas of their city; civic places and iconic scenery (see Figures 6.19 and 6.20). For example:

Mequity X: Another thing we said we'd miss if we moved was the sunsets in [our city]. Oh yeah I put it behind a tree cos that's important too.

Roxy-Perfume: That's the city at night.

Mary Shaw: [Our city] has lots of boats and stuff so we wanted to show that.

Bob: And that's [city] cos I just thought that it was quite cool. You can't see my house.

Figure 6.19 "We'd miss the sunsets in [our city]"

Photographer: Mequity X (14)

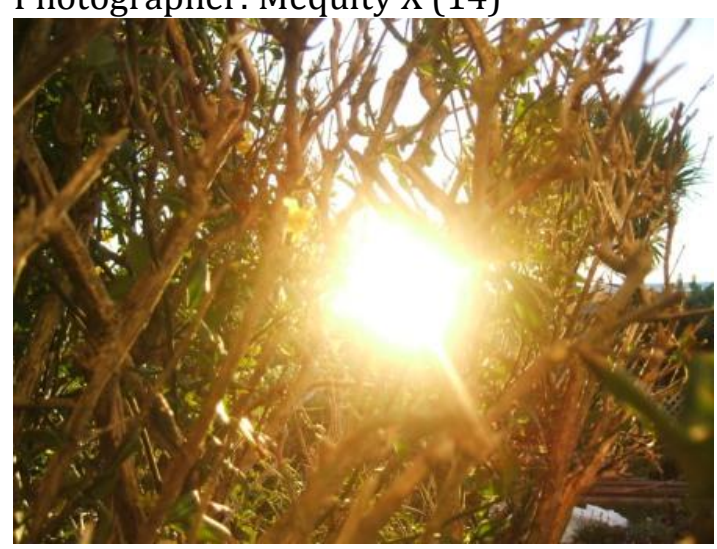

Figure 6.20 "That's the city at night" Photographer: Roxy-Perfume (14)

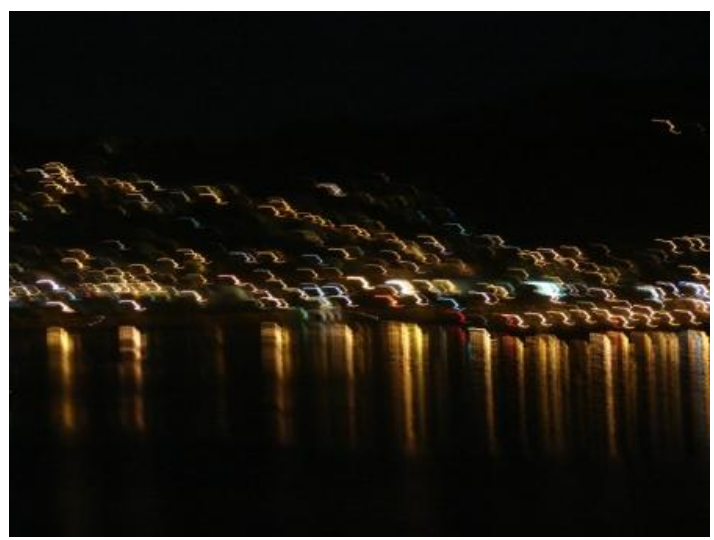

The sense of place conveyed in the quotes above is made in reference to the wider city and on only two occasions during my research did participants refer to their local suburb. Participants from this school did still exhibit a sense of identification with their immediate home/neighbourhood (see Saphira and Mequity X's photos Figures 6.1 and 6.2). However, it appeared that their daily movement into the central city to attend College $\mathrm{D}$, and their ability to access 
public transport from the suburbs to the city broadened their perception of place to a wider vision beyond their immediate suburb.

This impression was also heightened by their references to many civic places, the majority of which were in the inner city, such as the museum, a central city square, and a public mall. These appeared to frame their perceptions of their place as well as give them a sense of pride. One group photographed an inner city direction board showing directions to a number of inner city civic sites and commented, "[that shows] all the places - cos there's lots of cool places in [city]." (Azure, 14, female). Roxy-perfume (14) took a photo of some civic art as it had been recently altered and "some of the boxes are gone missing. So I took a picture of them cos they're missing. Perhaps someone stole them." Her attention to this public art indicated her awareness of it and its presence in her sense of place.

Another aspect of their place raised by the participants was the relative levels of freedom they experienced. When I asked the class to reflect on what it was like growing up in their city, members of the class discussed issues of rules, safety and freedom (all 14, female):

Azure: It's sort of a changing every day around you. Like when you first started growing up in [city] things were different and there weren't as many laws put in place and stuff. And now every day there's more rules and you can't do this like the alcohol ban in [a central city] Street.

Roxy-perfume: It feels really kind of free. Cos you know it's just so near everything - you've got beaches and mountain tracks and the city and the rules and laws people were talking about gives you kind of safe feel so if you do go out, you're ok.

Jenny: Also, we have free speech and stuff and most people, I guess, have education, so most people go to school so that contributes to the whole feel of [city].

Interestingly, while Azure found the new alcohol ban restrictive, Roxy-perfume saw this as a way of ensuring their safety. 


\section{Reported issues of importance at College D}

All participants in the café style focus groups at College D reported that environmental issues were important. In particular, they noted that global warming (5/5), issues of environmental diversity (such as decreasing biodiversity and resources) (5/5) and water conservation (4/5) were especially important. The participants from College D (all female) also had higher rates of reporting of issues related to health and wellbeing than other co-ed schools (such as anorexia and obesity (2/5), teen pregnancies (2/5) and suicide (1/5) and mental health (1/5) - issues which may have a gendered explanation.

Many of their reported issues of importance corresponded closely with the topic currently being studied - the management, conservation and use of water and water issues at a global, national and then local level (see Appendix R) and was reflected in related issues such as sustainability and biodiversity. The reported issues of slavery [1/5], racism [4/5] and prejudice [1/5] may also have reflected the topic of human rights and child labour studied in the previous term. College D also had higher reporting of war [2/5] than participants from College B and C. The following keyhole narrative revisits the theme of "being kind of free" (Roxyperfume) which was reflected in the spatial practices of everyday life, in their patterns of home to school travel.

\section{"It's like our place - and it's quite important to us"}

This "freedom of the city" theme can be seen in participants' patterns of mobility as well as in the social issues that were drawn to their attention as part of their everyday experiences of the urban environment, and reflected their economic, social and cultural capital. For one group of young females in the class, this freedom also included claiming a spot in the inner city most week-ends as their own (Figure 6.21). Mequity X, Angelican and Capt. Quark describe this place to members of the class during the Photovoice debrief:

Student: It's an actual homeless person?

Mequity X: It's a really bad photo. No, it's just cos, me and my mates go to [central city] cinema all the time and we've got this one particular spot [there] that no one else goes, and we sit there every week and it's like our place - and that's quite important to us.

Bron: So it's you guys [in the photo]? 
Mequity X: It's us. I swear I've never seen anyone else sit there ever. It's in the corner.... it's hard to explain where it is...

Bron: Yeah. So it's a place where you hang out and you know it really well and its part of who you are kind of...?

Mequity X: Yeah. And they let you sit there if you buy something.

Mequity X pointed out the other friends in her class who meet each week in this designated place, stating "That photo was friends - that was us" (Figure 6.22).

Figure 6.21: "It's our place"

Photographer Mequity X (14)

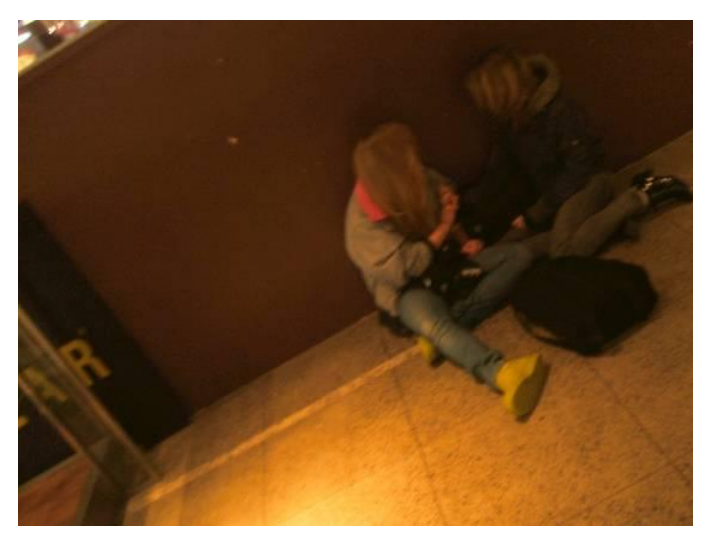

Figure 6.22: "That was friends - that was us" Photographer: Mequity X (14)

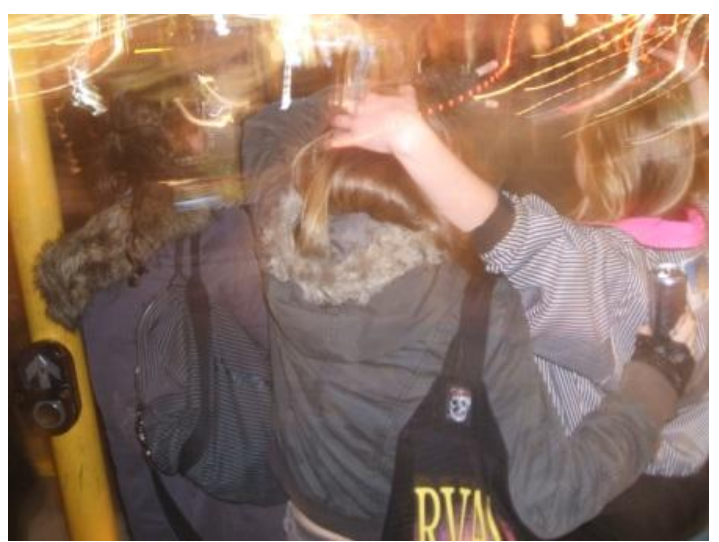

The reclaiming of spaces for the purpose of young people's use in the city has been a source of interest to many researchers (Hil \& Bessant, 1999; Matthews, et al., 1998; Skelton, 2000; F. Smith, 1998). In this example, Mequity X and her friends describe how this place where they hang out is vested with meaning and identity for them as a group of friends. As Mequity X says, “...it's like our place and that is quite important to us."

The experience these participants describe of freedom in the city, and their experiences on public transport also appeared to influence the issues that they noticed. For example, Azure, Mary Shaw, Jay Jazz and Zaze (all 14, female) photographed a bus timetable, "cos we were trying to make a statement they're always late." Dog (14, female) describes the issues which concern her on her daily commute on public transport between her suburb and the city. For example, she draws attention to the neglected environment around the station and states "Those are the train tracks - public transport and how people use it to 
get to places. But as you can tell it's quite disgusting. All overgrown, and people just dump stuff." She photographed a beer bottle (Figure 6.23) and commented:

There's only one beer bottle there now but the other day there was about two 12 packs all just dumped at the stairs of our train station. One bottle is right next to one of those electricity poles and if there was a crack and the beer or something got in it'd probably kill the electricity for [this suburb]. (Dog)

Figure 6.23: "Only one beer bottle there now..."

Photographer: Dog, 14, female

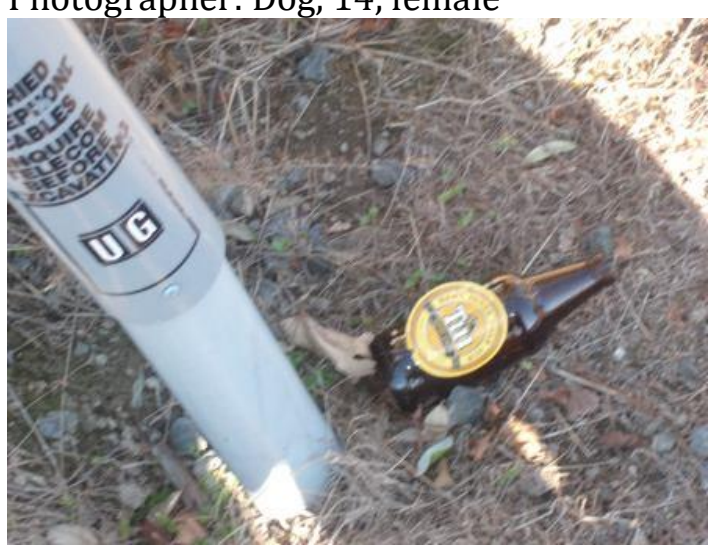

Figure 6.24: "It seems like scungy!"

Photographers: Dog, Quirke'n'ater, Saphira, Jimbo and Cheeky (14, female)

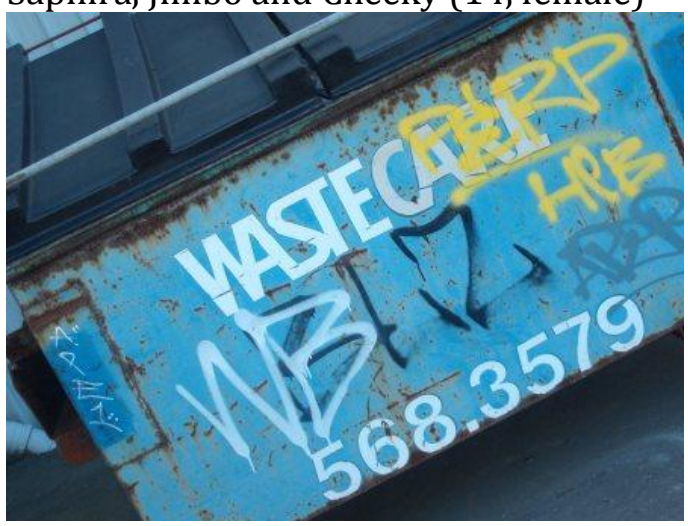

A number of groups also took photos of tagging and rubbish around the city's civic places to show that these issues were "not cool" (Azure, 15, female) (Figure 6.23 and 6.24). Dog explained that while the tagging in Figure 6.24 doesn't reflect her suburb as a whole, it is an issue that needs addressing as it ruins her feelings of pride and safety in her neighbourhood:

Dog: That one - all round my suburb, the way I'm describing it, it seems like...scungy! It's really not. If you look for it you'll find it, but pretty much just wherever people can, they graffiti. It's a rubbish bin and people find the need to graffiti! I don't like graffiti. I think it ruins everything. Bron: How does it make you feel about the place where you live then? Dog: It kind of makes it feel dirty and kind of unsafe in a way 'cos you're like...

Bron: ...not proud of it?

Dog: Yeah.

By way of contrast to this negative image of her community, Dog's group went on to photograph a local school playground which had been "built with community help - with their money and stuff, fund raising." They also photographed a local man with a mower who "doesn't get paid, he just comes and mows the school lawns." Her group's attention to the voluntary actions of 
many in her community is also indicative of the nature of their "citizenship imaginations" at play which was drawing attention to the quiet and often overlooked actions of citizens in their neighbourhood that contributed to the well being of others.

\section{Noticing issues in "our place"}

Contrary to some conceptions of young people as disinterested, disaffected and apathetic, young people in this study did notice social issues. Moreover, the findings presented in the keyhole narratives in particular highlight how young people not only noticed social issues, but were also developing opinions and perspectives about them. The issues youth participants from the 29 focus groups across all the four sites identified to be important showed a high degree of commonalities in light of the open-ended nature of the research activity and the variable geographic communities that the participants represented (see Table $6.2)$.

Table 6.2: Most commonly reported "important issues" in Colleges A-D

\begin{tabular}{|c|c|c|c|c|c|c|}
\hline & \multirow[b]{2}{*}{ Nature of issues } & \multicolumn{4}{|c|}{ No. of focus groups mentioning these issues } & \multirow{2}{*}{$\begin{array}{c}\text { TOTALS } \\
\text { FG }=29 \\
n=120\end{array}$} \\
\hline & & $\begin{array}{c}\text { College A } \\
\mathrm{FG}=16 ; \\
(n=57)\end{array}$ & $\begin{array}{c}\text { College B } \\
\text { FG = 2; } \\
(n=8)\end{array}$ & $\begin{array}{c}\text { College C } \\
\mathrm{FG}=6 ; \\
(n=29)\end{array}$ & $\begin{array}{c}\text { College D } \\
\text { FG }=5 ; \\
(n=26)\end{array}$ & \\
\hline \multirow{4}{*}{ 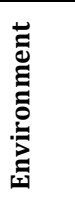 } & Climate change & 7 & 2 & 3 & 5 & 17 \\
\hline & Environment sustainability & 9 & 0 & 1 & 5 & 15 \\
\hline & Pollution & 6 & 1 & 2 & 4 & 13 \\
\hline & Littering & 5 & 0 & 5 & 0 & 10 \\
\hline \multirow{4}{*}{ 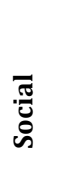 } & Family violence & 6 & 1 & 2 & 1 & 8 \\
\hline & Child abuse & 4 & 1 & 2 & 0 & 7 \\
\hline & Crime (e.g. burglary) & 2 & 1 & 2 & 3 & 8 \\
\hline & War & 7 & 0 & 0 & 2 & 9 \\
\hline \multirow{2}{*}{ 密 } & Racism & 9 & 1 & 0 & 4 & 14 \\
\hline & Bullying & 8 & 1 & 2 & 2 & 13 \\
\hline : & Corrupt government & 4 & 0 & 2 & 1 & 7 \\
\hline \multirow{3}{*}{ 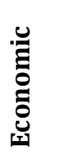 } & Economic Recession & 6 & 2 & 1 & 3 & 12 \\
\hline & Poverty & 7 & 1 & 0 & 2 & 10 \\
\hline & Unemployment & 5 & 1 & 3 & 0 & 8 \\
\hline \multirow{4}{*}{ 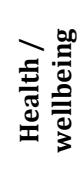 } & Alcohol abuse & 11 & 2 & 2 & 3 & 17 \\
\hline & Drug abuse & 9 & 2 & 3 & 3 & 17 \\
\hline & Smoking & 6 & 0 & 1 & 1 & 8 \\
\hline & Teen pregnancies & 1 & 2 & 2 & 2 & 6 \\
\hline
\end{tabular}


In examining Table 6.2, I want to draw attention to three themes that highlight the socio-historical and temporal nature of young people's perceived issues of importance. The first way this is highlighted is in the prevalence of issues related to the environment. Over half of the youth participants described climate change/global warming (17/29) as an important issue, and issues of environmental sustainability (15/29), pollution (13/29) and littering (10/29) similarly had high rates of reporting across schools. These findings are in keeping with other studies in Australia (for example, Harris \& Wyn, 2010; Sargeant, 2008), in England (Holden, et al., 2008), although in the United States there is some evidence of a decline in environmental awareness of young people in the past thirty years (Wray-Lake, Flanagan, \& Osgood, 2010). College A and D had examined environmental issues (climate change and water conservation) during their social studies programme and I would suggest this influenced findings in these schools.

Second, the high level of reporting of the economic recession in all schools $(12 / 29)$ is notable. If we take the bankruptcy of the Lehman Brothers on September 15, 2008 as an indicator of the outset of the global economic recession (although there are indicators of financial crisis before this), then my research in schools collection (from October 2008 to October 2009) took place at a time when media discussions about the recession were at a peak. This highlights the potentially transient and temporal nature of many perceived issues of significance. It also illustrates the importance of considering contextual factors and contemporary events when examining perceptions of important issues (Holden, et al., 2008; Warrick, 2008). An avenue for further research would be to consider where young people gained their sources of information about these issues.

Third, a significant number of issues that were reported to be important were youth-related issues. These included social issues such as alcohol and drug abuse (both 17/29), bullying (13/29), smoking (8/29) and teen pregnancies (6/29). While many of these issues could just as easily be described as "adult" issues, 
participants framed them as specific youth issues. For example, alcohol abuse was generally described as underage drinking or illegal drinking:

Alcohol. It's a big problem in [our town]. Heaps of underage drinking. It's kind of the thing to do in [our town]. It's 'cool'. (Pete, 14, female, College C)

I took a photo of these alcohols. I reckon its rubbish, like youth, young people drinking cos sometimes alcohol can be too cheap. (Bubbly gurl, 16, female, College B)

That's alcohol. Too easy to access. It's [an advertisement] on the window of our corner store. Buzz Lightyear, 14, female, College A)

The statements illustrate how young people often have a youth perspective on social issues, and that these perspectives reflect the levels of adult regulation which are part of their everyday experiences.

The findings reported in Table 6.2 point toward some interesting collective trends of young people in my research; however they also mask many of the significant differences within and between schools. These differences became more apparent in the keyhole narratives presented in this chapter, and through these narratives of imagined possibilities for change, we could gain a sense of young people’s citizenship dispositions.

\section{Citizenship imaginations in "our place"}

The findings presented in this chapter suggest that gaining an understanding of young people's sense of belonging to places and experiences in communities and schooling provides many new insights into why they viewed certain issues as "important." In the keyhole narratives from College B, C and D, young people expressed a sense of shame in the way their neighbourhoods appear.

Discussions about air pollution by participants from College A illustrated their disappointment in an issue that marred their preferred image of their city (the sun, the Bay, the mountains and beach). However, the insistence by A.S that air pollution was now "OK...cos they've done all that work," highlights how young people's perceptions and opinions were being shaped by their own knowledge and observations of air pollution, as well as a sense of agency derived from being 
part of the solution (see Figure 6.8). The keyhole narrative from College B exposed a sense of shame in the tagging in their neighbourhood which made it look very "naughty," "ugly," and "bad." This impression stood in stark contrast to their experience of this community as one of belonging and cultural pride. This was an issue which fuelled Bubbly gurl and other's desire to see change.

Many of the issues selected by young people to be important also reflected their everyday patterns of spatial mobility within their places. Experiences of inadequate public transport (College $\mathrm{C}$ ) and neglected public transport corridors (College D) illustrate how personal experiences fuelled an interest and stance on certain social issues. The spatial narratives of the participants at College D illustrated a sense of responsibility and concern over many places that otherwise could be regarded as "placeless spaces" (Relph, 1976), such as railway lines and rubbish bins in their neighbourhood. The scale of young people's spatial practices described here reflected their geographies of education which rely heavily on public and parental transport, and are still heavily demarcated within space (Harris \& Wyn, 2009; Skelton \& Valentine, 1998). For example, the descriptions of sites and landscapes by participants from College B were bounded by a walking distance (about a $5 \mathrm{~km}$ radius) of their school. In sharp contrast, the spatial practices of participants at College D operated to distances as far away as 15 kilometres from the school. Yet, young people were not passive in their experience of place and space. The keyhole narrative from College D illustrates how young people were carving out a space for themselves in the context of the "adult city" (R. White, 1996).

These findings appear to confirm Harris and Wyn's (2009) finding that "the meaningfulness of issues were very much connected to local environments and immediate experiences" (p. 339) and that "political and social issues took on greater meaning when interpreted through local experiences" (p. 335). At the start of the chapter I suggested that we could gain a sense of young people's sense of belonging to places by examining their spatial narratives and spatial practices. Through the spatial narratives and spatial practices outlined here, I argue that we also begin to get a sense of young people's "citizenship 
imaginations" at play - observing, caring, taking a critical position and (re)imagining social issues with the aim of "shaping the society we want to live in" (Vromen, 2003, p. 83).

Access to cultural capital appeared to be a significant factor in shaping young people's perceptions of important issues. In three out of the four schools, the topics that students were studying in social studies appeared to be influential in shaping participants' perceptions of important issues (see Appendices O-R). The school with the lowest concordance between social studies topics studied and issues noted to be important was College C. However, this school had high levels of concordance with issues that had been studied as part of the Community Issues programme. It would appear that exposing young people to specific social issues, raised students' awareness of those issues, and the degree to which they were considered "important".

It was also apparent that there were differences between and within the school sites in the nature and focus of reported important issues which reflected the degree to which issues of perceived importance were local or global. Older teens were generally more likely to report "global" issues. This was most apparent in the Year 12 and 13 participants from College A, who predominantly listed global issues over local. For example, seven out of eight focus groups of older teens at College A stated that war and conflict were important issues. In comparison, only four out of 19 focus groups of younger teens at Colleges A, C and D (all Year 10) reported that war or conflict were important issues (Table 6.2). Younger teens tended to report more personally significant issues related to health and wellbeing such as smoking (7/19), obesity (4/19), and truancy (3/19). These issues were not mentioned once by older teens.

The trend toward expanding perceptions of issues as young people grow older has also been found in a number of other studies (Buckingham, 2000; Gill \& Howard, 2009; Sargeant, 2008). However, this generalisation didn't hold for the older teens from the Decile 1 school, College B, who tended to have a much more locally-focussed conception of important issues which centred on issues such as 
youth leaving school without qualifications, teen pregnancy and alcohol abuse. Here an alternative explanation other than age could be operating, the powerful influences of habitus, social and cultural capital, and field. In Chapter 8, I will explore this in greater depth and consider how the cultural and social capital of these young people's teachers and communities could provide an explanation for their patterns of citizenship awareness, dispositions and actions. In the next chapter I turn to an examination of young people's definitions and practices of social action in the context of their everyday lived experiences and schooling. 


\section{CHAPTER 7: \\ DEFINING AND PARTICIPATING IN FORMAL AND INFORMAL CITIZENSHIP SPACES}

As stated in the introduction, one of the central propositions of my research was that we need to hear from young people themselves about how they define and participate as citizens in society. Previous research in this area has revealed that New Zealand young people rarely joined formal political, human rights or environmental organisations, but partook in many voluntary activities in the community such as collecting money for a cause (Schulz, et al., 2010) (see Chapter 2). It was my intention to provide participants in my research opportunities to move beyond these examples of participation, and to include more "generous" (Hall, et al., 1999), informal and everyday conceptions of citizenship (Lister, 2007a). In this chapter I employ a "spatiality of participation" (Weller, 2009) approach to draw attention to the less visible sites of everyday and local action in particular (Harris, et al., 2007; Marsh, et al., 2007). Building on the findings described in Chapter 6, I continue to explore how place-based, personal and everyday experiences of young people shape their definitions and participation in social action. I also examine the "barriers" to social action that young people identify as restricting and constraining their ability to participate as citizens.

\section{A spatiality of participation analysis}

Susie Weller (2009) suggests that a focus on the spatiality of participation in schools highlights the ways in which "inclusion in, and exclusion from participation in decision-making within schools is manifested spatially, as well as, the alternative and often hidden understandings and acts of citizenship and participation in which many teenagers engage" (p. 3). In this chapter I examine the spatiality of participation of young people in each of the four schools by considering three "sites" of participation. The first site of participation that I 
focus on is school-based participation. This includes opportunities specifically made available to students through their social studies programmes, but also school-wide opportunities for cultural and social volunteering, fundraising and participation (see Table 5.2). Many of these have already been discussed by the teachers of these students (Chapter 5), and in this chapter I examine these opportunities from the students' perspectives. A second site where young people provided examples of participation was through formal organisations in their own communities. These examples included participation in church and community organisations such as the SPCA. The third area included informal actions taken by young people in the domestic and everyday sites occupied by friends and family. These sites were harder to categorise, and included homes, neighbourhoods, school classrooms, playgrounds and even toilets!

\section{College A}

Participants at College A were familiar with the concept of social action and were quick to provide definitions of it:

Taking actions to address a social issue. (Year 13)

Working to change an issue that affects society. (Year 13)

Taking a stance against social problems. (Year 10)

Doing and trying to make a change in your social community. (Year 10)

When people work together to achieve something. Solve a problem. (Year 10)

These definitions highlighted a "problem-solving" approach to social issues and "social problems." The teachers from College A had described a wide range of social action opportunities that they provided for their students (Chapter 5). It was notable that the participants at College $A(n=57)$ cited many of these opportunities as their own examples of social action. This was the case for older teens (Years 12 and 13) in particular. For example, while working on a social studies unit called "Making a difference," Year 12 students had found out about 
the "Stand up: Take action campaign."52 The class decided they would lead a "stand up" campaign for their school at their senior assembly. Two members of this class presented some statistics about global poverty and then played a DVD clip and asked members of the assembly to "stand up" for the final minute. They described how amazed they were when "the whole school stood in a silent, spontaneous movement. It was awesome! We were blown away by the response"' (Teacher A1, College A, Field notes).

Year 12 College A participants described how they had sold friendship bracelets to raise money for Voluntary Services Abroad and worked together to get food for the food banks in their city (in response to their social studies unit on global poverty):

Shan: We gathered food for the food banks in [our city] as they were so low in stock this year. We made stickers and we went around and put them on students and when they arrived at school we were standing to collect their food. We got 15 boxes for the Floodbank. (17, female)

In late 2007, Teacher A had led a trip to a majority world country for 15 of her social studies students in response to their global citizenship focus in social studies. Two participants in my research, Bella (16, female) and Tae Woo Bang $(16$, male) had gone on this trip and gave examples of what they had done to take 'social action' during this experience:

We visited lots of schools and orphanages and spoke English with the kids. We took orphan kids swimming in [country] - is that social action? Some had togs, others had clothes on. (Bella, 18, female)

We did fundraising before we went and every place we donated some funds to them. We had raised about $\$ 1000$. [...] We also built a small bamboo house for a family of six. (Tae Woo Bang, 16, male).

They commented that it had...

... opened up our eyes...and made me want to go back and help in another Third world country. (Tae Woo Bang, 16, male)

The Year 12 and 13 participants recognised that their school ethos celebrated many such opportunities for student participation:

52 The Stand Up and Take Action campaign is a UN Millennium initiative supporting citizenship efforts to hold their governments accountable in order to achieve the Millennium Development Goals. 
Mind you, this school has it good with the [overseas] trip and things went well with that - they had great fun. (IT Master, 18, male)

The school is actually quite open-minded to a number of ideas and gets stuck in and supports it. (Student, Year 13)

Younger teen participants at College A (Year 10, 14-year olds) had fewer examples of school-related social action. Their most common social actions examples included planting trees (4/8), recycling (4/8) and fundraising (3/8) which had occurred through organised programmes (such as tree planting and a school mufti day 53 to raise money for children in Tanzania). Similarly, younger teens had only a few examples of community-related participation in social action. Joey Tribbiani (14, male) had done volunteer work at the SPCA, "but they don't need me now." And Pac Man (14, male) had made an environmental video with an organisation which he stated "wasn't really proving anything."

In contrast, a couple of older teens from College A described strong commitments to participation in community-organisations. Hip Hop Potamas (17, female), had been part of a youth-led environmental group with two of her friends (same aged females) since the age of 14. Their goal was to reduce the use of plastic in their city by $20 \%$. I asked her to elaborate on what she had written on her poster about a "plastic - not so fantastic" campaign.

Hip Hop Potomas: We started off small, raising awareness with young children and adults. [...] So we did things like painting ecobags, gave out free ecobags, told people more about them. We decided promoting ecobags was more positive than just banning plastic bags. [Then] this year we did an Eco Bag Month. So we got every supermarket in X-Town to do benefits for people who use ecobags for a month. So every time you spent over ten items, you got one free ecobags, and every time you use your ecobags, your local school got into the draw to win $\$ 500$. And that was backed by supermarkets and managers and the Council.

Bron: So they really liked the idea?

Hip Hop Potomas: Yeah. It actually took years to get that involved. We started off having a ten cent levy - and that went really badly.[...] Nothing we said could change them...so we decided we could work on a benefits scheme. Since then we've had meetings with the Council and other groups around, and they've decided that they do want to do a levy on plastic bags. The district Council will be backing us.

\footnotetext{
${ }^{53}$ Mufti day - a New Zealand term for a day students are allowed to attend school in casual clothes, not the school uniform.
} 
The actions of Hop-Hop-Potamas and her friends over Ecobag month reduced the turnover of plastic bags in local supermarkets by 48000 . They had won international recognition and awards for their work to promote environmental change in their city (field notes, October, 2008). Hip Hop Potomus went on to describe how she drew on her experience to support the Environmental Committee at College A. She describes how they "worked on publicity and did the same kind of things that [her teen-initiated environment group] did." The Environmental Committee had subsequently grown from ten members to forty and had recently had been given $\$ 3000$ of funding that year from the school to support their work (Field notes, October, 2008).

IT Master (18, male) also described his responsibilities as a youth representative on the local Council:

We just done a whole lot of consultancy work and we've had a major event of ours in the [local] area. We've been working closely with the other local Councils to see what we can do next year as part of more events for youth to get involved in instead of this whole "boredom" as I've heard from many people.

Claire (18, female) also did voluntary work for a church-related childcare programme with children largely from single parent families or abusive families. She also helped out in running a youth group "to get people out of doing nothing." Many of these older teens showed a keen interest in politics, and five (aged 18) were able to vote in the upcoming national elections in late 2008. However, many also showed a cynicism about the political process, such as in a discussion about not signing petitions because "petitions don't do jack...they don't listen to them" (IT Master, 18, male). Others showed a distrust of politicians, such as the statement by Inky Pinky Ponky (17, female):

I don't believe that anybody who's trying to be our government right now is worthy enough to be our government.

While the main focus of these older teens at College A was on examples of social action that could be described as "formal" (see Chapter 2), Claire advocated for examples of social action that didn't "have to be anything big... it can just be small things that we do...it doesn't have to be huge things." These comments 
were made to her focus group to encourage Wonder woman (17, female) to contribute:

Claire [to Wonder Woman]: What have you done?

Wonder woman: [I've done] nothing really great.

Claire: It doesn't have to be anything big. It can be like giving a couple of bucks to charity.

Wonder woman: Oh yeah. I coach different teams and things. That's a social action.

Claire: That's cool. It's helping encourage kids to fulfil their potential.

ET (18, male) also expressed a similar sentiment in his café-style focus group when another participant had defined social action as "when people take action over social issues." He responded by stating "actually I think that social action is also when you start caring about social issues."

These participants gave a few other examples of informal actions they had taken specifically to address a cause. Allie (17, female) described boycotts she undertook to address her ethical concerns with battery chickens and the soft drink industry. She had stopped drinking coca cola products...

I try not to anyway. Because Coca Cola is bad. But everything is made by Coke...Powerade, Me2, Sprite, Fanta. And I also don't eat chicken. Because chickens are battery farmed and I don't like that.

Shan (17, female) described how she was "supporting a cause through clothing...like wearing a bandana [...] people look at it and say 'that's right, that's the Canteen thing that saves little kiddies with cancer."' A number of young people referred to actions they took on their social networking sites to support a cause, and Happy-go-lucky (14, female, College A), described how she found the internet a significant way for young people to communicate:

People use the Internet to make a difference towards different causes. That makes sure that we can have a say in the world. The internet can often be our only source of letting out because people find it hard to speak out around other people.

Younger teens had many more examples of social action that could be described as informal - in the context of their friends, families and neighbourhoods. In particular, they showed that they were interested in taking action to address the issues of bullying in particular (identified as important by five out of eight focus groups). For example, R Mohammed T (14, male) recorded one of his social 
actions to be that he had "worn a pink top on that Pink Shirt day"...and in doing so "I gave people hope that were being bullied." ${ }^{4}$ EE $(14$, female) gave an example of how she had taken social action by "going to the principal when someone was being bullied." A group of 14 year-old boys also discussed bullying, with Joey Tribianni stating, "I've stood up for friends." TC and Rodney Hyde, (both 14, females) called me over to ask if their actions toward a fellow student could count as 'social action':

There's this guy called [Darren] and he's got heaps of learning difficulties and basically he has no friends and gets teased and bullied a lot. So, every lunch time we find him and invite him to hang out with us so that they can't tease him. Do you think that is social action?

I encouraged them to record this on their poster, and they wrote as an example of social action "Hanging out with loners and stopping a bully."

In keeping with the theme identified in Chapter 6, younger participants at College A in particular identified a number of "barriers" to their participation that centred on the stereotypes of young people in their city. Eight of 12 focus groups stated that "society's perception of young people," "not being taken seriously" or "our status in society since we're younger" was a barrier to their participation in social action. Shan (16, female) (along with 6/12 groups) identified that exposure to knowledge was also a barrier:

We are constrained by what we are taught, as to the type of issues we focus on and the way to take action.

In the following narrative ("I'm just saying it's a stereotype"), I take a closer look at these participants' responses toward the issue of racism through an incident which occurred when I was conducting research in the classroom. I share this narrative as an example of how young people are establishing themselves as active citizens in response to the highly charged issue of racism. This discussion exposes the sensitive and complex territory which one enters when raising

\footnotetext{
54 Year 10 participants described this day for me:

EE: It started in America.

Bat boy: Like there was a guy whose friend was being bullied, so he said, "hey everybody wear a pink shirt tomorrow" and they did.

EE: ...and the guy came to school and saw all these pink shirts and felt a lot better.
} 
many social issues, and also highlights the active way these young people deal with conflict and disagreement in ways more courageous than many adults.

\section{“I'm just saying it's a stereotype"}

Racism was identified as an important issue by four out of eight focus groups of younger teens at College A. TC (14, female) had identified that the most important issue she felt that needed addressing was racism:

'Cos everyone is sometimes mean to the black people. Cos they're black.

When I was conducting the first café-style focus groups with this class, a heated exchange took place between Blinky, A.S. and Jazzie in one focus group and TC and Rodney Hyde (all 14-year-old females) in another. ${ }^{55}$ The exchange began when Blinky's group stated:

Blinky: I don't know if this is racist or not, but Māoris are an issue...

A.S Yes, Māoris are...

Blinky: ...Māoris are generally seen as violent...

A.S.: because of their socio-economic status.

At this stage, TC, in the neighbouring café-style focus groups, overhears this comment and yells out "Real? Oh racist! That is very racist." The following exchange between TC and Blinky and their groups ensues:

Blinky: It's a generalisation, or a stereotype or whatever you want to call it. A.S.: A generalisation or a stereotype.

TC: Oh! (disgust)

Blinky: But Māoris, a lot of people see them as, you know, that sort of thing, so they think they should carry out that.

Rodney Hyde: But do you believe that or are you saying it's bad?

Blinky: I'm just saying that it's bad.

TC: Well, what about Māoris - they're bad?

Blinky: NO! No! More like they're generally looked down on to be like smokers and non-workers, but they could change and make us not look at them like that.

A.S.: You're making it worse. Stop it.

Blinky: It's hard to explain. It's just a stereotype...

The tone of the whole discussion changed quickly when Rodney Hyde, TC's friend, reveals that TC is in fact Māori56 - a fact unknown to anyone in the class:

Rodney Hyde: TC's half Māori, she doesn't smoke or do drugs...she's not poor, she's rich as!

\footnotetext{
${ }^{55}$ Teacher A was out of the room supervising the other half of the class at this time.

56 On the biographical data card for this study, TC had self-identified her ethnicity as "New

Zealand."
} 
Blinky: Are you? Is that why you're brown?

TC: [laughs] I'm not rich.

Rodney Hyde: Her mum's from Canada.

Blinky: So you half Māori?

TC: Yeah.

Student in background: I told you that.

Blinky: I thought with your name you'd be French or something like that.

Student: Oh it is. French Canadian?

Rodney Hyde: She's French Canadian and Māori aren't you?

TC: Yup.

Blinky: That's so cool. [...]

A.S.: So that's why she taking offence.

Blinky: I'm sorry TC.

TC: I'm never going to talk to you again [said with a smile in voice - all laugh].

The delicate area of generalisations, stereotypes and racism is an issue that many adults also struggle to explain and the discussion between these two groups highlights how easily statements can be misinterpreted and misunderstood. What was interesting to me, was that the personal information about TC's identity as Maori/French Canadian appeared to shift the discussion from a conversation about a distant "other" social group, to focus on the immediate presence of a young woman who is part of this class, thus exploding the stereotypes raised earlier.

At the end of class, Blinky and TC left together to go to orchestra practice with no apparent hard feelings following the interchange that had occurred during this lesson. However, a final conversation was captured on the audio between TC and Rodney Hyde that showed a bit more of TC's personal response to the issue of racism:

Rodney Hyde: (quietly) Does it actually hurt your feelings when people make comments about Māoris?

TC: Oh not really. [mumbles] I'm used to it.

Rodney Hyde: But does it still like hurt your feelings a little bit?

TC: Yeah.

Rodney Hyde: Yeah.

During the Photovoice activity a few weeks later, TC followed up on this theme by taking a photo to represent racism (Figure 7.1). While the photo was dark and difficult to see, she had obviously gone to some effort to capture this image. She identified once again during the Photovoice debrief that racism was the most important issue needing addressing in her place and highlighted this 
further with a photo of a lone student walking toward school in the morning

(Figure 7.2). One thing she said that she valued was that "people can be themselves - and not be judged." Her actions, relayed earlier about inviting a "loner" to hang out with her and Rodney Hyde at lunch time, speaks volumes about her personal commitment to work toward acceptance of all people in her school and community.

Figure 7.1: "Racism"

Photographer: TC, 14, female
Figure 7.2: "People can be themselves - and not be judged"

Photographer: TC, 14, female
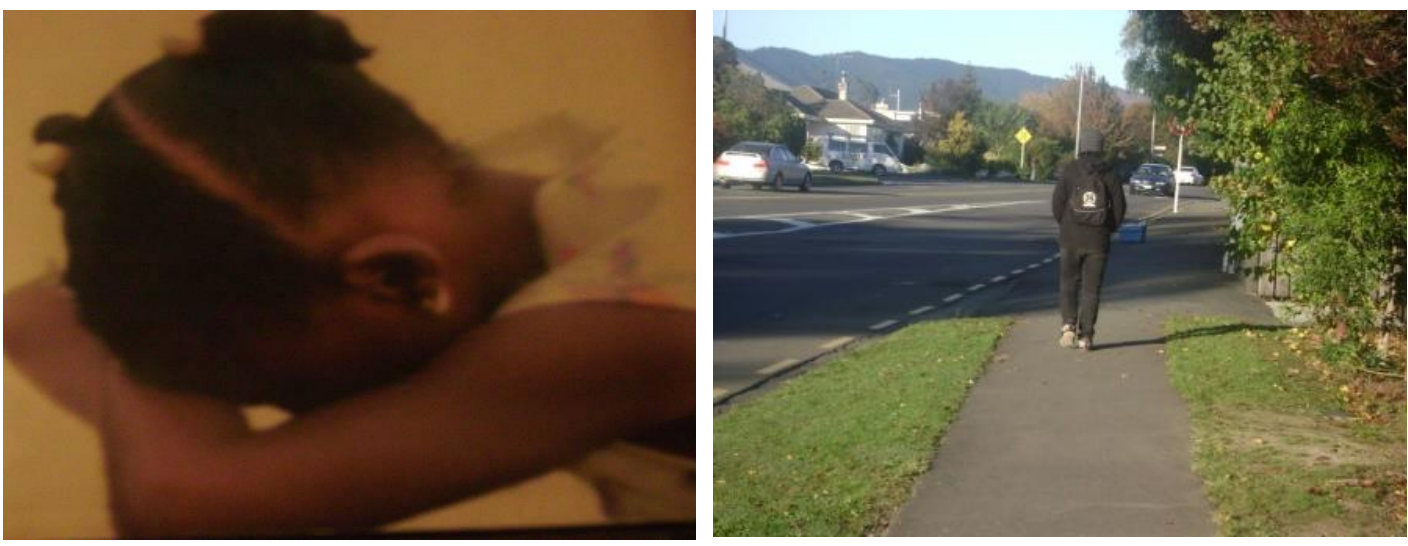

\section{College B}

The importance of family, cultural groups and the local community to participants from College B has already been highlighted by both teacher and youth participants in Chapters 5 and 6. For example, the teachers' description of whanaungatanga, in which participation is placed within familial, friendship or reciprocal relationships, was reinforced by the youth participants' descriptions of their community, "like a Pacific community - everyone just gets along" (Bubbly gurl). Definitions of social action described by youth participants from this school mirrored these community-focused themes further, with close links made between social action and community service:

Actions taken by the community, or individuals to help improve our social lives.

The community working together to solve the issues affecting the community.

It's like a community working together. 
Participants at College B didn't refer to any specific social studies-related examples of social action; however, they spoke of a number of school-based opportunities for leadership and participation within the school. For example, when participants were discussing what they could do about the issue of alcohol and drug abuse for young people in their school community, the Student Council featured highly in their proposed plan:

Smoove Cullen: Maybe we could go through the Student Council meeting to organise a place where people who have drinking problems - you know how people who have smoking problem go to meet. $(17$, female)

Emmett Cullen: [We could take it to the] Student Council - like, discuss the ways students can help other students out on drugs. (15, female)

Members of this class were perhaps more aware of the Student Council than some students as three students out of ten had leadership roles on the Student Council or Board of Trustees. Participants also gave examples of raising money for the World Vision Fundraiser 40 Hour Famine by holding a mufti day at College B. Attending school was given as an example of social action to address the issue of students leaving school without qualifications: "for us kids in education, we come to school to learn and get qualifications" (Doodlebop, 16, female).

Most examples of social action for participants at College B related to community participation, and in particular, involvement in social action through their local churches. In this capacity, participants at College B gave examples of visiting and helping the elderly in the church, cleaning up the stadium and selling sausages to raise funds for the church. Doodlebop had undertaken to "fast" and avoid products such as caffeine, drugs and alcohol as part of her church participation. The church was also a place where many young people had leadership roles and responsibilities, such as lead singer for the church band (Bubbly gurl), secretary for the young women (Doodlebop), and playing the piano and doing services for the elderly with the youth group (Emmett Cullen).

One of the examples of everyday social action that participants from College B gave, was how "socialising" can be a way to address cultural and status differences: 
Doodlebop: And we (um), we make friends with others that are not the same colour or culture as us. (16, female)

Smoove Cullen: Oh true - so having that special bond... (16, Female)

Doodlebop: Socialising with cultures...different cultures, social

status...socialising with different race and social status.

Bron: Can you elaborate on that - why is socialising important for social action?

Emmett Cullen: 'Cos it's social! Social is like, mingling and getting to know other people. And, so that we can get a fair idea of what it's like to be from their culture and how they're treated.

The friendship actions that Smoove Cullen, Doodlebop and Emmett Cullen describe demonstrate how the actions they take reflect their desire to have a warm and accepting community. Similarly, access to state-provided education and welfare was seen to be an important way of promoting equality:

Bubbly gurl: Yes, because not all of us young people are the same. And you know, as always there will be some who will, you know, make it on top and some that still...so I think that society, for example, take [a local technical college], I think that helps those other young people. Just to get everyone equal. That's the main thing.

Doodlebop: And plus, they may not have all the things that they need but they still need the support of society to be able to "make it."

This conversation is evocative of a kind of community which looked out for all members, their differing talents, abilities and struggles, and endeavoured to create a more level playing field, "to get everyone equal." Participants at this school identified that "put downs," "lack of resources" and "fears of community disapproval" were potential barriers to taking action.

In the following keyhole narrative, Bubbly gurl demonstrates her "citizenship imagination" by describing her sense of responsibility, protection and provision for the children and youth of this community.

\section{"To keep our children safe, that's the important thing"}

As outlined in Chapter 6, participants at College B had a strong sense of the value of local community and family and had raised a number of concerns about issues relating to families, children and young people in their community. These included issues such as family violence, child abuse, teenagers dropping out of school, teen pregnancy (numbers rising), homeless teenagers and street kids, not enough facilities for us teenagers and underage alcohol usage. In keeping with 
these themes, Bubbly gurl (16, female) emphasised the importance of children in this community through her Photovoice narratives. She photographed a sign at the side of the road promoting child safety through the use of child seats and restraints and identified this as an important aspect of her community (Figure 7.3):

Bubby gurl: To keep our children safe - that's an important thing. That's something that our community holds strongly...to keep our children safe, so they promote these sorts of images.

Figure 7.3: "To keep our children safe, that's the important thing"

Figure 7.4: "Sometimes alcohol can be too cheap"

Photographer, Bubbly gurl (16, female)

Photographer: Bubbly gurl (16, female)
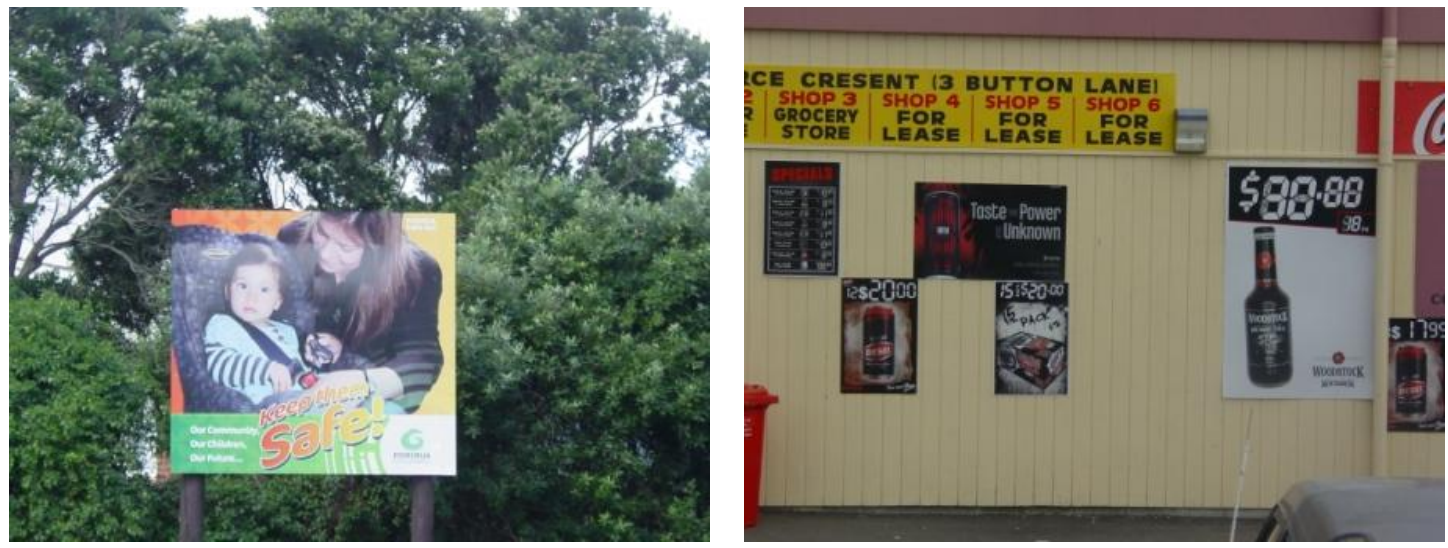

The majority of female participants at College B also described how looking after children was one of their responsibilities. For example, Doodlebop (16) states, "I have to look after seven of them - yay for me! My sisters' and my brothers' kids." Bubbly gurl highlighted a number of social issues related to children and young people in her community that she wanted to change. She took a number of photos of "the Cage" - a small, fenced-in area with a half pipe and a basketball hoop which was one of the only playing facilities in her community (see Figure 7.5 and 7.5).. The Cage is surrounded by some shops, a Liquor Bar (Figure 7.4) and a residential area. She describes why she took these photos:

Bubbly gurl: That's where we play. And like I took that photo because I reckon they should build more.

Smoove Cullen: That's "The Cage."

Bron: So this is the little skateboard place and the kids hang out and play basketball and it's all in a big cage?

Bubbly gurl: Ya. And I reckon that's one social issue that I want to... [change] Yukki Chan: And sometimes drunks go toilet...they urinate everywhere. Bubbly gurl: I reckon kids deserve to have more playing facilities in our community, in our area. 
Her close identification with these children, expressed in her statement "that's where we play", highlights her sense of belonging and identification with this community. Her feelings of responsibility for local children and an impression that they "deserve better" fuels her desire for an improvement in these facilities.

Figure 7.5: "That's where we play"

Photographer, Bubbly gurl (16, female)

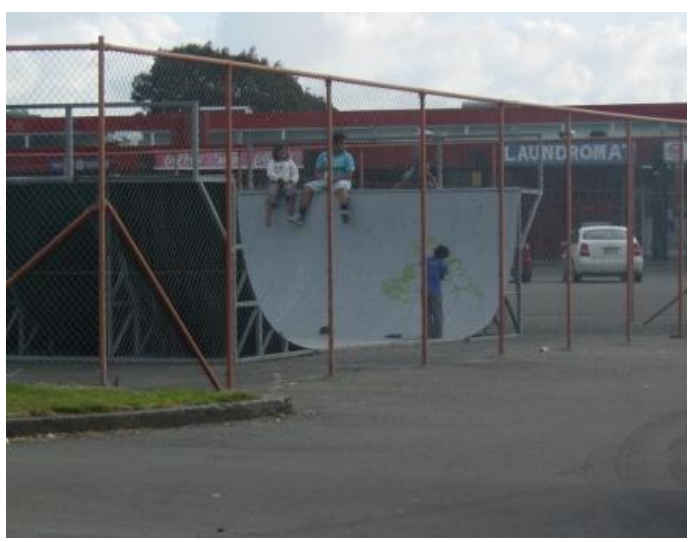

Figure 7.6: "The Cage"

Photographer, Bubbly gurl (16, female)

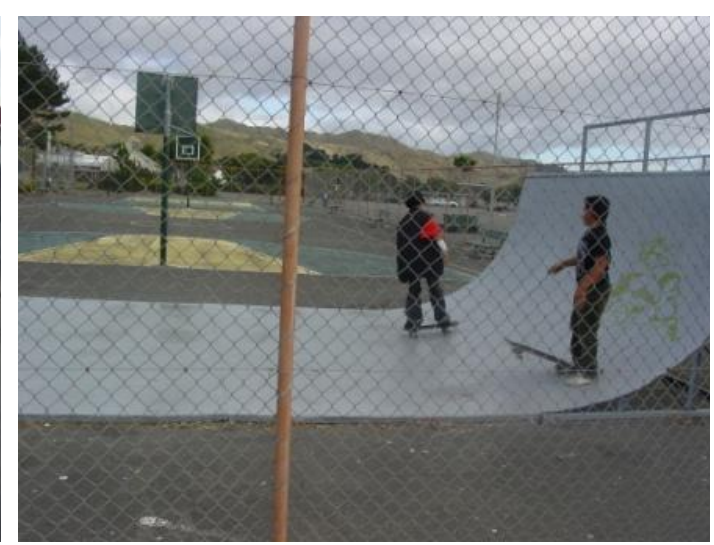

She shows similar concern at the prevalence of liquor shops and their aggressive marketing of cheap alcohol in her community - with a particular concern for the impact this is having on young people:

Bubbly gurl: That's just a shop - a dairy. I took a photo of these alcohols. I reckon its rubbish. Like youth, young people drinking cos sometimes alcohol can be too cheap.

Bron: And are there quite a few bars and liquor stores around? There have been a few photos of them.

Yukki-Chan: There's one at the [local shops]

Smoove Cullen: There's one at every corner shop.

Bubbly gurl: Yeah every corner shop...except for the [one local group of shops]...It's just not on.

Her discussion about liquor outlets echoed the findings of a recent report in New Zealand which concluded that people who live in lower decile (more deprived) urban neighbourhoods are exposed to more liquor outlets than people who live in wealthier suburbs (Hay, Whigham, Kypri, \& Langley, 2009). In the class discussion that followed Bubbly gurl's Photovoice report back, participants shared how more than 100 local people had protested at the court before a Liquor Licensing Authority hearing in 2008. Their protest prevented a liquor outlet from setting up at one of the last remaining community shopping areas without a liquor outlet in their suburb (Field notes, March, 2009). It is likely that 
the example of this local protest had contributed to participants' sense that 'it's just not on."

\section{College C}

Social action was a concept that was not easily understood by some participants from College C. Two (out of six) focus groups of Year 10 students indicated that they were unsure of the term. For example, one group stated that social action is "socialising with others/communicating," and later on (following a conversation with the Teacher $\mathrm{C}$ ) added "taking action against the problem that we think is important." Another conversation also showed some ambiguity:

Rev: What is social action? [14, male]

Kiwi: Isn't it like a discussion of a group of people and then deciding on action as a result of majority vote? [14, female]

However, other groups did have a firmer conception of social action:

A group of people (e.g. Greenpeace) taking action against an issue with an impact on a lot of people.

When one person/ a group of people try to encourage others to take action too. Take a stand.

Participants gave a few examples of social action in relation to school-organised opportunities. For example, Captain Awesome (14, male) included his participation in the community issues class as an example of his social action. Another participant, Joker (14, female) was a member of her school environment group. In this capacity she states:

Recently we've been going round to primary schools and creating awareness [about the environment] ... and we're getting the new bin thingies [to encourage recycling in the school]. We also do beach clean ups.

Other participants also cited school-based groups such as a support groups for gay and lesbian youth and one to promote healthy living (Table 5.2). Being informed and learning about issues was also seen as social action by the following groups of 14- year-old females:

Martha: Examples of what we've done to take action. We haven't done anything...

Sally: We've talked about it.

Autti: That's an example.

Mad-Dowg: We've made posters and learnt about the issue.

Sally: We've thought long and hard about it. 
Examples of social action in response to environmental issues were the most common in keeping with the high reporting of this as an important issue (Chapter 6). Four out of six focus groups gave a description of actions that they had taken in response to environmental issues - these included recycling, planting trees and joining environmental groups.

Cadalacwormwald: Recycled - is that one? Biked places - is that good enough? $(14$, male)

Happy dog: Biked instead of taking transport that pollutes the air. (14, male) Papercup: [writes on poster] Environmentally-friendly transport. (14, male)

Rangatangtang: I helped DOC57 a couple of years. In the rat traps we got a pig once. (13, male)

Many examples of social action took place as part of their everyday lives in the informal sites of home and neighbourhoods. Joker (14, female) described how she had boycotted a certain brand of rabbit food after finding a bag that she had bought was rotten and "they refused it believe it was their fault." Reow (14, female) also described a number of online causes she had joined on the internet: I joined the Stop Animal Cruelty thing on Bebo and I did this thing on Bebo (www.freerice.com) and it's like an application and you do these literacy questions and every question you get right you donate rice to a poor person ...and I felt connected afterwards knowing that I'd helped someone's day.

A couple of younger participants described how social action could be something that you didn't do. For example, Lil Man and Ranga (both 14, male), examined their list of social issues and describe their social action in response:

Lil Man: What have we done?

Ranga: Not drank, not done drugs, not over-fished, not [brought in] didymo, not boy raced, not done graffiti, not got pregnant...

Participants identified a number of barriers to their participation in social action. These included barriers related to age and status ("not being old enough to sign a petition") (4/6), and fear of community judgement or critique (3/6).

In the following keyhole narrative, these participants demonstrate their observations of the impact of a number of new businesses upon their small rural town.

\footnotetext{
${ }^{57}$ The Department of Conservation (DOC).
} 


\section{"We're saying we have too much [fast food] for a small town"}

The opening of The Warehouse ${ }^{58}$ in the past two years, and the arrival of a McDonald's restaurant six months prior to my research in College $\mathrm{C}$ were events that generated a lot of discussion among participants at this school. Their discussions about the arrival of McDonalds in particular seemed to crystallise around many of the themes already identified in Chapter 6 which related to these young people's sense of being connected to others, yet isolated; integrated to a wider economy (through tourism and trade), yet "on the edge."

The arrival of the new businesses provided a small number of participants with a sense of pride and affinity with a "cool” global youth culture (see Figure 7.7). With reference to The Warehouse, participants said:

Reow: It shows how small we are but we've got a big shop. (14, female)

Pete: It's the only place you can get anything good - even though it's not very good... yeah, it's a good thing. Otherwise we'd be bored. (14, female)

Captain Kewi: I play tag at The Warehouse. Throw the balls around. (14, male)

And of McDonalds:

Captain Kewi: I love it. I love McDonalds! (14, male)

Lil man: It's an icon. (14, male)

However, most of the participants had concerns about the negative impact McDonalds could have on young people especially, but also the identity of their beautiful, small town set in a mountainous region near to famous National Parks (features they had related with pride - see Chapter 6). In even the short time since McDonalds had arrived, participants noticed some negative changes to their town:

Sally: WAY more litter. I think there's more traffic at the corner. There's lots more traffic at the corner now.

Papercup: Yes, lots more traffic. I can't cross the road properly.

58 The Warehouse is a large red retail outlet which stocks most household items. A relatively recent presence in smaller New Zealand towns, it is at times seen to threaten the viability of local shops. 
Figure 7.7: "That's showing all the companies"

Photographer: Reow, 14, female

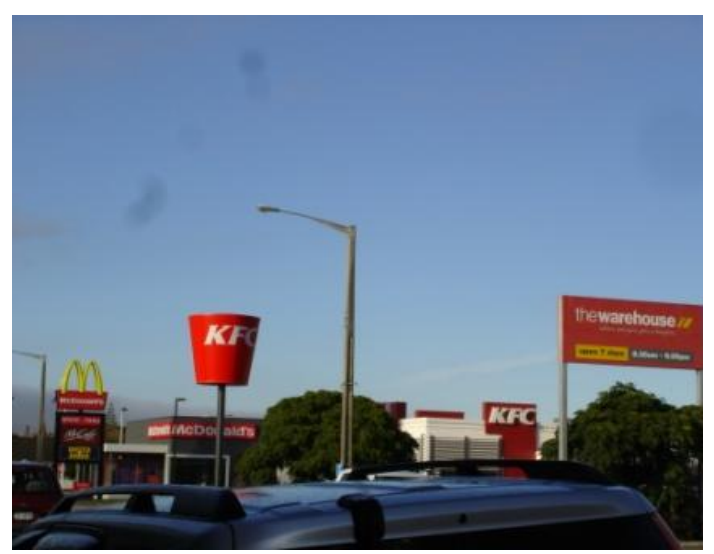

Figure 7.8: "McDonalds is making us fat" Photographers: Joker, Autti and Bubbles (all 14, female)

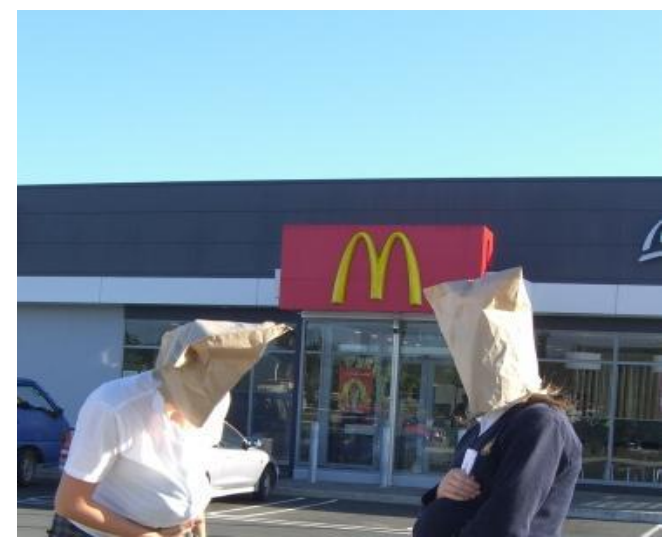

Reow and Bubbles (both 14, female) had very immediate concerns about the effect on young people in particular and potential obesity (see Figure 7.8) with the McDonalds now located about 400 metres from their high school:

Reow: Yes, we're saying we have too much [fast food[ for a small town. And how they're all in a cluster and at McDonalds you get cheaper food if you're a student in uniform and that's basically promoting obesity cos...that's giving it to children, and children like food like that....(14, female).

Bubbles: McDonalds is making us fat. And they've put it just down from the school so it's like making all the school students go in and think they need a snack and it's not good for us! (14, female)

The arrival of McDonalds was an interesting issue to highlight these young people's sociological imagination' as they could notice changes that happened within their lifetime - and in the past six months in particular. The following conversation shows these participants' sense of loss at the tearing down of a local hotel to make way for McDonalds, only to find out that a further fast-food outlet (Burger King) was also applying to set up in their town. These events served to heighten Sally and Martha's position ("we don't need it"), even further:

Sally: I just think we don't need it cos we already had...

Bron: ...the Flammin' Chippie? [a local fish and chips shop]

Sally: Yeah. And KFC and Subway are just next door and lots and lots of fish and chips.

Cadalacwormwald: Burger King's coming to [town] soon.

Sally: Really?

Martha: We don't need it.

Cadalacwormwald: They've got three building options and one of them has been cancelled out so they have two others.

Sally: Oh what! We don't need it. 
Bianca: Remember the old [name] Hotel? That used to be there. The [name] Hotel was really cool.

The sense of agency and the sociological imagination implicit in the narratives of many of these participants is obvious. Underlying Martha, Sally and Reow's sentiment was a strong sense of responsibility, belonging to and protection for this place and what it symbolised. In light of the potential threat of multinational companies upon their small town, Flora made the following statement: (see Figures 7.9 and 7.10):

See how they've got like McDonalds and KFC on one corner...and see how we've got our mountains in the background and it kind of just kills it. It kills our town's identity. Identification... It kind of spoils the nice scenery. (14, female)

Figure 7.9: "It kills our town's identity" Photographers: Flora, Feathers (14, female), Captain Awesome, Rangatangtang $(14$, male)

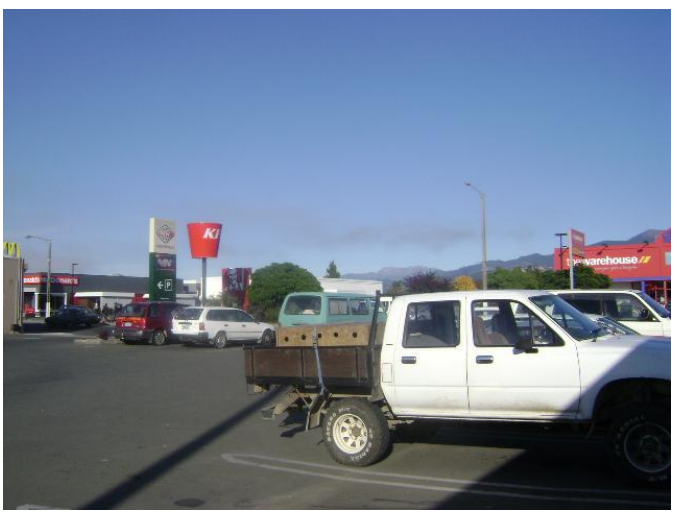

Figure 7.10: "It kind of spoils the nice scenery"

Photographers: Flora, Feathers (14, female), Captain Awesome, Rangatangtang $(14$, male)

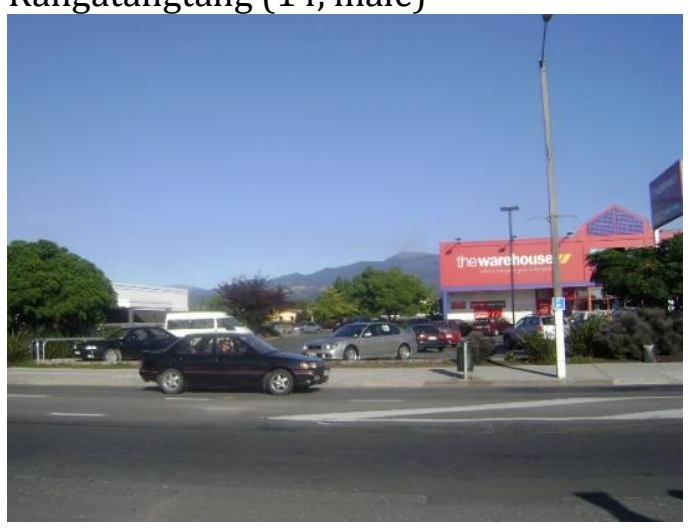

The Community Issues class appeared to have had a pivotal role in creating an awareness of these issues. The 2008 Community Issues class had taken a survey of 452 townspeople about the proposed establishment of McDonalds (before it had arrived) and found that while 67\% had supported the establishment of McDonalds in their town, a large number (42\%) had concerns about its location and the potential for litter. The students of the 2008 Community Issues class had invited the directors of McDonalds to hear a presentation about their findings, and in response to their concerns about increases in litter, McDonalds had funded a daily litter cart collection through the town (Field notes, March 2009). Sally made a specific reference to the survey conducted by the Community 
Issues class and how this had been a point of discussion in her Year 9 social studies class the year before:

Sally: We talked about it last year with $\mathrm{Mr}$ [name] in social studies about all the things that could result from having McDonalds and that was like obesity, more litter and lots more traffic. (14, female)

It is possible that the impact that a previous class had on modifying the practice of a huge global corporation, had enhanced the ability of these young participants profiled here to notice and to take an opposing position in response to the negative impact they felt McDonalds was now having on their small town.

\section{College D}

The female participants (all aged 14) at College D defined social action with a sense of collective and communal action to bring about change:

Saphira: Speeches. Like Obama. He's doing social action.

Dog: That's what social action is, interacting with others in our community to change something.

Taking steps to combat social issues.

An action - something you do as a result of a view or perspective on something in the community - community action.

To be involved with people possibly within and/or without your community.

As discussed in Chapter 5 by the teachers at this school, Enterprise Education was a feature of this school's social studies curriculum and most students in the class had taken part in classes for Enterprise Education. This was evident in discussions by students in this class who specifically referred to aspects of Enterprise Education in shaping their perceptions of social action. For example:

Dog: Could you say enterprising? For social action?

Jimbo: Yeah you could.

Jenny: [A good citizen] thinks of ways to enterprise and fun ways of doing things.

Whale: Makes new ways to help the community - which is basically enterprise!

A number of focus groups (3/5) associated social action and good citizens with being "enterprising." A "good" citizens was seen by participants to hold many of these "enterprising attributes" (see for "official" examples of these attributes, 
Ministry of Education, n.d.). A "good" citizen would be a "future planner," "strategic thinker," "self sufficient" and "learns from their mistakes." Yet, participants also exhibited more maximal conceptions of citizens, such as in the following conversation when they were trying to define a "good" citizen:

Jenny: A good citizen is Rosa Parks - because she broke the law...

Sonny Bill Williams: But she did it for a good cause.

Bron: And what was her cause?

Sonny Bill Williams: For getting integration...

Manaia: ...on the bus.

Student: [A good citizen is] someone who's not afraid of confrontation.

Being informed was also identified by participants from three out of five focus groups. They suggested that "reading the news," "keeping up and discussing the government" and "becoming informed about issues" by learning about them was social action.

Participants in three out of five focus groups gave descriptions of fundraising in relation to their school as examples of social action. Saphira (14) photographed this to highlight how common this experience was for many young people (Figure 7.11). In this case they were selling chocolates to raise money for their own participation at a national sports tournament. Participants were also involved in fundraising for more water storage tanks as part of their unit on water conservation (see more on this in the keyhole narrative "A waste of water" below).

Figure 7.11: "They're fundraising..." Photographer: Saphira (14, female)

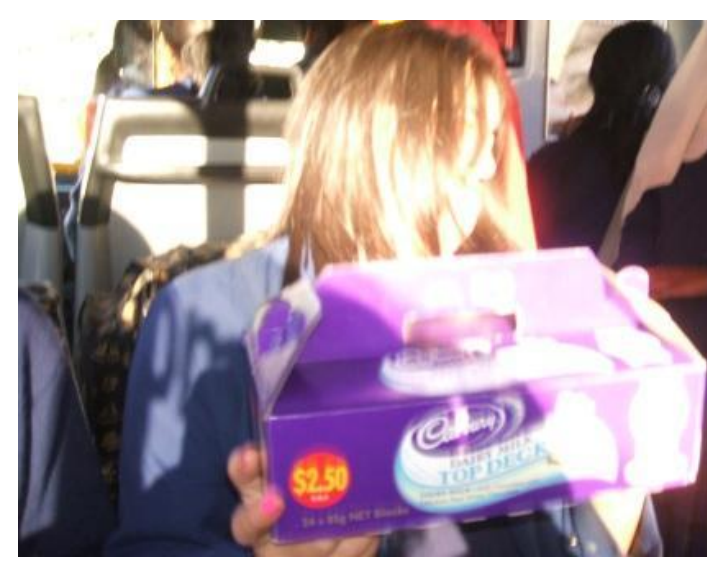

Figure 7.12: "That's us donating clothes for charity"

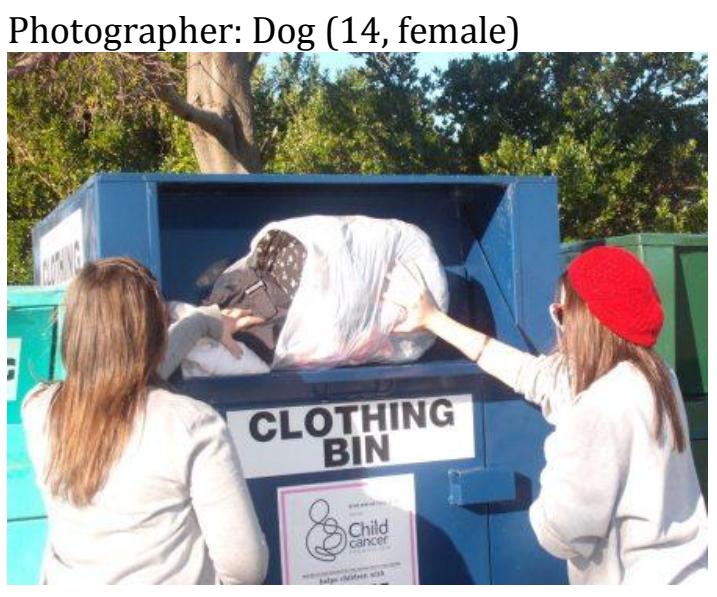


Another common example of social action given by the participants at College D was recycling (4/5). During the Photovoice activity, which occurred for this class over a week-end, Dog photographed the group recycling clothes and donating to charity (see Figure 7.12). She comments:

We thought it was showing helping people in need with stuff we don't need that we can share and that other people can find useful.

Participants at College D identified a few barriers to participation. These included "community attitudes and judgement" (2/5), "lack of resources" (3/5) and the low status of young people in society (4/5).

The issue of water conservation, which had featured highly as an important issue from these participants (see Chapter 6), corresponded with many examples of actions they had taken to address this issue of concern. I explore this further in the following keyhole narrative.

\section{"That's a waste of water"}

College D's teachers' interactive and student-led approach to their social studies unit on water (as detailed in Chapter 5) had provided students with a number of opportunities for social action. As an integrated unit with science, they audited water flows in their school and examined where water was wasted. One aspect that they drew attention to in the Photovoice activity was the rain water which was collected in their school for emergency use as discussed by Roxy-Perfume and Bob (both 14):

Roxy-perfume: It's rain water but we don't use it for anything. It's like why??? It's wasted!

Bob: It's for emergencies, but aren't we working on using it for the whole school? That's what they're making us learn.

The attention to the issue of water conservation, and what these participants saw as "social action" in response to the need for conservation and preservation of waterways, was also highlighted during a fieldtrip to a local stream which coincided with the Photovoice research with this class. Part of their social action in this unit involved picking up rubbish during this field trip (see Figure 7.13):

Azure: That's the stream. If you look there's a big pile of rubbish.

Student: That was all the stuff that we'd picked up when we were there. 
Figure 7.13: "That's the stuff we picked up" Photographer: Azure (14, female)

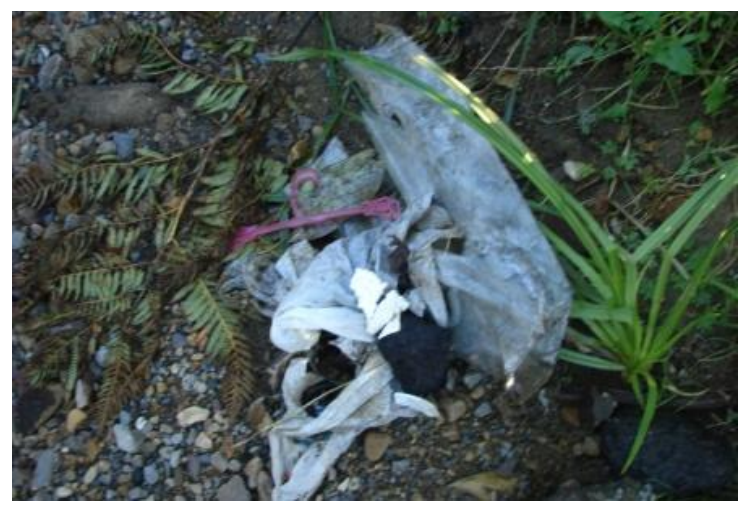

Figure 7.14: "That's the drain pipe...and it looked a bit dodgy"

Photographer: Bob, (14, female)

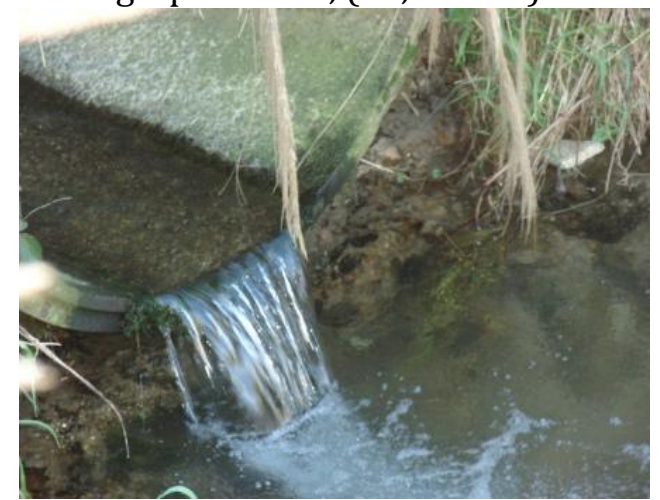

Participants also demonstrated understandings and concern about the impact of

polluted storm water and human alterations on this natural environment:

Bob: That's the rubbish you can see all around.

Student: People don't know that the water they put into the ground are storm water drains and they don't get treated and go out to sea, they go straight into the rivers and so on.

Bob: And that's [a photo of] of a drain pipe that was going in and it looked a bit dodgy. [Figure 7.14]

Bron: Storm water or dirty water?

Bob: Yeah, but I didn't really know.

Bron: And are the eels in the same pool?

Student: That's how they get there. A lot of the time eels come through the drain pipes.

It was significant that many of the descriptions of social action given by these participants also reflected the interest in the issue of water conservation. The following quotes represent comments from four of the five focus groups:

I used the little flush, the half flush.

I am trying at the moment to conserve water - to make up for my long showers. It's not quite working yet cos I still have them!

I turn off the tap when I brush my teeth [to conserve water].

We've been raising money to conserve water.

I've turned off dripping things [taps].

A discussion at College D between Capt. Quark, Mequity X, Faerie and Angelican about some of the actions they had taken to encourage others to conserve water was also insightful: 
Capt. Quark: People who run the taps in the bathroom while they go 'weewee' are really annoying.

Angelican: Yeah! That's actually an issue. I hate that. . .

Capt. Quark: ... I always turn them off. I always make sure they're in the cubicle and I always turn them off then run away. I've made a few enemies.

Mequity X: Excessive swearing !

Faerie: These aren't important issues!

Capt. Quark: Let's just do little issues. But people who leave the taps on that's a waste of water.

While Faerie stated that these "aren't important issues," the attention given by others in her group to actions that wasted water showed how their perception of this as an issue warranted action - even at the risk of "making a few enemies." This example also highlights how the participatory and experiential learning approach taken by the school, was having a significant impact on their personal actions in their everyday spaces, often beyond the gaze of teachers and adults.

\section{The nature of social action in "our place"}

The findings presented in this chapter point to the multiple and diverse ways these young people were defining and taking action. The spatiality of participation approach used in this chapter highlighted the different sites of participation, but also the degree to which participation was adult or studentinitiated/formal or informal. While mainstream measures of participation have frequently highlighted formal expressions of citizenship, the keyhole narratives in this chapter in particular provide examples that illustrated young people's ability to analyse and critique social issues (sociological imagination) in the context their everyday lives and places.

Yet, expressions of participatory citizenship took place in the context of a number of "barriers." The most common of these, identified by 16 out of 26 focus groups, was the status of young people in society. The low status of young people meant that, "at our age, we don't have the respect of adults...or the support" (ET, 17, male, College A) and "they don't trust us and our ideas" (Claire, 18, female, College A). A number participants also linked low status to low levels of efficacy so "you don't have the power to change it" (Martha (14, female, College $\mathrm{C}$ ). The prevalence of these comments surprised me even after a number 
of years of teaching high school students. Lack of resources, time and money were also identified as a significant barrier to participation $(14 / 26)$ as well as judgemental attitudes/criticism (10/26) and restrictions by adults (10/26). These expressions of exclusion from adult society by the younger teens in particular, underscore the limitations of exploring youth participation within formal and adult-centred contexts alone (Harris \& Wyn, 2009). These "barriers" are also likely to have had an impact on the patterns of participation described below.

The findings from all four schools in this research highlighted how older teens had many more opportunities for leadership and participation in decisionmaking (such as the School Council) and social action in social studies than younger teens. This was most obvious in College A where I had participants from Years 10, 12 and 13, but was also apparent in the discussions of older teens at College B who described many opportunities they had for leadership within the school and (church). In contrast, younger teens in Colleges A, C and D referred to far fewer opportunities for formal participation, and therefore their informal participation featured more highly in their conversations. The difference in age between these teens was as little as two years, yet the choices and opportunities they were offered reflect the very marked hierarchies of age that operate within high schools (Marsh, et al., 2007).

School opportunities and the social and cultural capital that teachers offered through their social studies programmes appeared to be influential in how young people conceived of, and practised social action. Two keyhole narratives in this chapter illustrated the significance that studying social issues in social studies had on their own perceptions, dispositions and actions. First, the narrative describing the arrival of McDonalds, and the concerns youth participants described over how this could "kill" the identity of their small town, was informed, at least initially, by the Community Issues class's research in this area. Participants referred to the findings of the survey conducted by members of the Community Issues class in 2008, and discussions with their social studies teachers during the previous year. This appeared to have heightened their 
awareness of the impact McDonalds was having on their town. This also served to quicken their sociological and citizenship imaginations and their ability to critique the subsequent changes. Second, the attention to water conservation in the studies programme at College D appeared to be having a significant effect on the personal conservation actions of students. In both these examples, it appears that exposing young people to these issues and providing them with information through their formal education (cultural capital) and opportunities to take action (participatory capital) had resulted in the development of their citizenship perceptions and agency.

The most commonly cited examples of social action given by participants fitted the participatory citizenship (Westheimer \& Kahne, 2004) or social movement citizenship category which Kennedy (2006) describes as the "civic virtues" approach to citizenship (see Appendices B and C). Examples in this vein included involvement in fundraising for charities and organisations (both donating and collecting), with the 40 Hour Famine the most commonly mentioned cause. ${ }^{59}$ Fundraising and donating money has been found as a commonly cited civic participation of younger teens (Benton, et al., 2008; Harris, et al., 2010; Schulz, et al., 2010), prompting Harris et al. (2010) to surmise that, "donating money to a cause is an uncontroversial, ordinary act that also reflects young people's position as consumer-citizens who are perhaps better able to make their views heard through economic rather than political means" (p. 23). Other examples of social movement citizenship given by young people included joining a group, coaching sports teams, sponsoring a child and collecting for the food bank.

Participants gave very few examples or definitions of social change citizenship (Kennedy, 2006), or justice-oriented citizenship (Westheimer \& Kahne, 2004). A small number of (mostly older) participants gave examples of signing petitions, and writing letters. A few described what some refer to as "new engagements" (Coleman, 2005) such as boycotting products, wearing something to support a cause, or participating on social networking sites, such as joining a cause or

${ }^{59}$ The 40 Hour Famine is an annual fund-raising event organised by World Vision, which is notable for its organisational structure which involves training young people to lead this campaign in schools, largely without adult help. 
contributing to online discussions (see Happy-go-lucky, Allie and Shan from College A in this chapter for examples). The example of vertical and transformative actions directed toward environmental change by Hip Hop Potamas and her youth-led environmental activist group was quite exceptional in this regard. In keeping with a number of projects researching youth political participation (see, Furlong \& Cartmel, 2007; Torney-Purta, et al., 2001), many of these participants also exhibited a lack of trust in politicians, political parties and democratic processes, such as IT Master who commented that "petitions don't do jack."

It was largely through informal and voluntary examples of social action, and through young people's citizenship imaginations (seen in the keyhole narratives), that I suggest that we gain more of a sense of young people's maximal and justice-oriented citizenship dispositions. Schaefer-McDaniel (2004) suggests that exploring children (and young people's) voluntary participation, as opposed to their coerced participation by parents, teachers and other adults, is more relevant to understanding their social capital. She also explains that voluntary participation is seen as an outcome of social capital (rather than an "element of the construct" (Schaefer-McDaniel, 2004, p. 16)). Many of the examples provided by young people would be barely perceptible to traditional research approaches and measures of youth participation in citizenship (O'Toole, et al., 2003). For example, participants described a number of ways that they were taking action to address environmental concerns such as riding a bike, recycling, picking up rubbish, turning off taps and reducing the length of showers. Participants (younger teens in particular) gave a number of examples of what could be termed friendship citizenship. These included "standing up for friends," "stopping a bully" and "hanging out with loners." In addition, five groups described influencing others as an example of their social actions, such as "encouraging others not to smoke or do drugs" (College A), "giving advice" and "taking a friend to the guidance counsellor" (College B) and "influencing peers to make good decisions" (College D). Participants in College B specifically mentioned befriending people from other races and social statuses to gain more understanding of other cultures. 
More radical and transformative expressions of citizenship participation were also apparent through young people's citizenship imaginations and the issues of concern they identified (such as racism, safety in the context of gangs, and inequalities of access for rural young people to urban areas). To address these issues of social justice and human rights in communities would require a longterm commitment to communities and social change which Mills suggest is the prerogative of all social scientists.

These informal examples of lived participation (rather than performed participation), are inseparable from young people' everyday relational and spatial experiences within places. They are also illustrative of the way that young people not only "inherit" social capital, but also are active in contributing to the social capital of communities through the connections and networks they form (Weller \& Bruegel, 2009). Whilst there are some critics of this "softer" (Skelton, 2010) definition of participation (for example Print, 2007), I suggest that an everyday perspective on participation offers researchers the opportunity to reconfigure the traditional landscapes of young people's participation by recognising the radical potential of everyday and local citizenship. I will follow up on this theme in the following chapter when I begin to consider more closely the patterns and possibilities of youth participation. 


\section{CHAPTER 8: \\ DISCUSSION: \\ PATTERNS AND POSSIBILITIES OF YOUTH PARTICIPATION}

Over the past three chapters, I have explored the practices and conceptions of both social studies teachers and their students toward social action. These findings revealed that participants held multiple and diverse understandings of participatory citizenship, but that there was some similarities within the four sites that warrant further site-based analysis. In this chapter I explore three patterns of participation that could be seen from the data. The first pattern relates to young people's personal and lived experiences within places. It was apparent that contextual, lived experiences influenced the nature of issues that young people were aware of (and perceived to be important), and that in turn, young people were developing opinions and responses toward. The second pattern relates to both teachers and young people and the nature of participation and the degree to which participation was formal or informal; horizontal or vertical. The third pattern of participation relates to the spatial orientation of participants' perceptions of issues and expressions of social action (local/global). I will consider each of these in turn.

I have used Bourdieu's conceptual triad (habitus, capital and field) and Mills' sociological imagination to provide a theoretical and conceptual approach underpinning this research. In this chapter I will explore how these theoretical frameworks provide insights into the patterns of youth participation described here by suggesting that participatory capital is generated by exposure to the social, economic and cultural capital belonging to social groups, and results in differing citizenship dispositions. I argue that a Mills-Bourdieu framework offers a theoretical framework to explain differences and similarities in patterns of participation that are apparent between the school sites in this research. 


\section{Identity, belonging and citizenship spaces}

The first pattern relates to the pervading influence that young people's lived experiences within places had on their citizenship dispositions and actions. The descriptions provided in the eight keyhole narratives in Chapters 6 and 7 in particular, illustrated how young people's perceptions and expressions of citizenship were shaped by experiences within neighbourhoods, school and communities. Furthermore, and in keeping with the findings of Harris and Wyn (2009) and Marsh et al. (2007), participants' engagement with issues in terms of their perceptions as well as their (proposed and actual) actions appeared to be heightened not only when they had a local expression, but also a personal identification. Identification with places was also expressed through a sense of responsibility or protection for that place, and the desire to improve experiences for people associated with that place - or what I have termed, the citizenship imagination.

At the beginning of Chapter 6, I suggested (in keeping with Leach (2002) that one way of begin to gain an understanding of people's sense of belonging and identification with a place, was through their spatial narratives and spatial practices. Through the descriptions participants gave of what was special about their places, the issues that gained their attention (Chapter 6) and the nature of many of their social actions they took (Chapter 7), I propose that we observed a sense of their belonging and attachment to place. Similarly, a sense of not belonging to places, and experiences of exclusion and alienation, also influenced their perceptions, personal politics and participation/non-participation.

In drawing a link between belonging and participation, I do not suggest a type of linear causality in which experiences of place and community result in certain, predictable responses and actions of citizenship. Instead, I re-focus attention on to the often overlooked influence of context and everyday experiences (Faulks, 2000) upon citizenship perceptions, imagination and actions. 


\section{Spaces of belonging}

The "portraits of our place" outlined for each school community in Chapter 6, provided many examples of how experiences of identity and belonging within places triggered an interest and a desire to take action on certain issues. For example, the importance of the natural environment of the beach, the mountains and the bay, described by participants at College $A$, became a key explanation for the significance of the issue of air pollution and their responses. Similarly, the action of befriending people from other cultures described by participants from College B, was framed within their personal experience of belonging to "a Pacific community, everyone just gets along" (Bubbly gurl, 16, female). Their identification of issues of concern, such as tagging, the presence of gangs and oversupply of liquor, was made starker by the affront that these issues presented to their experience of belonging.

Distant issues, such as global warming or global water conservation also became more immediate and tangible when they could be noticed at the local level. For example, the descriptions of the local problem of air pollution from College $\mathrm{A}$ (Chapter 6) and water wastage by participants from College D (Chapter 7) illustrated high levels of awareness and personal responsiveness (such as taking shorter showers) than issues that were less tangible. Similarly, the threat that the arrival of McDonalds and other fast-food outlets presented to a small town known for its surrounding beauty, led some participants from College $\mathrm{C}$ to express the view that these multinational companies were "killing our identity" (Chapter 7). Perceptions of the significance of issues and the need to take actions in these three examples were heightened by what participants had been taught in their social studies programme (appendices P-S). I will explore this in greater depth, later in this chapter when I examine the importance of teachers and cultural participatory capital.

\section{Spaces of exclusion}

Nevertheless, while experiences of belonging to places shaped the issues young people noticed and took action on, the data also reveal that experiences of 
exclusion and alienation within places also shaped their responses. In Chapter 6, I described how older teens at College A expressed their perception that young people in their community had it "pretty good compared with other places round the country" (IT Master, 18, male), "considering there are so many older people [in our city]" (Hip Hop Potamas, 17, female). However, the discourses of the younger teens at the school reflected quite a different story. They described spaces of exclusion in their city. For example, they had been asked to leave The Warehouse simply because of their age and presence in the shop without their parents. They voiced a perception that the label many adults put on young people in their city, ("they think you smoke and drink and beat each other up" (Happy Go Lucky, 14, female), meant that "there's no good places for young people to hang out" (Pineapple Lumper, 14, female). These experiences led to the majority of these young people reporting that their status in society ("since we're younger") was a significant barrier to their ability to participate in social action.

Experiences of inclusion and exclusion within the community described by young people at College B also illustrated the contradictions and complexity of young people's experience of citizenship. For example, Bubbly Gurl and Doodlebop described how at church "they get listened to a lot", and described a number of positions of responsibility they held within the church. In contrast, participants in this class claimed that young people in their community were "not listened to" and "they stereotype those little teenagers" (Yukki-Chan, 15, female). They laughed at the idea that the local Council might consult with them as "we're not famous enough" (Doodlebop, 16, female). It follows that their formal examples of social action were primarily through experiences within church and cultural groups they affiliated with, rather than in decision-making at local government levels. Doodlebop described how expressions of vandalism or tagging reflected young people's frustrations and exclusion within their community. Her sentiment reflects research in England which suggested that young people's disenfranchisement from local planning processes was a major contributor to their experiences of "landscapes of powerlessness" and social marginality (Matthews, et al., 1998). 


\section{Personal politics}

Participants' perceptions of the significance of issues appeared to be elevated when young people had a specific sense of personal identification with an issue. Buckingham's (2000) research into young people's perceptions and responses to the news raised a similar and related observation: that when it came to political issues that were closer to young people's own experience, over which they might have some power to influence, they were much more engaged (p. 70). Two individuals in this research in particular (TC and Bubbly gurl) illustrated how a specific issue (racism and the wellbeing of children) had personal significance and resulted in personal responses. In both these examples, it was not a sense of belonging, but a sense of injustice, discrimination or inequity that fuelled their attention to these issues.

In Chapter 7, TC (14, female, College A) voiced her concern about the issue of racism, describing it as the most important issue that needed addressing in her place. In the keyhole narrative, "I'm just saying it's a stereotype," her strong response to perceived racist comments in her classroom, underscored just how strongly she felt about the issue of racism. Her commitment to this issue involved wading in to a volatile and confrontational situation which ended with a public statement of her identity as Māori to her classmates. Beyond this incident, she also demonstrated a personal response to issues of discrimination by "hanging out with a loner" to prevent him from being bullied. Her admission to her friend (Rodney Hyde) that it did at times hurt her feelings "when people made comments about Maoris," reveals that her political stance is likely to be informed by personal experiences regarding this issue.

In a similar way, Bubbly gurl's (17, female) expressions of concern about the lack of facilities for children, the prevalence of liquor outlets and their aggressive marketing fuelled her response that "it's just not on." Her perceptions were driven by a concern for children and young people in her community in particular who she thought deserved a better deal. Her actions (making crosscultural friendships) were one way she saw she could work toward positive change in her community. TC and Bubbly gurl's narratives highlighted a moment 
when their "life experiences gave voice to 'ordinary politics' - conveying their relationship to socio-economic and political structures through the lens of their own experiences" (Llewellyn \& Westheimer, 2009, p. 52). At the intersection of TC and Bubbly gurl's personal biographies and what they perceived to be important issues, was an indication of what they valued for their communities a place where it was safe for children and young people to grow up, that was free from judgement and discrimination and where young people "could be themselves" (TC, see Figure 7.2).

The choice to evaluate one issue as "more important" than another is a valueladen act. Mills (1959) suggests that knowing which social problems are to be perceived as important ones (thus warranting study by sociologists) is a moral one as well as 'scientific'; political as well as intellectual. He elaborates:

A problem to one man [sic] is no problem to another; it depends upon what each is interested in, and upon how aware he is of his interests. Moreover, an unfortunate ethical issue arises: Men are not always interested in what is to their interests. Everyone is not so rational as social scientists often believe themselves to be. (Mills, 1959, p. 76)

Taking a stance on an issue requires young people to make an evaluation which Mills (1959) would argue is based on ethical, moral and political grounds. The capacity to notice social issues in the context of wider societal and historical factors (through the sociological imagination) is the basis for "caring" about such issues and taking some sort of responsibility for them. As ET (18, male, College A) stated, "actually I think that social action is also when you start caring about social issues."

The idea that expressing concern and awareness of issues could be an example of civic engagement is a contestable one (Cremin, et al., 2009). However, acknowledging that care, compassion and concern are examples of citizenship dispositions also goes some way to addressing the limitations of many citizenship surveys that only focus on narrowly defined examples of "what counts" as participation. This position also acknowledges the citizenship constraints experienced by young people as a result of their differences from adults in status, and access to resources and power in society (Lister, 2003, 
2008b; Roche, 1999). The tendency toward informal expressions of participatory citizenship by the less empowered younger teens in particular, is likely to be a reflection of their very real issues of limited access to decisionmaking and participatory power in society. In the following section I draw attention to youth participant's patterns of participation within everyday and informal spaces.

\section{Informal and everyday citizenship actions}

The attention to everyday and place-based perspectives in my research design revealed a much more complex and nuanced picture of youth engagement than many presented in international citizenship reports. Rather than indicating whether young people were active or apathetic, this approach revealed that young people's sites of participation included many adult-centred and formal sites, but also personal and informal sites. It is likely that many of the informal examples of social action provided by participants would not have been captured in these predominantly survey-based reports (see, for example Schulz, et al., 2010; Torney-Purta, et al., 2001), as many were removed from the gaze of adult society. Recognising informal participation is even more important in light of some young people's experiences of exclusion from society as discussed earlier. In this section I will explore some of these less visible examples of participatory citizenship further and in doing so, highlight the political possibilities that these mundane, everyday citizenship examples provide.

There is some evidence from these largely informal examples of participation to support Pippa Norris's (2007) concept of "cause oriented critical citizens." A number of students gave examples of informal actions related to environmental concerns (such as actions to conserve water, recycling, and picking up rubbish). Norris suggests that participation must move beyond the formal institutions to recognise new protest movements and micro-politics with "more fluid boundaries, looser networked coalitions, and decentralized organisational structures" (p. 638). The attention young people in this study showed toward environmental issues (see Table 6.2), and the high reporting of actions taken to 
address environmental concerns across all schools (see Chapter 7) could be an example of a "cause-oriented repertoire" in Norris's conception. However, many of their examples of action would not have been visible in the recent ICCS study in 2009, where very few New Zealand students (well below the ICCS average) indicated that they had participated in formal environmental organisations (Schulz, et al., 2010).60

The findings in my research also support Harris' (2010) conclusion from research with Australian young people that some young people are "using informal and peer-to-peer activities that involve the common good and personalising engagement by emphasising their own behaviour in terms of taste, lifestyle and consumption" (p. 585). A small number of participants referred to their commitment to avoid battery-farm hens or coca cola products (such as Allie, College A, Chapter 7), reflecting a commitment to single-cause political expressions. While only a few participants described their internet participation as an example of social action, Happy-go-Lucky (14, female, College A) expressed the importance of this as a site for young people's action as the "internet can often be our only source of letting out because people find it hard to speak out around other people."

As discussed in Chapter 7, informal actions cited by youth participants included friendship citizenship, (such as influencing and supporting friends, standing up against bullies, and befriending people from other ethnicities). Harris (2010) suggests that informal friendship networks emerge as one of the most important forms of civic connection as a result of many young people's experiences of exclusion from civic spaces and decision-making. While such actions may seem insignificant, my research also reveals that informal friendship actions could also be justice-oriented and transformative - such as hanging out with a bully (TC and Rodney Hyde) and befriending people of other cultures to reduce cultural misunderstandings (College B).

\footnotetext{
${ }^{60}$ The ICCS survey asked students to state whether they had participated in an environmental organisation "within the last 12 months," "more than a year ago" or "never" (Schulz, et al., 2010, p. 129).
} 
While youth participants in all schools gave many informal examples of social action, their teachers had almost exclusively formal definitions of social action. Their definitions centred on providing opportunities for their students to engage with social issues, considering people's perspectives toward issues and working toward ways to solve societal problems. In fact, during the feedback sessions when I described the informal examples of their students, they were very surprised to know that young people had such broad definitions of social action, and that they were taking actions in their personal and everyday lives in ways that they had never known. In many ways, teachers' conceptions of social issues were less radical than those of their students who identified a wide range of social issues which required attention (such as racism, issues of children's safety and human rights, access to public transport and alcohol advertising targeting young people). Through young people's citizenship imaginations their status as citizens in society now, as opposed to the future, becomes more distinct.

These findings highlight the tension between "lived participation", which refers to everyday and informal actions of participation and "performed participation," in which children and young people are invited (by adults) to contribute to decision-making processes or offer their opinions and skills (Pells, 2010). The requirement for students to "perform" their participation to meet the requirements of curricula or assessments (such as the new senior social studies Achievement Standards at Levels 1-3) underscores this tension, especially in light of broader neoliberal agendas of responsibilisation of youth in order to fulfil both societal and economic goals of self regulation and autonomy (Harris, 2006).

Furthermore, performed social action becomes more contentious in view of the value-laden nature of responses to social issues which teachers in all of the schools raised this point as one of the "risks" of taking action. Teachers described the need for students to have "genuine empathy" (Teacher A2) for social issues if they were expected to be able to respond to them. They were also aware of multiple and contested perspectives toward social action and 
recognised the potential for social action to become an imposition of their values upon their students:

And that's something that bothers me that maybe the things that we think are relevant, that we're taking action on, are not theirs. (Teacher D6)

These comments highlight the importance of exploring values and perspectives inseparably from social action. Taking time to listen to young people's concerns and how they want to respond, may be one way to counter some of these risks. I reflect on this point further in the section later in this chapter on partnerships of participation. The third pattern of participation that I suggest the data reveal was the orientation toward either local or global participatory citizenship.

\section{Local/global patterns of perception and participation}

The attention to "place" in this research revealed some interesting patterns between school communities of what was defined as "our place." As outlined in Chapter 4, I had left this term deliberately open. In general, as noted in Chapters 5, 6 and 7, Colleges B and C were more community (locally) oriented in their conceptions and practices of social action, and Colleges A and D were more globally-focused. These local/global orientations were seen in the teachers' conceptions and practices of social action, in the students' perceptions of "important issues" and in the students' examples of social action. Within this local/global orientation divide, further differences in the age of participants and the decile rating of the school community could be observed. In this section, I suggest that these patterns closely relate to the social, economic and cultural capital that young people were exposed to through their schooling and community experiences.

In general, older students had higher rates of reporting of global issues than younger participants. This was most apparent at College A where my research involved three social studies classes taught by the same social studies teacher (A1). For example, one group of older participants at this school (Year 13, aged 17-18 years) scribbled out the words "important issues in our place," on their poster and replaced it with the sentence "important issues in the world." They 
then proceeded to list 28 "important issues," 19 of which they defined to be "global" in nature. Year 10 participants at this same school reported far fewer global issues (see appendix P), and across all schools, younger teens reported fewer global and more personal and health-related issues (such as bullying, smoking and obesity) than older teens.

This pattern of older children exhibiting more global conceptions of social issues has been found by research with children in Australia (Gill \& Howard, 2009; Sargeant, 2008) and in England (Buckingham, 2000; Holden, et al., 2008). A focus on more "global" social issues with older social studies students also reflects an "expanding communities" (Halvorsen, 2009) approach to New Zealand's assessment and curriculum requirements for social studies in which social studies contexts and issues become increasingly "global" as students move higher through the school. For example, a recent survey of 58 senior social studies teachers (working at Years 11-13) revealed that 73\% of their selected topics were "global" and 23\% had a national focus (Taylor, 2008). However, this pattern did not hold when it came to analysing the site of focus for participants in the Year 12 class at College B. These participants had high levels of reporting of local issues that were more similar to the younger teens in College $\mathrm{C}$, than the older teens in College A, as shown in Figure 8.1.

Figure 8.1: Perceived importance of local and global issues by participants in Colleges A-D

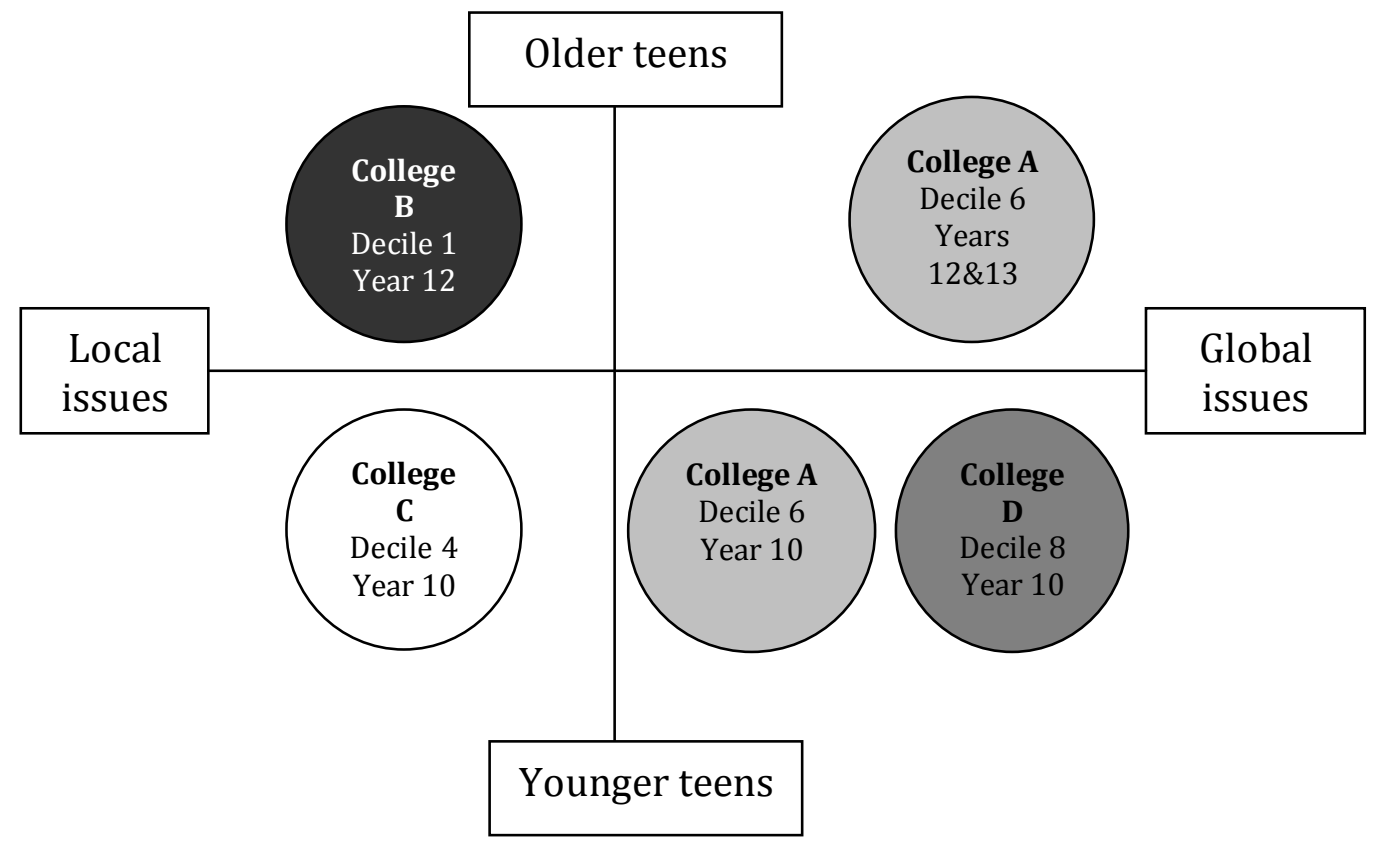


These patterns of local/global orientation were reinforced in data from the teachers at each of these schools. As discussed in Chapter 5, College A exhibited the most "global" conceptions and practices, and College C and B the least (see Chapter 5). College D had quite global conceptions of social issues, but practices of social action were more focused on the local setting (for example on fund raising for water tanks for the school itself). These local/global orientations appear to be reinforced by pedagogical approaches taken by teachers, which in turn shaped the participatory citizenship actions of students (see Table 8.1).

Table 8.1: Pedagogical approaches toward social action in social studies

\begin{tabular}{|c|c|c|c|}
\hline $\begin{array}{l}\text { Pedagogical } \\
\text { approaches }\end{array}$ & $\begin{array}{l}\text { Local-global } \\
\text { focus }\end{array}$ & Pedagogical style & $\begin{array}{l}\text { Students' } \\
\text { participatory } \\
\text { citizenship } \\
\text { actions }\end{array}$ \\
\hline $\begin{array}{l}\text { College A } \\
\text { Global, } \\
\text { cosmopolitan } \\
\text { citizenship } \\
\text { approach }\end{array}$ & $\begin{array}{l}\text { High level of interest in } \\
\text { global issues and } \\
\text { citizenship responses in } \\
\text { social studies } \\
\text { programme }\end{array}$ & $\begin{array}{l}\text { Multiple opportunities } \\
\text { offered for students to } \\
\text { participate in social } \\
\text { action through social } \\
\text { studies. For example, } \\
\text { organising assembly; } \\
\text { selling bracelets to raise } \\
\text { money for an } \\
\text { international agency etc. } \\
\text { Focus on constructivist } \\
\text { and competency-based } \\
\text { social action }\end{array}$ & $\begin{array}{l}\text { High levels of student } \\
\text { engagement in formal } \\
\text { participation, esp. } \\
\text { fundraising and } \\
\text { consciousness raising by } \\
\text { older teens }\end{array}$ \\
\hline $\begin{array}{l}\text { College B } \\
\text { Community- } \\
\text { belonging } \\
\text { citizenship } \\
\text { approach }\end{array}$ & $\begin{array}{l}\text { Strong awareness of } \\
\text { needs of community and } \\
\text { strong connections to } \\
\text { community, cultural } \\
\text { groups and churches }\end{array}$ & $\begin{array}{l}\text { Fewer opportunities for } \\
\text { social action in social } \\
\text { studies programme; } \\
\text { strong emphasis on } \\
\text { cultural performance } \\
\text { and cultural and } \\
\text { language preservation } \\
\text { within school }\end{array}$ & $\begin{array}{l}\text { High levels of student } \\
\text { participation in } \\
\text { community } \\
\text { organisations (especially } \\
\text { cultural and church- } \\
\text { based); high levels of } \\
\text { student empathy }\end{array}$ \\
\hline $\begin{array}{l}\text { College C } \\
\text { Local } \\
\text { community } \\
\text { issues } \\
\text { citizenship } \\
\text { approach }\end{array}$ & $\begin{array}{l}\text { Strong interest in local } \\
\text { community issues and } \\
\text { strong links with local } \\
\text { groups and businesses in } \\
\text { community }\end{array}$ & $\begin{array}{l}\text { Student-involved } \\
\text { approach to selection of } \\
\text { issue in Community } \\
\text { Issues class); fewer } \\
\text { opportunities for social } \\
\text { action within social } \\
\text { studies but teachers } \\
\text { were looking to develop } \\
\text { further opportunities }\end{array}$ & $\begin{array}{l}\text { High levels of student } \\
\text { knowledge about issues } \\
\text { they had researched } \\
\text { through the Community } \\
\text { Issues class. Students } \\
\text { articulated critical } \\
\text { opinions toward } \\
\text { community issues they } \\
\text { had explored. }\end{array}$ \\
\hline $\begin{array}{l}\text { College D } \\
\text { Global-local } \\
\text { student-led } \\
\text { citizenship } \\
\text { approach }\end{array}$ & $\begin{array}{l}\text { Both global and local } \\
\text { issues focus in social } \\
\text { studies units and } \\
\text { programmes }\end{array}$ & $\begin{array}{l}\text { Progressive, student- } \\
\text { centred approaches to } \\
\text { social action, } \\
\text { responsibility given to } \\
\text { students to "drive actions" } \\
\text { e.g. students led fund } \\
\text { raising at end of unit; } \\
\text { emphasis on development } \\
\text { of key competencies }\end{array}$ & $\begin{array}{l}\text { High levels of student } \\
\text { engagement with social } \\
\text { issues studied; } \\
\text { personal and informal } \\
\text { actions described by } \\
\text { students to social issue } \\
\text { studied }\end{array}$ \\
\hline
\end{tabular}


For example, at College $\mathrm{A}$, the attention drawn to global issues and opportunities provided for young people to take action upon global issues (such as fundingraising for an international non-governmental organisation, or raising levels of consciousness about issues such as poverty) appeared to have heightened young people's awareness of global issues and influenced their responses. The "student-led" approach to social action at College D that encouraged independent learning, risk taking (an enterprising attitude) and student responsibility for social action appeared to have influenced the attention students gave to the global/local social issue they were studying at the time (water conservation), and resulted in personal, everyday responses (such as turning off dripping taps).

College B had fewer opportunities for social action in their social studies programme, but opportunities offered through the school to support cultural performance; language and identity were also valued highly by the students at this school. Teachers at this school were proud of the levels of empathy and care for others that they could see in their students. The student-involved approach at College C's Community Issues class which enabled the students to select their local issue of choice, conduct a local-survey (where students had to interview members of the public) and their own research and then present their summary and arguments back to the community (Field notes, April, 2009) also appeared to contribute to high levels of student knowledge of these local issues. To explore these differences between school sites further, in the following section I analyse these patterns through Bourdieu's concepts of capital, habitus and field and consider how these reflect the citizenship dispositions of teachers and students.

\section{Participatory capital and citizenship dispositions}

Participatory citizenship does not happen in a vacuum. The patterns of participation discussed in this chapter thus far reveal that while teachers and students hold multiple and varying conceptions and practices of social action between the four school sites, they also hold surprisingly high levels of agreement within school sites. This finding points to the importance of using a 
context-based analysis of participatory citizenship, by paying attention to what Bourdieu would refer to as "field." In this section I will suggest that it is possible to characterise participatory citizenship dispositions that reflect the school as a "social field," or the "socially structured space in which agents struggle" (Bourdieu \& Wacquant, 1992, p. 17). Mutch (2006) suggests that viewing a school or department as a social field on a micro-level reveals insights into how similar processes may be operating at wider social contexts and related fields. Mutch notes, that applying Bourdieu in this way emphasises a descriptive rather than prescriptive use of his conceptual triad (see also Reay, 2004 on this approach).

This study has similarly drawn attention to how citizenship dispositions were developed within the social, economic and cultural conditions within participants' communities and schools. Bourdieu suggests that in order to move beyond the constraints of mechanical structuralism and teleological individualism, he proposes a social praxeology which "weaves together a 'structuralist' and a 'constructivist' approach" (Bourdieu \& Wacquant, 1992, p. 11). To do this he employs a consideration of firstly, the objective structure (spaces or positions) that define constraints on the interactions and representations. Second, he introduces "the immediate, lived experiences of agents in order to explicate the categories of perception and appreciation (dispositions) that structure their action from inside" (Bourdieu \& Wacquant, 1992, p. 11). Taking a social praxeology approach, I suggest that the differences between these four schools can usefully be explained by considering the social, economic and cultural capital shared by teachers in the social studies department, students in the same school and members of the community (although not a direct focus in this research) - i.e. their field. The contribution of these capitals within these schools/school communities enables a shared "habitus of participation" to develop, which is reflected in teacher's and young people's perceptions, appreciations and actions. I will examine social capital, economic (and spatial mobility) capital, and cultural capital in turn. 
The section on belonging and citizenship earlier in this chapter illustrated how experiences of inclusion and exclusion and social interactions and networks within communities shaped young people's ability to develop social capital (Schaefer-McDaniel, 2004) and therefore shaped their dispositions toward participation. For examples, the high rates of church attendance amongst participants from College B appeared to have influenced their conception of social action as "community service" which was largely framed within their participation of church related activities (see Chapter 7). The church was also the place where they described opportunities for leadership for young people, whereas they felt that in the community young people generally were not listened to. In this case, it appears that the strong pattern of church-related attendance in this community contributed toward the participatory capital of young people that was largely framed as community service.

Differences between schools are also likely to have been influenced by spatial mobility which is closely related to economic and cultural capital in communities. The participation in an international field trip to a majority world country within their social studies programme for some participants at College A had given them exposure to, and awareness of many more "global" issues than participants, for example, from the rural school (College C). Youth participants from College A pointed to the opportunities that their school and social studies programme offered to them as an explanation for their global focus, stating that "this school has it good, with the [overseas] trip" (ITMaster, 18, male) and "it opened up our eyes...and made me want to go back and help in another Third world country" (Tae Woo Bang, 16, male). Similarly, the degree of mobility of young participants at College D around their city as part of their daily geographies of education to and from school, matched their sense of wide vistas and civic places that they saw as characteristic of their city (Chapter 6), and in turn, the issues they perceived to be important (Chapter 7).

In contrast, the more limited spatial movements of the lower decile participants also from a large city (College B), evidenced through their Photovoice activity and their patterns of commuting to school (all walked), highlighted a much more 
localised focus on issues within their immediate local neighbourhoods. The participants at College B explained their more localised patterns of perception and action by reflecting that "our students don't travel so far. Our world is smaller" (Doodlebop, 15, female). These differences are likely to reflect differing social, economic and cultural capital of working class/middle-class families in the communities of these respective schools, and their differing ability to give opportunities for their children to attend overseas trips, or go to a school outside their immediate suburb. These differences are also likely to relate to a school's ability to "attract" students, which has been found to be stronger for higher decile schools (Wood, 1995).

The findings from my research also reveal that exposure to forms of cultural capital through the knowledge, programmes and opportunities for social action presented within schools influenced students' citizenship dispositions. In Chapter 6, I suggested that teachers' profiling of certain social issues in their social studies programmes (or, in College C's case, the Community Issues programme) seemed to strongly influence their students' awareness of these issues, and perception of their importance. Similarly, teachers' focus on local or global issues and the pedagogical practices they employed toward social action also influenced students' perceptions and practices of social action (Table 8.1).

While these findings go some way toward reinforcing how social and cultural capital and a habitus of participation are socially reproduced within schools/school communities in a deterministic way, I concur with McFarland and Thomas (2006) who draw attention to the potential for other factors to "loosen such a deterministic conception of class reproduction" (p. 403). In particular, this includes the degree to which people "activate" their participatory capital through opportunities which enhance or erode this capital through familial, educational and social experiences (McFarland \& Thomas, 2006). Bourdieu pointed out this potential on a number of occasions when he stated that habitus, as well as being a product of history (that is of social experience and education) is also changed by history, that is by new experiences, such as 
education or training (pedagogic effort); "The habitus is not a fate, not a destiny" (Bourdieu, 2002, p. 29).

I argue that there were a number of ways that young people in this research moved beyond more deterministic forms of participatory capital allocated through familial socialisation. First, it was apparent that young people did not only receive social capital, but they also created social capital. This was evident through the friendships they were developing in their schools and communities, many of which went "against the grain" of social interactions (such as befriending a bully or a person from another culture). Weller and Bruegel (2009) argue that children play an important role in contributing toward neighbourhood social capital through 'hanging out', helping neighbours and building social networks. Second, a number of educational experiences afforded to young people within their schools and communities also opened up new avenues for participatory capital. These took the form of topics studied, opportunities for participation provided and social interactions between young people and adults. These forms of social and cultural capital provided opportunities to widen the horizons of young people's knowledge and experiences of participation. Importantly, participatory experiences and opportunities that appeared to have an impact on young people were within the context of relationships of trust with significant adults. Rather than a tension between youth-initiated or adult-led participation (such as the heirarchy suggested in Hart's (1992) ladder of participation), I suggest that a focus on "partnerships of participation" highlights the potential that intergenerational approaches can offer in supporting young people's expressions of citizenship (Fielding, 2007; Mannion, 2007). In the following section, I provide two examples of this from my study.

\section{Partnerships of participation}

There were a number of examples from all the four sites that highlighted the importance of seeing participation within a framework of intergenerational participation. Opportunities for social action which were provided by social studies teachers in all of the four colleges in the context of their social studies 
programmes became part of young people's conceptions and practices of social action. The Community Issues class at College $\mathrm{C}$ appeared to have contributed significantly to the young people's awareness of community issues and their strong sense of agency shown by these young participants as they spoke about preserving and protecting what was important and special about their place. The church-initiated expressions of social action for participants from College B similarly shaped these young people's expressions and social action. Moreover, the actions of adults in this College B's community in protesting against the proliferation of alcohol outlets and their aggressive marketing campaigns targeting young people in their neighbourhood, is also likely to have influenced these young people's sentiment toward alcohol outlets in their community: "it's just not on". The exposure to these largely adult-led opportunities for social action appears to have had a powerful role in shaping conceptions, practices and indeed, dispositions toward participation.

A focus on partnerships of participation recognises that the identities and spaces of children and adults are intimately related (Mannion, 2007). Attending only to children's voices and their personal and micro-political affairs "cannot in itself illuminate the tangled politics (and political economies) that determine the childhoods 'made' by adults for children in their societies" (Philo \& Smith, 2003, p. 107). I would suggest that if we take a closer examination of the intergenerational and partnership nature of youth participation, we provide spaces which allow young people and adults to work together to support participatory practices, rather than seeing it as a battle of rights between generations.

In the last part of this chapter I reflect on two related questions as a result of the findings in this research and discussion so far: First, to what degree was social action in these schools conceived and practised with maximal or minimal conceptions of citizenship?; and second, does participatory capital also have symbolic capital, and if so, how is this represented within the schools in this research? 


\section{Maximal or minimal social action?}

In Chapter 5, I suggested that teacher's conceptions and practices of social action appeared to reflect the goals of creating both participatory learners and participatory citizens. Teachers suggested that the "participatory learning" strategies employed through the integration of social action in their programmes would enable students to develop skills in problem-solving, lifelong learning, group skills, self management and critical thinking. It appeared that teachers at the two higher decile schools (Colleges A and D) had adopted ideas suggested in the new curriculum (key competencies and enterprise in particular) and integrated them with their conceptions of social action in this way. For example, Teacher D3 describes how she "looked at enterprising [and key competencies] as a process that led toward social action", and teachers at College A were working to integrate social action and key competencies more closely.

Conceptions of creating more participatory citizens were also seen in opportunities offered in their schools. These were primarily focused on social movement (Kennedy, 2006) experiences, such as fund raising to support a cause, collecting for the food bank and raising awareness and knowledge of social issues through examples of individuals and groups. Teachers also highlighted a number of "risks" associated with taking action, which included concerns over the imposition of their values, setting their students up for failure, and potential conflict with their community (College B).

The two goals of creating participatory learners and participatory citizens sit together with some degree of tension, especially in light of the policy context (outlined in Chapter 2) that the inclusion of participatory citizenship was established within. Many of the teachers' conceptions of social action, especially those that viewed social action as a way to encourage participatpry learners, reflected minimal conceptions of citizenship found within the Knowledge society rhetoric with its aims to create flexible, innovative, self managing lifelong learners. Duhn (2006) describes these as the characteristics of "neoliberal subjects - the lifelong learner, the flexible worker, the autonomous decision- 
maker" (p. 195). These conceptions expose the potential for participatory citizenship to become an instrumental tool for promoting narrowly defined participation "within carefully delineated economic and social parameters that reinforce neoliberal ideologies" (Kidman, 2005, p. 96). Instead of maximal participatory citizens, participation within this framework focuses on the creation of neoliberal subjects as lifelong learners and flexible workers, thus supporting the interests of those in power, rather than providing the potential to challenge existing power relations (Duhn, 2006). It is difficult not to conclude that social action was being "fitted into" an already busy programme of activities and programmes (Taylor, 2008), and was designed to achieve a level of acceptability in the community. However, I suggest that this is not the end of the story.

While the findings presented here suggest that neoliberal conceptions of participation had shaped the conceptions and practices of social action held by teachers, I argue that it is also possible to see ways in which teachers were also presenting a more justice-oriented and maximal conceptions of citizenship to their students, thus highlighting their agency both within and beyond neoliberal frameworks. Sim's (2010) research in Singapore is illuminating for this approach. She demonstrated that a number of social studies teachers showed high levels of autonomy and agency within a heavily regulated compulsory curriculum by taking a stand on what knowledge they regarded as most worthy for citizenship education as well as selecting the pedagogies they felt would best serve these ends (see also Baildon \& Sim, 2009). In a similar way, many of the practices and conceptions of social action shown by teachers across these four schools demonstrated a commitment to creating maximal and justice-oriented citizens.

Commitments to more maximal conceptions of citizenship were evident in a number of social studies programmes operating in the schools. For example, teachers at College $C$ showed creativity and commitment to social action by establishing the Community Issues programme a number of years prior to my research in the school. Through this programme, they had presented their own 
research findings and successfully lobbied a wide range of community organisations including the local Council, McDonalds and environmental groups on a number of issues of equity, justice and environmental sustainability. College B's school-wide commitment to language acquisition and cultural expression was acknowledged nationally as a rare feature in secondary schools today. Their provision of a wide variety of opportunities for students to both preserve and develop their cultural identities through the performing arts, can also be read as a commitment to social change as the cultural groups represented in this school (mostly Pacific) are minority cultures in New Zealand today.

Teachers provided a number of opportunities for vertical participation, such as writing submissions to the council (Colleges A and D) and letters to businesses to critique their environmental practices (College $\mathrm{C}$ ). They also showed levels of personal commitment to activism and social action that extended beyond a conception of students as active learners. For example, Teacher A1 stated how it was one of her greatest goals as a teacher to promote citizenship engagement in her students that extended even beyond the school experience of these young people (see quote in Chapter 5). These beliefs were reflected in the opportunities she offered her students to gain experience of participation whilst still at school. Teachers at College D actively encouraged a student-initiated activism group in their school, and spoke with pride about many of the leaders of this group, many of whom had been their social studies students (Field notes, May, 2009).

The selection of topics to study was another way teachers introduced justiceoriented citizenship conceptions. Their choice to study contested social issues such as child labour, fair trade, conflict in the Middle East and access to water, was based upon a commitment to human rights and social justice themes. These findings highlight not only the malleability of social action as a concept, but also the agency of teachers in "reclaiming" aspects of curricula and making them their own (Deuchar, 2006), thus supporting Thornton's (2005) notion of teachers as curriculum "gatekeepers". 


\section{Participatory capital as "symbolic" capital?}

Underlying the findings presented here remains an unexplored question of whether the participatory capital exhibited within schools also has symbolic capital? Bourdieu suggests that forms of capital do not exist and function except in relation to a field (Bourdieu \& Wacquant, 1992). In this case, the educational field that "social action" and participatory citizenship is embedded in is likely to attribute certain forms of participatory capital with symbolic capital, and therefore award them "distinction" (Bourdieu, 1984).

While the findings from my research did not focus on how participation was measured (assessed) or viewed by members of the public and community around the school, it is possible to surmise that certain forms of participation are more "acceptable" than others and that certain practices of participation are likely to receive more approval than others. Indeed, this is supported by a number of New Zealand-based examples, where school-aged young people have been reprimanded for more radical expressions of participation (Beals \& Wood, 2011; Kidman, 2005). Within an educational framework that has been influenced by Knowledge economy, Third way ideas, and a business model of education which views students as human capital, participation that encourages young people to respond with flexibility, innovation and entrepreneurship to the changing needs of global markets and therefore fuel economic growth and development (Grossman, 2008), is likely to be met with approval. It is also likely that "global" knowledge and "global" participation in the sense of participation toward global economic competitiveness and employability will be valued highly. For this reason, it is possible to speculate that social, cultural and economic capital that favours global orientations is likely to hold greater symbolic capital within an educational field than local orientations.

This analysis has implications for the local-oriented, lower decile schools (Colleges B and C) in particular. By focusing on community issues and local action, teachers were possibly restricting their student's access to the "powerful knowledge" (Young, 2008) that is held in the hands of globally-oriented elites. If so, this would render these young people unable to access the symbolic (and 
associated economic, cultural and social) capital associated with global knowledge economies. The dilemma this question presents is heightened by findings from this research and others (Gruenewald, 2003; Harris \& Wyn, 2009; Weller, 2007; Zipin \& Reid, 2008) which suggests that political and social issues take on greater meaning for young people when interpreted through local experiences, and that young people had greater levels of insight, critique, and agency over issues which were part of their everyday, lived experiences.

In the final section of this chapter, I explore an approach to this issue through Mills' sociological imagination that could provide a way to reduce the more deterministic aspects of differences in participatory capital by exploring the interconnectedness between the local and the global, the personal and the political, and in doing so suggests that this can also develop transformative citizenship dispositions.

\section{Radical participation in the practices of everyday life}

What young people produce may not be the same as what adults produce, but does that mean that what they articulate is less worthy, less of a genuine political analysis that might lead to change? (Skelton, 2010, p. 147)

The attention paid to everyday and informal citizenship is an important one, and my research has demonstrated that it reveals many nuanced understandings of the relationship between young people's lived experiences and their participatory citizenship. In particular, these findings have highlighted the subtle ways that belonging to communities is closely tied up with expressions of transformation and protection seen through young people's citizenship imaginations about those communities. However, an emphasis only on informal participation may reduce the role that engagement in the formal institutions of democracy often requires. Chris Philo and Fiona Smith (2003) argue against collapsing the categories of personal and political completely. They suggest that:

The message is not that politics should be redefined solely in terms of the personal and localised experiences of children and young people and nor does it mean producing child-centred political geographies with blinkers against the macro-politics of the (adult) public sphere. What is does suggest is that we should concentrate on connections between the micro and the macro.... (Philo \& Smith, 2003, p. 111) 
Similarly, Massey (1998) suggests that a more helpful approach to the conceptualisation of scale (rather than, for example, local or global) is a "notion of space as organised not into distinct scales, but rather through a vast complexity of interconnections" (Massey, 1998, p. 124, my emphasis). I propose that starting with young people's experiences within local and everyday places, and extending them to consider how these reflect wider societal patterns and processes, is an alternative way to encourage young people's participation in society. In fact this was the stated aim of C. Wright Mills' sociological imagination - to start with personal conditions as the basis for examining structural conditions in society with the aim of transformative change.

The use of the sociological imagination in this project illustrates one way that the interconnections between local and global, personal and public can be approached. Through the Photovoice activity, participants had an opportunity to, in Mills (1959) terms, reflect upon their "personal troubles of milieu," (p. 8) which occur within the range of his or her immediate relations with others, and then place these within "the public issues of social structure," (p. 8) which are issues which transcend the individual i.e. a public matter. Mills suggest that the process of articulation (of personal issues) reformulates these as problems of public society and the social sciences, thus moving beyond positions of apathy, uneasiness and indifference. While many of these reflections through Photovoice did not arrive in political action, giving permission for young people to use their citizenship imagination, or their "political imaginaries" (Marsh, et al., 2007) provides us with a glimpse of their "political consciousness" (Llewellyn \& Westheimer, 2009) and citizenship dispositions.

Gruenewald (2003) takes a similar stance to Mills and suggests that the starting point for place-based education is a pedagogy that relates directly to student experience of the world, so that "the education of citizens may have some direct bearing on the well being of the social and ecological places people actually inhabit" (p. 3). Rather than reducing the significance of the local, a pedagogy of place foregrounds local and regional politics, and recognises the connectedness of local experiences with global trends (Gruenewald, 2003). 
Zipin and Reid (2008) advance this position further. As a result of their work with students from disadvantaged backgrounds in Adelaide, they propose that citizenship education would benefit by "making the community curricular." They suggest that the dominant conceptions of democracy assume an individualistic and competitive market economy in which citizens play minimal or participatory roles that reinforce the status quo. The concept of community in this conception is an arena that becomes an object of study or a site for participation and problem solving. Zipin and Reid critique these dominant models of citizenship as they "reify official knowledges that encode the cultural capital of power elite groups - which 'less advantaged' learners are seen to 'lack' - over experiences and knowledges that students gain in their lives beyond school" (p. 534). They argue that these dominant models fail to address issues of social justice and inequality and argue are in turn instrumentalist and individualistic.

As an alternative, they call for more expansive views of democracy, citizenship and community, and follow Arendt (1958) who proposes that the quality of human interaction, rather than particular characteristics possessed by individuals, construct democratic subjectivity. Similar to Lister's $(2003,2007 a)$ ideas introduced in Chapter 2, they suggest that young people learn to be citizens within the actual practices that make up their lives (lived citizenship). They suggest that this means giving value to the learning assets that young people currently hold in their lives and communities and integrating these into curriculum. Then, in the reverse direction, re-making communities through curriculum work in which students create new knowledge about, and for, their locales (Zipin \& Reid, 2008, p. 536). They propose that such efforts “(a) enable critical appreciation of local complexities, avoiding simplistic stereotypes and (b) galvanise imagination and ethical impulse to engage local community life proactively" (p. 542). Similar to Mills, they suggest that consciousness about local issues in relation to wider structural contexts provides opportunities to seek socially just change. 
These insights (of Mills, Gruenewald and Zipin \& Reid) have informed the position I have arrived at as a result of this research, in acknowledging the radical and transformative potential of locally-conceived and practised citizenship. This starting point allows opportunities for young people's citizenship to be conceived of within their everyday and place-based experiences of life, yet, rather than remaining here, seeks to explore the connections of these experiences to broader societal and political structures beyond the personal. Buckingham (2000) suggests that this is a major challenge for teachers - to find ways of establishing the relevance of politics and of connecting the micropolitics to the macro-politics of the public sphere whilst still enabling young people to be critical citizens in the context of their everyday citizenship. This position recognises the interconnections between private and public participation, citizenship imaginations and citizenship actions and micro and macro politics, rather than trying to falsely separate these binaries that often exist simultaneously in young people's lives (Skelton, 2010). Rather than viewing their current experiences of participation as deficient, they provide the opportunity to cultivate, explore and practice citizenship now. 


\section{CHAPTER 9: \\ CONCLUSION}

In the introductory chapter to this thesis I proposed that it was necessary to explore the area of youth citizenship participation in light of the more "active" conceptions of citizens portrayed in the New Zealand Curriculum, and more participatory conceptions of young people in society in general (Kirby, et al., 2003; Prout, 2003; Prout, et al., 2006). I also set out a number of propositions which guided how I would go about this, in order to widen the traditional conceptions of the political and emphasise young people's everyday, place-based perspectives on citizenship participation. In this final chapter, I will review the findings of this research and draw together a number of conclusions. I also suggest some opportunities for further research in this area.

\section{Review of findings}

The first question I set out to answer was "what are social studies teachers' conceptions of social action and how do these inform their practices of social action?" My discussions with 29 teachers across the four schools revealed that while most of these teachers were enthusiastic about the idea of "taking action" within social studies, they had multiple and varied conceptions of what social action was, and how it could be integrated in social studies programmes (Chapter 5). These varying conceptions were reflected in the spatial orientations toward social action (local or global) and pedagogical practices (see Table 8.1). For example, Colleges A and D could be described as being more "globallyfocused" in their participation orientation, and Colleges B and C more "community-focused." Social action was seen by teachers to provide opportunities to create active learners (adept at problem-solving, innovative thinking, lifelong learners) and active citizens (able to challenge those in power and address issues of social justice). The tension in these two approaches reflected largely "safe" and risk-free practices of social action, yet some examples of more change-oriented conceptions and practices of social action were also evident. 
The practices of teachers appeared to contribute toward their students' perceptions of which issues were "important". This was the focus of my second research question which explored the issues young people reported to be important and why (Chapter 6). The close correspondence between topics studied in social studies and the reported issues of importance by social studies students in these classes underscores the influence of a teachers' cultural capital. For example, the attention drawn to community issues in College $\mathrm{C}$ also appeared to have shaped student's perceptions of issues and awareness of a considerable number of local and community issues.

Awareness of issues was also shaped by young people's experiences beyond school. These were seen through their expressions of belonging/exclusion within places, their spatial mobility and relationships with others (such as through church). Their sense of identification, caring and responsibility to preserve or protect places (and groups) in their communities (what I have termed citizenship imagination) was seen in the issues they focused on and their statements of concern or celebration. These findings point toward how young people's participatory capital, habitus and citizenship dispositions were formed through exposure to social and cultural capital in the context of their schools and communities.

By linking the development of young people's citizenship identities to their everyday places, we gain new insights into how their political identities as citizens are forged. However, with the exception of College C's Community Issues class, it appeared that the potential for hearing the place-based issues concerns and attributes which young people were interested in transforming and/or conserving appears to have been largely overlooked by their social studies teachers. In failing to seize the opportunities to make "community curricular" (Zipin \& Reid, 2008), teachers had also reduced the opportunity for young people to focus on some of the more radical and socially transformative issues in their communities, and ones which they had arguably a greater ability to make a difference in. 
My final question was addressed in Chapter 7, and asked "how do social studies students define and participate in social action?" One of the central proposition I began my study with, was the need to look beyond adult-centric definitions of participation and consider the meanings that young people themselves hold toward social action. This included paying attention to both formal and informal experiences of participation, as well as employing a place-sensitive approach to highlight the where of participation. This approach revealed insights into the complex, diversified and nuanced landscape of young people's participation in citizenship.

Young people had wider and more diverse conceptions of social action than their teachers. In particular, they drew attention to less formal conceptions of social action expressed within the context of their everyday friendships and patterns of behaviour (such as daily actions toward recycling, consumption of goods and conservation of resources). Differences between young people's conceptions and practices of social actions were also notable by their age. Older teens described more formal conceptions and examples of social action than young teens, and it was apparent that they were given many more formal opportunities for participation than younger teens (even within one school). Younger teens' participation reflected the fewer formal opportunities afforded them by nature of their age and status, yet they demonstrated many ways they were taking action in their personal, everyday spaces upon issues they saw as significant such as racism, bullying and water wastage. A significant number of young people (16/28 focus groups) reported that the status of young people in society was a barrier to their participation in social action. It could be that the tendency toward informal expressions of participatory citizenship by the less empowered younger teens in particular reflected the very real issues of constrained access to decision-making and participatory power in society.

Young people's conceptions and practices of social action and their awareness of social issues appeared to be closely linked to their relational interactions and the respective access to social, cultural and economic capital gained through these 
interactions. I suggest that Bourdieu's concepts of social, cultural and economic capital provide an explanation of how and why participatory capital can differ between social groups and fields (in this case, the educational field of a school community). The interaction between social groups in this field, and the participatory capital they value and had access to, resulted in differing expressions of participation. For young people in this study, teachers played a pivotal role in providing access to the social, cultural and economic capital that shaped conceptions and practices of participation. However, I have also shown that young people's own social capital, gained through their experiences of growing up in communities, played a vital role in shaping their citizenship dispositions. Moreover, young people were also contributing to social capital in their schools and neighbourhoods through their actions. These findings point to the importance of spatial and relational-centred understandings of young people's participation in society.

\section{Avenues for further research}

This study raises a number of avenues for further exploration in this area that would advance and complement the findings presented in this thesis. Some of the trends observed in this study would benefit from a larger scale study to find if these hold true across wider populations. For example, this study showed that young people showed considerable interest in both environmental issues and environmental actions. Yet, they also demonstrated some cynicism toward issues such as global warming. It would be interesting to explore this issue further with a larger group of young people, and if possible with a longitudinal process in place to gauge changes in perceptions over time.

The use of a Mills-Bourdieu framework to provide an analytical approach to the area of youth participatory citizenship revealed a number of insights. By applying Bourdieu's concepts of habitus, capital and field, and Mills' sociological imagination as a "both method and theory" (Reay, 2004, p. 439), I was able to propose a new perspective on youth participation. Rather than viewing youth participation as a process removed from the places and experiences of young 
people growing up in society, through Bourdieu's conceptual triad I suggested that young people gain participatory capital through the exposure they have to various conceptions and practices of social action. It appeared that these differences in participatory capital (gained through access and exposure to social, cultural and economic capital) led to differences in orientation (global or locally-focussed) and dispositions toward participation within school communities. Furthermore, applying Mills' sociological imagination through the Photovoice activity in particular enabled young people's citizenship imaginations to be brought to the fore, thus highlighting their agency within structural constraints and adult limitations. The Mill's-Bourdieu framework suggested in this research would be usefully followed up by research in other settings. For example, applying a similar approach with young people who share similar neighbourhoods but attend different schools may accentuate the role of teachers' capital over spatial and social experiences. As noted in Chapter 4, future research in this area could more specifically examine how familial social and cultural capital informs young people's participation. It would also be valuable to extend similar research internationally with young people with different official curricula and environments.

Further research into how a sociological imagination approach could be employed within a school curricula context would also be valuable. The focus of this study did not lend itself to the participatory action research approach that this would require, and, as noted in Chapter 4, issues of confidentiality reduced my ability to explore place-based social change and historical contexts more thoroughly within this study. Further research in this area would also align particularly well with the new social inquiry approach in the social sciences learning area of the New Zealand Curriculum.

\section{Concluding reflections}

In concluding, I wish to make three final points based on the findings from this doctoral research. First, this research has drawn attention to the importance of "a coherent understanding of context" (Barber, 2009, p. 38) in exploring young 
people's participation and citizenship. This supports Malone and Hartung's (2010) suggestion that a "one size fits all model" of young people's participatory citizenship will fail to account for the contextualised and unique ingredients that contribute to young people's experiences and expressions of citizenship and participation. By drawing attention to context and everyday spaces, this study accentuated how many of the social issues young people noticed were shaped by their lived experiences in communities and schools. Social and political issues appeared to take on a greater degree of significance and meaning for young people when they had a lived experience of them in their local contexts. Moreover, this level of local awareness and engagement also led to higher levels of critical analysis of these issues and an enhanced sense of agency to respond as citizens. Acknowledging these contextual complexities and grappling with tensions and contradictions of child participation in practice, is likely to be one of the most rewarding aspects of youth participation (Naker, Mann, \& Rajani, 2007).

Second, this research has highlighted the importance of viewing young people as “experts in their own citizenship" (Weller, 2007, p. 167). Hearing how young people themselves are making meaning of their roles, responsibilities and participation as citizens in society reveals the complexity of their thinking and their consciousness of their everyday way of making a difference. For example in the discussion that I began this thesis with (p. 1), two female participants at College A described how they had given "a couple of bucks to charity" (Claire, 18) and "coached different teams" (Wonderwoman, 17) as part of their social action. Their discussion highlights the multiple and varied understandings young people hold toward social action and how many of their examples would fall beneath the radar of many adult-centric conceptions of social action.

Third, schools constitute one of the most significant spaces in which young people learn about and experience democracy, participation and citizenship (Benton, et al., 2008; Evans, 2006; Ireland, et al., 2006; Warrick, 2008; Weller, 2009). This study has highlighted the strategic role that teachers play in shaping and supporting young people's citizenship participation and dispositions 
through the topics they study, the opportunities they offer for social action, and the conceptions of citizenship which they hold. While there was some evidence that their conceptions of social action reinforced neoliberal conceptions of social action to create active learners and employable citizen-workers, I have also argued that teachers in this study did far more than "generate technically skilled workers via required classes" (McFarland \& Thomas, 2006, p. 421). For example, the development of the Community Issues class at College $\mathrm{C}$ in response to limited opportunities afforded to social action through the 1997 social studies curriculum, demonstrates high levels of commitment to maximal participatory citizenship, and shows considerable creativity and agency in the context of heightened levels of management in education (Ball, Goodson, \& Maguire, 2007).

These findings present a number of challenges to teachers, curriculum developers and youth workers since I suggest that place-based, locally-derived, everyday experiences of participation need to drive participatory citizenship, not the agendas of policy makers. Taking time to find out about the issues which interest young people and motivate them to take action is an important step toward encouraging participatory citizenship that is meaningful to young people as citizens now, and reduces the potential for fears of indoctrination and valueimposition. Acknowledging the deep significance of places in shaping young people's identities and responses as citizens, and allowing these places to penetrate the realms of the classroom and become the starting point of social action is an important way to bridge the "unnatural' cultural-ecological divide" (Greenwood, 2008) that is dominant in classroom discourse. Greenwood 61 (2008) advocates that the people who know the peculiarities of their places best should have a strategic role in answering the questions: what needs to be conserved, transformed, restored or created here? This study has highlighted that young people are indeed current critics, observers and carers of places. Seeing young people in this light presents a number of fresh opportunities for social studies teachers to maximise on the transformative learning potential of including what young people currently know and experience as "care-takers" and "change-leaders" (Warrick, 2008) within their communities.

\footnotetext{
${ }^{61}$ Formerly Gruenewald (David, A.).
} 
The inclusion of participatory citizenship goals within school curricula will present a continuing challenge in light of the malleability of the concepts of social action and participatory citizenship which has been illustrated on a number of occasions in this thesis. Openshaw (2004) postulates that a central dilemma for social studies educators in the early twenty-first century has become whether they should stick with the kind of citizenship that is highly adaptable to the status quo (thus creating employable and quiet future citizens/consumers), or whether they should encourage citizens to challenge existing structures.

In conclusion, these findings hold the potential to shift the debate about whether young people today are "active" or "apathetic", to a focus on the interaction between young people's everyday lived experiences in places, and their participation in society. By using the sociological imagination through the "lens of their own experiences" (Llewellyn \& Westheimer, 2009, p. 52) to explore young people's citizenship participation, we have gained fresh insights into young people's current engagement as citizens. Furthermore, acknowledging expressions of participatory citizenship within young people's socio-spatial experiences of schools and communities highlights the potential to cultivate the participatory capital which social groups currently hold, rather than assuming that one model of participation applies to all. In drawing attention to young people's everyday, place-based citizenship participation, I suggest that these actions not only "count," but also provide a powerful starting point for justiceoriented and transformative citizenship in society. 


\section{REFERENCES}

Abowitz, K. K., \& Harnish, J. (2006). Contemporary discourses of citizenship. Review of Educational Research, 76(4), 653-690.

Aitken, G. (2005). Curriculum design in New Zealand social studies: Learning from the past. Unpublished Doctor of Education thesis, University of Auckland, Auckland.

Aitken, G., \& Sinnema, C. (2008). Effective Pedagogy in Social

Sciences/Tikanga-a-iwi: Best Evidence Synthesis Iteration (BES).

Retrieved from

http://www.educationcounts.govt.nz/publications/series/2515/32 879/35263.

Aitken, S. (2001). Geographies of young people: The morally contested spaces of identity. London/New York: Routledge.

Alderson, P. (1995). Listening to children; Children's ethics and social research. Barkingside, UK: Barnardos.

Allen, L. (2008). Young people's 'agency' in sexuality research using visual methods. Journal of Youth Studies, 11(6), 565-577.

Allen, L. (2009). 'Snapped': Researching the sexual cultures of schools using visual methods. International Journal of Qualitative Studies in Education, 22(5), 549-561.

Anderson, J., \& Jones, K. (2009). The difference that place makes to methodology: Uncovering the 'lived space' of young people's spatial practices. Children's Geographies, 7(3), 291-303.

Annette, J. (2009). 'Active learning for active citizenship': Democratic citizenship and lifelong learning. Education, Citizenship and Social Justice, 4(149-160).

Apple, M. (1979). Ideology and curriculum. London: Routledge/Kegan Paul.

Apple, M. (1993). Official knowledge: Democratic education in a conservative age. London: Routledge.

Archer, E., \& Openshaw, R. (1992). Citizenship and identity as 'official goals' goals in social studies. In R. Openshaw (Ed.), New Zealand Social Studies: Past, Present and Future (pp. 19-33). Palmerston North: Dunmore Press.

Arendt, H. (1958). The human condition. Chicago: The University of Chicago Press.

Arthur, J. (2003). Community involvement and communitarian theory. from Citized [online resources]:

www.citized.info/pdf/commarticles/Community Involvement James Arth $\underline{\text { ur.pdf }}$

Arthur, J., Davies, I., \& Hahn, C. (2008). The Sage handbook of education for citizenship and democracy. London: Sage.

Baildon, M., \& Sim, J. B.-Y. (2009). Notions of criticality: Singaporean teachers' perspectives of critical thinking in social studies. Cambridge Journal of Education, 39(4), 407-422.

Ball, S., Goodson, I. F., \& Maguire, M. (2007). Education, globalisation and new times. London: Routledge. 
Bang, H. (2009). 'Yes we can': Identity politics and project politics for a latemodern world. Urban Research \& Practice, 2(2), 117-137.

Barber, T. (2009). Participation, citizenship and well-being: Engaging with young people, making a difference. Young, 17(1), 25-40.

Barker, J., \& Smith, F. (2001). Power, positionality and practicality: carrying out fieldwork with children. Ethics, Place \& Environment, 4(2), 142147.

Barker, J., \& Weller, S. (2003). 'Is it fun?': Developing children centred research methods. International Journal of Sociology and Social Policy, 23(1/2), 33-59.

Barr, H. (1998). The nature of social studies. In P. Benson \& R. Openshaw (Eds.), New horizons for New Zealand social studies. Palmerston North: ERDC Press, Massey University.

Barr, H., Graham, J., Hunter, P., Keown, P., \& McGee, J. (1997). A position paper: Social studies in the New Zealand school curriculum. Hamilton: University of Waikato School of Education

Batan, C. (2010). Istambay: A sociological analysis of youth inactivity in the Philippines. Unpublished PhD, Dalhousie University, Halifax, Nova Scotia, Canada.

Beals, F., \& Wood, B. E. (2011). Negotiating agency: Local youth activism in Aotearoa New Zealand. In K. Brison \& S. Dewey (Eds.), Super girls, gangstas, freeters, and xenomaniacs: Gender and modernity in global youth cultures. New York: Syracuse University Press.

Beck, U. (1992). Risk society: Towards a new modernity (M. Ritter, Trans.). London: Sage Publications.

Beck, U. (2007). A new cosmopolitanism is in the air. Literaturen, November 2007.

Ben-Porat, G., \& Turner, B. (2008). Contemporary dilemmas of Israeli citizenship. Citizenship Studies, 12(3), 195-201.

Benton, T., Cleaver, E., Featherstone, G., Kerr, D., Lopes, J., \& Whitby, K. (2008). Citizenship educational longitudinal study (CELS): Sixth annual report: Young people's civic participation in and beyond school: Attitudes, intentions and influences. [online]: National Foundation for Educational Research.

Berg, B. L. (2007). Qualitative research methods for the social sciences (6th ed.). Boston: Pearson Education Ltd.

Bernstein, B. (1971). On the classification and framing of education knowledge. In M. Young (Ed.), Knowledge and control: New directions for the sociology of education (pp. 47-69). London: Collier Macmillan.

Bessant, J. (2004). Mixed messages: Youth participation and democratic practices. Australian Journal of Political Studies, 39(2), 387-404.

Best, A. L. (2007). Introduction. In A. Best (Ed.), Representing youth: Methodological issues in critical youth studies (pp. 1-36). New York: New York University Press.

Bourdieu, P. (1977a). Cultural reproduction and social reproduction. In J. Karabel \& A. Halsey (Eds.), Power and ideology in education. New York: Oxford University Press.

Bourdieu, P. (1977b). Outline of a theory of practice (R. Nice, Trans.). Cambridge: Cambridge University Press. 
Bourdieu, P. (1984). Distinction: A social critique of the judgement of taste. London: Routledge \& Kegan Paul.

Bourdieu, P. (1990). The logic of practice. Stanford: Stanford University Press.

Bourdieu, P. (1999). The weight of the world: Social suffering in contemporary society. Cambridge: Polity Press.

Bourdieu, P. (2000). The politics of protest. Socialist Review, (242). Retrieved from http://pubs.socialistreviewindex.org.uk/sr242/ovenden.htm

Bourdieu, P. (2002). Habitus. In J. Hillier \& E. Rooksby (Eds.), Habitus: $A$ sense of place (pp. 27-34). Aldershot: Ashgate.

Bourdieu, P., \& Passeron, J.-C. (1977). Reproduction in education, sociaty and culture (R. Nice, Trans.). London: Sage.

Bourdieu, P., \& Wacquant, L. (1992). An invitation to reflexive sociology. Chicago: The University of Chicago Press.

Brooks, R., \& Holford, J. A. (2009). Citizenship, learning and education: Themes and issues. Citizenship Studies, 13(2), 85-103.

Brown, J., \& Isaacs, D. (2005). The world café: Shaping our futures through conversations that matter. San Francisco: Berrett-Koehler Publishers Inc.

Buckingham, D. (2000). The making of citizens: Young people, news and politics. London: Routledge.

Cahill, C. (2000). Street literacy: Urban teenagers strategies for negotiating their neighbourhood. Journal of Youth Studies, 3(3), 251-277.

Castells, M. (2000). The Rise of the Network Society. Malden, MA: Blackwell Publishing.

Catt, H. (2005). Now or never. Paper presented at the 6th Child and Family Policy conference. Retrieved from http://www.elections.org.nz/study/researchers/litrevsbiblios/now-or-never-lit-review.html

Chisholm, L. (2001). Youth in knowledge societies: Challenges for research and policy. Young, 9(1), 61-72.

CIRCLE. (2002). Youth civic engagement: Facts and trends. Maryland: Centre for Information and Research on Civic Learning and Engagement.

Clark, A., \& Percy-Smith, B. (2006). Beyond consulation: Participatory practices in everyday spaces. Children, Youth and Environments, 16(2), 1-9.

Codd, J. (2005a). Education policy and the challenges of globalisation: Commercialisation or citizenship? In J. Codd \& K. Sullivan (Eds.), Policy directions in Aotearoa New Zealand (pp. 3-16). Southbank Victoria: Thomson Dunmore Press.

Codd, J. (2005b). Introduction: Is there a 'Third Way' for educational policy? In J. Codd \& K. Sullivan (Eds.), Education policy directions in Aotearoa New Zealand (pp. xiii-xviii). Melbourne: Thomson/Dunmore Press.

Cogan, J., \& Derricott, R. (2000). Citizenship for the 21st century: An international perspective on education. London: Kogan Page Ltd.

Cohen, L., Manion, L., \& Morrison, K. (2000). Research methods in education. New York: Routledge. 
Coleman, S. (2005). Remixing citizenship: Democracy and young people's use of the internet (Research Report). London: Carnegie Young People's Initiative.

Comstock, D. (1982). A method for critical research. In E. Bredo \& W. Feinberg (Eds.), Knowledge and values in social and educational research (pp. 370-390). Philadelphia: Temple University Press.

Cook, Tina, \& Hess, E. (2007). What the camera sees and from whose perspective: Fun methodologies for engaging children in enlightening adults. Childhood, 14(1), 29-45.

Cornbleth, C. (1990). Curriculum in context. London: Falmer Press.

Cremin, H., Warwick, P., Harrison, T., \& Mason, C. (2009). Building voice, civic action and learning: What can we learn from young people living in socio-economically disadvantaged communities?: Interim report. Cambridge: University of Cambridge, University of Leicester, Community Service Volunteers, Society for Educational Studies.

Cresswell, T. (2002). Bourdieu's geographies: In memorium. Environment and Planning D: Society and Space, 20, 379-382.

Cresswell, T. (2004). Place: A short introduction. Malden: Blackwell Publishing.

Crick, B. (1998). Education for citizenship and the teaching of democracy in schools: Final report of the Advisory Group in Citizenship. Retrieved from http://www.citizenship.org.uk/data/files/crick-report-19981201554.pdf

Davies, B., \& Bansel, P. (2007). Neoliberalism and education. International Journal of Qualitative Studies in Education, 20(3), 247-259.

Davis, J. M., \& Hill, M. (2006). Introduction. In E. K. Tisdall, J. M. Davis, M. Hill \& A. Prout (Eds.), Children, young people and social inclusion: Participation for what? (pp. 1-19). Bristol: The Policy Press.

de Certeau, M. (1988). The practice of everyday life (S. Rendall, Trans.). Berkeley/LA: University of California Press.

DeJaeghere, J. (2007). Intercultural meanings of citizenship in the Australian secondary curriculum: Between critical contestations and minimal constructions. In S. Doyle \& L. Bradley (Eds.), Reimagining civic education: How diverse societies form democratic citizens. Lanhan: Rowman \& Littlefield Publishers.

Denzin, N., \& Lincoln, Y. (2003). The discipline and practice of qualitative research. In N. Denzin \& Y. Lincoln (Eds.), Strategies of qualitative inquiry (2nd ed., pp. 1-45). Thousand Oaks: Sage.

Denzin, N., \& Lincoln, Y. (2005). The Sage handbook of qualitative research. Thousand Oaks: Sage.

Department of Education. (1944). The post-primary school curriculum: Report of the Committee appointed by the Minister of Education in November, 1942 (The Thomas Report). Wellington: Government Printer.

Department of Education. (1961). Social studies in the primary school. Wellington: Government Printer.

Department of Education. (1977). Social studies syllabus guidelines: Forms 1-4. Wellington: Government Printer. 
Deuchar, R. (2006). "Not only this, but also that!": Translating the social and political motivations underpinning enterprise and citizenship education into Scottish schools. Cambridge Journal of Education, 36(4), 533-547.

Dickinson, J., Andrucki, M. J., Rawlins, E., Hale, D., \& Cook, V. (2008). Introduction: Geographies of everyday citizenship. ACME: An International E-Journal for Critical Geographies, 7(2), 100-112.

Dodman, D. (2003). Shooting in the city: An autobiographic exploration of the urban environment in Kingston, Jamaica. Area, 35(3), 293-304.

Duhn, I. (2006). The making of the global citizens: Traces of cosmopolitanism in the New Zealand early childhood curriculum, Te Whariki. Contemporary Issues in Early Childhood, 7(3), 191-202.

Duhn, I. (2008). Globalising childhood: Assembling the bicultural child in the New Zealand early childhood curriculum, Te Whariki. International Critical Childhood Policy Studies, 1(1), 82-105.

Dwyer, C., \& Limb, M. (2001). Introduction: Doing qualitative research in geography. In M. Limb \& C. Dwyer (Eds.), Qualitative methodologies for geographers: Issues and debates (pp. 1-20). London/NY: Arnold/Oxford University Press.

Dyck, I. (2005). Feminist geography, the 'everyday', and local-global relations: Hidden spaces of place-making. The Canadian Geographer, 49(3), 233-243.

Dyck, I., \& Kearns, R. (1995). Transforming the relations of research: Towards culturally safe geographies of health and healing. Health and Place, 1(3), 137-147.

Education Review Office. (2007-2010). Education Review Reports, http://www.ero.govt.nz/. Wellington: ERO.

Edwards, K. (2007). From deficit to disenfranchisement: Reframing youth electoral participation. Journal of Youth Studies, 10(5), 539-555.

Electoral Commission (NZ). (2005). Briefing to the incoming Minister 2005. Retrieved from http://www.elections.org.nz/news/2005-mediareleases/ec-bim-2005.html.

Electoral Commission (NZ). (2007). e-news, No 10, November '07. Retrieved October 2008, from http://www.elections.org.nz/news/2007-media-releases/ecenews-nov07.html

Elwood, S., \& Martin, D. (2000). 'Placing' interviews: Location and scales of power in qualitative research. Professional Geographer, 52(4), 649657.

Enviroschools webpage. (n.d.). Summary of participation. Retrieved 21 May, 2010, from http://www.enviroschools.org.nz/aboutenviroschools/enviroschools-stats/summary-of-participation

ERO. (2001). The New Zealand Curriculum: An ERO perspective, Part 4: Social Studies. Retrieved from http://www.ero.govt.nz/ero/publishing.nsf/Content/3B47D7E571 DE3E1DCC2571D30014618E?Open.

Evans, M. (2006). Educating for citizenship: What teachers say and what teachers do. Canadian Journal of Education, 29(2), 410-435. 
Fahmy, E. (2006). Social capital and civic action: A study of youth in the United Kingdom. Young, 14(1), 101-118.

Farthing, R. (2010). The politics of youthful antipolitics: Representing the 'issue' of youth participation in politics. Journal of Youth Studies, 13(2), 181-195.

Faubion, J., \& Marcus, G. (2008). Constructionism in anthropology. In J. Holstein \& J. Gubrium (Eds.), Handbook of constructionist research (pp. 67-84). NY: The Guilford Press.

Faulks, K. (2000). Citizenship. London: Routledge.

Fielding, M. (2007). 'Beyond voice': New roles, relations and contexts in researching with young people. Discourse: Studies in the Cultural Politics of Education, 28(3), 301-310.

Fitzsimons, P. (2006). Third way: Values for education? Theory and Research in Education, 4(2), 151-171.

Flyvbjerg, B. (2004). Five misunderstandings about case-study research. In C. Seale, G. Gobo, J. BGubrium \& D. Silverman (Eds.), Qualitative research practices (pp. 420-434). London: Sage.

Freeman, C. (2010). Children's neighbourhoods, social centres to 'terra incognita'. Children's Geographies, 8(2), 157-176.

Freire, P. (1973/1996). Pedagogy of the oppressed. London: Penguin Books.

Freire, P. (1985). The politics of education: Culture, power and liberation. South Hadley: Bergin \& Garvey.

Friedmann, J. (2002). Placemaking as project? Habitus and migration in transnational cities. In J. Hillier \& E. Rooksby (Eds.), Habitus: A sense of place (pp. 299-316). Aldershot: Ashgate.

Furlong, A., \& Cartmel, F. (2007). Young people and social change: New perspectives (2nd ed.). Maidenhead: Open University Press.

Gallagher, M. (2008). 'Power is not evil': rethinking power in participatory methods. Children's Geographies, 6(2), 137-150.

Gallagher, M. (2009). Data Collection and analysis. In E. K. Tisdall, J. Davis \& M. Gallagher (Eds.), Researching with children and young people (pp. 65-88). London: Sage.

Giddens, A. (1984). The constitution of society: Outline of a theory of structuration. Cambridge: Polity Press.

Giddens, A. (1994). Living in a post-traditional society. In U. Beck, A. Giddens \& S. Lash (Eds.), Reflexive modernisation: Politics, traditions and aesthetics in the modern social order (pp. 56-109). Cambridge: Polity Press.

Giddens, A. (2000). The Third Way and its critics. Oxford: Polity Press.

Gilbert, J. (2003). 'New' knowledges and 'new' ways of knowing: Implications and opportunities. Paper presented at the NZCER conference: Educating for the 21st century, Rethinking the educational outcomes we want for young New Zealanders.

Gilbert, J. (2005). Catching the knowledge wave? The knowledge society and the future of education. Wellington: NZCER Press.

Gilbert, J. (2007). "Catching the knowledge wave": Redefining knowledge for the Post-Industrial age. Education Canada, 47(3), 4-8.

Gill, J., \& Howard, S. (2009). Knowing our place: Children talking about power, identity and citizenship. Camberwell: ACER Press. 
Giroux, H. (1997). Ideology, agency and the process of schooling. In H. Giroux (Ed.), Pedagogy and the politics of hope: Theory, culture and schooling (pp. 71-94). Colorado/Oxford: Westview Press.

Giroux, H. (2009). Introduction: Democracy, education and the politics of critical pedagogy. In P. Mclaren \& J. Kincheloe (Eds.), Critical pedagogy: Where are we now? NY: Peter Lang.

Greenwood, D. A. (2008). A critical pedagogy of place: From gridlock to parallax. Environmental Education Research, 14(3), 336 - 348.

Grossman, D. (2008). Introduction. In D. Grossman, W. On Lee \& K. Kennedy (Eds.), Citizenship Curriculum in Asia and the Pacific (Vol. 22, pp. 110). Hong Kong: Camparative Education Research Centre.

Grudens-Schuck, N., Lundy Allen, B., \& Larson, K. (2004). Focus group fundamentals. Retrieved from

http://www.extenison.iastate.edu/Publications/PM1969B.pdf

Gruenewald, D. (2003). The best of both worlds: A critical pedagogy of place. Educational Researcher, 32(4), 3-12.

Gruenewald, D., \& Smith, G. (2008). Place-based education in the global age: Local diversity. Mahwah, NJ: Lawrence Erlbaum.

Gubrium, J., \& Holstein, J. (2003). Analyzing interpretive practice. In N. Denzin \& Y. Lincoln (Eds.), Strategies for qualitative inquiry (pp. 214248). Thousand Oaks: Sage.

Gubrium, J., \& Holstein, J. (2008). The constructionist mosaic. In J. Holstein \& J. Gubrium (Eds.), Handbook of constructionist research (pp. 3-10). NY: The Guilford Press.

Hahn, C. (2008). Education for Citizenship and Democracy in the United States. In J. Arthur, I. Davies \& C. Hahn (Eds.), The Sage Handbook of Education for Citizenship and Democracy (pp. 263-278). London: Sage.

Hall, T., Coffey, A., \& Williamson, H. (1999). Self, space and place: Youth identities and citizenship. British Journal of Sociology of Education, 20(4), 501-513.

Halvorsen, A.-L. (2009). Back to the future: The expanding communities curriculum in geography education. The Social Studies, 115-119.

Harker, R. (1990). Bourdieu - Education and reproduction. In R. Harker, C. Mahar \& C. Wilkes (Eds.), An introduction to the work of Pierre Bourdieu: The practice of theory (pp. 86-108). Houndsmills: The Macmillan Press Ltd.

Harris, A. (2006). Introduction: Critical perspectives on child and youth participation in Australia and New Zealand/Aotearoa. Children, Youth and Environments, 16(2), 220-230.

Harris, A. (2008). Young women, late modern politics, and the participatory possibilities of online cultures. Journal of Youth Studies, 11(5), 481495.

Harris, A. (2010). Young people, everyday civic life and the limits of social cohesion. Journal of Intercultural Studies, 31(5), 573-589.

Harris, A., \& Wyn, J. (2009). Young people's politics and the microterritories of the local. Australian Journal of Political Science, 44(2), 327-344. 
Harris, A., \& Wyn, J. (2010). Special issue of Young on emerging forms of youth participation: Everyday and local perspectives Young, 10(1), 3-7.

Harris, A., Wyn, J., \& Younes, S. (2007). Young people and citizenship: An everyday perspective. Youth Studies Australia, 26(3), 19-27.

Harris, A., Wyn, J., \& Younes, S. (2010). Beyond apathetic or activist youth: 'Ordinary' young people and contemporary forms of participation. Young, 18(1), 9-32.

Harrison, K. (1998a). Social studies in the New Zealand curriculum: Dosing for amnesia or enemy of ethnocentrism? In P. Benson \& R. Openshaw (Eds.), New horizons for New Zealand social studies (pp. 63-82). Palmerston North: ERDC Press.

Harrison, K. (1998b). Teaching trouble: Social action and social analysis in the classrooms of two US teachers. New Zealand Journal of Social Studies, 7(2), 7-10.

Hart, R. (1979). Children's experience of place. New York: Irvington Publishers Inc.

Hart, R. (1992). Children's participation: From tokenism to citizenship. Florence: UNICEF Innocenti Research Centre.

Hart, R. (1997). Children's participation: The theory and practice of involving young citizens in community development and environmental care. London: Earthscan Publications.

Hay, G., Whigham, P., Kypri, K., \& Langley, J. (2009). Neighbourhood deprivation and access to alcohol outlets: A national study. Health and Place, 15(4), 1086-1093.

Heater, D. (1999). What is citizenship? Malden, MS: Polity Press.

Heath, S., Brooks, R., Cleaver, E., \& Ireland, E. (2009). Researching young people's lives. London: Sage.

Hil, R., \& Bessant, J. (1999). Spaced-out? Young people's agency, resistance and public space. Urban Policy and Research, 17(1), 41-49.

Hilfinger Messias, D., Jennings, L., Fore, M. E., McLoughlin, K., \& ParraMedina, D. (2008). Societal images of youth: Representations and interpretations by youth actively involved in their communities. International Journal of Qualitative Studies in Education, 21(2), 159178.

Hillier, J., \& Rooksby, E. (2002). Habitus: A sense of place. Aldershot: Ashgate.

Holden, C., Joldoshalieva, R., \& Shamatov, D. (2008). 'I would like to say that things must just get better': Young citizens from England, Kyrgystan and South Africa speak out. Citizenship Teaching and Learning, 4(2), 6-17.

Holland, J. (2008). Young people and social capital: What can it do for us? London: Families \& Social Capital Research Group.

Holland, J., Reynolds, T., \& Weller, S. (2007). Transitions, networks and communities: The significance of social capital in the lives of children and young people. Journal of Youth Studies, 10(1), 97-116.

Holloway, S., \& Valentine, G. (2000). Children's geographies: Playing, living, learning. Oxon: Routledge. 
Holt, L. (2008). Embodied social capital and geographic perspectives: Performing the habitus. Progress in Human Geography, 32(2), 227246.

Horton, J., Kraftl, P., \& Tucker, F. (2008). The challenges of 'Children's Geographies': A reaffirmation. Children's Geographies, 6(4), 335-348.

Huberman, M., \& Miles, M. (1998). Data management and analysis methods. In N. Denzin \& Y. Lincoln (Eds.), Collecting and interpreting qualitative materials (pp. 179-210). Thousand Oaks: Sage.

Information Technology Advisory Group. (1999). The Knowledge Economy. Wellington: ITAG.

Invernizzi, A., \& Williams, J. (2008). Children and citizenship. London: Sage.

Ireland, E., Kerr, D., Lopes, J., Nelson, J., \& Cleaver, E. (2006). Active citizenship and young people: Opportunities, experiences and challenges in and beyond school: Citizenship education longitudinal study: Fourth annual report: National Foundation for Educational Research, .

Isin, E., \& Turner, B. (2007). Investigating citizenship: An agenda for citizenship studies. Citizenship studies, 11(1), 5-17.

James, A., \& James, A. (2008). Key concepts in childhood studies. Los Angeles: Sage.

James, A., Jenks, C., \& Prout, A. (1998). Theorizing childhood. New York: Teachers College Press.

James, A., \& Prout, A. (1990). Constructing and reconstructing childhood. Basingstoke: Falmer Press.

Janesick, V. (2000). The choreography of qualitative research design. In N. Denzin \& Y. Lincoln (Eds.), Handbook of qualitative research (2nd ed., pp. 379-399). Thousand Oaks: Sage.

Jensen, V., Kaiwai, H., McCreanor, T., \& Moewaka Barnes, H. (2006). 'Back off Ma this is our project': Youth Photovoice research in Clendon and Mangere: Report to Ministry of Youth Development. Auckland: Massey University Whariki Research Group.

Jochum, V., Patten, B., \& Wilding, K. (2005). Civil renewal and active citzienship: A guide to the debate. Retrieved November, 2010, from NCVO: http://www.ncvovol.org.uk/sites/default/files/UploadedFiles/NCVO/Publications/Publicat ions Catalogue/Sector Research/civil renewal active citizenship.pdf

Jorgenson, J., \& Sullivan, T. (2010). Accessing children's perspectives through participatopry photo interviews. Forum: Qualitative Social Research, 11(1), Art. 8.

Kelsey, J. (2002). At the crossroads: Three essays. Wellington: Bridget Williams Books.

Kemp, D. (1997). Discovering democracy: Civics and citizenship education. Canberra: Ministerial statement.

Kennedy, K. (2006). Towards a conceptual framework for understanding active and passive citizenship: Unpublished report, cited in Nelson, J. 7 Kerr, D. (2006). Active citizenship in INCA countries: Definitions, policies, practices, and outcomes. 
Kennedy, K. (2007). Student constructions of 'active citizenship': What does participation mean to students? British Journal of Educational Studies, 55(3), 304-324.

Kennedy, K. (2008a). The citizenship curriculum: Ideology, content and organisation. In J. Arthur, I. Davies \& C. Hahn (Eds.), The Sage Handbook of Education for Citizenship and Democracy (pp. 483-491). London: Sage.

Kennedy, K. (2008b). Globalised economies and liberalised curriculum: New challenges for national citizenship education. In D. Grossman, W. On Lee \& K. Kennedy (Eds.), Citizenship curriculum in Asia and the Pacific (pp. 13-26). Hong Kong: Comparative Education Research Centre.

Kennedy, K., Hahn, C., \& Lee, W.-O. (2007). Constructing citizenship: Comparing the views of students in Australia, Hong Kong and the United States. Comparative Education Review, 52(1), 53-91.

Keown, P. (1998). Values and social action: Doing the hard bits. In P. Benson \& R. Openshaw (Eds.), New horizons for New Zealand social studies (pp. 137-159). Palmerston North: ERDC Press.

Kerr, D. (1999). Citizenship education in the curriculum: An international review. UK: National Foundation for Educational Research.

Kerr, D., Cleaver, E., Ireland, E., \& Blenkinsop, S. (2003). Citizenship education longitudinal study first cross-sectional survey 2001-2003. London: DfES.

Kidman, J. (2005). Dissenters in the ranks: Young people, citizenship and the global village. In J. Codd \& K. Sullivan (Eds.), Education policy directions in Aotearoa New Zealand (pp. 87-98). Southbank Victoria: Thomson Dunmore Press.

Kidman, J. (2009). Visual methodologies: Exploring indigenous constructions of self and environment. In D. Zandvliet (Ed.), Diversity in environmental education research (pp. 65-76). Rotherdam: Sense.

Kimberlee, R. (2002). Why don't British young people vote at general elections? Journal of Youth Studies, 5(1), 85-98.

Kincheloe, J. (2007). Critical pedagoggy in the twenty-first century: Evolution for survival. In P. Mclaren \& J. Kincheloe (Eds.), Critical pedagogy: Where are we now? (pp. 9-42). NY: Peter Lang.

Kincheloe, J., \& McLaren, P. (2008). Rethinking critical theory and qualitative research. In N. Denzin \& Y. Lincoln (Eds.), The landscape of qualitative research (pp. 403-455). Thousand Oaks: Sage.

Kirby, P., Lanyon, C., Cronin, K., \& Sinclair, R. (2003). Building a culture of participation: Involving children in policy, service planning, delivery and evaluation. London: Department for Education and Skills.

Klein-Nixon, K. (2009). Lower Hutt bus-stop vibe to grate on young ears. Newswire.co.nz. Retrieved from http://www.newswire.co.nz/2009/07/mall\%E2\%80\%99s-bach/

Kliebard, H. (1986). The struggle for the American curriculum, 1893-1958. Boston: Routledge and Kegan Paul.

Knowles, C., \& Sweetman, P. (2004). Picturing the social landscape: Visual methods and the sociological imagination. London: Routledge. 
Leach, N. (2002). Belonging: Towards a theory of identification with space. In J. Hillier \& E. Rooksby (Eds.), Habitus: A sense of place (pp. 281295). Aldershot: Ashgate.

Lee, J., \& Abbott, R. (2009). Physical activity and rural young people's sense of place. Children's Geographies, 7(2), 191-208.

Liebel, M. (2008). Citizenship from below: Children's rights and social movements. In A. Invernizzi \& J. Williams (Eds.), Children and citizenship. London: Sage.

Lister, R. (1997). Citizenship: Feminist perspectives. London: Macmillan.

Lister, R. (2003). Citizenship: Feminist perspectives (2nd ed.). London: Macmillan.

Lister, R. (2007a). Inclusive citizenship: Realising the potential. Citizenship Studies, 11(1), 49-61.

Lister, R. (2007b). Why citizenship: Where, when and how children? Theoretical Inquiries into Law, 8(2), Article 13.

Lister, R. (2008a). Inclusive citizenship, gender and poverty: Some implications for education for citizenship. Citizenship Teaching and Learning, 4(1), 3-20.

Lister, R. (2008b). Unpacking children's citizenship. In A. Invernizzi \& J. Williams (Eds.), Children and citizenship (pp. 9-19). London: Sage.

Lister, R., Smith, N., Middleton, S., \& Cox, L. (2003). Young people talk about citizenship: Empirical perspectives on theoretical and political debates. Citizenship Studies, 7(2), 235-253.

Llewellyn, K., \& Westheimer, J. (2009). Beyond facts and acts: The implications of 'ordinary politics' for youth political engagement. Citizenship Teaching and Learning, 5(2), 50-61.

Loveridge, J. (2010). Involving young people in research in educational settings: Report to the Ministry of Education. Retrieved from http://www.educationcounts.govt.nz/publications/schooling/8044 $\underline{0}$

Mahar, C., Harker, R., \& Wilkes, C. (1990). The basic theoretical position. In R. Harker, C. Mahar \& C. Wilkes (Eds.), An introduction to the work of Pierre Bourdieu: The practice of theory (pp. 1-25). Houndsmill: The MacMillan Press.

Maira, S., \& Soep, E. (2005). Youthscapes: The popular, the national, the global. Philadelphia: University of Pennsylvania Press.

Malone, K., \& Hartung, C. (2010). Challenges of participatory practice with children. In B. Percy-Smith \& N. Thomas (Eds.), A handbook of children and young people's participation: Perspectives from theory and practice (pp. 24-38). Oxon/NY: Routledge.

Mannion, G. (2007). Going spatial, going relational: Why 'listening to children' and children's participation needs reframing. Discourse: Studies in the Cultural Politics of Education, 28(3), 405-420.

Marsh, D., O'Toole, T., \& Jones, S. (2007). Young people and politics in the UK: Apathy or alienation? Basingstoke: Palgrave MacMillan.

Marshall, T. H. (1950). Citizenship and social class. Cambridge: Cambridge University Press. 
Mason, M. (2008). Series editor's foreword. In D. Grossman, W. On Lee \& K. Kennedy (Eds.), Citizenship curriculum and Asia and the Pacific (Vol. 22, pp. xi-xii). Hong Kong: Comparative Education Research Centre.

Massey, D. (1998). Spatial construction of youth cultures. In T. Skelton \& G. Valentine (Eds.), Cool places: Geographies of youth cultures (pp. 121129). London: Routledge.

Matthews, H. (2001). Children and community regeneration: Creating better neighbourhoods. London: Save the Children.

Matthews, H., Limb, M., \& Percy-Smith, B. (1998). Changing worlds: The micro-geographies of young teenagers. Tijdschrift voor Economische en Sociale geografie, 89(2), 193-202.

Matthews, H., Limb, M., \& Taylor, M. (2000). The 'street as thirdspace'. In S. Holloway \& G. Valentine (Eds.), Children's geographies: Playing, living, learning (pp.63-79). Oxon: Routledge.

McFarland, D., \& Thomas, R. (2006). Bowling alone: How youth voluntary organisations influence adult political particiption. American Sociological Review, 71, 401-425.

McGee, J. (1998). Curriculum in conflict: Historical development of citizenship education in social studies. In P. Benson \& R. Openshaw (Eds.), New horizons for New Zealand social studies (pp. 43-62). Palmerston North: ERDC Press, Massey University.

McLaughlin, T. (1992). Citizenship, diversity and education: A philosophical perspective. Journal of Moral Education, 21(3), 235-250.

McLeod, J., \& Yates, L. (2006). Making modern lives: Subjectivity, schooling and social change. Albany: State University of New York Press.

Milligan, A., Taylor, M., \& Wood, B. E. (forthcoming). Teachers' conceptions of citizenship in New Zealand social studies education. Citized: Citizenship and Teacher Education.

Milligan, A., \& Wood, B. E. (2010). Conceptual understandings as transition points: Making sense of a complex social world. Journal of Curriculum Studies, 42(4), 487-501.

Mills, C. W. (1959). The sociological imagination. London: Oxford University Press.

Ministry of Education. (1994). Social studies in the New Zealand curriculum: Draft. Wellington: Learning Media.

Ministry of Education. (1996). Social studies in the New Zealand curriculum: Revised draft. Wellington: Learning Media.

Ministry of Education. (1997). Social studies in the New Zealand curriculum. Wellington: Learning Media.

Ministry of Education. (2002). Curriculum stocktake report. Wellington: MOE.

Ministry of Education. (2004). Social Sciences Community Cafe: April. Retrieved 23 July 2008, from The New Zealand Curriculum Online: http://centre4.interact.ac.nz/modules/page/page.php?space key=4 78\&module key $=19272$ \&link key $=19897$ \&group key $=0$

Ministry of Education. (2007). The New Zealand curriculum. Wellington: Learning Media Ltd.

Ministry of Education. (n.d). How the decile is calculated. Retrieved November 2008, from 
http://www.minedu.govt.nz/educationSectors/Schools/SchoolOper ations/Resourcing/OperationalFunding/Deciles/HowTheDecileIsCa lculated.aspx

Ministry of Education. (n.d.). Enterprising attributes. Retrieved August, 2010, from http://education-for-enterprise.tki.org.nz/AboutE4E/The-NZ-Curriculum-and-E4E/Enterprisingattributes\#resources

Ministry of Youth Development NZ. (2008). Third and fourth periodic report for the United Nations Committee. Wellington.

Mitchell, H., Kearns, R., \& Collins, D. (2007). Nuances of neighbourhood: Children's perceptions of the space between home and school in Auckland, New Zealand. Geoforum, 38, 614-627.

Moorfield, J. C. (2003-2011). Māori Dictionary Online/Te Aka MāoriEnglish, English-Māori Dictionary and Index. http://www.maoridictionary.co.nz/

Morrow, R., \& Brown, D. (1994). Critical theory and methodology. Thousand Oaks: Sage.

Morrow, V. (2001). Using qualitative methods to elicit young people's perspectives on their environments: Some ideas for community health initiatives. Health Education Research, 16(3), 255-268.

Morrow, V. (2008). Ethical dilemmas in research with children and young people about their social environments. Children's Geographies, 6(1), 49-61.

Morrow, V., \& Martin, R. (1996). The ethics of social research with children: An overview. Children and Society, 10(1996), 90-105.

Mutch, C. (2005a). Confident, informed and responsible citizens: By what means? In P. Benson \& R. Openshaw (Eds.), Towards effective social studies (pp. 69-84). Palmerston North: Kanuka Grove Press.

Mutch, C. (2005b). Developing global citizens: The rhetoric and the reality in the New Zealand Curriculum. In C. White \& R. Openshaw (Eds.), Democracy at the crossroads; International perspectives on critical global citizenship education (pp. 187-209). Lanham: Lexington Books.

Mutch, C. (2006). Adapting Bourdieu's field theory to explain decisionmaking processes in educational policy. In V. Anfara \& N. Mertz (Eds.), Theoretical frameworks in qualitative research (pp. 155-174). Thousand Oaks: Sage.

Mutch, C. (2008). 'Creative and innovative citizenry:' Exploring the past, present and future of citizenship education in New Zealand. In D. Grossman, W. On Lee \& K. Kennedy (Eds.), Citizenship education in Asia and the Pacific (pp. 197-203). Hong Kong: Comparative Education Research Centre.

Nairn, K., Munro, J., \& Smith, A. (2005). A counter-narrative of a 'failed' interview. Qualitative Research, 5(2), 221-244.

Nairn, K., Panelli, R., \& McCormack, J. (2003). Destabilizing dualisms: Young people's experiences of rural and urban environments. Childhood, 10(1), 9-42. 
Nairn, K., Sligo, J., \& Freeman, C. (2006). Polarizing participation in local government: Which young people are included and excluded? Children, Youth and Environments, 16(2), 248-271.

Naker, D., Mann, G., \& Rajani, R. (2007). The gap between rhetoric and practice: Critical perspectives on children's participation. Children, Youth and Environments, 17(3), 99-103.

Nava, M. (2007). Visceral cosmopolitanism: Gender, culture and the normalisation of difference. Oxford: Berg.

Nelson, J., \& Kerr, D. (2006). Active citizenship in INCA countries: Definitions, policies, practices, and outcomes. Retrieved from http://www.inca.org.uk/pdf/Active Citizenship Report.pdf.

Nelson, J. L. (2001). Defining social studies. In W. B. Stanley (Ed.), Critical issues in social studies research for the 21st century (pp. 15-38). Greenwich: Information Age Publishing.

Norris, P. (2003). Young people and political activism: From the politics of loyalties to the politics of choice? Strasborg: Report for the Council of Europe Symposium, 27-28 November.

Norris, P. (2007). Political activism: New challenges, new opportunities. In C. Boix \& S. Stokes (Eds.), The Oxford handbook of comparative politics (pp. 628-652). Oxford: Oxford University Press.

NZQA. (2010). Senior social studies assessment matrix. Retrieved from http://legacy.tki.org.nz/e/community/ncea/docs/socstudies matri xfor2011 dec10.doc.

O'Toole, T., Lister, M., Marsh, D., Jones, S., \& McDonagh, A. (2003). Turning out or left out?: Participation and non-participation among young people. Contemporary Politics, 9(1), 45-61.

OECD. (1996). The Knowledge-based Economy. Paris: OECD.

OECD. (2005). The definition and selection of key competencies: Executive summary. Retrieved from http://www.pisa.oecd.org/dataoecd/47/61/35070367.pdf.

Openshaw, R. (2004). Able to take their part? Social studies and the curriculum framework In A. O'Neill, J. Clark \& R. Openshaw (Eds.), Reshaping culture, knowledge and learning: Policy and content in the New Zealand Curriculum Framework (pp. 245-264). Palmerston North: Dunmore Press.

Osler, A., \& Starkey, H. (2005). Changing citizenship: Democracy and inclusion in education. Maidenhead: Open University Press.

Owen, D. (1996). The young active citizen: Dilemmas and opportunities. Youth Studies Australia, 15(1).

Painter, J. (2001). Pierre Bourdieu. In M. Crang \& N. Thrift (Eds.), Thinking space (pp. 239-259). London: Routledge.

Panelli, R., Atwool, N., \& McCormack, J. (2002). 'Hanging out:' Print media constructions of young people in 'public space'. Youth Studies Australia, 21(4), 38-48.

Parker, W. C. (2001). Toward enlightened political engagement. In W. B. Stanley (Ed.), Critical issues in social studies research for the 21st century (pp. 97-118). Greenwich: IAP.

Pells, K. (2010). 'None ever listens to us': Challenges to the participation of children and young people in Rwanda. In B. Percy-Smith \& N. 
Thomas (Eds.), A handbook of children and young people's participation (pp. 196-203). Oxon/NY: Routledge.

Percy-Smith, B., \& Thomas, N. (2010). A handbook of children and young people's participation: Perspectives from theory and practice. Oxon/NY: Routledge.

Philo, C., \& Smith, F. (2003). Guest editorial: Political geographies of children and young people. Space and Polity, 7(2), 99-115.

Pink, S. (2007). Doing visual ethnography. London: Sage.

Powell, M. A., \& Smith, A. (2006). Ethical guidelines for research with children: A review of current research ethics documentation in New Zealand. Kotuitui: New Zealand Journal of Social Sciences Online, 1(125-138).

Powell, M. A., \& Smith, A. (2009). Children's participation rights in research. Childhood, 16, 124-142.

Prasad, P. (2005). Crafting quality research: Working in the postpositivist traditions. New York: M.E. Sharp c2005.

Print, M. (2007). Citizenship education and youth participation in democracy. British Journal of Educational Studies, 55(3), 325-345.

Print, M., Saha, L., \& Edwards, K. (2004). Youth Electoral Study: Report 1. Canberra: Australian Electoral Commission.

Prior, W. (1999). Concepts of citizenship: Teacher perceptions of civics and citizenship education. The Social Educator, September(5-15).

Prior, W. (2005). Perceptions of citizenship in Australia. In C. White \& R. Openshaw (Eds.), Democracy at the crossroads: International perspectives on critical global citizenship education. Oxford: Lexington Books.

Prout, A. (2003). Participation, policy and the changing conditions of childhood. In C. Hallett \& A. Prout (Eds.), Hearing the voices of children (pp. 11-25). London: RoutledgeFalmer.

Prout, A., Simmons, R., \& Birchall, J. (2006). Reconnecting and extending the research agenda on children's participation: Mutual incentives in the participation chain. In E. K. Tisdall, J. Davis, M, A. Prout \& M. Hill (Eds.), Children, young people and social inclusion. Bristol: The Policy Press.

Punch, S. (2002). Interviewing strategies with young people: The 'secret box', stimulus material and task-based activities. Children and Society, 16(1), 45-56.

Putnam, R. (2000). Bowling Alone: The collapse and revival of American community. New York: Simon and Schuster.

QSR International. NVivo (Version 8). Australia.

Reay, D. (2004). 'It's all becoming a habitus': Beyond the habitual use of habitus in educational research. British Journal of Educational Studies, 25(4), 431-444.

Relph, E. (1976). Place and placelessness. London: Pion.

Ritchie, J., \& Rau, C. (2006). Whakawhanaungatanga: partnerships in bicultural development in early childhood care and education: Teaching and Learning Research Initiative. 
Robertson, M. (2009). Young "netizens" creating public citizenship in cyberspace. International Research in Geographic and Environmental Education, 18(4), 287-293.

Roche, J. (1999). Children: Rights, participation and citizenship. Childhood, 6(4), 475-493.

Rosaldo, R. (1989). Culture and truth: The remaking of social analysis. Boston: Beacon Press.

Rose, E., Huakau, J., Huckle, T., Casswell, S., Perry, P., Howden-Chapman, P., et al. (2005). Public Life Values. Auckland: Centre for Social and Health Outcomes Research and Evaliation \& Te Ropu Whariki, Massey University.

Rose, G. (2007). Visual methodologies: An introduction to the interpretation of visual materials (2nd ed.). London: Sage.

Ross, A. (2008). Organizing a curriculum for active citizenship education. In J. Arthur, I. Davies \& C. Hahn (Eds.), The Sage handbook of education for citizenship and democracy. London: Sage.

Sargeant, J. (2008). Australian children: Locally secure, globally afraid? In R. Gerber \& M. Robertson (Eds.), Children's lifeworlds: Locating indigenous voices (pp. 119-133). New York: Nova Science Publishers Inc.

Sayer, A. (2005). The moral significance of class. Cambridge: Cambridge University Press.

Schaefer-McDaniel, N. (2004). Conceptualizing social capital among young people: Towards a new theory. Children, Youth and Environments, 14(1), 153-172.

Schulz, W., Ainley, J., Fraillon, J., Kerr, D., \& Losito, B. (2010). ICCS 2009 International Report: Civic knowledge, attitudes, and engagement among lower-secondary students in 38 countries. Amsterdam: IEA.

Sibley, D. (1995). The geographies of exclusion. London: Routledge.

Silverman, D. (2006). Interpreting qualitative data: Methods for analyzing talk, text and interaction (3rd ed.). London: Sage.

Silverman, D., \& Marvasti, A. (2008). Doing qualitative research: $A$ comprehensive guide. Los Angeles: Sage.

Sim, J. B.-Y. (2010). Simple ideological 'dupes' of national governments'? Teacher agency and citizenship education in Singapore. In K. Kennedy, W. On Lee \& D. Grossman (Eds.), Citizenship pedagogies in Asia and the Pacific (pp. 221-242). Hong Kong: Comparative Education Research Centre.

Skelton, T. (2000). 'Nothing to do, nowhere to go?': Teenage girls and 'public space' in the Rhondda Valleys, South Wales. In S. Holloway \& G. Valentine (Eds.), Children's geographies: Playing, living, learning (pp. 80-99). Oxon: Routledge.

Skelton, T. (2001a). Cross-cultural research: issues of power, positionality and 'race'. In M. Limb \& C. Dwyer (Eds.), Qualitative methodologies for geographers: Issues and debates. London: Arnold.

Skelton, T. (2001b). Girls in the club: Researching working class girls' lives. Ethics, Place \& Environment, 4(2), 167-173. 
Skelton, T. (2008). Research with children and young people: Exploring the tensions between ethics, competence and participation. Children's Geographies, 6(1), 21-36.

Skelton, T. (2010). Taking young people as political actors seriously: Opening the borders of political geography. Area, 42(2), 145-151.

Skelton, T., \& Valentine, G. (1998). Cool places: Geographies of youth cultures. London/NY: Routledge.

Smith, F. (1998). Between east and west: Sites of resistance in East German youth cultures. In T. Skelton \& G. Valentine (Eds.), Cool places: Geographies of youth cultures. London/New York: Routledge.

Smith, G. (2008). Oxymoron or misplaced rectification. Environmental Education Research, 14(3), 349 - 352.

Smith, L. T., Smith, G. H., Boler, M., Kempton, M., Ormond, A., Chueh, H. C., et al. (2002). Do you guys hate Aucklanders too? Youth: Voicing difference from the rural heartland. Journal of Rural Issues, 18, 169178.

Smith, N., Lister, R., Middleton, S., \& Cox, L. (2005). Young people as real citizens: Towards an inclusionary understanding of citizenship. Journal of Youth Studies, 8(4), 425-443.

Smith, S. (2001). Doing qualitative research: from interpretation to action. In M. Limb \& C. Dwyer (Eds.), Qualitative methodologies for geographers: Issues and debates (pp. 23-40). London: Arnold.

Stokowski, P. (2001). Languages of places and discourse of power: Constructing new senses of place. Journal of Leisure Research, 34, 368-382.

Strack, R., Magill, C., \& McDonagh, K. (2004). Engaging youth through photovoice. Health Promotion Practice, 5(1), 49-58.

Strathdee, R. (2006). The creation of contrasting education and training markets in England and New Zealand. Journal of Education and Work, 19(3), 237-253.

Taylor, R. (2008). Teachers' conflicting responses to change: An evaluation of the implementation of senior social studies for the NCEA 2002-2006. Unpublished Doctor of Education thesis, Massey University, Palmerston North.

Thomas, N., \& Percy-Smith, B. (2010). Introduction. In B. Percy-Smith \& N. Thomas (Eds.), A handbook of children and young people's participation (pp. 1-7). Oxon/New York: Routledge.

Thomson, P. (2008). Doing visual research with children and young people. New York: Routledge.

Thomson, P., \& Holdsworth, R. (2003). Theorizing change in the educational 'field': Re-readings of 'student participation' projects. International Journal of Leadership in Education, 6(4), 371-391.

Thornton, S. (2005). Teaching social studies that matters: Curriculum for active teaching. New York: Teachers' College Press.

Torney-Purta, J., Lehmann, R., Oswald, H., \& Schulz, W. (2001). Citizenship and education in twenty-eight countries: Civic knowledge and engagement at age fourteen. Amsterdam: IEA.

Torney-Purta, J., Richardson, W. K., \& Barber, C. H. (2005). Teachers' educational experience and confidence in relation to students' civic 
knowledge across countries. Citized: International Journal of

Citizenship and Teacher Education, 1(1), 32-57.

Trevett, C., \& McKenzie-Minifie, M. (2007, November 7). Pupils will learn how to learn. New Zealand Herald.

Valentine, G. (1999). Being seen and heard? The ethical complexities of working with children and young people at home and school. Ethics, Place \& Environment, 2(2), 141-155.

Valentine, G., Skelton, T., \& Chambers, D. (1998). Cool places: An introduction to youth and youth cultures. In T. Skelton \& G. Valentine (Eds.), Cool places: Geographies of youth cultures. London/New York: Routledge.

Vromen, A. (2003). 'People try to put us down...': Participatory citizenship of 'Generation X'. Australian Journal of Political Science, 38(1), 79-99.

Wallace, C. (2001). Youth, citizenship and empowerment. In H. Helve \& C. Wallace (Eds.), Youth citizenship and empowerment (pp. 11-31). Hampshire: Ashgate Publishing.

Wang, C. (1997). Photovoice: Concept, methodology, and use for participatory needs assessment. Health, Education and Behavior, 24(3), 369-387.

Wang, C., \& Burris, M. A. (1994). Empowerment through photo novella: Portraits of participation. Health, Education \& Behavior, 21(2), 171186.

Wang, C., Cash, J., \& Powers, L. (2000). Who knows the street as well as the homeless? Promoting personal and community action through photovoice. Health Promotion Practice, 1(1), 81-89.

Warrick, P. (2008). The development of apt citizenship education through listening to young people's voices. Educational Action Research, 16(3), 321-333.

Weller, S. (2006a). Situating (young) teenagers in geographies of children and youth. Children's Geographies, 4(1), 97-108.

Weller, S. (2006b). Skateboarding alone: Making social capital discourse relevant to teenagers' lives. Journal of Youth Studies, 9(5), 557-574.

Weller, S. (2007). Teenagers' citizenship: Experiences and education. Oxon: Routledge.

Weller, S. (2009). Exploring the spatiality of participation: Teenagers' experiences in an English secondary school. Youth \& Policy, 101(Winter 2009), 15-32.

Weller, S., \& Bruegel, I. (2009). Children's 'place' in the development of neighbourhood social capital. Urban Studies, 46(3), 629-643.

Westheimer, J., \& Kahne, J. (2004). What kind of citizen?: The politics of educating for democracy. American Research Journal, 41(2), 237269.

White, C. (2005). Critical Democratic Education for Social Efficacy. In C. White \& R. Openshaw (Eds.), Democracy at the Crossroads: International Perspectives on Critical Global Education (pp. 77-104). Lanham: Lexington Books.

White, R. (1996). No go in the fortress city: Young people, inequality and space. Urban Policy and Research, 14(1), 37-50. 
White, R., \& Wyn, J. (1998). Youth agency and social context. Journal of Sociology, 34(3), 314-327.

Wierenga, A. (2009). Young people making a life. Hampshire: Palgrave Macmillan.

Willis, P. (1990). Common culture: Symbolic work at play in the everyday culture of the young. Milton Keynes: Open University Press.

Wilson, N., Dasho, S., Martin, A., Wallerstein, N., Wang, C., \& Minkler, M. (2007). Engaging young adolescents in social action through photovoice: The Youth Empowerment Strategies (YES!) Project. The Journal of Early Adolescence, 27(2), 241-261.

Wolmuth, A. (2009). Two contrasting interpretations of the aims of citizenship education. Retrieved from http://www.citized.info/pdf/students/Anna\%20Wolmuth.pdf

Wood, B. E. (1995). The geopolitics of school choice: Auckland secondary school selection. Unpublished Master of Arts thesis, University of Auckland Auckland.

Wood, B. E. (2007). Conflict, controversy, and complexity: Avoiding the 'slippery stuff' in social studies. Critical Literacy: Theories and Practices, 1(2), 42-49.

Wood, B. E. (2009). Comparing the New Zealand Curriculum and youth conceptions of the 'ideal' citizen: Re-examining trust, participation and responsibility. Youth Studies Ireland, 4(2), 3-21.

Woodhead, M. (2010). Foreword. In B. Percy-Smith \& N. Thomas (Eds.), $A$ handbook of children and young people's participation: Perspectives from theory and practice (pp. xix- xxii). Oxon/New York: Routledge.

Woodman, D. (2010). Class, individualisation and tracing processes of inequality in an changing world: A reply to Steven Roberts. Journal of Youth Studies, 13(6), 737-746.

Wray-Lake, L., Flanagan, C., \& Osgood, W. (2010). Examining trends in adolescent environmental attitudes, beliefs and behaviours across three decades. Environment and Behavior, 42(1), 61-85.

Wyn, J., \& Harris, A. (2004). Youth research in Australia and New Zealand. Young, 12(3), 271-289.

Wyn, J., \& White, R. (1997). Rethinking Youth. London: Sage Publications.

Young, M. (1971). Knowledge and control: New directions for the sociology of education. London: Collier MacMillan.

Young, M. (2008). Bringing knowledge back in: From social constructivism to realism in the sociology of education. London: Routledge.

Zipin, L., \& Reid, A. (2008). A justice oriented curriculum: Making community curricular. In J. Arthur, I. Davies \& C. Hahn (Eds.), The Sage handbook of education for citizenship and democracy (pp. 533544). London: Sage. 


\section{APPENDICES}

\section{Appendix A: The changing face of 'social action' in official social studies curriculum documents in New Zealand (1944-2007)}

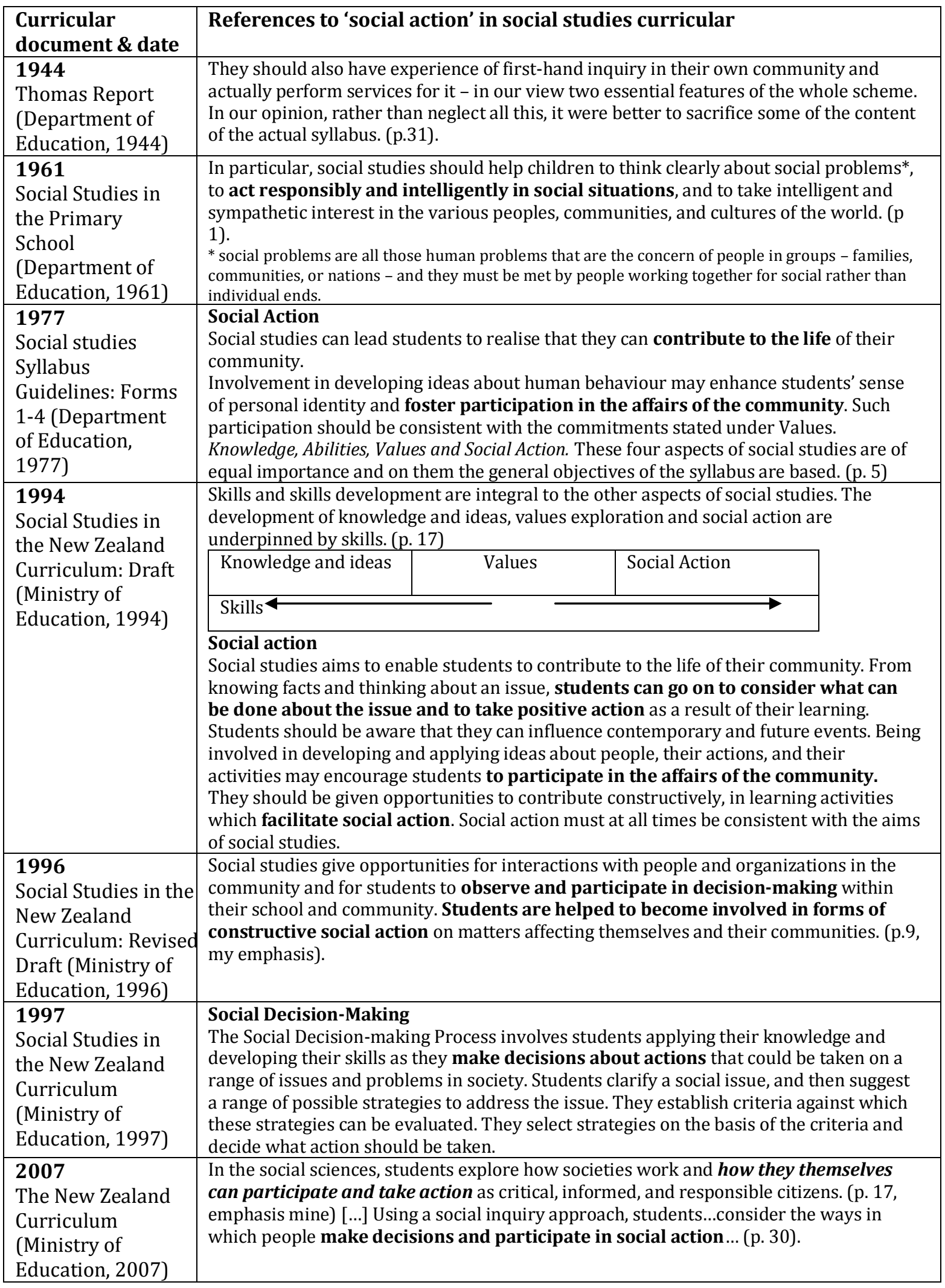


Appendix B: Westheimer and Kahne's "Kinds of citizens"

\begin{tabular}{|c|c|c|c|}
\hline & $\begin{array}{l}\text { Personally } \\
\text { responsible } \\
\text { citizens }\end{array}$ & $\begin{array}{l}\text { Participatory } \\
\text { citizens }\end{array}$ & $\begin{array}{l}\text { Social-justice oriented } \\
\text { citizens }\end{array}$ \\
\hline Description & $\begin{array}{l}\text { Acts responsibly in } \\
\text { their community; } \\
\text { Works and pays taxes } \\
\text { Picks up litter, } \\
\text { recycles and gives } \\
\text { blood; } \\
\text { Helps those in need; } \\
\text { Obeys laws. }\end{array}$ & $\begin{array}{l}\text { Active member of } \\
\text { community } \\
\text { organizations and/or } \\
\text { improvement efforts; } \\
\text { Organises community } \\
\text { efforts to care for those } \\
\text { in need, promote } \\
\text { economic development } \\
\text { or to clean up } \\
\text { environment; } \\
\text { Knows strategies for } \\
\text { accomplishing collective } \\
\text { tasks. }\end{array}$ & $\begin{array}{l}\text { Critically assesses social, } \\
\text { political and economic } \\
\text { structures; } \\
\text { Explores strategies for } \\
\text { change that address root } \\
\text { causes of problems; } \\
\text { Knows about social } \\
\text { movements and how to } \\
\text { effect systematic change; } \\
\text { Seeks out and addresses } \\
\text { areas of injustice. }\end{array}$ \\
\hline Sample action & $\begin{array}{l}\text { Contributes food to a } \\
\text { food drive. }\end{array}$ & $\begin{array}{l}\text { Helps to organize a food } \\
\text { drive. }\end{array}$ & $\begin{array}{l}\text { Explores why people are } \\
\text { hungry and acts to solve root } \\
\text { causes. }\end{array}$ \\
\hline $\begin{array}{l}\text { Core } \\
\text { assumptions }\end{array}$ & $\begin{array}{l}\text { To solve social } \\
\text { problems and } \\
\text { improve society } \\
\text { citizens must have } \\
\text { good character; they } \\
\text { must be honest, } \\
\text { responsible and law- } \\
\text { abiding members of } \\
\text { the community. }\end{array}$ & $\begin{array}{l}\text { To solve social problems } \\
\text { and improve society } \\
\text { citizens must actively } \\
\text { participate and take } \\
\text { leadership positions } \\
\text { within established } \\
\text { systems and community } \\
\text { structures. }\end{array}$ & $\begin{array}{l}\text { To solve social problems and } \\
\text { improve society citizens } \\
\text { must question and change } \\
\text { established systems and } \\
\text { structures when they } \\
\text { reproduce patterns of } \\
\text { injustice over time. }\end{array}$ \\
\hline
\end{tabular}

Source: (Westheimer \& Kahne, 2004, p. 240). 


\section{Appendix C: Kennedy's (2006) conceptual framework of citizenship}

\begin{tabular}{|c|c|c|c|}
\hline & $\begin{array}{l}\text { Type of active } \\
\text { citizenship }\end{array}$ & Examples & Characteristics of approach \\
\hline \multirow{4}{*}{ 范 } & $\begin{array}{l}\text { 1. Conventional } \\
\text { citizenship } \\
\text { Engage and participate } \\
\text { in conventional political } \\
\text { activities }\end{array}$ & $\begin{array}{l}\text { a. Voting } \\
\text { b. Joining a political party } \\
\text { c. Being a candidate for } \\
\text { political office }\end{array}$ & $\begin{array}{l}\text { This is the traditional, conformist view } \\
\text { usually held by political scientists. } \\
\text { It focuses on participation in civic as } \\
\text { opposed to civil society. } \\
\text { It is about horizontal (taking part) and } \\
\text { vertical (bringing about change) } \\
\text { participation }\end{array}$ \\
\hline & $\begin{array}{l}\text { 2. Social movement } \\
\text { citizenship } \\
\text { Engage and participate } \\
\text { in voluntary community } \\
\text { activities }\end{array}$ & $\begin{array}{l}\text { a. Working with } \\
\text { community care agencies } \\
\text { b. Collecting money for a } \\
\text { good cause }\end{array}$ & $\begin{array}{l}\text { This is often called the 'civic virtues' } \\
\text { approach to citizenship. It focuses on } \\
\text { participation in civil society. It is largely } \\
\text { about horizontal participation. It is } \\
\text { conformist and, in some instances, } \\
\text { coercive. }\end{array}$ \\
\hline & $\begin{array}{l}\text { 3. Social change } \\
\text { citizenship } \\
\text { Engage and participate } \\
\text { in activities that seek to } \\
\text { change political and } \\
\text { social directions }\end{array}$ & $\begin{array}{l}\text { Legal } \\
\text { i. writing letters to a } \\
\text { newspaper } \\
\text { ii. collecting signatures } \\
\text { on a petition } \\
\text { Illegal } \\
\text { i. Blocking traffic } \\
\text { ii. Writing graffiti on } \\
\text { walls } \\
\text { iii Occupying a building }\end{array}$ & $\begin{array}{l}\text { This is often called 'the conflict' model of } \\
\text { citizenship. } \\
\text { It focuses on participation in both civic } \\
\text { and civil society. } \\
\text { It is about vertical participation } \\
\text { (bringing about change) through } \\
\text { attempts to influence the decision- } \\
\text { making process. }\end{array}$ \\
\hline & $\begin{array}{l}\text { 4. } \\
\text { Economic/enterprise } \\
\text { citizenship } \\
\text { Engage and participate } \\
\text { in selfregulating } \\
\text { activities }\end{array}$ & $\begin{array}{l}\text { a. Becoming financially } \\
\text { self supporting } \\
\text { b. Becoming a self- } \\
\text { directed learner } \\
\text { c. Becoming a creative } \\
\text { problem solver } \\
\text { d. Adopting } \\
\text { entrepreneurial values }\end{array}$ & $\begin{array}{l}\text { This is often referred to as the economic } \\
\text { model of citizenship. It is individualistic } \\
\text { rather than collective. } \\
\text { It is shaped by conformity to traits } \\
\text { associated with being a good and } \\
\text { responsible citizen }\end{array}$ \\
\hline \multirow{3}{*}{ 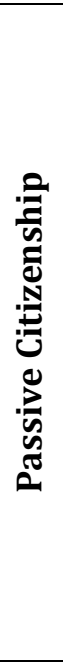 } & 1. National Identity & $\begin{array}{l}\text { a. Knows and values the } \\
\text { nation's history } \\
\text { b. Supports the nation's } \\
\text { symbols (e.g. flag, } \\
\text { anthem) }\end{array}$ & $\begin{array}{l}\text { All nation states attempt to promote } \\
\text { national identity of this kind. There is an } \\
\text { emphasis on the transmission of } \\
\text { knowledge through civic education in } \\
\text { schools }\end{array}$ \\
\hline & 2. Patriotism & $\begin{array}{l}\text { a. Willing to serve in the } \\
\text { military } \\
\text { b. Supports the claims of } \\
\text { the state against other } \\
\text { nation-states }\end{array}$ & $\begin{array}{l}\text { Patriotism is related to national identity, } \\
\text { but is a more extreme form that seeks to } \\
\text { protect the nation state from external } \\
\text { threats. }\end{array}$ \\
\hline & 3. Loyalty & $\begin{array}{l}\text { a. Citizens are obedient } \\
\text { b. Citizens work hard }\end{array}$ & $\begin{array}{l}\text { These attributes are often internalized } \\
\text { values that nation states seek to } \\
\text { promote through education. There are } \\
\text { daily rituals in society that reinforce the } \\
\text { importance of collective loyalty and } \\
\text { obedience. }\end{array}$ \\
\hline
\end{tabular}

Source: (Kennedy, 2006 in J. Nelson \& Kerr, 2006, pp. 12-13) 
Appendix D: Principal' information/consent letter

VICTORIA UNIVERSITY OF WELLINGTON

Te Whare Wananga o te Upoko o te Ika a Maui

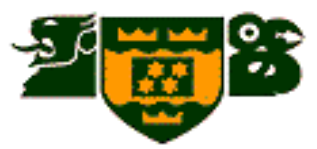

[Contact details]

Dear [Principal]

Cc: Head of Social Sciences

Title of project: Youth participation in social action: Voices from the classroom.

Researcher: Bronwyn Wood, School of Education, Victoria University of Wellington

Research Information Sheet:

School Principals

I am a Doctoral student in Education at Victoria University of Wellington. As part of this degree, I am undertaking research in social studies students' participation in social action in reference to the New Zealand Curriculum (2007). My PhD research is supervised by Dr Joanna Kidman and Mark Sheehan, both at the Faculty of Education, Victoria University. My research has been approved by the Victoria University Research and Human Ethics Committee (reference RM 15818).

This research aims to provide greater understanding about how social studies students define 'social action' and what they believe influences and motivates their participation in social action. This includes exploring how social studies teachers define and integrate 'social action' in their social studies programmes. The research will provide valuable information to schools and educators with an interest in the implementation of the new New Zealand curriculum.

I would like to invite your school, as one of four secondary schools in New Zealand to participate in this research. Your school has been invited as a reflection on the strength of your social studies programmes and/or community engagement/interest in social action. As the University requires that ethics approval be obtained for research involving human participants, I would like you to consider giving your consent for the research to be conducted in your school.

\section{What does this research involve?}

By agreeing to be involved in this project, you could expect that I would work with the Head of Social Sciences (or a delegate in that Department/Faculty) to conduct this research (I have included an additional information sheet for this teacher). In consultation with this delegated teacher, I would visit the school approximately six times. My aim is to conduct focus group interviews with a class of social studies students. These interviews would be conducted at school (for example, during a social studies lesson) and would last approximately 2-3 hours. I would manage the timing of these interviews in consultation with the HOD/nominated teacher. Following the focus group interview, students will be offered an opportunity to participate in pairs/groups in a Photovoice activity. Students would be provided with Digital Cameras to take photos of aspects of their local community (or wider issues) which motivate them to 'take action'. Students will be encouraged to take photos of images, places and sites and to avoid photos of identifiable humans to ensure the photos do not present any risk to the students/members of community or school. 
I also aim to invite the social studies teachers as well to explore their perceptions of social action in a one-off focus group discussion, during, for example, an social sciences department meeting. Participation in this would be voluntary and teachers would require informed consent.

What will I do to ensure your school's privacy is protected, and that I have student/parental consent to participate in this research?

All names of schools, teachers and students in this research will remain confidential to the researcher (and her supervisors). Your school and community will not be named in the final reports (unless you request otherwise) and will be given a pseudonym. All data collected in this research will be stored with care to protect the confidentiality of participants. The information from this research will be published in my $\mathrm{PhD}$ thesis and some articles will be submitted for publication in academic journals and conferences.

Students will be fully informed about the nature and requirements of the research and participation is voluntary, with parental/guardian consent also required for those under 16 years. Following the research, I would like to offer the school a chance to hear the findings and/or receive a copy of the summary of findings. Your school will be offered the opportunity to have student work returned to them and audio tapes returned or wiped following analysis.

If you require further information or clarification on any of the above points, please do not hesitate to contact me (details above) or my supervisors at Victoria University of Wellington (details below).

I look forward to your reply.

Regards,

Bronwyn Wood

[supervisor contact details supplied]

Consent to participation in research:

Principal of [school]

Title of project: Youth participation in social action: Voices from the classroom

Researcher: Bronwyn Wood, Faculty of Education, Victoria University of Wellington

I give consent for Bronwyn Wood, a Doctoral student at Victoria University of Wellington, to invite teachers and students in (school)

to participate in her research project.

Name of Principal

Signed [Principal]

$(\sqrt{ })$ I have emailed my consent to Bronwyn.wood@vuw.ac.nz

The Head of Social Sciences or nominated social studies contact person is: 
Appendix E: Student information/consent letter

VICTORIA UNIVERSITY OF WELLINGTON

Te Whare Wananga o te Upoko o te Ika a Maui

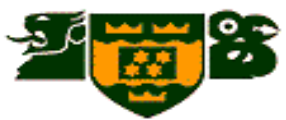

[Contact details]

[Date]

Title of project: Youth participation in social action: Voices from the classroom.

Researcher: Bronwyn Wood, Faculty of Education, Victoria University of Wellington

\section{Research Information Sheet: Social Studies Students}

Dear social studies student at [X] College,

I am a PhD student at Victoria University of Wellington doing some research into social studies students and social action. My doctoral research is supervised by Dr Joanna Kidman and Dr Mark Sheehan, both at the Faculty of Education, Victoria University. My research has been approved by the Victoria University Research and Human Ethics Committee (reference RM 15818).

I would like to invite you to participate in my research. You can choose to be part of it as it not part of your regular teaching and learning in social studies. However, it is research that will benefit many other students and teachers in New Zealand and I would welcome your involvement.

\section{What does this research involve?}

If you agree to participate in the research, you would join a Student Focus Group Interview with other social studies students in your class. These interviews would be conducted at school, during school hours during your social studies lesson. The interview will involve discussions and activities in small groups related to social studies and social action. I will work closely with your social studies teacher to make sure the timing of the interviews will minimise disruptions to student learning. These interviews will be taped so I can record what was said at a later stage.

The second part of the research involves using digital cameras to capture what is special about your local area and what you would like to change or 'take action' on now or in the future. This activity will be done in groups during your social studies lesson or after school according to the advice given me by your social studies teacher. In your photography you will need to avoid taking photos with people in them unless they can't be recognised as the project can't use images of people for whom we do not have consent. Once you have taken the photos I will talk to you about what the images are and why you took them. Copies of the photos will be made and given to you to keep, and I will keep a digital copy for my research.

The University requires that ethics approval be obtained for research involving human participants. I also need you parent's consent for you to participate in this research if 
you are under sixteen. If you are willing to be involved, can you please sign the attached form and take home the additional letter to inform your parent's and get their consent. Your parents are very welcome to contact me or my supervisors if they require further information - my details are supplied above.

What will I do to make sure you willing to be involved and that your privacy is protected?

All names of schools, teachers and students in this research will remain confidential to the researcher (and her supervisors). You will get a chance to choose a 'code name' (pseudonym) for this project and I won't use your real name (or your school's name) in the final report. You will get a chance to see a summary of the findings of the research before fianl publication and you will have a chance to make suggestions at this stage. You can choose to withdraw from the project at any stage with no questions asked up to when the research is analysed.

The information from this research will be published in my PhD thesis and I hope to write some articles or present at conferences. Your school will be offered the opportunity to have student work returned to them and audio tapes returned or wiped following analysis.

If you require further information or clarification on any of the above points, please do not hesitate to contact me or my supervisors using the contact details provided above.

Regards,

Bronwyn Wood

[supervisor contact details suplied] 


\section{VICTORIA UNIVERSITY OF WELLINGTON \\ Te Whare Wananga o te Upoko o te Ika a Maui

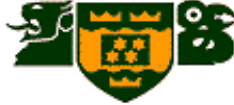 \\ Consent to participation in research: Students and Parents/Guardians}

Title of project: Youth participation in social action: Voices from the classroom.

Researcher: Bronwyn Wood, School of Education, Victoria University of Wellington

I have been given information about this research project and I have understood an explanation of this research project. I have had an opportunity to ask questions and have them answered to my (student to $\sqrt{ }$ ) satisfaction.

I understand that I may withdraw myself (or any information I have provided) from this project (before data collection and analysis is complete) without having to give reasons or without penalty of any

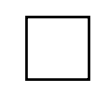
sort.

I understand that any information I provide will be kept confidential to the researcher, her supervisors, and that the published results will not use my name, and that no opinions will be attributed to me in any way that will identify me.

I understand that the tape recording of the focus group interviews will be electronically wiped at the end of the project unless my school indicates that it would like it returned.

I understand that the digital photos will be returned to me or electronically wiped at the end of the project.
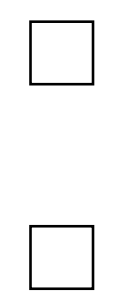

I would like to receive feedback on the findings of this research.

Name of student

Signed [student

OR

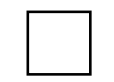

$(\sqrt{ })$ I have emailed my consent to Bronwyn.wood@vuw.ac.nz

I agree that who is my son/ daughter/ under my

guardianship, may take part in this research

Signed [parent/guardian] Date

(parental consent required only if student is under 16 years of age).

OR

$(\sqrt{ })$ I have emailed my consent to Bronwyn.wood@vuw.ac.nz 
Appendix F: Parent information letter

VICTORIA UNIVERSITY OF WELLINGTON

Te Whare Wananga o te Upoko o te Ika a Maui

[Contact details supplied]

[Date]

Title of project: Youth participation in social action: Voices from the classroom.

Researcher: Bronwyn Wood, Faculty of Education, Victoria University of Wellington

\section{Research Information Sheet: Parents/Guardians of Social Studies Students}

Dear Parents/guardians of a social studies student at [X] College,

I am currently involved in a doctoral research project looking at social studies students' involvement in social action. My PhD research is supervised by Dr Joanna Kidman and Dr Mark Sheehan, both at the Faculty of Education, Victoria University of Wellington. My research has been approved by the Victoria University Research and Human Ethics Committee (reference RM 15818).

The New Zealand Curriculum (2007) describes students 'taking action' as one important aspect of social studies education. I am interested in finding out about how social studies students define 'social action' and what they believe influences and motivates their ability to participate in social action. I will also be talking to social studies teachers about social action.

\section{What does this research involve?}

If your son/daughter agrees to participate in this research s/he will be asked to join a Student Focus Group Interview with about other social studies students. These interviews will be conducted at school, during a social studies lesson. I will work closely with your son/daughter's social studies teacher to make sure the timing of the interviews will minimise disruptions to student learning and arrangements will be made for students who participate to catch up on missed class work. These interviews will be taped so I can transcribe what was said at a later stage.

The second part of the research involves using digital cameras to capture what is special about your local area and what students would like to change or 'take action' on now or in the future. This activity will be done in groups during a social studies lesson or after school according to the advice given me by your son/daughter's social studies teacher. Following the photography activity, students will discuss their photos with me and why they took them. Copies of the photos will be made and given to the students to keep/dispose of as they wish.

What will I do to ensure your child's privacy is protected and that I have their consent to participate in this research?

I would like to invite your son/daughter to participate in my research. Your child's participation in this research is voluntary. It is not part of their regular teaching and learning in social studies. However, it is research that will benefit many other students 
and teachers in New Zealand and I would welcome your consent for your son/daughter's involvement. Consent is required from parents/guardians for children under 16 years of age.

All names of schools, teachers and students in this research will remain confidential to the researcher (and her supervisors) in the final reporting. Your son/daughter will get an opportunity to choose a 'code name' (pseudonym) and a chance to check how their words appear before the final report. Students will be encouraged to take photos of places, sites, images and things (objects) rather than people to avoid issues of privacy and consent. The use of the photos in this research will be done in consultation with your child and s/he will have an opportunity to make changes or withdraw their photos at any stage. Your son/daughter can choose to withdraw from the project at any stage with no questions asked, up to when the research is analysed.

The information from this research will be published in my $\mathrm{PhD}$ thesis and some articles will be submitted for publication in academic journals and conferences.

If you require further information or clarification on any of the above points, please do not hesitate to contact me or my supervisors using the contact details provided. If you are willing for your child to be involved, please sign the attached consent form and return to school. As an alternative, you can email your consent (including your son/daughter's name/class) to me at Bronwyn.wood@vuw.ac.nz

Regards,

\section{Bronwyn Wood}

[supervisor contact details suplied] 


\section{Appendix G: Teachers' information/consent letter}

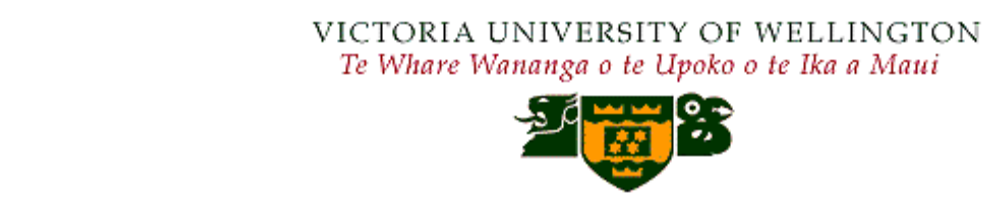

[Contact details supplied]

[Date]

Dear Social Studies Teacher

Title of project: Youth participation in social action: Voices from the classroom. Researcher: Bronwyn Wood, School of Education, Victoria University of Wellington

\section{Research Information Sheet Social Studies Teachers}

I am currently involved in a Doctoral research Project (Victoria University of Wellington) looking at social studies students' involvement in social action in reference to the New Zealand Curriculum (2007). My PhD research is supervised by Dr Joanna Kidman and Mark Sheehan, both at the Faculty of Education, Victoria University. My research has been approved by the Victoria University Research and Human Ethics Committee.

The New Zealand Curriculum (2007) describes students 'taking action' as one important aspect of social studies education. I am interested in finding out about how social studies students define and take 'social action' and how social studies teachers integrate 'social action' into their programmes.

\section{What does this research involve?}

I am inviting social studies teachers from your school to participate voluntarily in this project. If you agree to participate in the research, you would join a Focus Group Interview. This interview would be conducted at school, after school hours (for example, at a Social Sciences Department/Faculty meeting). The interview will last about 1-11/2 hours and and will involve small groups/whole group discussions and an examination of your current social studies programme/documents. This interviews will be audiotaped so I can transcribe what was said at a later stage.

The University requires that ethics approval be obtained for research involving human participants. If you are willing to be involved, can you please sign the form below and return to me at the time of our Focus Group interview or email your consent to me before then.

What will I do to make sure you willing to be involved and that your privacy is protected?

All names of schools, teachers and students in this research will remain confidential to the researcher (and her supervisors) in the final reporting. I won't use your real name (or your school's name) in the final report. You will receive feedback on your participation in this focus group. You can choose to withdraw from the project at any 
stage with no questions asked up to when the research is analysed. I will leave my contact details with you after the Focus Group Interview. All data collected in this research will be stored securely to protect the confidentiality of participants.

The information from this research will be published in my $\mathrm{PhD}$ thesis and some articles will be submitted for publication to academic journals and conferences. Your Department will be offered the opportunity to have the audiotape of the Focus Group interview returned or wiped at the conclusion of this research.

If you require further information or clarification on any of the above points, please do not hesitate to contact me or my supervisors using the contact details provided above.

I look forward to your reply.

Regards,

Bronwyn Wood

[supervisor contact details suplied]

Consent to participation in research: Teachers

Title of project: Youth participation in social action:

Voices from the classroom.

Researcher: Bronwyn Wood, Faculty of Education, Victoria University of Wellington

I have been given information about this research project and I have understood an explanation of this research project. I have had an opportunity to ask questions and have them answered to my satisfaction.

I understand that I may withdraw myself (or any information I have provided) from this project (before data collection and analysis is complete) without having to give reasons or without penalty of any

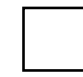
sort.

I understand that any information I provide will be kept confidential to the researcher, her supervisor, and that the published results will not use my name, and that no opinions will be attributed to me in any way that will identify me.

I understand that the tape recording of the focus group interviews will be electronically wiped at the end of the project unless my school indicates that it would like it returned.

I would like to receive feedback on the findings of this research.

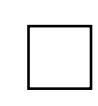

Name of teacher Date

Signed 
Appendix H: Information sheet for Photovoice activity and use of digital cameras

Photovoice research activity information

The purpose of this Photovoice activity is to capture in photos...

\begin{tabular}{|l|l|}
\hline $\begin{array}{l}\text { What is special or important about } \\
\text { your place? }\end{array}$ & $\begin{array}{l}\text { What you would like to 'take action' } \\
\text { on to change or improve? }\end{array}$ \\
$\begin{array}{l}\text { What would you miss if you left or it } \\
\text { was altered? }\end{array}$ & $\begin{array}{l}\text { What makes you mad? /sad? / } \\
\text { disappointed? }\end{array}$ \\
What makes you feel like you belong? & What needs attention? \\
\hline
\end{tabular}

\section{Care of cameras}

\section{Using digital cameras}

I want you to enjoy using the cameras, and hope you take some good pictures. Remember that some of the equipment can get broken if it's handled roughly. I trust you to look after it well.

\section{Being respectful}

Act responsibly and respect the rights and privacy of others.

Don't take pictures that might get you, your whānau, or the people around you into any trouble.

Try to avoid taking photos of people that are recognisable as we can't always get their consent easily. If you do want photos with people in them, try and be clever use shadows, silhouettes or blurred photos so people can't be recognised.

\section{Photo tips}

\begin{tabular}{|c|c|c|}
\hline $\begin{array}{c}\text { Move in closer } \\
\text { If you want to highlight } \\
\text { one feature of the photo - } \\
\text { move in closer - leave out } \\
\text { things that don't matter } \\
\text { as much. }\end{array}$ & $\begin{array}{c}\text { Look at the light } \\
\text { well if you take it directly } \\
\text { into the light - unless you } \\
\text { want a silhouette. Watch } \\
\text { how the sun/shadows are } \\
\text { falling on your subject. }\end{array}$ & $\begin{array}{c}\text { Be quick } \\
\text { - be quick to capture } \\
\text { them on camera. }\end{array}$ \\
\hline $\begin{array}{c}\text { Keep it simple } \\
\text { It is better to keep the } \\
\text { focus of a photo on one } \\
\text { theme or idea. Take two } \\
\text { shots if you have two } \\
\text { ideas. }\end{array}$ & $\begin{array}{c}\text { Look at the edges - what } \\
\text { should be in? What should } \\
\text { be out? }\end{array}$ & $\begin{array}{c}\text { Have a go ifyou have a } \\
\text { crazy idea for a shot - it's } \\
\text { easy to delete! }\end{array}$ \\
& & \\
\hline
\end{tabular}


Appendix I: Poster activity 1: Important issues in "our place"

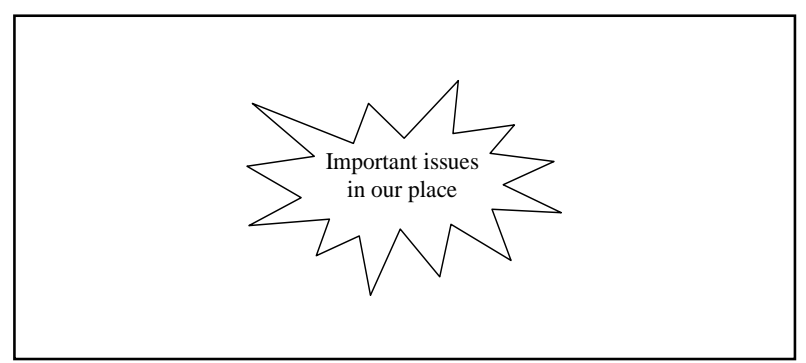

Appendix J: Poster activity 2: Location of "important issues"

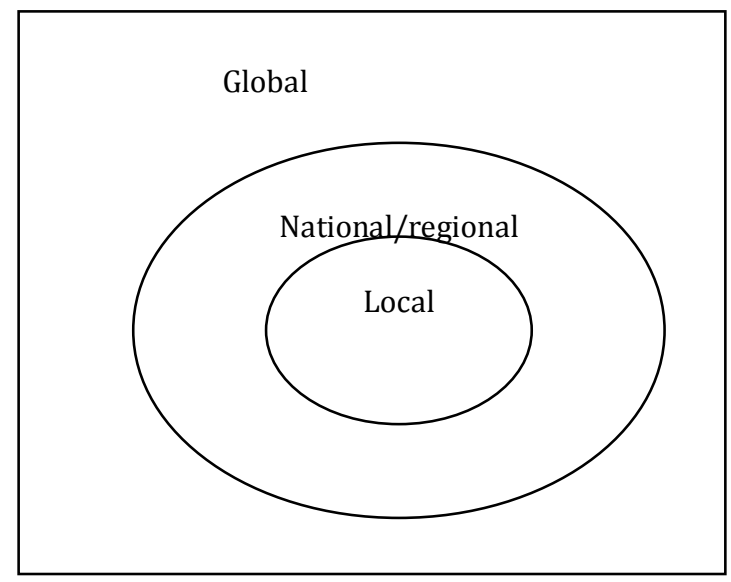

Appendix K: Poster activity 3: Social action is...

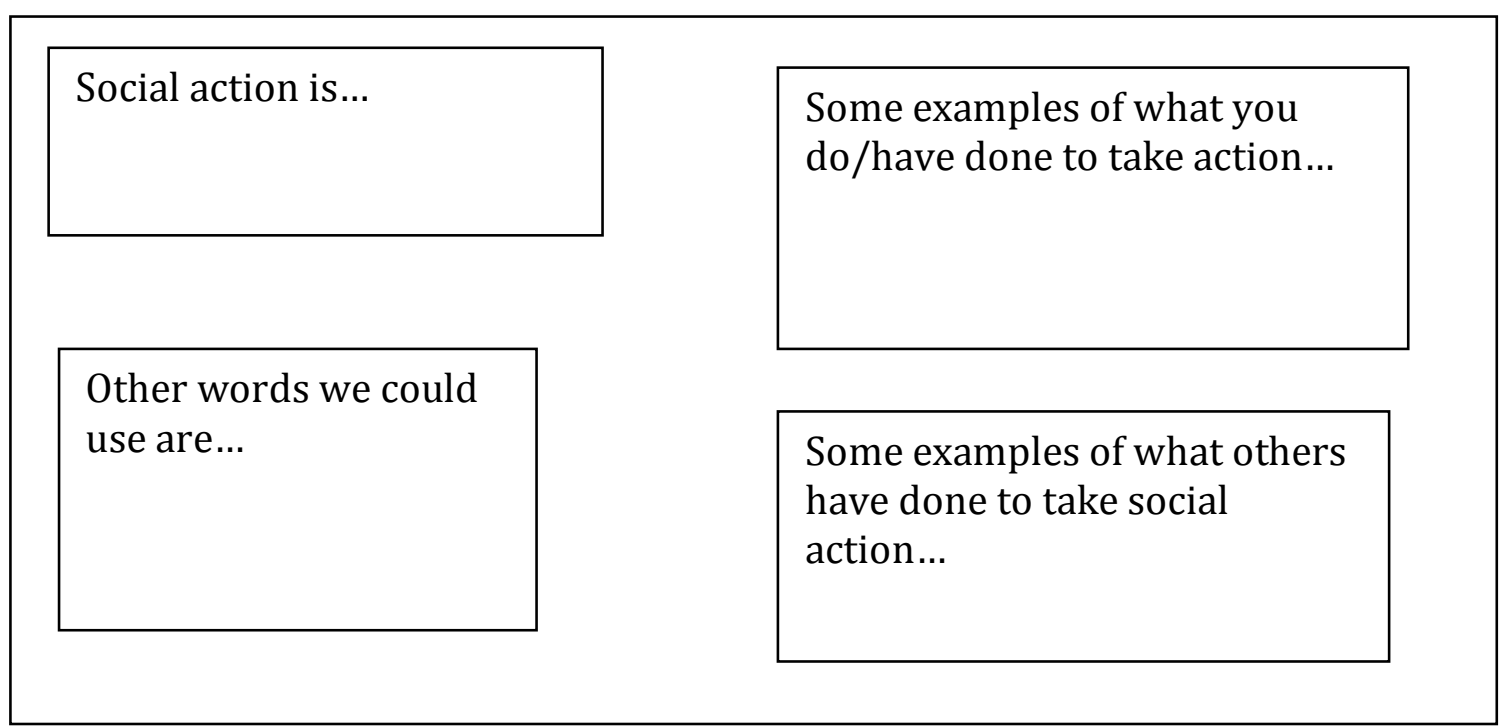


Appendix L: Poster activity 4: A "good" citizen is...

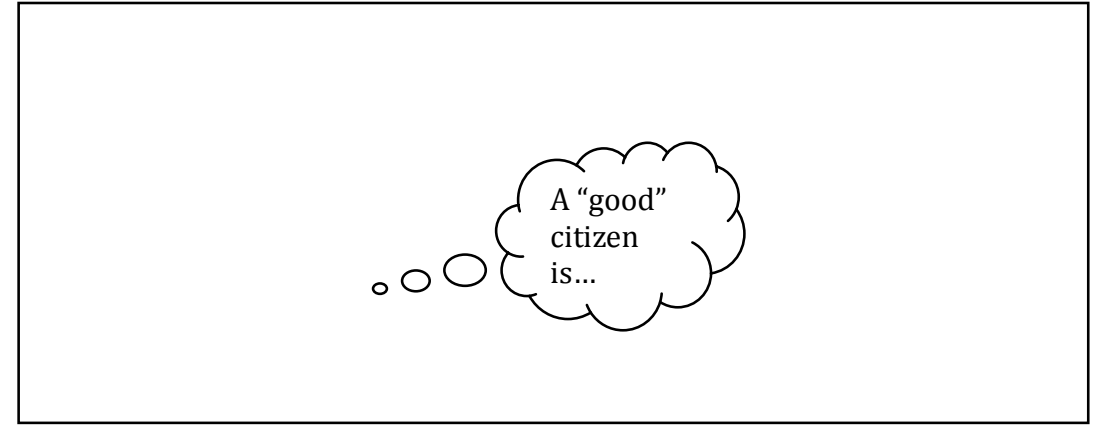

Appendix M: Poster activity 5: Rights and responsibilities of young people

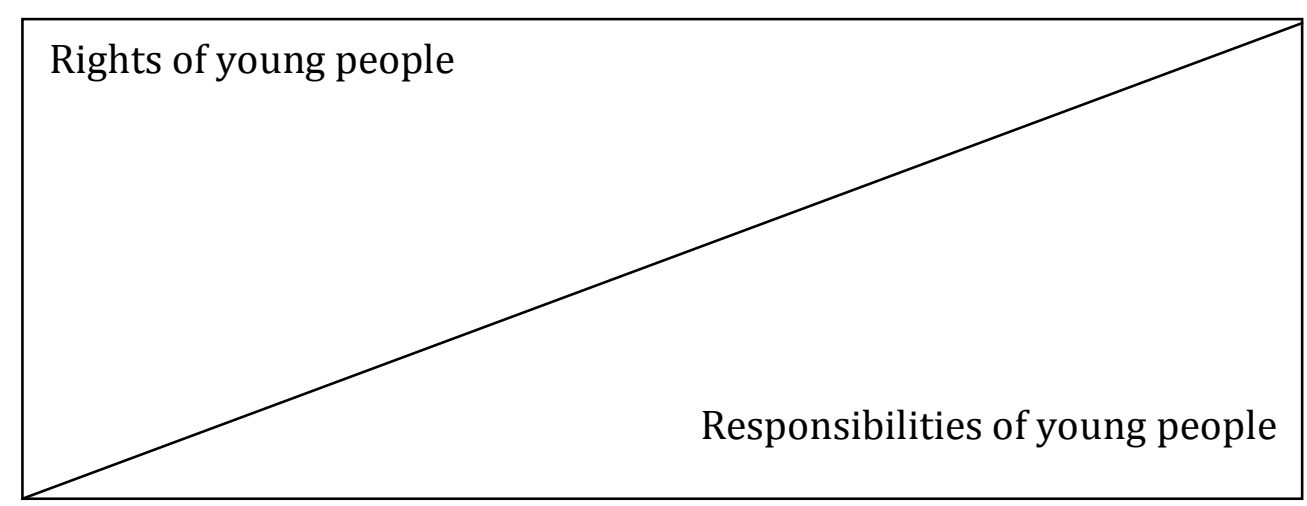

Appendix N: Poster activity: PMI chart (positive, negative and interesting) outcomes/challenges to taking social action

\begin{tabular}{|l|l|l|}
\hline Positive & Minus & Interesting \\
\hline $\begin{array}{l}\text { Positive outcomes to taking } \\
\text { social action }\end{array}$ & $\begin{array}{c}\text { Negative } \\
\text { outcomes/challenges to } \\
\text { taking social action }\end{array}$ & $\begin{array}{c}\text { Interesting points to } \\
\text { note }\end{array}$ \\
\hline$\bullet$ & $\bullet$ & $\bullet$ \\
$\bullet$ & $\bullet$ & $\bullet$ \\
\hline & $\bullet$ & $\bullet$ \\
\hline & $\bullet$ & $\bullet$ \\
\hline
\end{tabular}




\section{Appendix O: College A: Topics studied and reported "important issues" in focus groups}

\begin{tabular}{|c|c|c|}
\hline $\begin{array}{l}\text { College } \\
\text { A }\end{array}$ & $\begin{array}{l}\text { Topics studied in social } \\
\text { studies programme in year } \\
\text { research was conducted }\end{array}$ & $\begin{array}{l}\text { Reported 'important issues' in } \\
\text { focus groups } \\
\text { [a/b where } a=\text { reported in } F G \text {; } b=\text { total of focus } \\
\text { groups in class] }\end{array}$ \\
\hline \multicolumn{3}{|r|}{ 年 } \\
\hline Term 1 & $\begin{array}{l}\text { Global issues (global disparities; } \\
\text { impacts, international organisations) }\end{array}$ & $\begin{array}{l}\text { Poverty }[3 / 4] \\
\text { Food shortages }[3 / 4] \\
\text { Lack of education }[3 / 4]\end{array}$ \\
\hline Term 2 & Child labour & Child labour [1/4] \\
\hline Term 3 & Gender issues in developing world & Gender disparities/dowry [1/4] \\
\hline Term 4 & $\begin{array}{l}\text { Religious diversity (Islam, Hinduism, } \\
\text { Christianity, NZ diversity) and conflict }\end{array}$ & Religious conflict/war [3/4] \\
\hline \multicolumn{3}{|c|}{ Year 12} \\
\hline Term 1 & $\begin{array}{l}\text { Political / economic conflict } \\
\text { (e.g. Cambodia, Ethiopia, Vietnam) }\end{array}$ & $\begin{array}{l}\text { Poverty / starvation [4/4] } \\
\text { Natural disasters }[2 / 4]\end{array}$ \\
\hline Term 2 & Ethnic conflict (Rwanda/South Africa) & $\begin{array}{l}\text { Racism }[2 / 4] \\
\text { Government corruption e.g. Mugabe [1/4] }\end{array}$ \\
\hline Term 3 & Religious conflict (Palestine/Israel) & $\begin{array}{l}\text { Israel/Palestinian conflict }[2 / 4] \\
\text { Conflict/war in general }[3 / 4]\end{array}$ \\
\hline Term 4 & Land conflict (TOW) & - \\
\hline \multicolumn{3}{|c|}{ Year 10} \\
\hline Term 1 & $\begin{array}{l}\text { Resource management - issue: global } \\
\text { warming }\end{array}$ & $\begin{array}{l}\text { Climate change/global warming [4/8] } \\
\text { Pollution [4/8] } \\
\text { Resource management [1/8] } \\
\text { Environment in general }[2 / 8] \\
\text { Littering [3/8] }\end{array}$ \\
\hline Term 1 & Changing patterns of work & $\begin{array}{l}\text { Unemployment [3/8] } \\
\text { Recession }[3 / 8]\end{array}$ \\
\hline Term 2 & Human rights & $\begin{array}{l}\text { Bullying }[5 / 8] \\
\text { Racism [4/8] } \\
\text { Sexual discrimination/homophobia [4/8] }\end{array}$ \\
\hline Term 3 & Treaties & Land disputes $[1 / 8]$ \\
\hline
\end{tabular}

Appendix P: College B: Topics studied and reported "important issues" in focus groups

\begin{tabular}{|c|c|c|}
\hline $\begin{array}{l}\text { Year } \\
12\end{array}$ & $\begin{array}{l}\text { Topics studied in social studies } \\
\text { programme in year research was } \\
\text { conducted }\end{array}$ & $\begin{array}{l}\text { Reported 'important issues' in } \\
\text { focus groups } \\
\text { [a/b where } a=\text { reported in } F G ; b=\text { total of } \\
\text { focus groups in class] } \\
F G=2, n=8\end{array}$ \\
\hline Term 1 & Topical Issues - Landmines and Boy Racers & boy racers (speeding), [1/2] \\
\hline & 'Legislation to increase the drinking age... & $\begin{array}{l}\text { drinking and driving [1/2] } \\
\text { underage drinking [1/2] }\end{array}$ \\
\hline & $\begin{array}{l}\text { Current social issue" The Child Discipline } \\
\text { Bill }\end{array}$ & smacking law $[1 / 2]$ \\
\hline
\end{tabular}


Appendix Q: College C: Topics studied and reported 'important issues' in focus groups

\begin{tabular}{|c|c|c|}
\hline Year 10 & $\begin{array}{l}\text { Topics studied in social studies } \\
\text { programme in year research was } \\
\text { conducted }\end{array}$ & $\begin{array}{l}\text { Reported 'important issues' in } \\
\quad \text { focus groups } \\
\text { [a/b where } a=\text { reported in } F G ; b= \\
\text { total of focus groups in class] } \\
F G=6, n=29\end{array}$ \\
\hline Term 1 & $\begin{array}{l}\text { Trade; fair trade/free trade } \\
\text { Community Issues class topic: } 1080 \text { poison }\end{array}$ & $\begin{array}{l}\text { Fair trade }[1 / 6] \\
1080[4 / 6]\end{array}$ \\
\hline Term 2 & Civil rights and protest & \\
\hline
\end{tabular}

Appendix R: College D: Topics studied and reported 'important issues' in focus groups

\begin{tabular}{|c|c|c|}
\hline Year 10 & $\begin{array}{l}\text { Topics studied in social studies } \\
\text { programme in year research was } \\
\text { conducted }\end{array}$ & $\begin{array}{l}\text { Reported 'important issues' in focus } \\
\text { groups } \\
\text { [a/b where } a=\text { reported in } F G ; b=\text { total of } \\
\text { focus groups in class }] \\
F G=5, n=26\end{array}$ \\
\hline Term 1 & $\begin{array}{l}\text { Human rights: incl. child labour case } \\
\text { study }\end{array}$ & $\begin{array}{l}\text { Racism }[4 / 5] \\
\text { Bullying }[2 / 5] \\
\text { Slavery }[1 / 5] \\
\text { Prejudice }[1 / 5] \\
\end{array}$ \\
\hline Term 2 & Water issues and resource management & $\begin{array}{l}\text { Water issues[4/5] } \\
\text { Scarcity of resources [3/5] } \\
\text { Global warming [5/5] } \\
\text { Pollution [4/5] } \\
\text { Decreasing biodiversity [3/5] } \\
\text { Deforestation [2/5] } \\
\text { Sustainability [1/5] } \\
\end{array}$ \\
\hline
\end{tabular}

